\title{
Limits to fluid availability during exercise
}

Citation for published version (APA):

Rehrer, N. J. (1990). Limits to fluid availability during exercise. [Doctoral Thesis, Maastricht University]. De Vrieseborch. https://doi.org/10.26481/dis.19901220nr

Document status and date:

Published: 01/01/1990

DOI:

10.26481/dis.19901220nr

Document Version:

Publisher's PDF, also known as Version of record

\section{Please check the document version of this publication:}

- A submitted manuscript is the version of the article upon submission and before peer-review. There can be important differences between the submitted version and the official published version of record.

People interested in the research are advised to contact the author for the final version of the publication, or visit the DOI to the publisher's website.

- The final author version and the galley proof are versions of the publication after peer review.

- The final published version features the final layout of the paper including the volume, issue and page numbers.

Link to publication

\footnotetext{
General rights rights.

- You may freely distribute the URL identifying the publication in the public portal. please follow below link for the End User Agreement:

www.umlib.nl/taverne-license

Take down policy

If you believe that this document breaches copyright please contact us at:

repository@maastrichtuniversity.nl

providing details and we will investigate your claim.
}

Copyright and moral rights for the publications made accessible in the public portal are retained by the authors and/or other copyright owners and it is a condition of accessing publications that users recognise and abide by the legal requirements associated with these

- Users may download and print one copy of any publication from the public portal for the purpose of private study or research.

- You may not further distribute the material or use it for any profit-making activity or commercial gain

If the publication is distributed under the terms of Article $25 \mathrm{fa}$ of the Dutch Copyright Act, indicated by the "Taverne" license above, 


\section{LIMITS TO FLUID AVAILABILITY DURING EXERCISE}

\section{PROEFSCHRIFT}

ter verkrijging van de graad van doctor aan de Rijksuniversiteit

Limburg te Maastricht, op gezag van de Rector Magnificus, Prof. Dr. F.I.M. Bonke, volgens het besluit van het College van

Dekanen, in het openbaar te verdedigen op donderdag 20 december 1990 om 16.00 uur

door

Nancy Jane Rehrer 
Promotores:

Prof. Dr. Ir. W.H.M. Saris

Prof. Dr. F. ten Hoor

Co-promotor:

Dr. F. Brouns

Beoordelingscommissie:

Prof. Dr. P.B. Soeters (voorzitter)

Prof. Dr. C. Foster, University of Wisconsin, Milwaukee, U.S.A.

Dr. J.H. Kleibeuker, Rijksuniversiteit Groningen

Dr. H. Kujpers

Prof Dr. R.W. Stockbrügger

The work presented in this dissertation was done at the Nutrition Research Centre of The University of Limburg, within the framework of the project nutrition, energy exchange and body composition and was supported by a research grant from Wander Ltd., Bern, Switzerland.

Publication and promotion costs were also, in part, sponsored by the Dr. Ir. J.H.J. van de Laar Association for Biochemical Research. 
ter nagedachtenis aan Hal F. Rehrer en Geessina Baartmán 
CIP-GEGEVENS KONINKLIJKE BIBLIOTHEEK, DEN HAAG

Rehrer, N.J.

Limits to fluid availability during exercise / N.J.

Rehrer. - Haarlem : De Vrieseborch. - I11. -

(Sportwetenschappelijke onderzoekingen; 19)

Ook verschenen als proefschrift Maastricht, 1990. - Met

lit. opg.

ISBN 90-6076-327-0

SISO 628.44 UDC 613.2:796 NUGI 468

Trefw.: sport en voeding.

1990 N.J. Rehrer

(c) Foto"s: Fred Brouns

No part of this book may be reproduced in any form, by print, photoprint, microfilm or any other means, without written permission from

B.V. Uitgeverij De Vrieseborch

facobijinestract 5

2011 TG Haarlem

the Netherlands

ISBN 9060763270 


\section{SCOPE OF THE INVESTIGATION}

The studies described herein were conducted to gain information concerning the following problems:

1. The effect of type and intensity of exercise on gastric emptying of fluids in man.

2. The effect of other factors on gastric emptying of fluids (including repeated drinking versus one bolus, carbohydrate composition, the presence of potassium and sodium, and dehydration).

3. The effect of exercise and beverage characteristics on gastric secretions.

4. The effect of beverage characteristics on intestinal absorption of water and carbohydrate.

6. The amount of orally ingested carbohydrate oxidised relative to the amount emptied from the stomach with various carbohydrate containing solutions.

7. The prevalence of gastrointestinal dysfunction during different types of endurance exercise and correlates with dietary intakes, fluid balance and other physiological changes occurring as a result of exercise. 


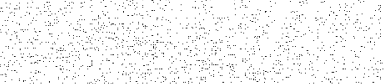




\section{CHAPTERS}

1. Introduction:

The theory and practice of oral supplementation 11 during exercise

1.1. what and why

-fluid and $\mathrm{CHO}$

-for health and performance

1.2. limitations

-availability and ingestion

-gastric emptying

-intestinal absorption

-utilisation

1.3. Problems interfering with supplementation during exercise: gastrointestinal dysfunction and symptoms

2. Exercise and training effects on gastric emptying of carbohydrate beverages

3. Gastric emptying with repeated drinking during running and bicycling

4. Biomechanical vibration of the abdominal region during running and bicycling

5. Gastric emptying, secretion and electrolyte flux at rest, after ingestion of beverages with varying electrolyte compositions

6. Effects of dehydration on gastric emptying and gastrointestinal distress while running 
7. Limits to supplementation during exercise: gastric emptying, intestinal absorption, and oxidation

8. Fluid intake and gastrointestinal problems in runners competing in a $25-\mathrm{km}$ race and a marathon

9. Gastrointestinal symptoms and physiological changes as a result of ultra-endurance running

10. Gastrointestinal complaints in relation to dietary intakes in triathletes

\section{Discussion}

Combined results of both laboratory and field studies and relevance in light of others' findings

Summary points

Nederlandse samenvatting

Dankwoord/Acknowledgements

Curriculum vitae

Publications from this thesis 


\section{CHAPTER 1}

\section{Introduction}

\section{THE THEORY AND PRACTICE OF ORAL SUPPLEMENTATION DURING EXERCISE}

\subsection{What and why}

The first mention of beverage provision for international athletic competition in the IAAF regulations was in 1953. In marathon competition, beverage could be consumed only after $15 \mathrm{~km}$ (IAAF Handbook, 1953, p. 65). For shorter events no allowance was made. The rules have changed since this time allowing more frequent drinking in all races of $10 \mathrm{~km}$ and longer (IAAF Handbook, 1990, p. 125). Presently, fluid consumption is not only allowed but advocated during endurance exercise, for health as well as performance reasons, except in some team sports such as football (soccer) in which drinking is not technically permitted. The American College of Sports Medicine, in its position statement: The Prevention of Thermal Injuries During Distance Running, advocates drinking $100 \mathrm{ml}$ every 2-3 $\mathrm{km}$ (ACSM, 1987). Beverages are commonly provided by sponsors, organisers, coaches and athletes themselves. The choice is not always based upon knowledge. There exists much mysticism as to what and how much (if anything) should be consumed.

The ideal beverage composition and intake regimen have not been identified. One ideal solution and one ideal drinking regimen (quantity and timing) for all individuals in all sporting activities will never be found, although the search for it has led to an ever growing amount of scientific research. This research has resulted in increased knowledge of physiological function, substrate utilization and gastrointestinall function during exercise.

The reason that the search for one best solution and intake regimen has been unsuccessful is that, depending on the external situation and an individual"s physiological state, the ideal fluid supplementation regimen will vary. However, the major goals of supplementation for exercising individuals are well defined, based upon expected losses of endogenous reserves. Exercise duration, 
intensity, environmental conditions, body composition, raining and nutritional status, as well as one's unique physiology, will determine what losses occur and at what point losses become limiting to function.

The two major goals of supplementation during endurance exercise are to provide water and carbohydrate, in this order. Water is first in priority of supplementation since it is generally accepted that the most common health risk that an athlete faces is heat stress, or hyperthermia, which can result in heat stroke (Wyndham, 1977). Additionally, dehydration ( $\geq 2 \%$ body weight loss) reduces performance (Saltin, 1964).

During exercise core body temperature rises as a result of the increased "waste" heat produced with an increase in energy transformation from chemical energy to mechanical energy, as muscles contract. The higher the intensity of exercise, the greater the increase in metabolic rate and heat production will be (Nadel et al., 1977). To compensate, circulation (to the periphery) is increased (Johnson, 1977) and sweat production (cooling by evaporation) ensues, sweat rate increasing with the exercise intensity (Nadel et al., 1977; Maughan, 1985). It is the water loss, primarily from sweating during intense endurance exercise, which can make the body's own stores of water limiting and can result in dehydration. Although electrolytes are lost with sweat, sweat is hypotonic relative to plasma and intercellular and intracellular water (Costill, 1977). Electrolyte losses, except in some extreme situations, are usually not large enough to cause a deficit that will have an effect on performance capacity, and concentrations in the plasma actually may increase as a result of the relatively larger fluid loss (Kozlowski and Saltin, 1964). During exercise, compensation for the losses can be partly made by kidney retention of electrolytes. After exercise, dietary intakes may further compensate for losses. Where the sweat loss is of a magnitude to cause a significant electrolyte deficit, the dehydration itself (fluid loss) will be more debilitating. When rehydration is in excess of loss or loss and replacement are extreme, and supplementation is solely with water, hyponatraemia can occur. This has been most frequently observed in ultra-endurance athletes (Noakes et al., 1985).

In most situations, however, the primary reason to include sodium in rehydration beverages is not to replace losses in sweat, 
but to increase intestinal absorption of water and glucose. Net absorption of water in the intestine is essential for successful oral supplementation of fluids. The absorption of water is improved by the inclusion of sodium in combination with a low concentration of glucose in solution (Schedll and Clifton, 1963; Levinson and Schedil, 1965). The stimulatory effect of sodium in combination with glucose on water absorption forms the basis of oral rehydration therapy in clinical situations of large fluid loss (Farthing, 1990). Additionally, the ingestion of sodium with water increases fluid retention, resulting in better restoration of the body fluid compartments after dehydration (Nose et al., 1990).

The second goal is to provide carbohydrate to supplement endogenous carbohydrate reserves. Carbohydrate is the primary substrate metabolised during intense endurance exercise. The proportion of carbohydrate utilised is increased with iricreasing exercise intensity (Christensen, 1932). Thus, the total amount of carbohydrate utilised is dependent upon exercise intensity and duration. Nutrition (Bergström et al., 1967) and training (Bergström and Hultman, 1966; Saltin et al., 1978; Gollnick, 1985) are the most effective modifiers of the glycogen reserves (the largest endogenous supply of carbohydrate). At $70 \% \dot{\mathrm{V}}_{2} \max$ it is estimated that endogenous carbohydrate reserves (skeletal muscle and liver glycogen and blood glucose) are sufficient to provide energy to sustain this exercise intensity for approximately $90 \mathrm{~min}$ (Newsholme and Leech, 1983). Blood glucose, however is of such a small quantity that this reserve provides energy for only a few minutes during intense exercise (Newsholme and Leech, 1983). Adaptations to training include an increase in the proportion of energy derived from fat at a given intensity of exercise (relative and absolute) (Issekutz et al., 1965; Karlsson et $\mathrm{al}_{2,}$ 1974) and an increase in the glycogen reserves (van der Vusse et al., 1989). The latter, however, may be more of an acute effect of supercompensation than an actual long-term, training effect. The actual duration of exercise that is possible at a certain relative intensity may, because of these and other differences, vary widely between individuals.

In theory, carbohydrate becomes limiting, because of depleted glycogen stores, during exercise at $70 \% \quad \mathrm{\vee O}_{2} \max$ which lasts for more than $1.5 \mathrm{~h}$. Above this intensity, the maximal exercise 


\section{Chapter I}

duration may be even less. At supra-maximal intensities, such as that performed during interval or tempo training, the duration may be extremely limited. Supporting the theoretical calculations are research results demonstrating a performance decrease (Astrand et al., 1963; Hultman, 1967) and decreased time to exhaustion (Bergstrom et al., 1967) with low glycogen concentrations in the active muscles.

A similar relationship is observed with dietary manipulation (resulting in decreased muscle glycogen) and subsequent exercise time to exhaustion (Dill et al., 1932; Christensen and Hansen, 1939). Thus, a strong correlation has been observed between endogenous cárbohydrate availability and performance. Based on these data, one may hypothesise that by supplementing carbohydrate one may improve performance capacity and prolong time to exhaustion.

The additional supply of carbohydrate from gluconeogenesis has been neglected in the above discussion. Although gluconeogenesis does contribute to the carbohydrate supply, it is not alone sufficient to maintain exercise at a high intensity, as is evidenced by normal subjects with depleted glycogen reserves, as well as by McArdle's patients, who have a metabolic defect and cannot breakdown glycogen (Wagenmakers et al., 1990).

Even with the wealth of supporting evidence that has accumulated since Dill et al. (1932) first observed that muscular work capacity of a dog was greater when he was given a glucose solution than when he was given water, the mechanism or mechanisms responsible for improved performance with carbohydrate supplementation is still contested. Why does carbohydrate supplementation immediately prior to and/or during exercise improve performance? The answer is, based upon the experimental evidence to date, multi-faceted. In the case of long lasting, intense exercise, orally ingested carbohydrate can supplement the limited endogenous stores. Based upon research results, two theories of how the exogenous carbohydrate augments the availability of carbohydrate for metabolism have been proposed. One involves utilisation of the glucose ingested directly (after phosphorylation) (Pirnay et al., 1977), thus possibly sparing muscle glycogen. The other involves re-synthesis of glycogen in the muscles during exercise, thus compensating for glycogen breakdown. This has, however, only been demonstrated 
at a low intensity (40\% $\mathrm{VO}_{2}$ max) and only in fast twitch fibres (Kuipers et al., 1987). ${ }^{13} \mathrm{C}$ and ${ }^{14} \mathrm{C}$ labeled sugars have been used to follow oxidation of exogenous carbohydrate. Exhaled labeled $\mathrm{CO}_{2}$, originating from the orally ingested sugar, has demonstrated that the carbohydrates are oxidised fairly quickly after ingestion (15 min) and fairly completely if exercise is continued for a long enough time (Pirnay, 1977). Allhough it is uncertain if exogenous carbohydrate is first incorporated into glycogen before oxidation, it is certain that the exogenous $\mathrm{CHO}$ is available for oxidation.

Oral carbohydrate supplementation has also been shown to improve performance in exercise of shorter duration, in which the endogenous reserves may not be limiting (Murray et al., 1989; Neufer et al., 1987). The mechanism through which this improvement in performance is achieved is unknown. A second mechanism of improved performance with carbohydrate ingestion during exercise is theorised. In short-term aerobic exercise, it may be that carbohydrate supplementation shifts metabolism, for energy provision, to carbohydrate oxidation. During aerobic exercise, normally a mixture of carbohydrates and fats is metabolised (Christensen and Hansen, 1939). The oxidation of carbohydrate provides more ATP per second and utilises less oxygen for the amount of energy converted. By preferentially stimulating carbohydrate oxidation and increasing the proportion of energy provided by carbohydrate, exercise may be maintained at a higher intensity than when fat makes up a greater proportion of what is oxidised. A type of feed-forward mechanism of carbohydrate oxidation is proposed resembling the feed-forward model of glucose production from endogenous sources during exercise as proposed by Galbo (1983).

Whether this second possible mechanism of improved performance with oral carbohydrate ingestion, based upon substrate preference, explains the improvements in short-term exercise has yet to be thoroughly investigated. It cannot be discounted that the observed performance improvement, even in short-term intensive exercise is obtained via a sparing effect of muscle glycogen in specific, highly active muscle fibers.

Another benefit from inclusion of glucose (or glucose containing disaccharide or polymer) in a beverage designed solely for rehydration, when carbohydrate as a substrate possibly is of no benefit, is during low intensity, long lasting exercise during which 
dehydration may occur. The coupled active transport of glucose and sodium stimulates water absorption (Schedl and Clifton, 1963). The fact that the water absorption is greater from a gllucose and sodium containing solution undermines most arguments that pure water is the best (re)hydration beverage.

\subsection{Limitations to supplementation}

The efficacy of supplementation is dependent upon incorporation of the ingested substance(s) within the body pools where they can serve a function. The first step in supplementation is making fluids and solutes to be supplemented available to the athlete in a manner that the athlete can and will ingest, and at times appropriate for achieving the intended goal. If a beverage, no matter how "perfect" in terms of composition, is not ingested, it is of no use. One's attitude and the palatability and physical provision of a beverage are important in this respect. Included in physical provision are containers which allow for easy handling and drinking with minimal swallowing of air.

The second step in supplementation of fluids and carbohydrate is gastric emptying (GE). The stomach is primarily a holding tank, regulating fluid and solute availability to the intestine where most absorption occurs. Many factors influence GE (for review see Brouns et al., 1987 and Murray, 1989).

Macleod et al. (1930) observed that the emptying rates of sugar solutions varied inversely with the concentration. Hunt (1960) demonstrated that carbohydrate content and osmolality are two major factors which influence the rate of GE of fluids. As the carbohydrate concentration of a given solution increases, the osmolality also increases, making separation of the influences of these two factors difficult. A constant rate of energetic provision through the pylorus has been proposed based on the inhibiting efrect of increasing glucose content on GE rate (Brener et al., 1983; McHugh and Moran, 1979).

The effects of exercise on GE are less clear. Very early work provided evidence to support the theory that low intensity exercise (walking) accelerates emptying, while high intensity exercise slows emptying (Beaumont, 1833; Campbell et al., 1928; Hellebrandt and Tepper, 1934). More recent work has given no clear picture of the effect of exercise on GE. At exercise intensities 
of less than $70 \% \dot{\mathrm{VO}}_{2} \max$ no difference (Costill and Saltin, 1974; Owen et al., 1986; Feldman and Nixon, 1974) or an increase in GE rate has been observed (Neufer, 1986, 1989).

With exercise at $70 \% \mathrm{VO}_{2} \max$, no change (Costill et al. 1970; Feldman and Nixon, 1982) an increase (Neufer et al, 1986) and a decrease (Owen et al., 1986) in GE rate have been observed. At exercise intensities above $70 \% \quad \mathrm{VO}_{2} \max$ only a delay in GE rate has been observed (Fordtran and Saltin, 1967; Soles and Noakes, 1989; Neufer et al., 1989). There are no consistent results regarding fluid composition (carbohydrate solution versus water) in combination with exercise intensity on GE rate alteration.

Aspects of experimentation which may account for the varying results are the differences in solutions, study design, type of exercise and in the technique employed to measure GE. Particularly the differences in technique may cause large variation in results. If total gastric residue volumes are compared or if only drink volumes are compared (not including gastric secretion) different conclusions may be drawn from the same data. Additionally, when gastric (or beverage) residue is measured at only one time, the variability in time since ingestion may give different results. Furthermore, emptying rate until one specific time may not be representative of the rate averaged over the total time taken to empty completely. Some researchers approach this problem by doing several tests for each treatment on each individual; stopping after an increasing length of time in each successive trial. Here the inter-trial variability, possible effects of a previous test drink in the duodenum and time since last meal, are sources of variability which may disguise treatment effects.

The next stage in availability of the water and solutes ingested is absorption. Although slight water flux and electrollyte flux occur across the gastric mucosa, the major site of water and carbohydrate absorption is the intestine. Little work has been done on the effects of exercise on intestinal absorption. Blood flow to the splanchnic region has been observed to be reduced during exercise (Wade et al., 1956; Rowell et al., 1964; Clausen, 1977) and one might expect that alterations in absorption and/or secretion may be influenced by the decrease in blood flow. Early work by Fordtran and Saltin (1967), however, showed no effect of $71 \%$

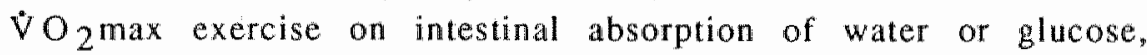
using jejunal perfusion. Indirect measurement of absorption, using 
time to initial appearance of orally ingested labeled glucose in the blood and in breath $\mathrm{CO}_{2}$, during exercise and rest, supports these results (Costill, et al., 1973). These results are contrary to what might be expected based upon observations in animals with reduced blood flow to the mesentery, if it is assumed that blood flow to the mesentery is reduced during exercise. Both Williams et al. (1964) and Varro et al. (1965) have observed reduced glucose absorption with reduced splanchnic blood flow in the dog.

In a more recent study in man, when jejunal perfusion during low intensity cycling exercise was conducted, a reduction in water and electrolyte absorption (from an electrolyte solution) was obserwed (Barclay and Turnberg, 1988). The uncontrolled nature of this study, however, prevents placing too much weight on these results. Recently, however, Maughan and co-workers (1990) have also observed that deuterium accumulation in the blood decreased with increasing exercise intensity after oral ingestion of a beverage labeled with ${ }^{2} \mathrm{H}_{2} \mathrm{O}$, which implies that $\mathrm{GE}$ and/or intestinal absorption of water are decreased with exercise.

These results also contradict the results of studies performed at rest in both animals and man with decreased circulation. Dehydration (with concurrent plasma volume decrease) (Levens, 1984.) and posture induced plasma volume decrease (human studies) (Sjovall et al., 1986), as well as direct stimulation of the mesenteric nerves (resulting in a $39 \%$ decrease in intestinal blood flow) (Sjovall, 1984) increase jejunal water absorption. However, Sjovall's work also suggests that separate nerve fibers may regulate blood flow and fluid absorption, since application of a ganglionic blocker did not alter fluid absorption but eliminated vasoconstriction (Bortoff, 1988). The relationship between blood flow, nervous stimulation and absorption is complex. Decreased intestinal blood fllow, as a result of reduced perfusion pressure, is different from that caused by sympathetic stimulation. With reduced perfusion pressure, villus blood inflow is unchanged but venous outflow is reduced, which can result in hypoxia in the villi tips as villus plasma volume increases and flow rate decreases, increasing the counter-current exchange (Bortoff, 1988). With sympathetic stimulation constriction of crypt arterioles occurs. Both serve to decrease oxygenation of the intestinal membrane, 
but may affect absorption and secretion differently. Whether the perfusion pressure actually drops during exercise and whether constriction of the arterioles of the crypts occurs during exercise as during direct nervous stimulation, is uncertain.

For orally ingested carbohydrate to be beneficial to an individual during exercise, it must be available to be metabolised or incorporated into muscle glycogen. Gastric emptying has been proposed to be the limiting factor in supplementation of fluids and nutrients during exercise (Costill and Saltin, 1974). The validity of this statement has yet to be tested and the relative importance of the different factors which determine gastric emptying rate during exercise has not been determined. Importance of the role of gastric emptying in determining rates of provision of fluid and substrate is speculative. Gastric emptying rate may or may not reflect the actual rate of water provision (incorporation into body water) and exogenous carbohydrate utilisation.

The work presented here particularly deals with these questions. Chapters 2 through 7 describe the research conducted to define a number of the factors which influence gastric emptying and to characterise the role of gastric emptying in oral, liquid supplementation during exercise.

In Chapter 2 an experiment is described in which the effects of training and exercise intensity on gastric emptying rates of various carbohydrate beverages and a beverage containing no carbohydrate were studied. Previous research exploring the effects of exercise has prowided contradictory results, possibly because of non-standardised protocol, type of exercise and technique to measure gastric emptying. In the research presented here, a technique was used in which multiple sampling at different times during emptying was possible and drink and secretion volumes could be calculated. The experiment presented in Chapter 3 was conducted to compare gastric emptying rates during bicycling and rumning with repeated drinking. Because of the inconsistency of previous researchers ${ }^{+}$results and the difference in prevalence of gastrointestinal dysfunction during running versus bicycling, it was speculated that gastric emptying rates would be different. Repeated drinking was conducted to find out if the fast-phase emptying, observed initially after ingestion of one large bolus, could be prolonged by repeatedly refilling the 


\section{Chapter I}

stomach. The study described in Chapter 4 was conducted to quantify the amount of movement of the abdominal region that occurs during bicycling and running, since this may, in part, explain the difference in prevalence of gastrointestinal symptoms which occur during these two different types of exercise. In Chapter 5 the effects of sodium and potassium concentration of a beverage on gastric emptying and secretion were evaluated, since these two minerals are frequently included in sport drinks without full knowledge of the influences on gastric function. Based upon earlier work, it was speculated that potassium may inhibit and sodium may stimulate gastric emptying. The effect of dehydration on gastric emptying was evaluated in Chapter 6. During endurance exercise, such as marathon running, dehydration is not uncommon. The fact that the prevalence of gastrointestinal symptoms has been observed to be greater in marathon runners with a greater relative body weight loss supports the premise that normal gastrointestinal function may be disrupted when exercise is combined with dehydration. The research described in Chapter 7 explores the role of gastric emplying and intestinal absorption in limiting the uptake of water and the utilisation of carbohydrates provided in a beverage.

\subsection{Problems interfering with supplementation during exercise: gastrointestinal dysfunction and symptoms}

Several reviews of gastrointestinal (GI) symptoms in athletes (Brouns et al., 1987; Moses, 1990; Volpicelli, 1981) and numerous case studies (Cantwell, 1981; Fogoros, 1980; Sullivan, 1981) expound upon the symptoms which occur in relation to athletic endeavour (particularly long distance running) and speculation has been made on the aetiology thereof. Several survey studies have also been conducted, in which the prevalence of GI symptoms among distance runners has been recorded (Keeffe et al., 1984; Riddoch and Trinick, 1988). Reports by Brouns et al. (1987) and Sullivan (1987) indicate that these problems occur more frequently during running than during bicycling or other sports, where the body does not experience as much vibration. The literature is inconclusive when attempts have been made to define the underlying causes of the disorders.

Chapters 8 through 10 represent research conducted in an 
attempt to define the GI symptoms in endurance athletes and possible causative factors. The relationship between type of exercise, dietary intakes and other biochemical and physiological changes which occur as a result of endurance exercise and the prevalence of GI symptoms was investigated. In Chapter 8 a field experiment was conducted to characterise and note the prevalence of gastrointestinal symptoms in distance runners during a marathon $(42.2 \mathrm{~km})$ and a shorter race $(25 \mathrm{~km})$. Data were collected regarding fluid consumption, fluid loss and possible relationships between these variables and the prevalence of gastrointestinal symptoms were noted.

A second field study was conducted (Chapter 9) in which Gl symptoms were recorded during extreme endurance running competition (67 km and mountainous). Hormonal and metabolic changes were monitored and fluid consumption was recorded. Relationships between symptoms and the various parameters measured were noted.

In Chapter 10 a survey of triathletes was conducted in which the prevalence of gastrointestinal symptoms as well as food and fluid consumption during each phase of competition, swimming, bicycling and running was recorded. Any relationships between dietary intakes, quantitative or qualitative, and prevalence of symptoms and the relative frequency of gastrointestinal symptoms during the different types of exercise were studied.

Through investigation of gastrointestinal function, as well as dysfunction, an attempt has been made to provide information which can be used to allow effective supplementation during exercise based upon physiology and practical application. 


\section{Chapter 1}

\section{References}

1. ACSM. position stand on the prevention of thermal injuries during distance running. Med Sci. Sports Exerc. 19: 529-533, 1987.

2. Astrand, P.O., I. Hallback, R. Hedman and B. Saltin. Blood lactate after prolonged severe exercise. J. Appl. Physiol. 18: 619-622, 1963.

3. Barclay, G.R. and L.A. Tumberg. Effect of moderate exercise on salt and water transport in the human jejunum. Gut 29: 816$820,1988$.

4. Beaumont, W. Experiments and observations on the gastric juice and the physiology of digestion. Reprinted by Andrew Come, Edinburgh, 1838.

5. Bergström, J., L. Hermansen, E. Hultman and B. Saltin. Diet muscle glycogen and physical performance. Acta Physiol. Scand. 71: 140-150, 1967.

6. Bergström, J. and E. Hultman. Muscle glycogen synthesis after exercise: an enhancing factor localized to the muscle cells in man. Nature 210: 309-310, 1966.

7. Bergström, J and E. Hultman. Nutrition for maximal sports performance. JAMA 221: 999-1006, 1972.

8. Bortoff, A. Influence of exercise on gastrointestinal function, In: Horton, E.S. and R.L. Terjung (Eds.) Exercise, Nutrition, and Energy Metabolism, pp. 159-171, Macmillan Publ. Co., New York, 1988.

9. Brener, W., T.R. Hendrix and P.R. McHugh. Regulation of the gastric emplying of glucose. Gastroenterology 85: 76-82, 1983.

10. Brouns, F., W.H.M. Saris and N.J. Rehrer. Abdominal complaints and gastrointestinal function during long-lasting exercise. Int. J. Sports Med. 8: 175-189, 1987. 
11. Brouns F., W.H.M. Saris, J. Stroecken, E. Beckers, R. Tijssen; N.J. Rehrer and $F$. ten Hoor. Eating, drinking and cycling, a controlled Tour de France simulation study. Pt. II Effect of diet manipulation. Int. I. Sports Med. 10 (Suppl. 1) : S41-S48, 1989.

12. Campbel1, J.M.H., G.O. Mitchell and A.T.W. Powell. The influence of exercise on digestion. Guy's Hospital Reports 78: 279-293, 1928.

13. Cantwell, J.D. Gastrointestinall disorders in runners. JAMA. 246: 1404-1405, 1981.

14. Christensen, E.H. Der Stoffwechsel und die respiratorischen Funktionen bei schwerer körperlicher Arbeit. Arb. Physiol. $5: 463-478,1932$.

15. Christensen, E.H. and O. Hansen. Arbeitsfähigkeit und Ernährung. Skand. Arch. Physiol. 81; 160-171, 1939.

16. Clausen, J.P. Effect of physical training on cardiovascular adjustments to exercise in man. Physiol. Rev. 57: 779-815, 1977.

17. Constable, S.H., J.C. Young, M. Higuchi and J.O. Holloszy. Glycogen resynthesis in leg muscles of rats during exercise. Am. J. Physiol. 247: R880-R883, 1983.

18. Costill, D.L. Sweating: its composition and effects on body fluids. In: The Marathon: Physiological, Medical. Epidemiological and Psychological Siudies, pp. 161-174, P. Milvy (Ed.), N. Y. Academy of Sciences, New York, 1977.

19. Costill, D.L., A. Bennet, G. Branam and D. Eddy. Glucose ingestion at rest and during prolonged exercise. I. Appl. Physiol, 34: 764-769, 1973.

20. Costill, D.L., W.F. Kammer and A. Fisher. Fluid ingestion during distance running. Arch. Environ. Health 21: 520-525, 1970. 


\section{Chapter I}

21. Costill, D.L. and B. Saltin. Factors limiting gastric emptying. J. Appl. Physiol. 37: 679-683, 1974.

22. Coyle, E.F., J.M. Hagberg, B.F. Huxley, W.H. Martin, A.A. Ensani and J.O. Holloszy. Carbohydrate feeding during prolonged strenuous exercise can delay fatigue. J. Appl. Physiol. 55: 230$235,1983$.

23. Dill, D.B., H.T. Edwards and J.H. Talbott. Studies in muscular activity. VII. Factors limiting the capacity for work. J. Physiol. 77: $49-62,1932$.

24. Farthing, J.G. (Ed.) Oral rehydration therapy past, present and future. Clin. Ther. 12:1-142, 1990.

25. Feldman, M. and J.V. Nixon. Effect of exercise on postprandial gastric secretion and emptying in humans. J.Appl. Physiol. 53: $851-854,1982$.

26. Fogoros, R.N. 'Runners trots': gastrointestinal disturbance in runners. JAMA 243: $1743-1744,1980$.

27. Fordtran, J.S. and B. Saltin. Gastric emptying and intestinal absorption during prolonged severe exercise. J. Appl. Physiol. 23: $331-335,1967$.

28. Galbo, H. Hormonal and metabolic adaptation to exercise. pp. 1- 116, Thieme-Stratten, Inc., Stuttgart, 1983.

29. Gollnick, P.D. Metabolism of substrates: energy substrate metabolism during exercise and as modified by training. Fed. Proc. 44: $353-357,1985$.

30. Hellebrandt, F.A. and R.H. Tepper. Studies on the influence of exercise on the digestive work of the stomach. II: Its effect on emplying time. Am. J. Physiol. 107: 355-363, 1934.

31. Hultman, E. Studies on muscle metabolism of glycogen and active phosphate in man with special reference to exercise and diet. Scand. J. Clin. Lab. Invest. 19: 1-63, 1967. 
32. Ivy, J.L., D.L. Costill, W.J. Fink and R.W. Lower. Influence of caffeine and carbohydrate feedings on endurance performance. Med. Sci. Sports Exerc. 11: 6-11, 1979.

33. Issekutz, B., H.I. Miller, P. Paul, K. Rodahl. Aerobic work capacity and plasma FFA turnover. J. Appl. Physiol. 20: 293296,1965 .

34. Johnson, J.M. Regulation of skin circulation during prolonged exercise. In: The Marathon: Physiological, Medical, Epidemiological and Psychological Studies, pp. 195-212, P. Milvy (Ed.), N.Y. Academy of Science, New York, 1977.

35. Karlsson, J., L.-O. Nordesjo and B. Saltin. Muscle glycogen utilization during exercise after physical training. Acta Physiol. Scand, 90: 210-217, 1974.

36. Keeffe, E.B., D.K. Lowe, R. Goss and R. Wayne. Gastrointestinal symptoms of marathon runners. West. J. Med. 141: 481-484, 1984.

37. Kozlowski, S. and B. Saltin. Effect of sweat loss on body fluids. J. Appl. Physiol. 19: 1119-1124, 1964.

38. Kuipers, H., H. A. Keizer, F. Brouns and W.H.M. Saris. Carbohydrate feeding and glycogen synthesis during exercise in man. Pflü. Arch. 410: 652-656, 1987.

39. Leiper, J.B. and R.J. Maughan. Experimental models for the investigation of water and solute transport in man: implications for oral rehydration solutions. Drugs 36 (suppl. 4): $65-79,1988$.

40. Levens, N.R. Modulation of jejunal ion and water absorption by endogenous angiotensin after dehydration. Am. J. Physiol. 246: 6700-6709, 1984. 
41. Levinson, R.A, and H.P. Schedl. Nat, Cl-, and water absorption associated with the transport of simple sugars. Fed. Proc. 24: $527,1965$.

42. Macleod, J.J.R., H.E. Magee and C.B. Purves. Selective absorption of carbohydrates. J. Physiol. 70: 404, 1930.

43. Maughan, R.J. Thermoregulation and fluid balance in marathon competition at low ambient temperature. Int. J. Sports Med. 6: 15-19, 1985.

44. Maughan, R.J., L.B. Leiper and B.A. McGaw. Elfects of exercise intensity on absorption of ingested fluids in man. Exp. Physiol. 75: $419-421,1990$.

45. McHugh, P.R. and T.H. Moran. Calories and gastric emptying: a regulatory capacity with implications for feeding. Am.J. Physiol. 236: R254-R260, 1979.

46. Moses, F. The effect of exercise on the gastrointestinal tract. Sports Med. 9: 159-172, 1990.

47. Murray, R. The effect of consuming carbohydrate-electrolyte beverages on gastric emptying and fluid absorption during and following exercise. Sports Med. 4: 322-351, 1987.

48. Murray, R., J.G. Seifert, D.E. Eddy, G.L. Paul and G.A. Halaby. Carbohydrate feeding and exercise: effect of beverage carbohydrate content. Eur. J. Appl. Physiol. 59: 152-158.

49. Nadel, E.R., C.B. Wenger, M.F. Roberts, J.A.J. Stolwijk and E. Cafarelli. Physiological defences against hyperthermia of exercise. In: The Marathon: Physiological, Medical, Epidemiological and Psychological Studies, pp. 98-109, P. Milvy (Ed.), N.Y. Academy of Science, New York, 1977.

50. Neufer, P.D., D.L. Costill, W.J. Fink, J.P. Kirwan, R.A. Fielding and M.G. Flynn. Effects of exercise and carbohydrate composition on gastric emptying. Med. Sci. Sports Exerc. 18: 658-662, 1986. 
51. Neufer, P.D., D.L. Costill, M.G. Flynn, J.P. Kirwan, J.B. Mitchell and J. Houmard. Improvements in exercise performance: effects of carbohydrate feedings and diet. J. Appl. Physiol. 62: 983-988, 1987.

52. Neufer, P.D., A.J. Young, M.N. Sawka. Gastric emptying during exercise: effects of heat stress and hypohydration. Eur. J. Appl. Physiol. 58: 433-439, 1989.

53. Newsholme, E.A. and A.R. Leech. Biochemistry for the Medical Sciences, p. 337, John Wiley and Sons, Chichester, 1983.

54. Noakes, T.D., N. Goodwin, B.L. Rayner, T. Branken and R.K.N. Taylor. Water intoxication: a possible complication during endurance exercise. Med. Sci. Sports Exerc. 17: 370-375, 1985.

55. Nose, H., G.W. Mack, X. Shi and E.R. Nadel. Role of osmolality and plasma volume during rehydration in humans. J. Appl. Physiol. 65: 325-331, 1990.

56. Owen, M.D., K.C. Kregel, P.T. Wall and C.V. Gisolfi. Effects of ingesting carbohydrate beverages during exercise in the heat. Med. Sci. Sports Exerc. 18: 568-575, 1986.

57. Pirnay, F., M. Lacroix, F. Mosora, A. Luyckx, P. Lefebvre. Glucose oxidation during prolonged exercise evaluated with naturally labeled ${ }^{13}$ C-glucose. J. Appl. Physiol., 43: 258-261, 1977.

58. Riddoch, C. and T. Trinick. Gastrointestinal disturbances in marathon runners. Brit. J. Sports Med. 22: 71-74, 1988.

59. Rowell, L.B., J.R. Blackman and R.A. Bruce. Indocyanine green clearance and estimated hepatic blood flow during mild to maximal exercise in upright man. J. Clin. Invest. 43: 1677$1690,1964$.

60. Saltin, B. Aerobic work capacity and circulation at exercise in man. Acta Physiol. Scand. 62 (Suppl. 230): 1-52, 1964. 
61. Schedl, H.P. and J.A. Clifton. Solute and water absorption by the human small intestine. Nature 199: 1264-1267, 1963.

62. Sjovall, H. Evidence for separate sympathetic regulation of fluid absorption and blood flow in the feline jejunum. Am. J. Physiol. 247: G510-G514, 1984.

63. Sjovall, H., H. Abrahamsson, G. Westlander, R. Gillberg, S. Redfors, M. Jodal and $O$. Lundgren. Intestinal fluid and electrolyte transport in man during reduced circulating blood volume. Gut 27: 913-918, 1986.

64. Sole, C.C. and T.D. Noakes. Faster emptying for glucose-polymer and fructose solutions than for glucose in humans. Eur.J.Appl. Physiol. 58: 605-612, 1989.

65. Sullivan, S. The gastrointestinal symptoms of running. Letter. N. Engl. J. Med. 304: 915, 1981.

66. Sullivan, S. Exercise-associated symptoms in triathletes. Phys. Sports Med. 15: 105-108, 1987.

67. Varro, V., G. Blaho, L. Csernay, I. Jung and F. Szarvas. Effect of decreased local circulation on the absorptive capacity of a small-intestine loop in the dog. Am. J. Digest. Dis. 10: 170-177, 1965.

68. Volpicelli, N. Section 2. Nutritional and gastrointestinal aspects of sports. In: Sporis Medicine, pp 53-95, O. Appenzeller and $\tilde{R}$. Atkinson (Eds.), Urban \& Schwarzenberg, Baltimore, 1981.

69. van der Vusse, G.J., G.M.E. Janssen, W.A. Coumans, H. Kuipers, R.J.M.M. Does and F. ten Hoor. Effect of training and 15-, 25-, and $42-\mathrm{km}$ contests on the skeletal muscle content of adenine and guanine nucleotides, creatine phosphate, and glycogen. Int. J. Sports Med. 10 (suppl. 3): s146-s152, 1989. 
70. Wade, O.L., B. Combes, A.W. Childs, H.O. Wheeler, A. Cournand and S.E. Bradley. The effect of exercise on the splanchnic blood flow and splanchnic blood volume in normal man. Clin. Sci. 15: $457-463,1956$.

71. Wagenmakers, A.J.M., J.H. Coakley and R.H.T. Edwards. Metabolism of branched-chain amino acids and ammonia during exercise: clues from McArdle's disease. Int. J. Sports Med. 11 (suppl. 2): s101-s113, 1990.

72. Willians, J.H., M. Mager and E.D. Jacobson. Relationship of mesenteric blood flow to intestinal absorption of carbohydrates. J. Lab. Clin. Invest. 63: 853-863, 1964.

73. Worobetz, L.J. Gastrointestinal symptoms during exercise in enduro athletes: prevalence and speculations on the aetiology. N. Z. Med. J. 98: 644-646, 1985.

74. Wyndham, C.H. Heatstroke and hyperthermia in marathon runners. In: The Marathon: Physiological, Medical, Epidemiological and Psychological Studies, pp "129-138, P. Milvy (Ed.), N.Y. Academy of Science, New York, 1977. 


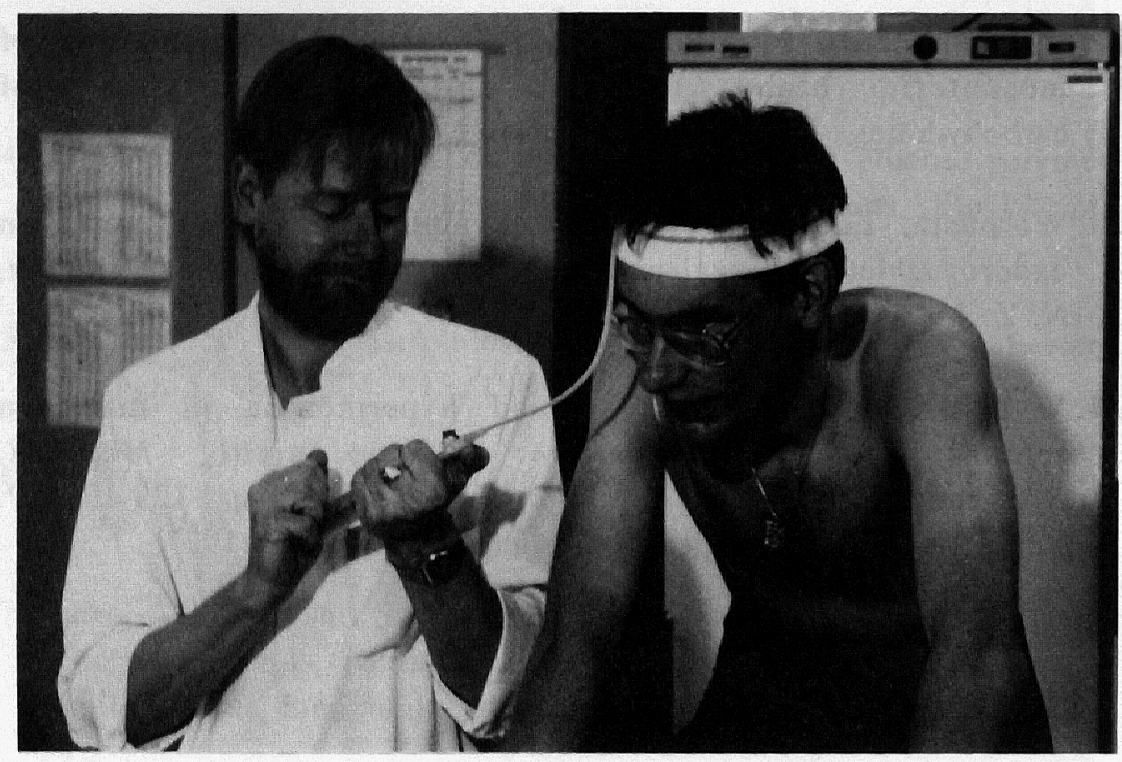




\section{CHAPTER 2}

\section{Exercise and training effects on gastric emptying of carbohydrate beverages}

\section{Abstract}

Carbohydrate containing drinks are commonly consumed as an ergogenic aid during endurance sports activities. The efficacy of a given drink is limited by the rate of absorption which is in turn limited by gastric emptying. A myriad of factors influence gastric emptying. The influence of several of these factors (training status, exercise intensity, and carbohydrate composition) was investigated by repeated experiments utilising a nasogastric tube and a double sampling, dye-dilution technique. A group of welltrained bicyclists and a group of untrained subjects performed similar experiments. Three different carbohydrate containing drinks (15 g. $100 \mathrm{ml}^{-1}$ glucose $(\mathrm{G}), 15 \mathrm{~g} .100 \mathrm{ml}^{-1}$ maltodextrin plus 3 g. $100 \mathrm{ml}^{-1}$ fructose (MD), 7 g. $100 \mathrm{ml}^{-1}$ sucrose (I)) and artificially sweetened water were compared during rest, $50 \%$ W max bicycling and $70 \%$ Wmax bicycling. Experimental design was cross-over. There was a trend for the carbohydrate drinks to empty initially slower under influence of exercise. The differences in mean percentage of bolus remaining in the stomach were significant $(p<.05)$ with $\mathbb{I}$ at $10 \mathrm{~min}(70 \%$ Wmax: $48.9 \%$, rest: $39.5 \%)$ and at $20 \mathrm{~min}(70 \% \mathrm{~W} \max : 28.9 \%$, rest: $23.8 \%)$ and with $\mathrm{MD}$ at $10 \mathrm{~min}(70 \%$ Wmax: $71.1 \%$, rest: $55.9 \%)$. A similar trend was also seen with $50 \%$ Wmax exercise, however this was only significant with $\mathrm{MD}$ at $10 \mathrm{~min}(50 \% \mathrm{Wmax}: 72.1 \%$, rest: $55.9 \%)$. Drink composition was a much stronger inhibitor of gastric emptying than exercise. However, all drinks emptied exponentially with a fast-phased initial emptying rate. No differences in gastric emptying or secretion were observed between trained and untrained subjects. 


\section{Introduction}

Fluid replacement during exercise, where sweat losses are substantial, is necessary to avoid dehydration and a concurrent reduction in performance $(7,30)$. In long lasting exercise another limiting factor in performance is energy supply, specifically carbohydrate. Since endogenous glycogen stores are limited the supplementation of a carbohydrate (CHO) source, which helps to maintain blood glucose (12), reduce endogenous CHO utilisation (27), and facilitate resynthesis of glycogen (25), can prolong exercise at a higher level of intensity $(3,10)$. The effectivity of hydration and supplementation is dependent upon transit and absorption in the gastrointestinal (GI) tract. Costill stated (9) that the rate of gastric emptying is one of the factors which limits the effectiveness of drinking nutrient containing fluids during marathon competition.

Numerous factors affect gastric emptying (GE), including volume, temperature, osmolality, energy density, acidity, as well as a number of specific nutrients. The influence of volume on GE is presumably related to pressure in the stomach. A linear increase in amount emptied has been shown with an increase in gastric content (20) up to a maximum of $600 \mathrm{ml}$ ingestate (11). Temperature of ingestate may also affect its emptying. In earlier studies, a cold meal or beverage has been observed to leave the stomach more quickly than a warm one $(18,11)$. It also appears that specific receptors in the duodenum sensitive to osmolality, energy density, and acidity as well as specific nutrients (e.g. fats, amino acids), when stimulated, delay GE.

Glucose solutions (at concentrations above $2.5 \%$ ) have been shown to empty slower than water as a function of concentration (11). Similarly, Brener et al. (4) found a fairly constant emptying rate of glucose from solutions, where the concentrations ranged from 5 g.100 ml-1 to $25 \mathrm{~g} .100 \mathrm{ml}^{-1}$, providing approximately 8.91 kJ.min ${ }^{-1}$ to the intestimes. This, as well as studies comparing solutions of differing osmolalities $(1,8)$, indicates that a feedback mechanism from the intestines acts upon the stomach. Hunt and Pathak (21) hypothesised a theory of receptor swelling (signal to allow GE) or shrinking (signal to inhibit GE) in response to a sodium shift induced by the osmolality of a given drink. 
Isotonic salline solutions have been found to empty more rapidly than water $(19,21,15)$. This is probably due to the presence of sodium influencing the sodium shifts into the osmoreceptor.

Studies on effects of exercise on GE are equivocal. It appears that exercise at a high level of intensity $\left(>70 \% \mathrm{VO}_{2} \max\right.$, bicycling) may inhibit $\mathrm{GE}$ (15). However, exercise at a lower intensity (50-70\%. $\stackrel{\mathrm{V}}{\mathrm{O}}{ }_{2} \max$, running) appears to enhance $\mathrm{GE}$ (28). Problems of interpreting results may stem from inconsistencies in procedure, type of exercise, and the practice of testing one type of drink after the other. Neufer et al. (28), Foster, Costill, and Fink (16), Costill and Saltin (11), and Fordtran and Saltin (15) all tested several drinks sequentially and in fasted subjects. This type of multiple testing in one experiment may confound experimental error, due to the fact that the duodenal contents from a previous drink may influence GE (6). Although Thompson and Foster (31) found no effect of a previous beverage, the time in between drinks was much less than is often found between two experiments. Furthermore, the simple determination of gastric residue after a certain period of time gives a figure with respect to the amount of fluid that has left the stomach but does not allow for conclusions on GE rate over time.

The number of studies cited which indicate GI problems occur frequently in runners compared to the absence of this type of reportage of similar problems in cyclists (6) suggests that the exercise induced influence on GI function and regulation may differ due to different types of body movement. This makes generalization from cycling experiments to running questionable. To sort out underlying principles and enable one to make practical suggestions as to drinking during exercise for optimal hydration and energy supply as well as minimal GI complaints, well controlled studies need to be done. Conditions should be as close to the practical situation as possible, and conditions should be held constant for various drinks which are to be tested as well as varying types of exercise which are to be compared. Beginning experimental testing of a sport drink in an athlete in the fasted state does not reflect the ypical pre-exercise situation.

The fact that practice indicates that GI disturbances occur frequently in runners especially at higher training intensities, and in those individuals who are less well trained, should also be considered $(23,29)$. 
These facts led to the development of a research project, addressing some of the questions regarding GE during exercise where conditions would be standardised. The various factors were taken into account which may blur results, while a practical situation was simulated. Although the protocol designed, including the ingestion of a large volume of fluid immediately prior to competition (pre-hydration), is not typically practiced by longdistance runners, an attempt has been made to create the ideal situation. Therefore the present study was designed, simulating an ideal practical situation in which $\mathrm{GE}$ and secretion in trained and untrained subjects were examined. The effects of exercise at two different intensity levels, and the efficacy of several commonly consumed $\mathrm{CHO}$ containing beverages in terms of fluid and energy delivery were also studied.

\section{Materials and methods}

\section{Subjects}

Sixteen healthy male subjects, eight trained and eight untrained, aged 18 to 30 , participated in the experiment. Selection was made according to strict criteria. Criteria for trained included bicycling $\geq 350 \mathrm{~km}$. week ${ }^{-1}$ and participation in official competitions. Although no prior selection was made according to whether drinking was practiced during exercise, post-selection questioning revealed that all trained subjects drank regularly during exercise, carbohydrate containing beverages being made continually available during competition by a coach or trainer. To be considered untrained one must not have bicycled more than 50 $\mathrm{km}$. week $\mathrm{k}^{-1}$ and not have been trained in any other endurance sport. All subjects were given complete details of the experiment and thereafter written informed consent was obtained. Mean values for maximal performance capacity achieved in an incremental cycle ergometer test (Wmax) as well as general characteristics of both groups of subjects are presented in Table 1. One subject among the untrained group brought up the average maximal values. However, in terms of his daily activities, lack of endurance training and competition, he fulfilled the prerequisites and was not omitted from this group. 
Table 1. Subject characteristics

Untrained Trained

\begin{tabular}{|c|c|c|}
\hline Age (yr) & $23.8 \pm 0.9$ & $20.8 \pm 1.1$ \\
\hline Weight $(\mathrm{kg})$ & $76.0 \pm 2.2$ & $74.8 \pm 3.2$ \\
\hline $\mathrm{V}_{2} \max \left(1 . \mathrm{min}^{-1}\right)$ & $4.1 \pm 0.2$ & $4.4 \pm 0.7$ \\
\hline$\left(\mathrm{ml} \cdot \mathrm{min}^{-1} \cdot \mathrm{kg}^{-1}\right)$ & $53.5 \pm 2.7$ & $59.0 \pm 2.5$ \\
\hline$W \max (W)$ & $324.0 \pm 14.9$ & $392.0 \pm 16.9$ \\
\hline$\left(W \cdot \mathrm{kg}^{-1}\right)$ & $4.3 \pm 0.2$ & $5.2 \pm 0.1$ \\
\hline
\end{tabular}

Wmax was obtained using cycle ergometry.

Values are mean $\pm S E . N=8$ for both trained and untrained.

\section{Treatments}

GE of four different drinks was compared: water (control), two different commercially available sport drinks, and a $15 \%$ glucose solution. The control drink was artificially sweetened with aspartame and contained no added minerals. The two sport drinks were an isotonic, primarily disaccharide drink (Isostar(B) and a hypertonic, primarily maltodextrin (glucose polymer) drink (Perform(B): Included in the maltodextrin drink were $63.4 \mathrm{~g}$.

$100 \mathrm{~g}^{-1}$ maltodextrin $10 \mathrm{DE}$ (dextrose equivalent: the reducing power of a starch product expressed as D-glucose on the dryweight basis) and $16.5 \mathrm{~g} .100 \mathrm{~g}^{-1}$ maltodextrin $40 \mathrm{DE}$. These two drinks were chosen for several reasons. One reason is that both beverages are commonly consumed by athletes in Europe. The other reason that these two commercial drinks were chosen is based upon the disparate carbohydrate compositions and consequently different usages. An isotonic beverage is assumed to empty and be absorbed quickly, and as such is recommended for fluid replacement regimes. For comparison, a hypertonic beverage was chosen which is recommended for carbohydrate supplementation during extremely long, intensive exercise, when endogenous glycogen reserves are limiting. This beverage was used in a Tour de France simulation experiment by Brouns et al. 


\section{Chapter 2}

and was found to improve performance significantly (5).

The $15 \%$ glucose drink was made in the laboratory. It had a simillar mineral composition and glucose concentration as that contained in the maltodextrin drink. Complete compositions of the beverages are presented in Table 2 .

\section{Table 2. Beverage compositions}

Treatments

Control Isotonic Maltodextrin Glucose

\begin{tabular}{lrrrr}
\hline Maltodextrin $\left(\mathrm{g.l} \mathrm{I}^{-1}\right)$ & - & 10.0 & 152.0 & - \\
Sucrose $\left(\mathrm{g. \textrm {I } ^ { - 1 }}\right)$ & - & 62.0 & - & - \\
Fructose $\left(\mathrm{g} . \mathrm{I}^{-1}\right)$ & - & - & 32.0 & - \\
$\mathrm{Glucose}\left(\mathrm{g} . \mathrm{I}^{-1}\right)$ & - & - & - & 152.0 \\
$\mathrm{Na}^{+}\left(\right.$meq. $\left.\mathrm{I}^{-1}\right)$ & - & 24.3 & 6.1 & 6.0 \\
$\mathrm{~K}^{+}\left(\right.$meq. $\left.\mathrm{I}^{-1}\right)$ & - & 3.9 & 16.9 & 15.8 \\
$\mathrm{Cl}^{-}$(meq. $\left.\mathrm{I}^{-1}\right)$ & - & 12.0 & 6.0 & 6.0 \\
\hline
\end{tabular}

$\mathrm{GE}$ at rest, during exercise (bicycling) at $50 \% \mathrm{~W}_{\max }$, and during exercise at $70 \% \mathrm{Wmax}$ were compared. Wmax was used instead of $\mathrm{VO}_{2} \max$ since no control of oxygen utilization was possible during exercise with the nasogastric tube in place. Each subject was tested no more than 2 weeks before his first experiment to determine the maximal workload that could be achieved during a standardised progressive bicycle ergometer test (24). Trained and untrained subjects performed identical tests. However, the trained subjects bicycled for $80 \mathrm{~min}$ and the untrained for $60 \mathrm{~min}$ due to the inability of most untrained subjects to maintain $70 \% \mathrm{Wmax}$ intensity for such a long period of time. 


\section{Experimental Design}

Control (C), maltodextrin (MD), and isotonic (1) drinks were consumed by all subjects under all conditions. The glucose trial (G) at $70 \%$ Wmax, was conducted by three of the eight trained and three of the eight untrained subjects as displayed in Table 3.

Treatments were assigned blind to the subjects in random order. All tests were conducted in the laboratory at $20{ }^{\circ} \mathrm{C}$ with continuous air conditioning and direct fans on each subject.

Subjects arrived at the laboratory in a $12 \mathrm{~h}$ fasted state. At 8:00 a.m. a standardised breakfast was administered to simulate the practical pre-exercise situation and to standardise the composition of duodenal contents at the time of the test as much as possible, since mutrients in the duodenum are known to influence GE. A low-fat liquid meal (Powerplay(B), $5 \mathrm{ml} . \mathrm{kg}$ body weight $(\mathrm{BW})^{-1}$ ) was chosen since fat is a strong inhibitor of GE and particulate matter from solid food could clog the nasogastric tube. The average energy content of the breakfast was $1500 \mathrm{~kJ}$, comprised of $24 \mathrm{en} \%$ protein, $63 \mathrm{en} \%$ carbohydrate, and $13 \mathrm{en} \%$ fat.

A nasogastric tube (silicon, French 14) was placed $75 \mathrm{~min}$ after breakfast was given and the stomach was emptied. Thereafter a recovery test was performed for control of the positioning of the tube tip: $100 \mathrm{ml}$ was infused and $80 \mathrm{ml}$ or more recovery was required. The stomach was then repeatedly washed with water until no further residue was obtained. Exercise protocol was designed to mimic the first part of a longer lasting endurance event.

Ten minutes prior to administration of the drink, subjects began bicycling for a warm-up at $30 \%$ Wmax. During the warm-up the drink was given. The administration of the test drink occurred exactly two hours after breakfast. The amount of drink given was based on body weight $\left(8 \mathrm{ml} . \mathrm{kg} \mathrm{BW}^{-1}\right)$ to account for differences in digestive capacity and energetic needs of subjects of varying body size. The selected drink contained a known amount of phenol red dye and was held at $15^{\circ} \mathrm{C}$. It was administered via the nasogastric tube and mixed with whatever gastric contents were remaining. The initial sample was taken immediately, so that remaining gastric contents could be accounted for in determining initial dye 


\section{Chapter 2}

concentration at time $=$ zero. Exercise continued immediately after administration of the drink. At intervals of 10 or $20 \mathrm{~min}$ according to schedule (Fig. 1) gastric samples were taken.

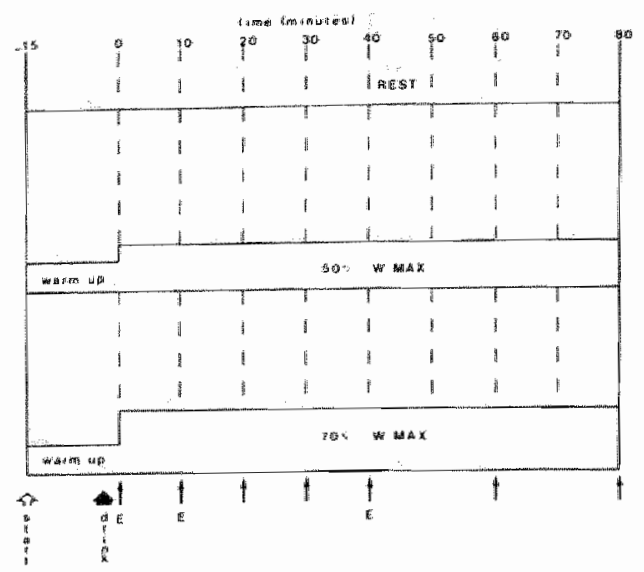

Fig. 1. Time schedule for each experiment. The arrows indicate gastric sampling. For each sample volume, secretion, osmolality, and chloride measurements were made. In the samples labeled $E$ energy content was also determined by bomb calorimetry.

Each sequential sampling was two phased. A first sample was taken of 3,5 , or $7 \mathrm{ml}$. At 0 and $40 \mathrm{~min}, 7 \mathrm{ml}$ samples were taken and at $10,20,60,80 \mathrm{~min} 5 \mathrm{ml}$ samples were taken and at $30 \mathrm{~min}$ a $3 \mathrm{ml}$ sample was taken. For volume/secretion measurements 3 $\mathrm{ml}$ was needed. Two $\mathrm{ml}$ was additionally needed for energy measurements and another $2 \mathrm{ml}$ was needed for mineral measurements (results described in Chapter 5). After the initial sample was taken, additional dye was added and mixed, and then a second sample $(1 \mathrm{ml})$ was taken. In this manner both secretion and volume changes could be calculated. The volume lost by sampling was replaced with phenol red dye. 
The method described is a modification of the method of George (17) where gastric volume and secretion can be determined. Additional calculations were added to allow for serial sampling. The basic formula is presented below:

$$
V_{n}=\frac{A_{n b}}{A_{(n-1) a}} \cdot \frac{A_{(n-1) b}}{A_{(n-2)} a} \cdot \frac{A_{2 b}}{A_{1 a}} V^{t_{1}}
$$

where $\mathrm{Vt}_{\mathrm{n}}=$ volume of test drink still present in the stomach at the $\mathrm{n}$-th determination of the volume of gastric contents $(\mathrm{ml}) ; \mathrm{V}^{\mathrm{t}}{ }_{1}$ $=$ volume of the original test drink $(\mathrm{ml}) ; A_{n b}=$ amount of dye in gastric contents before adding dye $\left(\mathrm{mg} \cdot \mathrm{ml}^{-1}\right) ; \mathrm{A}_{\mathrm{na}}=$ amount of dye in gastric contents after adding dye $\left(\mathrm{mg}^{-\mathrm{ml}^{-1}}\right)$ and where $\mathrm{n}$ designates sample and $n-1$ designates the prior sample. For complete details of calculations see Beckers et al. (2). As a double check chloride was also measured using the method of Hunt, for calculated secretion values (22).

\section{Analyses}

The changes in dye concentration were measured spectrophotometrically. Chloride was measured coulometrically using an Eppendorf 6610 Chloridmeter@. Osmolality was measured by the freeze-point method using a Osmomat 030 osmometer (Gonotech, Germany). Energy content of the samples was determined by bomb calorimetry (IKA, Germany).

Analysis of variance (ANOVA) for repeated measures was conducted to assess training effects and treatment effects and to look for possible interaction. Individual treatment effects at each sample point were compared using the Wilcoxon's signed-rank test for non-parametric data, with a confidence level of $\mathrm{p}<0.05$. 
Total emptying curves were compared using semi-log plots of gastric residue versus time since emptying curves were exponential. A comparison of slopes was used to indicate relative speed of emptying. Semi-log plots only included sampling times where the average amount of drink remaining in the stomach was equal to or greater than $1 \%$.

\section{Results}

\section{Gastric emptying}

Preliminary analysis of the results obtained in trained and untrained subjects did not reveal any significant differences between these two groups with respect to gastric emptying or secretion within the first $60 \mathrm{~min}$ of exercise. Analysis of variance confirmed this obserwation. Thus in tables and graphs data for all subjects are pooled.

The effect of exercise on gastric emptying at each sampling time is shown in Fig. 2. Semi-log plots of these data are displayed in Fig. 3. No significant differences were found with the control drink using Wilcoxon's signed-rank test in comparing gastric residues at each sampling time. With the isotonic drink (I) the mean volume remaining in the stomach was significantly greater during $70 \%$ Wmax exercise than at rest at $10 \mathrm{~min}(48.9$ and $39.5 \%$, resp. $\mathrm{p}<.05)$ as well as at $20 \mathrm{~min}(28.9$ and $23.8 \%$, resp. $\mathrm{p}<.05)$. With the hypertonic maltodextrin drink (MD) a significantly larger mean volume remained in the stomach during both $50 \%(72.1 \%$ ) and $70 \%$ Wmax exercise $(71.1 \%)$ than at rest $(55.9 \%)(p<.05)$ after 10 min. Although the trend continued throughout the sampling period the differences were only again significant at $40 \mathrm{~min}(70 \%$ Wmax: $33.8 \%$; rest: $28.1 \%, \mathrm{p}<.05$ ).

The ANOVA revealed no significant variation in remaining drink volume as a result of exercise. However the effects of drink $(F=91.88, \quad p<.05)$ and sample time $(F=354.84, p<.05)$ were significant.

There is, however, a trend towards decreased GE with increasing exercise intensity. This was observed only with the CHO containing beverages, with the largest notable differences occurring in the first 10-20 min. This is supported in the ANOVA model by significant interactions in the drink by sample time and exercise 
by sample time comparisons $(p<.01)$. When the residual volumes for rest, $50 \% \mathrm{Wmax}$, and $70 \% \mathrm{Wmax}$ are compared by drink at each sample time these differences are apparent.
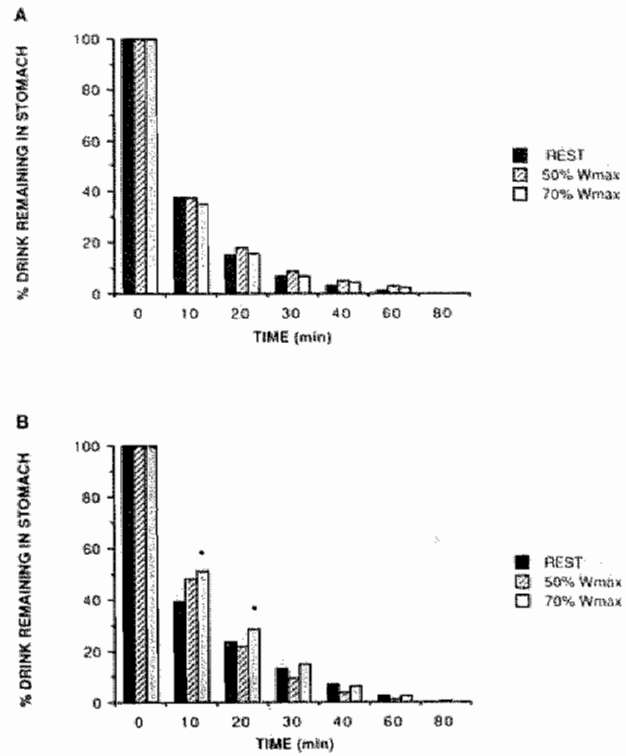

C
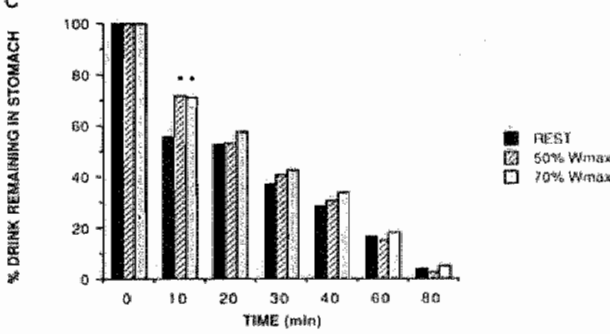

Fig. 2. Effects of exercise on emptying rates of control drink (A), isotonic drink (B) and maltodextrin drink (C). Asterisks represent significant difference from rest, $p<05$. 

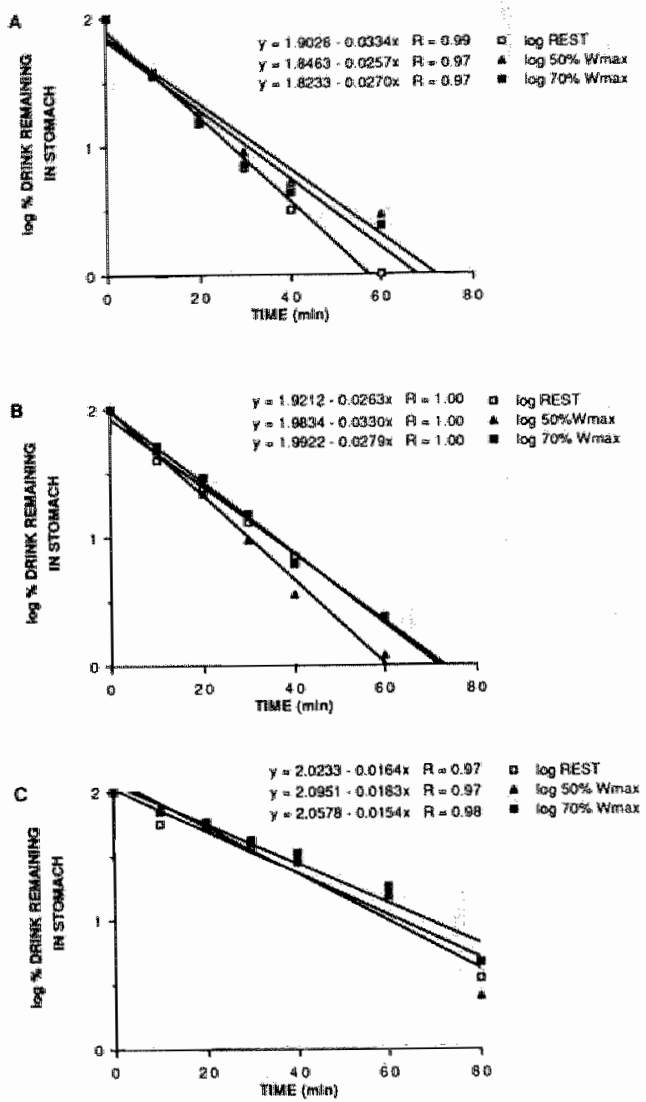

Fig. 3. Semi-log plot of gastric beverage residue versus time at each exercise intensity for control drink (A), isotonic drink (B), and maltodexirin arink (C). 
The effect of drink composition on gastric emptying is presented in Fig. 4 and semi-log plots of these data are presented in Fig. 5. Drink composition was observed to be a strong effector of gastric emptying.
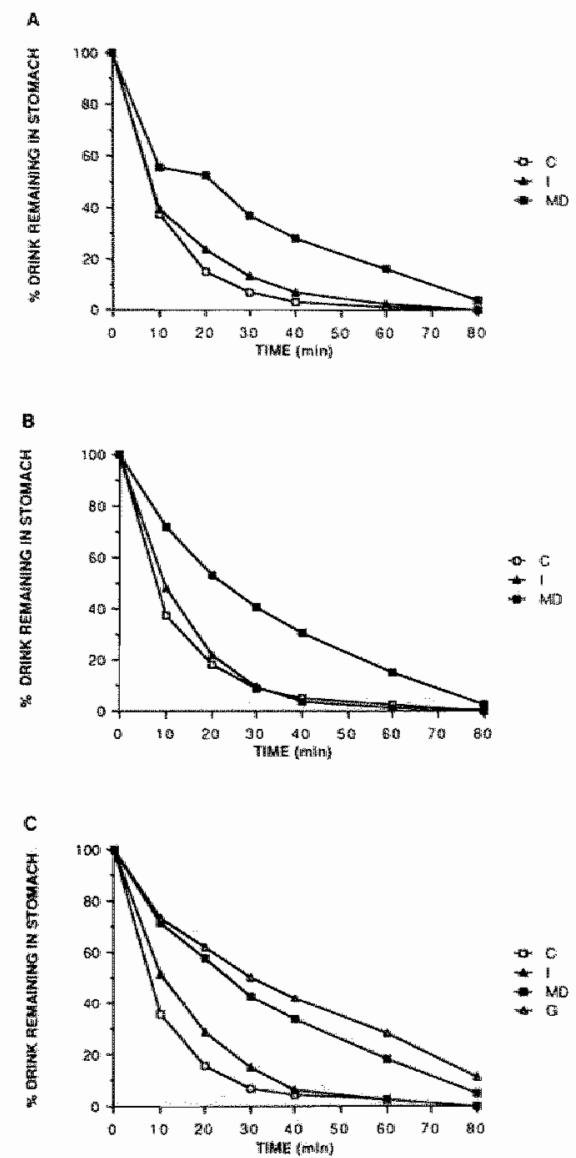

Fig. 4. Effect of drink composition on GE during rest (A), 50\% Wmax cycling $(B)$, and $70 \%$ Wmax cycling $(C)$. Under all conditions, at all times gastric beverage residue was significantly greater for $M D$ than for $C$ and I. In rest there were no significant differences between $I$ and $C$. During $50 \%$ Wmax exercise at $10 \mathrm{~min}$ and $70 \%$ Wmax exercise at 10, 20, $30 \mathrm{~min}$ beverage residue in $I$ was significantly greater than in $C$. Beverage residue of $G$ was significantly greater than $C$ and $I$ at all points and from $M D$ at 30 and $60 \mathrm{~min}$. 

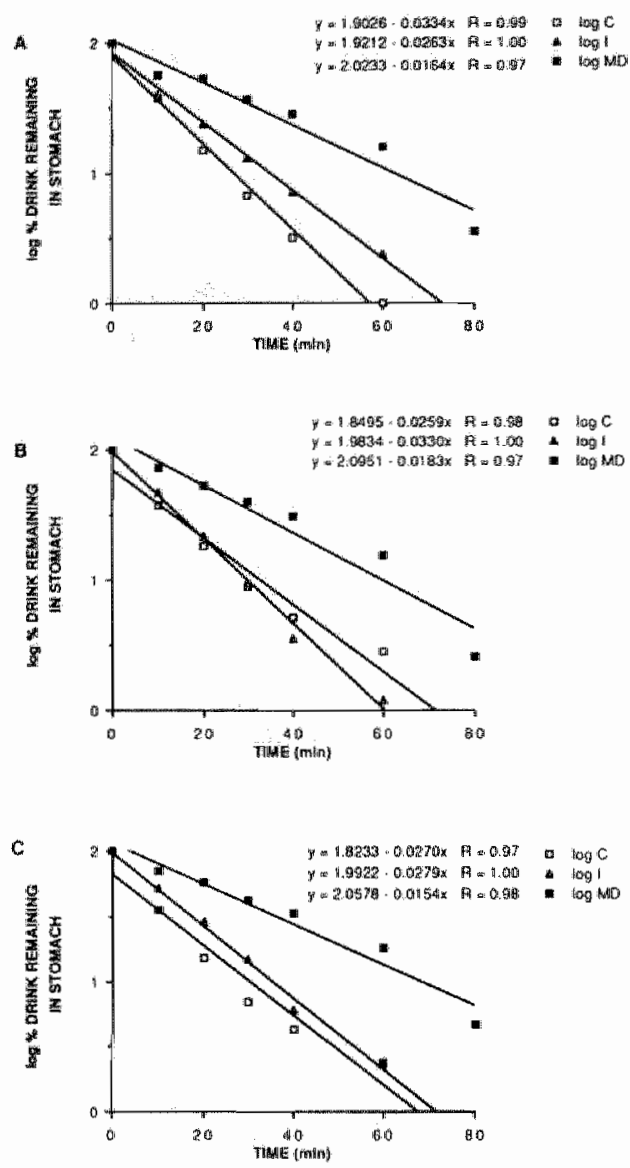

Fig. 5. Semi-log plot of gastric beverage residue versus time by drink sort during rest (A), 50\% Wmax bicycling (B), and $70 \%$ Wax bicycling $(C)$. 
The drink slowest to empty at $70 \%$ Wmax was the hypertonic glucose drink $(G)$. Although the rate of emptying of $G$ was consistently slower than that of $\mathrm{MD}$, the only significant differences in mean residual drink volume were observed at 30 $\min (\mathrm{G}: 50.0 \mathrm{ml} ; \mathrm{MD}: 42.2 \mathrm{ml}, \mathrm{p}<.05)$ and at $60 \mathrm{~min}(\mathrm{G}: 28.2 \mathrm{ml} ; \mathrm{MD}$ : $18.3 \mathrm{ml}, \mathrm{p}<.05$ ).

GE of MD was significantly slower than both $I$ and the control drink (C) over all sample points, under all conditions, rest, and $50 \%$, and $70 \%$ Wmax. In comparing semi-log emptying curves over the total time to emptying (Fig. 5) for rest, $50 \% \mathrm{Wmax}$ exercise, and $70 \%$ Wmax exercise, no consistent differences were observed between $\mathrm{C}$ and I. However, at several time points in the first half of the exercise experiments the amounts emptied for $C$ were larger than for I. At $10 \mathrm{~min}(\mathrm{p}<.05), 50 \% \mathrm{Wmax}$ and at $10 \mathrm{~min}$ $(p<.01), 20$ min $(p<.01)$, and $30 \mathrm{~min}(p<.01) 70 \%$ Wmax these differences were significant.

$G$ had the highest osmolality, however, a lower caloric density than the hypertonic, primarily glucose polymer solution (MD) which, although equal in glucose units, contained an added $3.2 \%$ fructose. Results of freeze-point osmolality and bomb calorimetry analyses are presented in Table 4. Emptying rates along with measured energy values set out as $\mathrm{kJ}$ passed per minute averaged over the first $40 \mathrm{~min}$ are also presented in Table 4 . When average emptying rates were compared no significant difference between $\mathrm{C}$ and I, at $70 \% \mathrm{Wmax}$, was observed. Although the energy content of $I$ is much less than that of $G$, the energy flow was nevertheless similar due to the approximately doubled emptying rate of I. MD emptied much slower than I, however the energetic contribution per min was greater from $\mathrm{MD}$.

The emptying curves were also analysed as to best line fit. The Rvalues for emptying rates (exponential lines) for $\mathrm{G}, \mathrm{MD}$, and I were all 0.98 and 0.99 for $C$. This validates what can be visually observed in all emptying curves presented, that with a bolus of approximately $600 \mathrm{ml}$, a fast-phase emptying occurs in the first $10 \mathrm{~min}$, thereafter followed by a tapering in the emptying rate.

Calculating the flow of energy out of the stomach per time interval (Table 5) reveals an energy delivery also exponential, which provides variable amounts of energy to the intestines over the time course of emptying. Energy flow is greatest when the volume remaining in the stomach is largest. 
Chapter 2

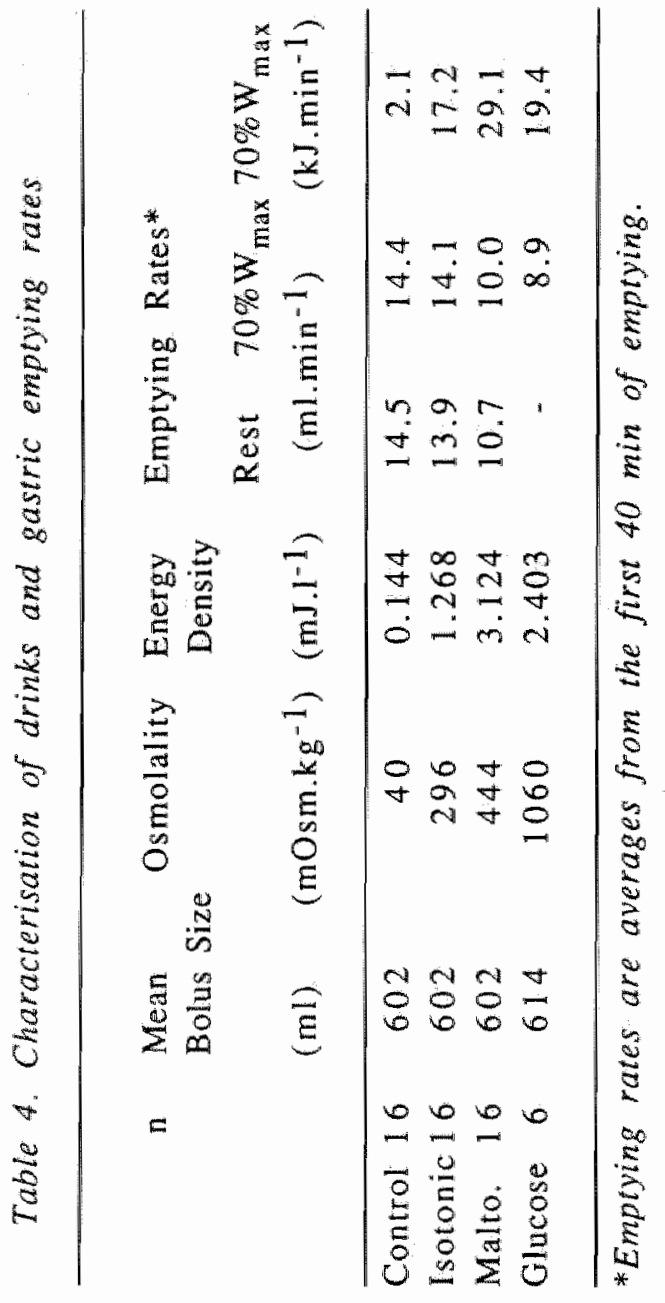




\section{Chapter 2}

\section{Gastric secretion}

Gastric secretion with $\mathrm{C}, \mathrm{I}$ and $\mathrm{MD}$ in rest, during $50 \% \mathrm{Wmax}$ bicycling and during $70 \%$ W $\max$ bicycling is presented in Fig. 6 . Total gastric secretion over the 30 min period in which $I$ and $C$ in the majority of subjects had emptied was nominally affected by exercise.
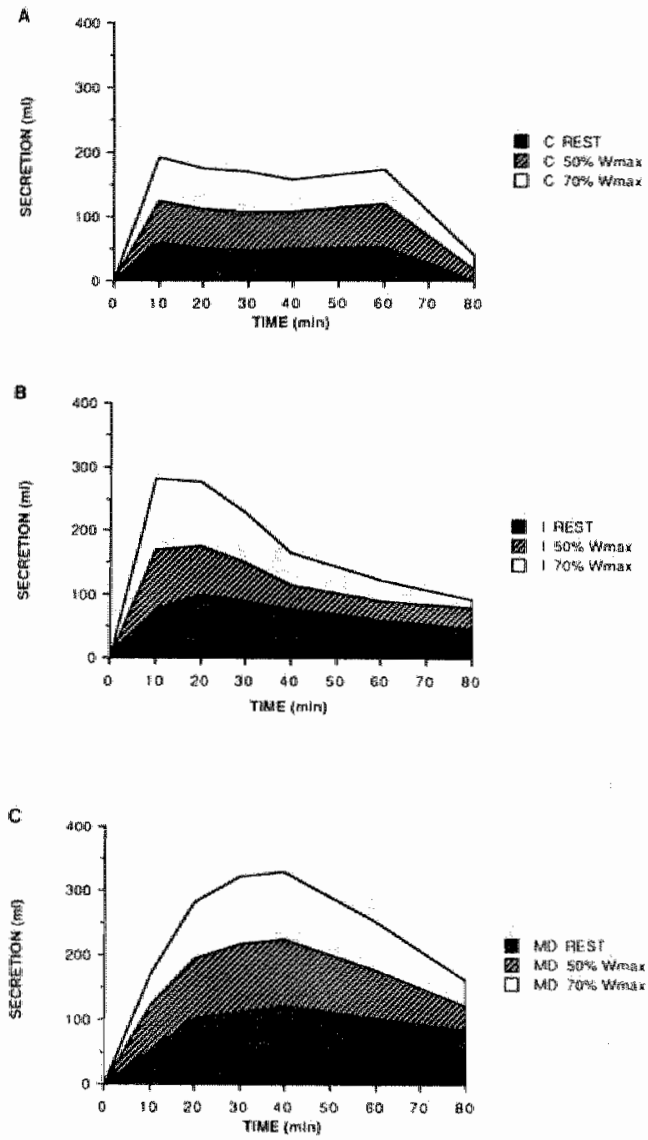

Fig. 6. Effect of exercise on gastric secretion with contral drink (A), isotonic drink (B), and maltodextrin (C). Curves are depicted one above the other and are not additive. 
There was a trend towards greater secretion with increased exercise intensity. During $50 \%$ Wmax cycling mean summation of secretion values over total exercise time was $247 \mathrm{ml}$, while during $70 \%$ Wmax cycling mean secretion was $364 \mathrm{ml}(\mathrm{p}<.05)$.

However, with MD, where the majority of subjects who completed the test to 80 min still had small but measurable amounts of drink in the stomach, the effect of exercise was reversed. During rest the largest total secretion was measured (mean $=627 \mathrm{ml}$ ). This was significantly greater than that measured during $50 \%$ Wmax exercise $(436 \mathrm{ml})$ or during $70 \%$ Wmax exercise $(344 \mathrm{ml})(\mathrm{p}<.05)$. In Fig. 7 the mean total secretion during $70 \%$ Wmax exercise with all four drinks is depicted. The mean gastric secretion with $G$ appears to be larger $(755 \mathrm{ml})$ than with $\mathrm{MD}$, however this difference was not significant.

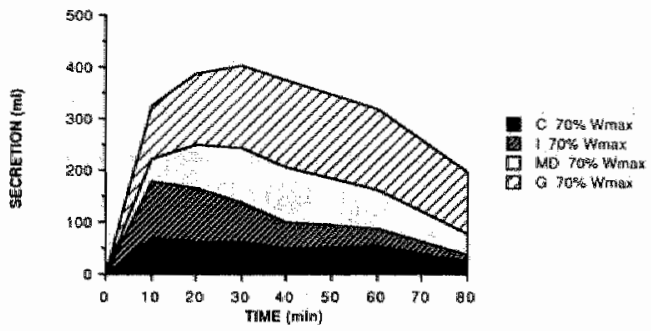

Fig. 7. Total gastric secretion with all four drinks at 70\%. Curves are depicted above one another and are not additive.

Since there were only complete secretion data for $80 \mathrm{~min}$ from only three individuals, statistics were conducted on the total secretion at $60 \mathrm{~min}$. Mean total secretion at $60 \mathrm{~min}$ was $461 \mathrm{ml}$ for $M D$ and $743 \mathrm{ml}$ for $G$ with $70 \%$ Wmax exercise. This difference in secretion was still not significant $(\mathrm{p}=079)$. The still small sample size $(n=5)$ and large standard deviations account for this lack of significance ( $S D=216$ and 162 , resp.). 


\section{Discussion}

Although GI distress is common in young and less well-trained runners $(23,24)$, a training effect on $\mathrm{GE}$ while bicycling based upon differences in aerobic capacity or the practice of drinking during strenuous exercise was not observed. This inconsistency may be a result of the varying types of exercise.

The shock, or increased vibration, resulting from running may induce $G$ disturbance more frequently in less well-trained runners where the surrounding musculature of the GI tract is less well developed. It may also be that young and inexperienced athletes exercise at a higher percentage of their maximal capacity. An altered $\mathrm{GE}$ is commonly associated with GI distress; however, it remains uncertain whether an altered GE induces this distress or results from it. The effect of exercise on GE is not large at exercise intensities equal to or less than $70 \% \mathrm{Wmax}$, when the body is "stationary" as in bicycling on an ergometer. However, the tendency towards decreased GE with increased exercise intensity (bicycling) is in line with the findings of Fordtran and Saltin (15) who found a slightly decreased GE of water but not of a $13 \%$ glucose solution with bicycling $>70 \% \mathrm{VO}_{2} \max$. Because the two drinks were tested sequentially on the same day it is difficult to conclude which drink actually effected this decrease. Unique in the present study was that the tendency towards decreased GE with increased exercise intensity was only revealed in drinks containing $\mathrm{CHO}$ and was most pronounced in the more concentrated $\mathrm{CHO}$ drink. However, because increased CHO concentration in the only two drinks tested at rest, $50 \%$ Wmax, and $70 \%$ Wmax is also coupled with increased osmolality, it is not clear which factor is more important, in combination with exercise, in reducing the gastric emptying rate.

Neufer et al. (28) found an increased GE with running intensities up to $70 \% \mathrm{VO}_{2} \mathrm{max}$. In the present study no evidence was gathered to support this result. However, in running, the biomechanically based vibrations experienced by the gastrointestinal region may result in another sort of emptying curve. Data from a controlled field study show that the amount of vibrational movement to the abdominal region is approximately doubled in running versus bicycling (Rehrer and Meijer, 1990). 
Also, in Neufer et al.'s work the stomach was not repeatedly sampled but a test was stopped after $20 \mathrm{~min}$ in every trial and the volume was determined at this point only. Thus, the prominent early effects, in which the fast-phase may be influenced, and the relative times to total emptying remain unknown.

Another possible source of error in other studies is an omission of measurement of initial volume of stomach content previous to the administration of the test drink. It is assumed that the stomach was "empty" when no further sample can be extracted. However, from our work, where the initial drink (with dye) was added to an "empty" stomach, mixed, and a sample immediately taken, this sample revealed, in the majority of cases, that the stomach was not completely empty. On the average ( \pm SE) a remaining volume of $78.9 \pm 5.4 \mathrm{ml}$ was found.

The accuracy of volume and secretion measurements is substantiated by conferring measurement of chloride concentration as well as energy content in gastric samples. The possibility for errors in measurements of remaining drink in the stomach at a particular time is small, compared to other methods which do not include an accurate calculation of secretion. Another advantage to this repeated, double sampling technique is the opportunity of continued sampling after one sample is taken. Continued sampling has an advantage over a test situation in which the first day a subject is tested $10 \mathrm{~min}$, the second day 20 min etc., in measuring the time course of emptying. The possible day-to-day variation within one emptying curve is omitted and the method saves time.

In comparing the different types of drink and their influence on GE one may conclude that osmolality is one of the largest determining factors. An effect of osmolality on $G E$ was first postulated by Carnot and Chassevant (8) and later substantiated by others $(18,21)$. Energy content, carbohydrate source and concentration may also play a role. However, based upon the results of this study, energy content is not the sole determining factor. 
Brener et al. (4) and McHugh and Moran (26) found a linear relationship between the caloric content within a given $\mathrm{CHO}$ source (glucose) and delay in GE, resulting in a fixed caloric flow through the pylorus; however in our study, with differing $\mathrm{CHO}$ sources and concentrations, the energy flow through the pylorus varied greatly.

The contribution of glucose to the energy content in $\mathrm{MD}$ and $\mathrm{G}$ was alike. However, added fructose in MD increased the total energy content of this drink. Nevertheless, MD did not empty slower than $\mathrm{G}$. One possible explanation is that fructose is passively absorbed and as such has little effect on GE, because it is not competing with glucose for active sites of transport. One other explanation is that the much lower osmolality of MD compensates for any increased nutrient or energy induced negative feed-back from the intestinal site of absorption to the stomach. However, the proposed theory of osmoreceptors, lying functionally deep to maltase and isomaltase (14) would imply that the osmolality would greatly increase by the time that the products of enzymatic degradation of maltodextrin would have reached the osmoreceptor, negating the original difference in osmolality between $G$ and MD. However " if the osmoreceptors are primarily found in the upper duodenum and if, as Davenport (13) suggests, the majority of oligosaccharidases are found in the lower jejunum and upper ileum, then some degree of osmotic difference between these two drinks would still be present because a large portion of maltodextrin will be enzymatically split after having passed the osmoreceptors. Foster, Costill, and Fink (16) found somewhat faster $\mathrm{GE}$ with a glucose polymer solution versus free glucose solution. Similar to the results from $M D$ and $G$ in the present study the gastric residues with free glucose were consistently larger than with a glucose polymer, but there was little statistical significance except at low concentrations ( $5 \mathrm{~g} .100 \mathrm{ml}^{-1}$ ). In their study Foster et al. also found increased gastric secretion with a free glucose solution versus a glucose polymer solution. However, the differences in emptying rate observed may well be accounted for by the secretion differences since only total gastric residue was compared. Nevertheless, results of the present study appear to support the findings of Foster et al., although the differences in $\mathrm{GE}$ rates of the free glucose and polymer solutions aren't of the 
magnitude of the differences in osmolality. It is possible that with a larger sample size the differences in G and MD would become significant for GE and particularly for gastric secretion where the standard deviation was large.

It is clear that several factors influence GE. One of the factors which was held constant at the onset of every test for each subject was bolus size. This factor appears to be one of the most influential. Apparently stretch receptors respond to distention of the stomach. The fast-phase emptying that was noted within the first $10-20 \mathrm{~min}$ after ingestion with all drinks, as well as the greater rates $\left(\mathrm{ml}^{\mathrm{min}}{ }^{-1}\right)$ of emptying when larger gastric residues were found, support this idea. This early fast emptying phase observed with all drinks, including the non-carbohydrate containing drinks, resulted in exponential emptying curwes when a large bolus was initially given.

An unanswered question remains: if the stomach is continuously refilled, thus maintaining this distention, is the fast-phase rate of emptying continued or do the other factors, e.g. feed back signals from the site of absorption, over-ride this stimulus?

An advantage of water above an isotonic, carbohydrate beverage in terms of GE was not found. The rate of fluid replacement from the isotonic beverage tested is comparable to a non-carbohydrate containing beverage (water). Because in both $\mathrm{I}$ and $\mathrm{C}$ more than $50 \%$ of the $8 \mathrm{ml} . \mathrm{kg} \mathrm{BW}^{-1}$ bolus was emptied in $10 \mathrm{~min}$ and, in the majority of subjects, the total bolus in $60 \mathrm{~min}$, the differences noted at two specific sample points are not of physiological significance. Thus an isotonic, carbohydrate solution may have the maximum replenishment rate of both water and energy. However, if energy is the prime limiting factor then a more concentrated solution would be advised, with maltodextrin (long-chained glucose polymer) as the preferred carbohydrate, based on the high energy flow and low secretion rates.

Differences in training or experience drinking during exercise appear to play no role in the determination of the gastric emptying curve of a large bolus consumed at the onset of bicycling exercise. If there is an influence of training on the incidence of GI dysfunction it is not simply related to a training effect on gastric emptying. 


\section{References}

1. Barker, G.R., G. McL. Cochrane, G.A. Corbett, J.N. Hunt, and S.K. Roberts. Actions of glucose and potassium chloride osmoreceptors slowing gastric emptying. J. Physiol. 237: 183186, 1974.

2. Beckers, E.J., N.J. Rehrer, F. Brouns, F. Ten Hoor, and W.H.M. Saris. Determination of total gastric volume, secretion, and residual meal using the double sampling technique of George. Gut 29: 1735-1729, 1988.

3. Bergström, J. and E. Hultman. A study of the glycogen metabolism during exercise in man. Scan. J. Clin. Lab. Invest. 19: $218-228,1967$.

4. Brener, W., T.R. Hendrix and P.R. McHugh. Regulation of gastric emptying of glucose. Gastroenterology 85: 76-82, 1983.

5. Brouns, F. Food and fluid related aspects in highly trained athletes. Ph.D. Thesis, University of Limburg, Maastricht, The Netherlands, June, 1988 .

6. Brouns, F., W.H.M. Saris and N.J. Rehrer. Abdominal complaints and gastro-intestinal function during longlasting exercise. Int. I. Sports Med. 8: 175 189, 1987.

7. Buskirk, E., P.F. Iampietro, and D.S. Bass. Work performance after dehydration: Effects of physical conditioning and heat acclimatization. J. Appl. Physiol. 12: 189-194, 1958.

8. Carnot, P., A. Chassevant. Modifications subies dans l'estomac et le duodenum par les solutions salines, suivant leur concentrations moleculaire. Le reflexe regulateur du sphincter pylorique. Comptes Rendus Soc. Biol. Paris 58: 173-176, 1905.

9. Costill, D.L., W.F. Kammer and A. Fisher. Fluid ingestion during distance running. Arch. Environ. Health 21: 520-525, 1970. 
10. Costill, D.L. and J.M. Miller. Nutrition for endurance sport: carbohydrate and fluid balance. Int. J. Sports Med. 1: 2-4, 1980 .

11. Costill, D.L. and B. Saltin. Factors limiting gastric emptying during rest and exercise. J. Appl. Physiol. 37: 679-683, 1974.

12. Coyle, E.F., A.R. Coggan, J.L. Ivy. Muscle glycogen utilization during prolonged strenuous exercise when fed carbohydrates. Abstract. J. Appl. Physiol. 61: 165-172.

13. Davenport, H.W. Physiology of the Digestive Tract, Chicago, Year Book Medical Publishers, Inc., 1982, p. 196.

14. Elias, E, G.J. Gibson, L.F. Greenwood, J.N. Hunt, and J.H. Tripp. The slowing of gastric emptying by monosaccharides and disaccharides in test meals. J. Physiol, 194: 317-326, 1968.

15. Fordtran, J.S. and B. Saltin. Gastric emptying and intestinal absorption during prolonged severe exercise. J. Appl. Physiol. 23: $331-335,1967$.

16. Foster, C., D.L. Costill, and W.J. Fink. Gastric emptying characteristics of glucose and glucose polymer solutions. Res. Q. 51: 299-305, 1980.

17. George, J.D. New clinical method for measuring the rate of gastric emptying: the double sampling test meal. Gut $9 ; 237$. 242,1968 .

18. Gershon Cohen, J. H. Shay and S. Fels. The relation of meal temperature to gastric motility and secretion. Am J. Roentgenol. Radium Therapy Nucl. Med. 43: 237-242, 1940.

19. Hunt, J.N. The site of receptors slowing gastric emptying in response to starch in test meals. J. Physiol. 154: 270-276, 1960.

20. Hunt, I.N. and W.R. Spurrel. The pattern of emptying of the human stomach. J. Physiol. 113: 157-168, 1951. 
21. Hunt, J.N. and J.O. Pathak. The osmotic effects of some simple molecules and ions on gastric emptying. J. Physiol. 154: 254$269,1960$.

22. Hunt, J.N. A modification to the method of George for studying gastric emptying. Gut 17: 812-813, 1974.

23. Keeffe, E.B., D.K. Lowe, J.R. Goss et al. Gastro-intestinal symptoms of marathon runners. West. J. Med. 141: 481-484, 1984 .

24. Kuipers, H., H. Keizer, F. Verstappen, P. Geurten and G. van Kranenburg. Variability of aerobic performance in the laboratory and its physiologic correlates. Int. J. Sports Med 6: $197-201,1985$.

25. Kuipers, H. H.H. Keizer, F. Brouns, and W.H.M. Saris. Carbohydrate feeding and glycogen synthesis during exercise in man. Pflü. Arch. 410: 652-656, 1987.

26. McHugh, P.R. and J.H. Moran. Calories and gastric emptying: a regulatory capacity with implications for feeding. Am. J. Physiol. 236: R254-R260, 1979.

27. Massicote, D., F. Peronnet, C. Allah, C. Hillaire-Marcel, M. Ledoux, G. Brisson. Metabolic response to $13 \mathrm{C}$ glucose and $13 \mathrm{C}$ fructose ingestion during exercise. J. Appl. Physiol. 61: 1180$1184,1986$.

28. Neufer, P.D., D.L. Costill, W.J. Fink, J.P. Kirwan, R.A. Fielding and M.G. Flynn. Effects of exercise and carbohydrate on gastric emptying. Med. Sci. Sports Exerc. 18: 658-652, 1986.

29. Rehrer, N.J., G.M.E. Janssen, F. Brouns, and W.H.M. Saris. Fluid intake and gastrointestinal problems in runners competing in a $25-\mathrm{km}$ race and a marathon. Int. J. Sports Med. 10 (Suppl. 1): $s 22-s 25,1989$. 
30. Saltin, B. Aerobic work capacity and circulation at exercise in man with special reference to the effect of prolonged exercise and/or heat exposure. Acta Physiol. Scand. Suppl. 230, 1964.

31. Thompson, N.N. and C. Foster. Serial gastric emptying studies: effect of preceding drinks. Med. Sci. Sports Exerc. 22: 484487, 1990. 


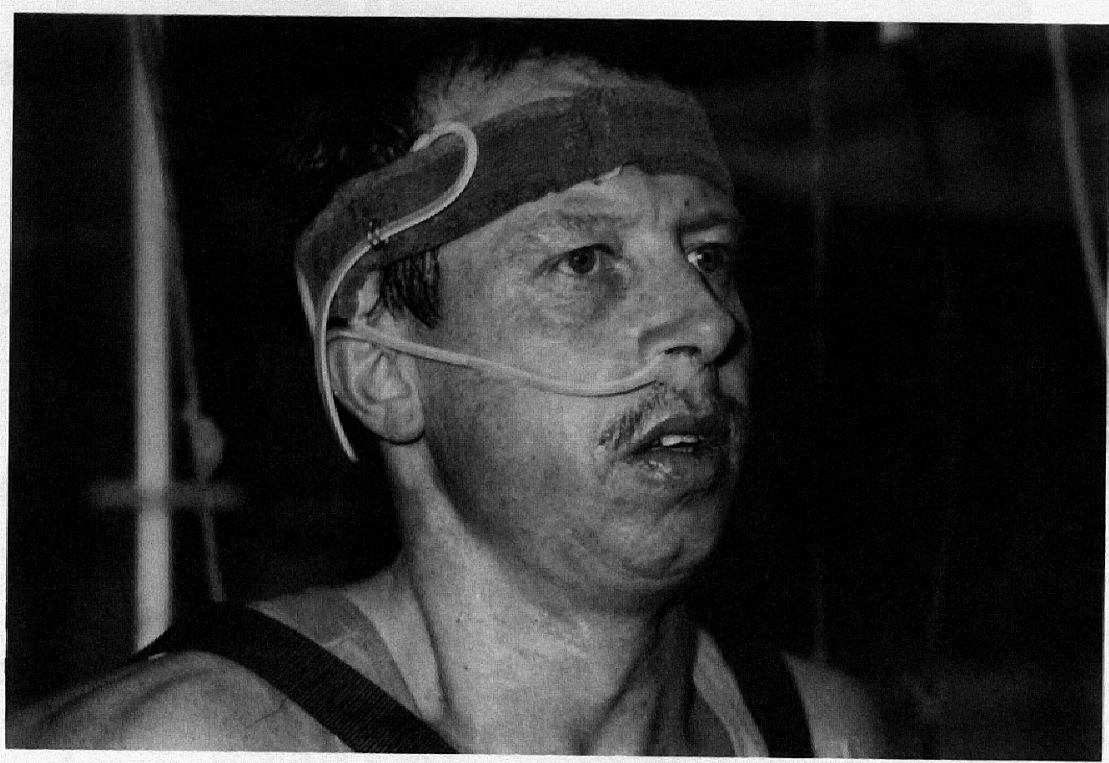




\section{CHAPTER 3}

\section{Gastric emptying with repeated drinking during running and bicycling}

\section{Abstract}

The high prevalence of gastrointestinal complaints in longdistance runners makes the movements specific to this type of exercise suspected of causing a disruption of normal gastrointestinal function. Gastric emptying rate is one indicator thereof. In the present study trained volunteers performed simillar repeated fluid ingestion tests while running and while cycling for $80 \mathrm{~min}$ at $70 \% \mathrm{VO}_{2} \max$. Control tests at rest were also conducted. Two drinks containing carbohydrate were tested, one hypertonic, and one isotonic. Non-nutritive, sweetened water was used as a control. Gastric emptying rate of the isotonic drink, expressed as a percentage of the volume in the stomach at the beginning of each measurement period, did not differ between cycling and running during the first $40 \mathrm{~min}$ and was larger during cycling than during running between 40 and $80 \mathrm{~min}$. With the hypertonic drink no differences between cycling and running were observed. In comparing gastric emptying rates after each sequential bolus, at rest, the isotonic drink was observed to maintain a high emptying rate, equal to that of water ${ }_{*}$ whereas the hypertonic drink emptied more slowly after the first 20 -min period. A simillar pattern was observed during both running and cycling. The isotonic drink continued to empty quickly after the initial $20 \mathrm{~min}$, whereas GE rate of the hypertonic drink decreased after the initial $20 \mathrm{~min}$. 


\section{Introduction}

Long-distance runners often experience gastrointestinal (GI) problems during competition. Problems of the upper and lower GI tract including stomach ache, mausea, vomiting, intestinal cramps, and diarrhoea are common. The prevalence of GI distress among marathon runners typically ranges from $30-50 \%(11,17,18,20)$. There is little documentation of these types of problems in cyclists and practitioners of other sports where the body remains relatively stable. This suggests that the type of body movements involved in running brings about alterations in normal GI function. However, the mechanisms by which the alterations occur are largely unkrown. One possibility is that gastric emptying (GE) may be delayed, possibly as a result of intestinal membrane alterations (absorption and/or secretion possibly being affected). Distension of the stomach, due to delayed emptying, and pressure in the intestines, due to increased secretion and/or malabsorption, may possibly result in distress in these areas. Also, altered GE rate may be a signal of a disturbed motor activity of the stomach (19) or hormonal milieu (5) and, as such, delayed GE may be a result of GI dysfunction rather than being causative. In either case, if GI function is disturbed, GE should be one of the indicators thereof. Since runners appear to be particularly prone to these problems, it is theorised that GE will be will be reduced to a greater degree while an individual is running than when he is bicycling.

Data from studies of gastric emptying during moderately to highly intensive exereise are conflicting. A delay, acceleration, or no change thas been observed $(6,8,13,15,16$, for review see 2$)$.

To evaluate other studies the protocol must be taken into consideration. The majority of GE studies done during exercise have been conducted following administration of one bolus. In the practical situation an endurance athlete consumes beverages repeatedly during competition, dictated by the organisation of refreshment posts at specific intervals in the case of running, or in the case of bicycling, by the route or situation among other cyclists (consumption taking place while coasting or riding where a less intense effort is required). 
It is possible to speculate that GE rate follows a different pattern where the stomach is continually refilled than when the stomach is filled only once and contains a gradually decreasing volume with the passage of time. Volume is one of the positive effectors of GE, a larger volume tending to empty at a quicker rate than a smaller one, up to a maximum of $600-700 \mathrm{ml}$ (6). It is theorised that pressure receptors respond to the load placed by an increased gastric content and signal for an enhanced GE (10). However, a number of other characteristics of the drink or meal can decrease the GE rate, such as glucose (energy) content and osmolality, pH, temperature, and the presence of other specific inhibitory nutrients. One may speculate that under identical circumstances a particular drink will continually empty at a rapid rate when a large volume is maintained through repeated feedings, similar to the rate seen early on in a one bolus study, when the volume is large.

The purpose of the present study was two-fold, to examine the effects of running and bicycling on gastric emptying and to test the effect of repeated drinking on GE rate. More specifically: Is the fast-phase emptying noted in the first $10-20 \mathrm{~min}$ after receiving a large bolus continued with repeated drink ingestion?

\section{Materials and Methods}

\section{Subjects}

Triathletes (male) were recruited via magazine advertisement as well as through personal contact with local triathlon clubs. Prospective subjects were required to have completed at least one half-triathlon and to be actively training in both cycling and running, and to have had no history of GI disease. No selection was made according to frequency of GI complaints resulting from running. However, whether an individual was a sufferer of GI distress as a result of running was noted. A list of symptoms was read to the subjects. The list was divided into "severe complaints" and "mild complaints". Severe complaints included stomach ache, intestinal cramps, nausea, diarrhoea and vomiting. Mild complaints included eructation, fullness or pressure in the stomach or intestinal region, and flatulence. 
The first twenty male triathletes who responded and who satisfied the minimum requirements were invited to the laboratory for preliminary tests. All potential subjects came to the laboratory on two separate days. On one of the two days maximal performance capacity $\left(\mathrm{VO}_{2} \mathrm{max}\right)$ was tested in an incremental cycle ergometer test (12) and on the other day, in an incremental treadmill test. The treadmill test was similar to the cycle ergometer test except that in place of 50 Watt increments every $2.5 \mathrm{~min}, 2 \mathrm{~km} . \mathrm{h}^{-1}$ increments were used. Above a heart rate of 160 b.p.m. increments of 25 Watt and $1 \mathrm{~km} \cdot \mathrm{h}^{-1}$, respectively, were used. On one of the two days, following the maximal exertion test and a cool-down, a nasogastric tube was placed and immediately thereafter removed.

Based upon tolerance of the nasogastric tube, homogeneity in terms of the maximal exertion tests, and availability to come to the laboratory on days required, a final selection of ten subjects was made. All subjects were given a full explanation of experimental procedures and were explained that they may stop the experiment at any time. After three trials one of the subjects voluntarily withdrew because of repeated nausea and vomiting during running with the nasogastric tube. The general characteristics and the results of maximal exertion tests of the remaining nine subjects are presented in Table 1 .

\section{Treatments}

Gastric emptying of two commercially available sport drinks was compared at rest as well as during exercise, and a control drink was given at rest only. Sport drink I was an isotonic, primarily disaccharide drink (296 mOsm. $\mathrm{kg}^{-1}$ ) which provided $127 \mathrm{~kJ}$ per $100 \mathrm{ml}$ (Isostar@ liquid). Drink $\mathrm{H}$ was a hypertonic, primarily maltodextrin containing beverage (444 mOsm.kg-1) which provided $312 \mathrm{~kJ}$ per $100 \mathrm{ml}$ (20 g.100 ml-1 Perform@). The

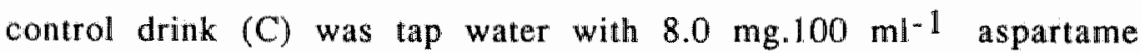
and similar flavorings as in drink $H$, added to mask its identity. These additions to $\mathrm{C}$ provided $1.44 \mathrm{~kJ}$ per $100 \mathrm{ml}\left(40 \mathrm{mOsm} . \mathrm{kg}^{-1}\right)$. Complete compositions are presented in Table 2 . 
Table 1. Subject characteristics

\begin{tabular}{|c|c|c|c|c|}
\hline & & mean & \pm & SE \\
\hline Age $(y r)$ & 3 & 31.0 & \pm & 1.5 \\
\hline Weight (kg) & & 72.9 & \pm & 1.8 \\
\hline \multirow[t]{4}{*}{ Cycling } & $\checkmark \mathrm{O}_{2} \max \left(1 \cdot \mathrm{min}^{-1}\right)$ & 4.5 & \pm & 0.2 \\
\hline & $\left(\operatorname{ml} . \min . \mathrm{kg} \mathrm{BW}^{-1}\right)$ & 60.8 & \pm & 1.4 \\
\hline & $\mathrm{HR} 70 \% \dot{\mathrm{V}}_{2} \max$ (b.p.m.) & 148.0 & \pm & 2.9 \\
\hline & Wmax (Watts) & 374 & \pm & 11.1 \\
\hline \multirow[t]{4}{*}{ Running } & $\dot{\mathrm{V}} \mathrm{O}_{2} \max \left(1 \cdot \min ^{-1}\right)$ & 4.4 & \pm & 0.2 \\
\hline & (ml.min.kg BW-1) & 61.6 & \pm & 1.1 \\
\hline & $\mathrm{HR} 70 \% \dot{\mathrm{V}} \mathrm{O}_{2} \max$ (b.p.m.) & 148.8 & \pm & 3.7 \\
\hline & $\mathrm{km} \max \left(\mathrm{km} \cdot \mathrm{h}^{-1}\right)$ & 17.7 & \pm & 0.3 \\
\hline
\end{tabular}

Table 2. Drink compositions

\begin{tabular}{|c|c|c|c|}
\hline Drink & 1 & $\mathrm{H}$ & $\mathrm{C}$ \\
\hline Osmolality (mOsm.kg-1) & 296.0 & 444.0 & 40.0 \\
\hline Energy $\left(\mathrm{kJ} .100 \mathrm{ml}^{-1}\right)$ & 126.8 & 312.4 & 14.4 \\
\hline $\mathrm{pH}$ & 4.0 & 4.5 & 3.0 \\
\hline Sucrose $\left(\mathrm{g} .100 \mathrm{ml}^{-1}\right)$ & 6.0 & 0.3 & - \\
\hline Maltose $\left(\mathrm{g} .100 \mathrm{ml}^{-1}\right)$ & 0.1 & 1.5 & - \\
\hline Maltodextrin $\left(\mathrm{g} .100 \mathrm{ml}^{-1}\right)$ & 0.9 & 13.7 & - \\
\hline Glucose $\left(\mathrm{g} .100 \mathrm{ml}^{-1}\right)$ & 0.1 & 0.4 & - \\
\hline Fructose $\left(\mathrm{g} .100 \mathrm{mi}^{-1}\right)$ & 0.1 & 3.2 & - \\
\hline $\mathrm{Na}$ (mg.100 mll-1) & 58.0 & 26.0 & - \\
\hline $\mathrm{K}$ (mg.100 ml-1) & 15.0 & 8.4 & - \\
\hline $\mathrm{Cl}$ (mg.100 $\left.\mathrm{ml}^{-1}\right)$ & 49.0 & 26.0 & - \\
\hline $\mathrm{Ca}$ (mg.100 ml-1) & 9.0 & - & - \\
\hline $\mathrm{Mg}$ (mg.100 ml-1) & 6.0 & 12.8 & - \\
\hline$P\left(\mathrm{mg} .100 \mathrm{ml}^{-1}\right)$ & 6.0 & - & - \\
\hline Aspartame (mg.100 $\left.\mathrm{ml}^{-1}\right)$ & - & - & 8.0 \\
\hline
\end{tabular}


Drink $C$ was only administered in rest to give control values of gastric emptying for each individual to compare with the various commercial drinks in a situation of repeated drinking. All three drinks were tested previously in single bolus experiments (16). GE of the isotonic drink (I) and of the hypertonic drink (H) were compared during rest as well as during cycling $\left(70 \% \quad \mathrm{VO}_{2} \mathrm{max}\right)$ and during running $\left(70 \%\right.$ V $\left.\mathrm{O}_{2} \max \right)$.

An initial bolus of $8 \mathrm{ml} . \mathrm{kg}$ body weight $(\mathrm{BW})^{-1}$ was given, followed every $20 \mathrm{~min}$ by additional boli of $2 \mathrm{ml.kg} \mathrm{BW-1}$. A complete schedule of dosing is presented in Fig. 1 .

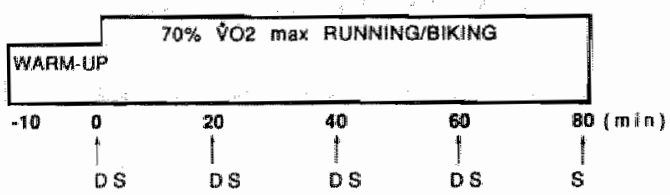

Fig. 1. Sampling schedule where $D$ indicates drink ingestion and $S$ indicates sample removal. At time $=0, D=8 \mathrm{ml.kg} \mathrm{BW-1}$ and at all other ingestion points $D=2$ ml.kg $B W^{-1}$.

\section{Experimental design}

All nine subjects conducted all seven tests (complete cross-over) and were assigned treatments in random order, without subject knowledge of what drink was being administered on a given day.

In exercise experiments, a 10 -min warming-up period $(100$ Watt or $10 \mathrm{~km} . \mathrm{h}^{-1}$ ) preceded $70 \% \quad v_{2} \max$ exercise. To ensure similar exertional stress on separate days, heart rate was used instead of absolute speed or Wattload. $\mathrm{VO}_{2}$ monitoring was impractical due to the nasogastric tube. Workload was increased on the cycle ergometer or speed of the treadmill was increased until a heart rate was achieved which corresponded to the heart rate at $70 \%$ $\mathrm{VO}_{2} \max$ during the maximal tests. The average running speed was $12.8 \mathrm{~km} \cdot \mathrm{h}^{-1}(\mathrm{SE} \pm 0.2)$ and workload on the cycle was 227.8 Watt (SE \pm 8.11 ). 


\section{Experimental procedure}

Daily protocol is fully described elsewhere (16). This included a standardised liquid breakfast $2 \mathrm{~h}$ before exercise began (8:00 a.m.) and placement of a nasogastric tube and complete emptying and rinsing of the stomach prior to exercise (9:15 a.m.). Amounts of breakfast ( $5 \mathrm{ml} . \mathrm{kg} \mathrm{BW}-1)$ and of test drink given ( $8 \mathrm{mg} \cdot \mathrm{kg}$ $B W-1)$ were based upon body weight. The protocol called for 80 min of exercise at $70 \% \dot{V}_{2} \max$. Warming-up was conducted for $10 \mathrm{~min}$ prior to administration of the test drink and the onset of $70 \% \quad \mathrm{VO}_{2} \mathrm{max}$ exercise (10:00 a.m.). Heart rate was continually monitored throughout exercise and workload or speed was adjusted when necessary to maintain a constant exertion level. All beverage boli were administered via the nasogastric tube. For dosing and sampling schedule see Fig. 1. To measure gastric secretion and volume changes, a modified double sampling technique of George (9) was applied using phenol red as a marker. At each interval the added bolus had an increased concentration of dye. For a detailed description of the calculations involved see Beckers et al (1). This procedure was slightly altered with the addition of successive boli. A sample was taken of the remaining gastric contents immediately prior to administration of additional beverage. Each new bolus was added to the partially emptied stomach, mixed with the remaining stomach contents, then a new sample was taken and a new begin point was achieved. Calculations can again be used similar to the ones applied after single bolus experiments.

Ambient temperature was $20 \pm 2{ }^{\circ} \mathrm{C}$ for all experiments with a fan constantly on in front of the cycle ergometer or treadmill. Body weight was measured immediately preceding exercise and immediately following exercise in order to give an indication of fluid losses. Total fluid losses were estimated by the difference in body weight. A correction was made for fluid intake. It is to be noted that these are approximations of net fluid loss since substrate utilization accounts for some body weight change, albeit a very small portion. Further, the sweat loss may also be somewhat underestimated due to sweat which may have remained in running shorts or hair. 


\section{Anglyses}

Wilcoxon"s signed-rank test for nonmparametric data was used to make paired comparisons. The proportion of drink remaining at each interval in running versus cycling for each drink was analysed separately. All three drinks were compared at rest. The relative amounts of drink (as a proportion of the drink content in the stomach at the beginning of each $20 \mathrm{~min}$ period) which had passed through the stomach were also compared to evaluate rates of emptying over time, taking into account the different gastric volumes.

The average GE rates (calculated in $\mathrm{ml}_{\mathrm{min}} \mathrm{m}^{-1}$ over $80 \mathrm{~min}$ ) in subjects who frequently had symptoms during exercise versus subjects who seldom or never had symptoms were compared. Wilcoxon"s rank sum test was used to compare these two groups. A confidence level of $\mathrm{p}<0.05$ was used in determination of significance in all analyses.

Results

Cumulative amounts of drink administered and emptied during exercise with $I$ are presented in Fig. $2 a$ and with $H$ in Fig. $2 b$. These are averages for nine subjects, also for the amount administered, since each individual received a different amount based upon his body weight $\left(8 \mathrm{ml} . \mathrm{kg} \mathrm{BW}^{-1}\right.$ initial bolus and 2 ml.kg BW-1, every sequential bolus). Although the amounts administered were large (mean $=1022 \mathrm{ml}, 80 \mathrm{~min}$ ) none of the subjects complained of gastrointestinal distress.

There was no significant difference in the average gastric emptying rate in those individuals who had a history of GI problems relating to running compared with the subjects who did not experience these problems. The mean emptying rate of $\mathrm{H}$ during $70 \% \forall \mathrm{V}_{2} \max$ running in individuals who had reported having experienced severe symptoms $(\mathrm{n}=4)$ was $10.4 \mathrm{ml}^{\mathrm{min}}{ }^{-1}$ and in those who had never or seldomly experienced these problems $(n=5)$ was $9.7 \mathrm{ml}^{-m i n}{ }^{-1}$. Within the group of individuals who had experienced sewere symptoms, two individuals reported having had these symptoms frequently. 
The mean GE rate of these two individuals, however did not differ from that of the others $\left(10.2,10.1 \mathrm{ml}_{\mathrm{min}}{ }^{-1}\right.$, resp.).

There were also no significant differences in absolute amounts emptied as a result of running as compared to cycling. However, since volume is one of the factors which influences the rate of emptying, the variabillity in the volume of drink present in stomach at any one time may mask effects of exercise. Therefore, a comparison of the relative emptying rates (percent of boli ingested) was made. The percentage of ingestate (rest volume plus new bolus) which was emptied during each 20 min period for each condition, was calculated. Statistical comparisons of cycling and running with $\mathbb{I}$ revealed a significantly greater mean percentage of ingestate emptied during cycling than during running between 40 and $60 \mathrm{~min}(77 \%, 62 \%$, resp., p<.05) and between 60 and $80 \mathrm{~min}(83 \%, 68 \%$, resp., $\mathrm{p}<.05)$. With $\mathrm{H}$, the hypertonic drink, no significant differences were observed between cycling and running.
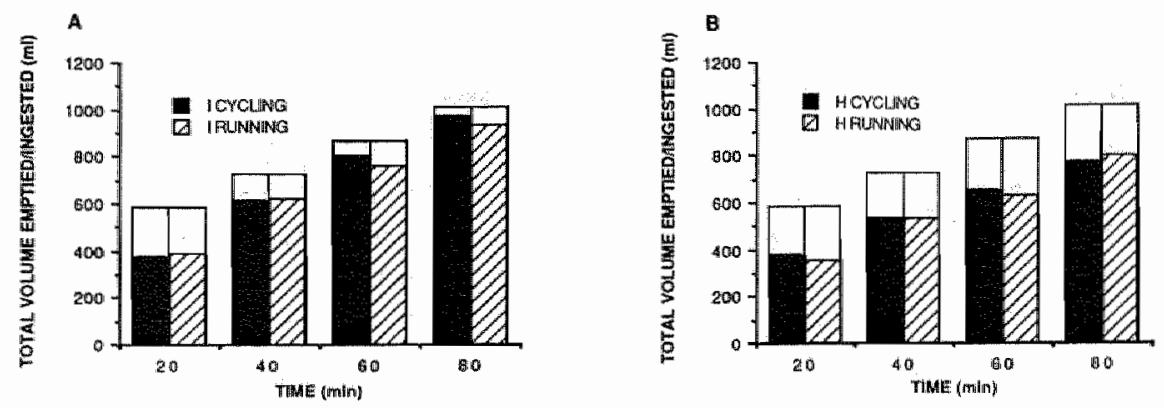

Fig. 2a. Cumulative volumes of drink empried (solid and striped) and rotal volumes given for cycling and ranning with drink $l$. Fig $2 b$. Cumulative volumes of drink emptied and lotal volumes ingested for cycling and runing with drink $H$.

To evaluate differences in emptying rate over time, percentages for each drink and condition were compared by 20 min intervals. During cycling the "fast-phased" emptying rate appeared to be maintained with I. Mean percentage of drink emptied is the same between 20 and $40 \mathrm{~min}$ and 40 and $60 \mathrm{~min}$ as between 0 and 20 


\section{Chapter 3}

min, and, in fact, the relative amount emptied between 60 and 80 min was significantly greater than that which was emptied between 0 and $20 \mathrm{~min}$ (83\%, 65\%, resp., p<.05). A graphic representation of emptying rates comparing a one bolus experiment, previously conducted in our lab (16), with repeated drinking of I during $70 \% \mathrm{VO}_{2}$ max cycling is shown in Fig. 3. With running, a similar pattern can be seen.

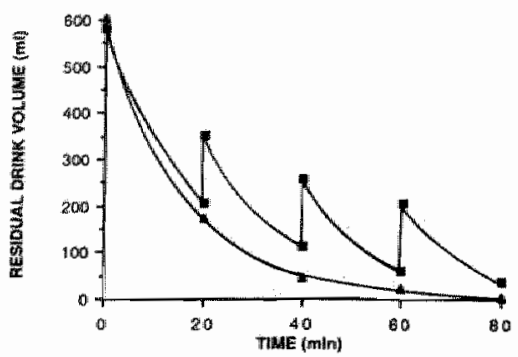

Fig. 3. Absolute amounts of drink (I) remaining in the stomach after a single bolus $\left(8 \mathrm{ml} . \mathrm{kg} B W^{-1}\right)$ and after one bolus $\left(8 \mathrm{~mL} . \mathrm{kg}^{-B^{-1}}\right)$ with repeated ingestion every $20 \mathrm{~min}\left(2 \mathrm{milkg} \mathrm{BW}^{-1}\right)$.

However, with $H$, after the initial $20 \mathrm{~min}$ fast phase, GE rate was reduced in both cycling and running. During cycling the mean percentage emptied at $60-80 \mathrm{~min}$ was significantly less than at 0 $20 \min (34 \%, 66 \%$, resp., $p<.05)$. During running with $H$, mean percentage ingestate emptied was significantly less during 40-60 $\min (32 \%)$ and $60-80 \mathrm{~min}(44 \%)$ versus $0-20 \mathrm{~min}(61 \%)(\mathrm{p}<.05)$.

The percentages emptied each 20 min interval with all three drinks during rest are presented in Table 3 . There were no significant differences in emptying rates between $I$ and $C$ at rest. $H$ emptied slower than $C$ at $20-40 \mathrm{~min}, 40-60 \mathrm{~min}$ and $60-80 \mathrm{~min}$ $(\mathrm{p}<.05)$.

Average sweat losses for $80 \mathrm{~min}$ cycling and $80 \mathrm{~min}$ running are presented in Fig. 4. During running the sweat loss was significantly greater than during bicycling $(\mathrm{p}<.05)$. 
Table 3. Volume of ingestate emptied during rest expressed as a percentage of start volume for each 20 min interval $(n=9)$

\begin{tabular}{rccc}
\hline Interval & \multicolumn{3}{c}{ Drink } \\
\cline { 2 - 4 }$(\mathrm{min})$ & \multicolumn{3}{c}{$\begin{array}{c}\mathrm{H} \\
(\text { mean } \pm \mathrm{SE})\end{array}$} \\
\hline & & & $\mathrm{C}$ \\
$0-20$ & $79 \pm 3.3^{\mathrm{a}}$ & $66 \pm 2.7^{\mathrm{a}}$ & $79 \pm 4.6^{\mathrm{a}}$ \\
$20-40$ & $72 \pm 8.3 \mathrm{a}$ & $49 \pm 8.2 \mathrm{a}^{*}$ & $85 \pm 0.3 \mathrm{a}$ \\
$40-60$ & $87 \pm 3.1^{\mathrm{a}}$ & $44 \pm 7.2 \mathrm{a}^{*}$ & $79 \pm 0.3^{\mathrm{a}}$ \\
$60-80$ & $86 \pm 2.9 \mathrm{a}$ & $37 \pm 6.5 \mathrm{~b}^{*}$ & $89 \pm 3.8^{\mathrm{a}}$ \\
\hline
\end{tabular}

No significant differences were observed between $I$ and $C$.

* Indicates significant difference $(p<.05)$ from control $(C)$.

$a, b$ Different superscripts represent significant difference $(p<.05)$ within a treatment.

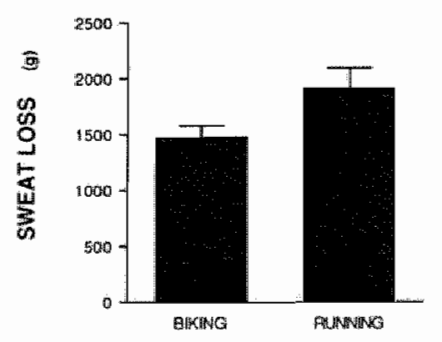

Fig. 4. Average sweat losses as measured by body weight change after 80 min. running or cycling. 


\section{Discussion}

Compared to fluid intakes measured during marathon running (17) the amounts administered were large and yet caused little GI upset or physical discomfort while running or cycling.

Although slight differences were noted between cycling and running with respect to $\mathrm{GE}$ rate, these were only significant with the isotonic drink (I) in the last two $20 \mathrm{~min}$ intervals, 40-60 min and $60-80 \mathrm{~min}$.

It is improbable that these differences are large enough to explain the difference in frequency of gastrointestinal problems in runners versus bicyclists. In fact, what is most noteworthy are the large amounts which are emptied during running as well as during bicycling.

Gastric emptying has been designated as one of the limiting factors during endurance competition $(6,8)$. However, from the present study, it has been demonstrated that it is not the effect of exercise per se on $G E$ which has the greatest influence. Drink content and hydration status $(14,16)$ are probably of greater importance (not to mention effects of GI contents from previous meal(s)). Carbohydrate source and content and effects of other nutrients, including specific minerals can act to limit or stimulate GE (7) and may also play a role in predisposition to GI disorders. Nevertheless, the fact that a high frequency of GI disorders is reported among distance runners, and that there is little documentation of these types of problems in cyclists, leads to speculation that the repeated concussions occurring during running (with a corresponding up and down movement of the internal organs) may play a role in the development of these disorders. However, the physical/mechanical effect that exists apparently does not exert its influence via gastric emptying. It cannot be denied that a delayed GE is one symptom of disturbed GI function. Since none of the nine subjects who completed all lests had GI complaints, it follows that GE delay, as a result of GI dysfunction, could not have been present.

A myriad of "stress factors" may be the real key to GI disturbance in runners in combination with the physical jostling. The competitive atmosphere of a race is completely missing in laboratory experiments. This may alter levels of circulating stress related hormones and metabolites. 
Another aspect which must be considered is the actual intakes found in participants of these two sports and fluid needs of individuals participating in both. Runners are known to consume far less fluid than is necessary to maintain euhydration. Body weight losses ranging from $3-5 \%$ are common in marathon runners.

The availability of a beverage, as well as the ease of consumption during bicycling, where one experiences little vertical movement during exercise, certainly play a rolle in the difference in fluid consumption between runners and cyclists. In addition, water losses may be even greater during running than during bicycling, partially due to greater heat dissipation due to convection in bicycling. Moreover, even in our laboratory setting where ventilation in the lab was similar for the same individuals while running and cycling, sweat losses were greater during running. This can be accounted for by the larger exercising muscle mass used while running.

Due to the afore mentioned differences in fluid losses and replacement, dehydration is seen to be a greater problem in runners than in cyclists. Although, compared to average fluid consumptions of marathon runners, the amounts consumed in the present experiment were large, they were not large enough to replace fluid losses.

It has also been observed that higher levels of dehydration are associated with an increased incidence of GI distress (17) and decreased GE rate (14), intestinal ischaemia possibly playing a role. Blood flow is also known to be decreased to the GI region during intense exercise (4) and a decreased mesenteric blood flow has been observed to reduce carbohydrate absorption from the intestine (21).

Despite common "track-talk" of GI complaints after beverage consumption during running, no evidence is found in the present study to attribute this symptom simply to the consumption of beverage during running. Moreover, it appears probable that this complaint could be initiated by drinking too late, after a state of dehydration has already been reached. If the blood flow is already decreased and a beverage is ingested which is hypertonic, demanding increased intestinal secretion, the effects could be exacerbated by further decreased blood volume and ischaemia of the GI region. 


\section{Chapter 3}

It is also possible that solid food present in the digestive tract during running may be improperly digested, causing a delay which could lead to abdominal discomfort. In support of this theory are anecdotal claims from runners that they can avoid problems by not consuming solid food for several hours previous to a hard run or race. The absence of problems in our subjects, who only received fluids, including a standardised liquid preexercise meal, also supports this theory.

In summary we could not find important differences in gastric emptying rates between running and cycling. Therefore it is not very likely that inherent differences in $G E$ due to exercise alone would account for the discrepancy of GI disorders. Furthermore, the high rate of fluid/energy intake and emptying which was observed to be well tolerated during running has implications for performance. Since improvement of endurance running performance could be improved to the same extent as was observed for cyclists who cycled for several hours at a high intensity with large intakes of the same hypertonic beverage (3). 


\section{References}

1. Beckers, E.J., N.J. Rehrer, F. Brouns, F. ten Hoor and W.H.M. Saris. Determination of total gastric volume, gastric secretion, and residual meal using the double sampling technique of George. Gut 19: 1725-1729, 1988.

2. Brouns, F., W.H.M. Saris and N.J. Rehrer. Abdominal complaints and gastrointestinal function during long-lasting exercise. Int. J. Sports Med. 1 8: 175-189, 1987.

3. Brouns F., W.H.M. Saris, J. Stroecken, E. Beckers, R. Tijssen, N.J. Rehrer and F, ten Hoor. Eating, drinking and cycling, a controlled Tour de France simulation study. Pt. II Effect of diet manipulation. Int. J. Sports Med. 10 (Suppl. 1) : S41-S48, 1989.

4. Clausen, J.P., K. Klausen, B. Rasmussen and J. Trap-Jensen. Central and peripheral circulatory changes after training of the arms or legs. Am. J. Physiol. 225: 675-682, 1973.

5. Cooke, A.R., T.E. Chvasta and N.W. Weisbrodt. Effect of pentagastrin on electricall and motor activity of the dog stomach. Am. J. Physiol. 223: 934-938, 1972.

6 Costill, D.L. and B. Saltin. Factors limiting gastric emptying during rest and exercise. J. Appl. Physiol. 37: 679-683, 1974.

7. Coyle, E.F., D.L. Costill, W.S. Fink and D.G. Hoopes. Gastric emptying rates for selected athletic drinks. Res. Q. 49: $119-124,1978$.

8. Fordtran, J.S. and B. Saltin. Gastric emptying and intestinal absorption during prolonged severe exercise. J. Appl. Physiol. 23: $331-335,1967$.

9. George, J.D. New clinical method for measuring the rate of gastric emptying: the double sampling test meal. Gut 9: 237$242,1968$. 
10. Hunt, J.N. Regulation of gastric emptying. In: Knox, M.T. (Ed.) Handbook of Physiol. Section 4., Bethesda, Maryland: American Physiological Society pp. 1917-1935, 1968.

11. Keeffe, E.B, D.K. Lowe, J.R. Goss and R. Wayne. Gastrointestinal symptoms of marathon runners. West J. Med. 141: 481-484, 1984.

12. Kuipers, H., H. Keizer, F. Verstappen, P. Geurten and G. van Kranenburg. Variability of aerobic performance in the laboratory and its physiological correlates. Int. J. Sports Med. 6: $197-201,1985$.

13. Neufer, P.D., D.L. Costill, W.J. Fink, J.P. Kirwan, R.A.Fielding and M.G. Flynn. Effects of exercise and carbohydrate on gastric emptying. Med. Sci. Sports Exerc. 18: 658-662, 1986.

14. Neufer, P.D., A.D. Young and M.N. Sawka. Gastric emptying during exercise: effects of heat stress and hypohydration. Eur. J. Appl. Physiol. 58: 433-439, 1989.

15. Ramsbottom, N. and J.N. Hunt. Effect of exercise on gastric emptying and gastric secretion. Digestion 10: 1-8, 1974.

16. Rehrer, N.J, E. Beckers, F. Brouns, F. ten Hoor and W.H.M. Saris. Exercise and training effects on gastric emptying of carbohydrate beverages. Med. Sci. Sports Exerc. 21: 540-549, 1989.

17. Rehrer, N.J. , G.M.E. Janssen, F. Brouns and W.H.M. Saris. Fluid intake and gastrointestinal problems in runners competing in a $25-\mathrm{km}$ race and a marathon. Int. J. Sports Med. 10: (suppl. 1): s22-s25, 1989.

18. Riddoch, C. and T. Trinick. Gastrointestinal disturbance in marathon runners. Br. J. Sports Med. 22: 71-74, 1988. 
19. Smout, A.J.P.M., L.M.A. Akkermans, J.M.M. Roelofs, F.G. Pasma, H.Y. Oei, P. Wittebol. Gastric emptying and postprandial symptoms after Billroth II resection. Surgery 101: 27-34, 1987.

20. Sullivan, S. N. The gastrointestinal symptoms of running. N. Engl. J. Med. 304: 203, 1981.

21. Williams, J.H., M. Mager and E.D. Jacobson. Relationship of mesenteric blood flow to intestinal absorption of carbohydrates. J. Lab. Clin. Med. 63: 853-863, 1964. 


\section{CHAPTER 4}

\section{Biomechanical vibration of the abdominal region during running and bicycling}

\section{Abstract}

The incidence of gastrointestinal (GI) distress reported among long distance runners and not in practitioners of other sports with more gliding movements, such as bicyclists, leads one to speculate that there is a difference in concussions and vibration of the GI region and that this may possibly be associated with the disparity in GI disorders. The present experiment was conducted to quantify the difference in vibration (accelerations/decelerations) of the GI region during running as compared to bicycling. An actometer was used which included a piezoelectric sensor. The sensor was placed on the abdomen of six subjects during identical trials bicycling and running. Movement in three planes was detected by the sensor and recorded. The accelerometer output (AO) is an integral of these measurements. AO was used in making comparisons of the two types of movement, expressed as counts per minute. Mean AO was more than doubled in running, $859.5 \pm$ 130.1 (SD), versus bicycling, $425.8 \pm 149.5$, (SD) $(\mathrm{p}<.0001)$. The common assumption that running results in more body vibrations than bicycling has been substantiated and quantified. Although the differences are large, it can only be specullated that these differences explain the high frequency of Gl symptoms among runners. 


\section{Introduction}

A commonly accepted fact is that running brings about more mechanical jarring of the gastrointestinal (GI) region than other sports such as bicycling, skating, or skiing, which are characterised by more gliding movement. Runners are known to exhibit gastrointestinal dysfunction more frequently and alter eating habits accordingly than participants in other gliding sports, such as bicycling, where solid food is even consumed during exercise. The most popular explanation for this disparity is the difference in body accelerations due to the different types of movements made while participating in the various sports. Movements with a large vertical component most commonly bring about the largest biomechanical vibration of the body. It has been well documented that runing brings about greater accelerometer output (vibrations) than walking (8) and that running speed increase increases vibrations of the body $(2,6)$ and that different types of running surfaces and shoe sole materials influence the resulting body vibration from running and walking. The severity of the vibration is most pronounced at the shank and least at the head (3), the body itself being able to absorb some of the vibration, during ambulatory activity. However, specific movements (jostling) of the human abdominal region during running and bicycling have not been thoroughly investigated. In an attempt to quantify these vibrations of the abdominal region experienced during running and bicycling an experiment was designed to make identical measurements of all movements measured at the surface of the abdomen during both activities.

\section{Materials and Methods}

A paved criterium course for bicyclists was measured with a hand-wheel via the shortest possible route (i.e. cutting corners). Subjects were instructed to similarly do so during experimental exercise sessions. The course was 2132 meter long, including one steep decline and one incline, each approximately $150 \mathrm{~m}$ in length. The surface was asphalt. There were three male and three female subjects. These subjects were all moderately to well-trained in bicycling and running. Each subject used his or her own bicycle, all 
of which had 'race' confirmation. An accelerometer was used which included a piezoelectric sensor which measured accelerations in three planes. The sensor was attached with tape to the midriff, $2 \mathrm{~cm}$ left of the navel. The accelerometer further consisted of a modifiea cassette tape recorder, used to record the signal, which was attached to a belt worn about the waist. Data were processed as described previously by Meijer et al. (7). For analysis the tape was played through a deck connected to a computer which was programmed to integrate accelerations. The resulting accelerometer output (AO) was expressed in counts per minute $\left(\mathrm{c} \cdot \mathrm{min}^{-1}\right)$. Subjects followed the same protocol for bicycling as for running. They were asked to warm-up for approximately 10 min prior to beginning exercise-recording experiments. Recorded exercise sessions consisted of 2 laps of the designated race course at a speed that subjects were allowed to determine themselves. They were asked to run and bike at at pace that they felt to be $60-70 \%$ of maximal potential (hard but not all-out). A stop watch was synchronously started with the tape recorder and lap times were noted so that the speed could be calculated. AO was analyzed as counts per minute $\left(c \cdot m^{-1}\right)$. The average for each subject during both activities was calculated. These individual means were also converted to counts per meter $\left(c, \mathrm{~m}^{-1}\right)$ by dividing by the average speed in meters per min for each individual during each activity. The ratio of $c \cdot \mathrm{min}^{-1}$ running over c.min-1 bicycling was also calculated to make comparisons wherein the influence of individual body compositions and size, which may result in different vibrational characteristics, would be removed.

Statistical analysis was done using the Student's paired t-test; differences with a $\mathrm{p}$-value $<.05$ were considered significant.

\section{Results}

The mean $A O$, a registration of abdominal vibration, was significantly greater as a result of running than as a result of bicycling (Table 1). AO was on the average 2.2 times greater during running than during bicycling, as seen by the ratio running over bicycling. If the $\mathrm{AO}$ is expressed per meter rather than per 


\section{Chapter 4}

minute this ratio is increased to an average of 4.23.

Speed was a less important factor in determining AO than interindividual differences. This is obvious when the data are converted to counts per meter, accounting for the differences in speed. Those individuals with relatively the largest $A O$ when expressed as counts per min also had the largest AO when expressed as counts per meter (Table 2).

Table 1. Accelerometer output (AO) as a result of running and bicycling in counts per minute (mean $\pm S D$ )

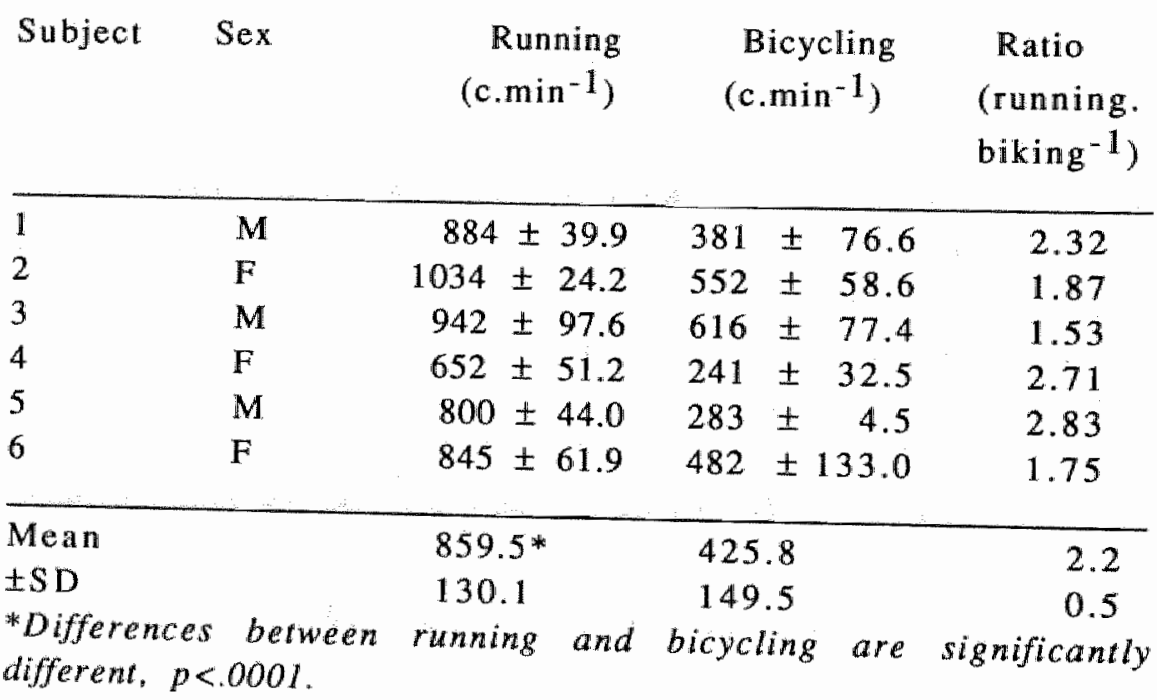


Vibration running v. cycling

Table 2. Average speed running and bicycling and accelerometer output $(A O)$ in counts per meter

\begin{tabular}{|c|c|c|c|c|}
\hline Subject & \multicolumn{2}{|c|}{$\begin{array}{l}\left.\text { Speed (m.min }{ }^{-1}\right) \\
\text { running bicyling }\end{array}$} & \multicolumn{2}{|c|}{$\mathrm{AO}\left(\mathrm{c} \cdot \mathrm{m}^{-1}\right)$} \\
\hline 1 & 229.9 & 481.5 & 3.84 & 0.79 \\
\hline 2 & 222.5 & 424.2 & 4.65 & 1.30 \\
\hline 3 & 284.3 & 487.0 & 3.31 & 1.26 \\
\hline 4 & 95.3 & 402.3 & 3.33 & 0.60 \\
\hline 5 & 257.3 & 531.9 & 3.11 & 0.53 \\
\hline 6 & 242.7 & 401.6 & 3.48 & 1.20 \\
\hline Mean & $238.7^{*}$ & 454.8 & $3.62 *$ & 0.95 \\
\hline$\pm \mathrm{SD}$ & 30.5 & 53.3 & 0.56 & 0.34 \\
\hline
\end{tabular}
different, $p<.0001$. 


\section{Chapter 4}

\section{Discussion}

The common assumption that running brings about more vibration of the abdominal region than bicycling is supported and given numerical magnitude by our results. AO is considered to give valid measurement of the accelerations and decelerations (vibration) at the point of attachment, which in this case is the abdomen. The increased $A O$, expressed as counts per min, was approximately two times greater during running than during bicycling. Inter-individual differences in AO during bicycling may, in part, be due to the fact that some individuals remained seated while others stood up occasionally while peddling, and by the different bicycles used. Other factors such as anatomy, running style, and type of shoe (sole) may also play a role in determining the concussions experienced during running. However, despite the large variation, the differences in vibration of the abdominal region in running versus bicycling are highly significant. Although the vibration is measured on the surface of the abdomen and does not accurately measure internal vibration, the differences between the two types of exercise are assumed to be of the same magnitude. It is speculated that muscles and surrounding tissues provide support of the internal organs and reduce the shock to the stomach and intestines. However, since the effect would be found during both running and bicycling, the difference observed is assumed to be real.

Whether this difference in vibration of the abdominal region can account for the difference observed between running and bicycling in frequency of Gl complaints is uncertain. Many other factors (eg. blood flow to the intermal organs (10), hydration status (9, 11), training status (4), hormonal changes (12) and motor activity (1) and dietary intakes (5)) appear to also be associated with GI dysfunction and as such may or may not exhibit their influence in conjunction with or as a result of the added vibrational component present during running. 


\section{References}

1. Akkermans, L.M.A., F. Jacobs, A.J.P.M. Smout, H. Y. Oei and P. Wittebol. Radionuclide measurement of normal and disturbed gastric motility. Scand. J. Gastroenterology 96: 19-24, 1984.

2. Bhattacharya, A., E.P. McCutcheon, W. Schraatz and J.E. Greenleaf. Body acceleration distribution and $\mathrm{O}_{2}$ uptake in humans during running and jumping. J. Appl. Physiol. 49: 881$887,1980$.

3. Dupuis, H.J., J. Draeger and E. Hartung. Vibrations transmission to different parts of the body by various locomotions. In: Komi P.V. (ed) Biomechanics V-A, V.P.P., Baltimore pp. 537-543, 1976.

4. Keeffe, E., D. Lowe, J. Gross and R. Wayne. Gastrointestinal symptoms of marathon runners. West J. Med. 14: 481-484, 1984.

5. Kemenade, van M.C., T.A. Meester and N.J. Rehrer. Voeding in relatie tot maag-darmklachten bij de triathlon. Ned. Tijdschrift voor Diëtisten 44: 8-12, 1989.

6. Meijer, G. and K.R. Westerterp. Assessment of daily physical activity using synchronous recording of heart rate and body acceleration. Proc. Nutr. Soc. 47: 25A, 1988.

7. Meijer, G.A., K.R. Westerterp, H. Koper and F. ten Hoor. Assessment of energy expenditure by recording heart rate and body accelleration. Med. Sci. Sports Exerc. 21: 343-347, 1989.

8. Montoye, H.J., R. Washburn, S. Servais, A. Ertl, J.G.Webster and F.J. Nagle. Estimation of energy expenditure by a portable accelerometer. Med. Sci. Sports Ex. 15: 403-407, 1983.

9. Neufer, P.D., A.J. Young and M.N. Sawka. Heat stress and hypohydration impair gastric emptying. Med. Sci. Sports Ex. 20(suppl.): $s 20,1988$. 


\section{Chapter 4}

10. Qamar, M.I. and A.E. Read. Effects of exercise on mesenteric blood flow in man. Gut 28: 583-587, 1987.

11. Rehrer, N.J., G.M.E. Janssen, F. Brouns and W.H.M. Saris. Fluid intake and gastrointestinal problems in runners competing in a 25-km race and a marathon. Int. J. Sports Med. 10 (suppl. 1): s22-s25, 1989.

12. Riddoch, $C$. and $T$. Trinick. Gastrointestinal disturbances in marathon runners. Brit. J. Sp. Med. 22: 71-74, 1988. 


\title{
CHAPTER 5
}

\section{Gastric emptying, secretion and electrolyte flux at rest, after ingestion of beverages with varying electrolyte compositions}

\author{
Abstract
}

Two experiments were done at rest to examine gastric residue composition and electrolyte flux in response to ingestion of beverages of varying composition. In the first experiment the effects of two different commonly consumed sport drinks, one isotonic (I) and one hypertonic $(\mathrm{H})$, and a control beverage $(0.08$ g.1-1 aspartame in water) on titratable acid, $\mathrm{pH}$, osmolality, and $\mathrm{Na}^{+}, \mathrm{K}^{+}$and $\mathrm{Cl}^{-}$flux were measured. Samples were taken via a nasogastric tube. A dye dilution technique for serial sampling was employed to determine drink and secretion volumes at each sampling time. After receiving a bolus of $8 \mathrm{ml} . \mathrm{kg}^{-1}$ body weight, samples of gastric residue were taken at $0,10,20,30,40,60$, and 80 min. Gastric secretion of $\mathrm{Na}^{+}, \mathrm{K}^{+}$and $\mathrm{Cl}^{-}$was fairly constant despite large differences in beverage composition. Changes in gastric residue $\mathrm{pH}$, titratable acid, osmolality, and ellectrolyte composition simply reflected the increasing proportion of the residue which was secretion.

In a second experiment, a $150{\mathrm{~g} . \mathrm{I}^{-1}}^{-1}$ maltodextrin solution was made. For comparison, similar solutions were made which also contained either 28 meq. $\mathrm{l}^{-1} \mathrm{Na}^{+}, 140 \mathrm{meq} \cdot \mathrm{l}^{-1} \mathrm{Na}^{+}, 28 \mathrm{meq} \cdot \mathrm{l}^{-1} \mathrm{~K}^{+}$, or 140 meq. $1^{-1} \mathrm{Na}^{+}$and 28 meq. $\mathrm{l}^{-1} \mathrm{~K}^{+}$. Beverages $\mathrm{H}$ and $\mathrm{C}$ and distilled water were also tested. Contrary to expectations, the effects of sodium and potassium (in a 150 g.1-1 maltodextrin solution) on gastric emptying were not large. Although not significant, the correlations between beverage $\mathrm{Na}^{+}$content and volume, with emptying rate were positive. There was also a trend for osmolality and $\mathrm{K}^{+}$to be negatively correlated with emptying 
rate. The directions of the correlations are in line with what would be expected based upon the literature. No differences were observed between water and the control drink. Secretion was decreased in these two solutions versus all the others. There was a trend for greater secretion in $H$ versus the other carbohydrate containing solutions in experiment 2 . This may be a result of the higher $\mathrm{pH}$ maintained after ingestion of this beverage. No consistent differences in electrolyte composition of secretion were observed. A transient absorption of $\mathrm{Na}^{+}$was observed in the beverage containing $140 \mathrm{meq} \mathrm{Na}^{+}$and of $\mathrm{K}^{+}$in the two $\mathrm{K}^{+}$ contaiming beverages.

\section{Introduction}

Electrolytes have been included in fluid replacement beverages, formulated for consumption during exercise, since the initial development of this type of drink. The rationale behind mineral inclusion is based upon the principal of replacement of elements lost in sweat. The question remains, however, if during exercise this is beneficial, when the primary goal is to provide, in order of priority, water and carbohydrate. In this context, the addition of sodium appears to be well founded. Gastric emptying (GE) of an isotonic sodium solution has been shown to be quicker than that of water alone (Shay \& Gershon-Cohen, 1934; Hunt \& Pathak, 1960 ) and, in a glucose solution, the addition of sodium chloride increases intestinal absorption of glucose and water (Fordtran, 1975; Ferrannini, et al., 1982), sodium and glucose being coupled in active transport (Schultz \& Curran, 1970). However, the wisdom of inclusion of potassium in a rehydration beverage is questionable. It has been demonstrated that potassium has no stimulatory effect on GE, but only an osmotic effect to decrease GE, similar to that of glucose (Hunt \& Pathak, 1960; Barker et al., 1974). There is some evidence to suggest that potassium may have a specific inhibitory effect on GE of carbohydrate containing beverages, above its osmotic effect. In an earlier study in this laboratory, decreased GE of a glucose solution with high potassium compared to a similar solution with low potassium was observed 
(unpublished data). Coyle et al. (1978) and Nielsen et al. (1986) also have obtained evidence suggesting that increasing potassium concentration in a beverage may decrease GE.

The present study includes two experiments. The first experiment was designed to measure sodium and potassium flux, and acidity and osmolality changes in the stomach after ingestion of beverages of varying composition. Two of these beverages were commonly consumed carbohydrate and electrolyte containing sport drinks and one was a control drink, water sweetened with aspartame. The second study was designed to study the specific effects of sodium and potassium on gastric emptying of, and gastric secretion in response to, a carbohydrate containing beverage.

\section{EXPERIMENT 1}

Materials and methods

\section{Subjects and experimental design}

Sixteen male volunteers, age 18-30 years, all with no history of gastrointestinal (GI) abnormality, participated in this experiment. Complete subject characteristics are presented in Rehrer et al. (1989). Subjects were given full explanation of the experiment and thereafter gave written consent. Before the actual experiments began each subject came to the laboratory for a trial run. A nasogastric tube was placed and removed. This preliminary trial was conducted to familiarise the subject with the technique (reducing the possibility of anxiety in a first treatment test, which could decrease GE rate). This trial run also gave the subject, with full awareness, the opportunity to make a final decision with regards to participation.

After a $12 \mathrm{~h}$ fast, subjects came to the laboratory at 8:00 a.m. and received a standardised breakfast of a low-fat, liquid meal (Powerplayß, 5 ml.kg BW-1), which provided@1500 kJ. Fasting time and pre-experimental meal were standardised so that intestinal contents were similar in all tests, since intestinal contents are known to influence GE (Shay \& Gershon-Cohen, 1934; Hunt \& Pathak,1960). 
Table 1. Beverage characteristics

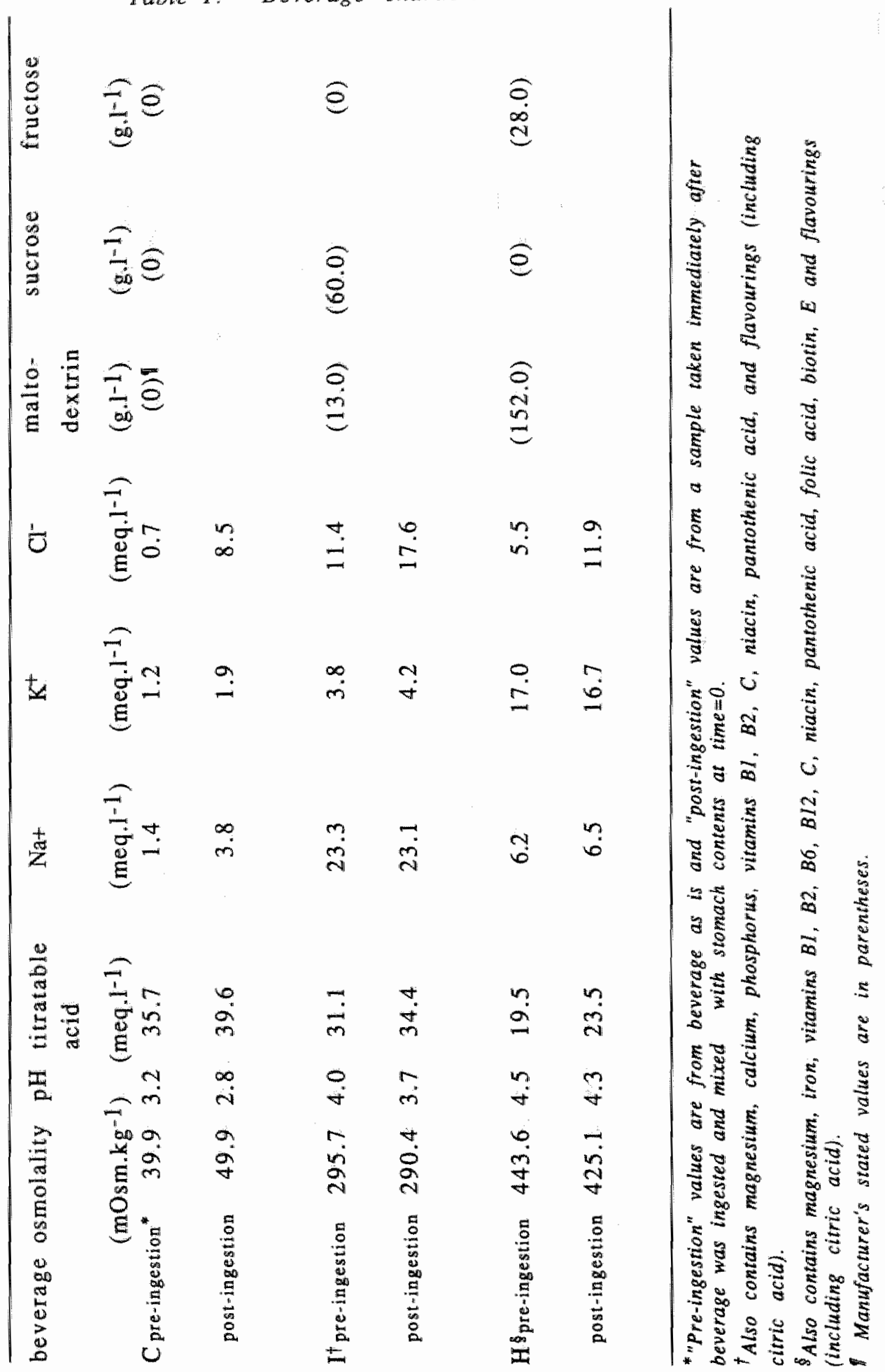


At 9:15 a.m. a nasogastric tube was placed and the stomach was emptied. Thereafter a recovery test was performed, and the stomach was repeatedly rinsed with water, until no further residue of breakfast was obtained, and emptied as thoroughly as possible. Subjects remained sitting until 10:00 a.m., at which time a test drink was given. The time schedule was strictly adhered to in order to avoid variation due to the circadian rhythm of gastric secretion (Moore \& Englert, 1970) and time since last meal.

A complete cross-over study was performed in which all subjects performed all treatments. Treatments consisted of infusion of one of three beverages via a nasogastric tube while the subject remained sitting. These beverages were a control drink (C) and two sport drinks (I and $\mathrm{H}$ ). C consisted of water with $0.08 \mathrm{g.t}-1$ aspartame and flavourings which also were to be found in $\mathbf{H}$. $\mathbf{H}$ was a hypertonic commercial sport drink which contained $180 \mathrm{~g}$ carbohydrate. $1^{-1}$, primarily maltodextrin. I was another commercially available, isotonic, sport drink which contained $73 \mathrm{~g}$ carbohydrate. $1^{-1}$, primarily sucrose. The complete compositions of these beverages and the measured osmolality, pH, titratable acid, and sodium, potassium and chloride concentrations are presented in Table 1.

\section{Gastric sampling and analyses}

Samples were taken of the original drink and gastric residue samples were taken immediately after instillation, after being mixed with any gastric residue remaining $(0 \mathrm{~min})$ and after 10 , $20,30,40,60$, and $80 \mathrm{~min}$. Saliva was to be expectorated rather than swallowed. For determining remaining drink volume/secretion, osmolality, and $\mathrm{pH}$ measurements $3 \mathrm{ml}$ samples were extracted. An additional $2 \mathrm{ml}$ was needed for energy measurements and another $2 \mathrm{ml}$ was required for acid titration and mineral analyses. A sample for volume and secretion measurements was taken at $0,10,20,30,40,60$ and $80 \mathrm{~min}$. Energy measurements were conducted on the original drinks as well as after mixing with the gastric residue at $0 \mathrm{~min}$, and after 10 and $40 \mathrm{~min}$. Mineral measurements were conducted at all sample times, and acid measurements were conducted on samples taken at 0,20 and $40 \mathrm{~min}$. Gastric volume and secretion measurements were done with a modification of the double sampling technique 
of George as applied by Beckers et al. (1988). This method includes the addition of phenol red dye to the original drink and subsequent addition of phenol red for sequential sampling. The phenol red concentration in the original drink was $15 \mathrm{mg} . \mathrm{l}^{-1}$ and during the second phase of each sampling $10 \mathrm{ml}$ of a $500 \mathrm{mg} . \mathrm{l}^{-1}$ phenol red solution was added. By mixing the bolus given with the remaining stomach contents and taking a sample immediately after ingestion, the volume of the non-beverage gastric residue (secretion and water remaining from the rinsing of the stomach) to which the beverage was added can be calculated.

Concentrations of phenol red in the original beverage and gastric samples were spectrophotometrically analysed at $560 \mathrm{~nm}$ after the sample $(0.1 \mathrm{ml})$ was diluted with $(1.9 \mathrm{ml}) \mathrm{NaOH} / \mathrm{NaHCO}_{3}$ buffer $(0.25 / 0.50 \mathrm{M})$. For a detailed description of calculating volume and secretion see Beckers et al. (1988). Gastric emptying data were converted to percent of original bolus remaining and thereafter a semi-log transformation was performed to obtain a linear interpretation of the emptying curve. Only drink residues of $1 \%$ or greater were used in calculation of semi-log transformation lines.

As a measure of gastric secretion, non-drink gastric volume was calculated. This was done by subtracting calculated drink volume from total gastric residue volume at each sample time. Secretion values are given in milliliters and represent the amount of secretion found in the stomach at that particular moment.

Sodium and potassium concentrations in the beverages and samples were measured by flame photometry (Instrumentation Laboratory 243, Lexington, Mass., U.S.A.). Calculation of concentration of the electrolytes $\mathrm{Na}^{+}, \mathrm{K}^{+}$, and $\mathrm{Cl}^{-}$in the gastric secretion was done with the following equation:

$$
\mathrm{CE}_{\mathrm{S}}=\frac{\left(\mathrm{V}_{\mathrm{GR}} * \mathrm{CE}_{\mathrm{GR}}\right)-\left(\mathrm{V}_{\mathrm{B}} * \mathrm{CE}_{\mathrm{B}}\right)}{\mathrm{V}_{\mathrm{S}}}
$$

where $\mathrm{CE}_{S}$ is concentration of electrolytes in secretion (meq.1-1), $V_{G R}$ is volume of gastric residue (l), CE $\mathrm{GR}_{\mathrm{G}}$ is concentration of 
electrolyte in gastric residue (meq. $\mathrm{I}^{-1}$ ), $\mathrm{V}_{\mathrm{B}}$ is volume of original drink given (l), $C E_{B}$ is concentration of electrolyte in original beverage (meq. $\mathbb{1}^{-1}$ ), and $\mathrm{V}_{S}$ is volume of secretion (1). At each sample point new data for $\mathrm{V}_{\mathrm{GR}}, \mathrm{CE}_{\mathrm{GR}}$, and $\mathrm{V}_{\mathrm{S}}$ are put into the equation.

Energy content was determined with bomb calorimetry (IKA C700, Staufen, Germany). $\mathrm{pH}$ was determined with a standard $\mathrm{pH}$ meter ( $\mathrm{pH}$ M82, Radiometer, Copenhagen, Denmark). Acid content was determined using titration with $0.1 \mathrm{~N} \mathrm{NaOH.} \mathrm{Osmolality} \mathrm{was}$ measured using freeze-point depression (Osmomat 030, Gonotech, Berlin, Germany).

\section{Statistical methods}

Repeated measures, 2-way, ANOVA was used to assess main treatment (beverage) effects and the Wilcoxon's signed-rank test was applied to designate differences in treatment means. Data are expressed as mean ( \pm SE), unless otherwise stated.

\section{Results}

In experiment 1 a mean bolus of 598 ( \pm 15 ) $\mathrm{ml}$ was given. A mean non-beverage gastric residue of $71( \pm 22) \mathrm{ml}$ was found at the time of ingestion $(t=0)$. Changes in electrolyte concentrations in the total gastric residue are displayed in Fig. 1.

Gastric emptying and secretion data (including sodium, potassium, and chloride concentrations in the secretion) are presented in Table 2. GE and secretion data for these same subjects with the same beverages during exercise, and the analyses of transformed data comparing rest with exercise, are published elsewhere (Rehrer et al., 1989).

A fairly constant concentration of $\mathrm{Na}^{+}, \mathrm{K}^{+}$and $\mathrm{Cl}^{-}$in the secretion was observed. As a consequence, when a beverage is ingested with a greater concentration of sodium or potassium than in the secretion, the concentration of these electrolytes in the gastric residue decreases. With all beverages tested a leveling off of mineral concentration in the gastric residue was found, as the amount of drink remaining in the stomach became negligible and the majority of gastric residue was composed of secretion. 

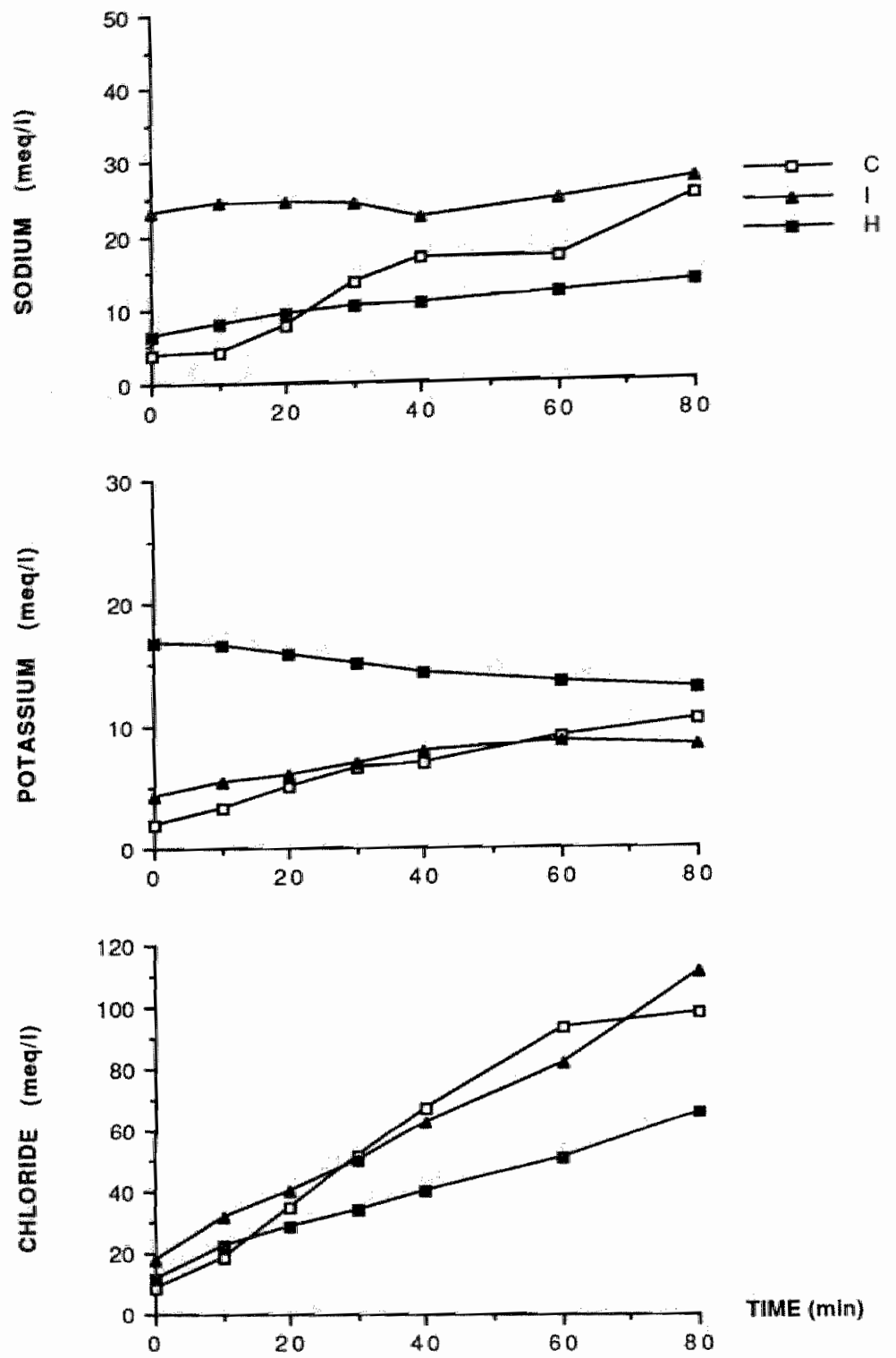

Fig. 1. Exp. 1: Electrolyte concentrations of gastric residue after ingestion of one of three beverages: $C$ (control) water with aspartame, 1.6 meq. 1 $\mathrm{Na}^{+}, 1.2 \mathrm{meq} \mathrm{I}^{-1} \mathrm{~K}^{+}$, and $0.8 \mathrm{meq} \mathrm{l}^{-1} \mathrm{Cl}: 1$ (isotonic) including $73 \mathrm{g.r}^{-1}$ carbohydrate, 23.8 mequ $\mathrm{I}^{-1} \mathrm{Na}^{+}, 3.8$ meq. $\mathrm{H}^{-1} \mathrm{~K}^{+}$, and $12.0 \mathrm{mequ}^{-1} \mathrm{Cl}^{-} ; \mathrm{H}$ (hyperionic) including $18 \mathrm{~g} . \mathrm{r}^{-1}$ carbohydrate, 5.9 meq. $\mathrm{I}^{\mathrm{l}} \mathrm{Na}^{+}$. 17.0 meq. $1 K^{+}$, and 5.6 meq. $I^{-1} \mathrm{Cr}$. 


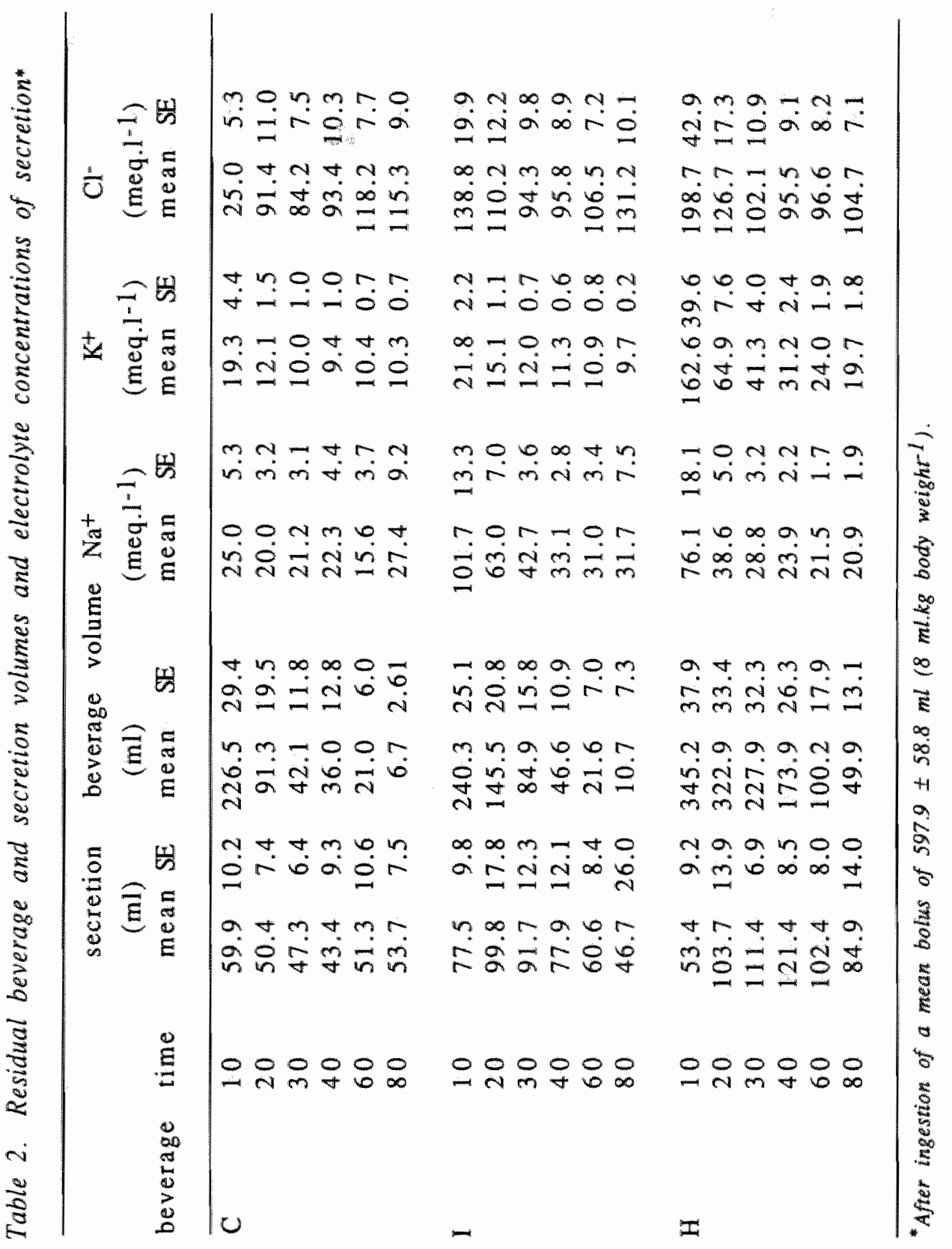




\section{Chapter 5}

A similar situation was observed with gastric $\mathrm{pH}$. The $\mathrm{pH}$ of the gastric residue remained higher when the drink volume remaining in the stomach made up a greater proportion of the gastric residue (Table 3 ). Additionally the titratable gastric acid correlated well with $\mathrm{pH}$ and chloride concentrations (Fig. 2).

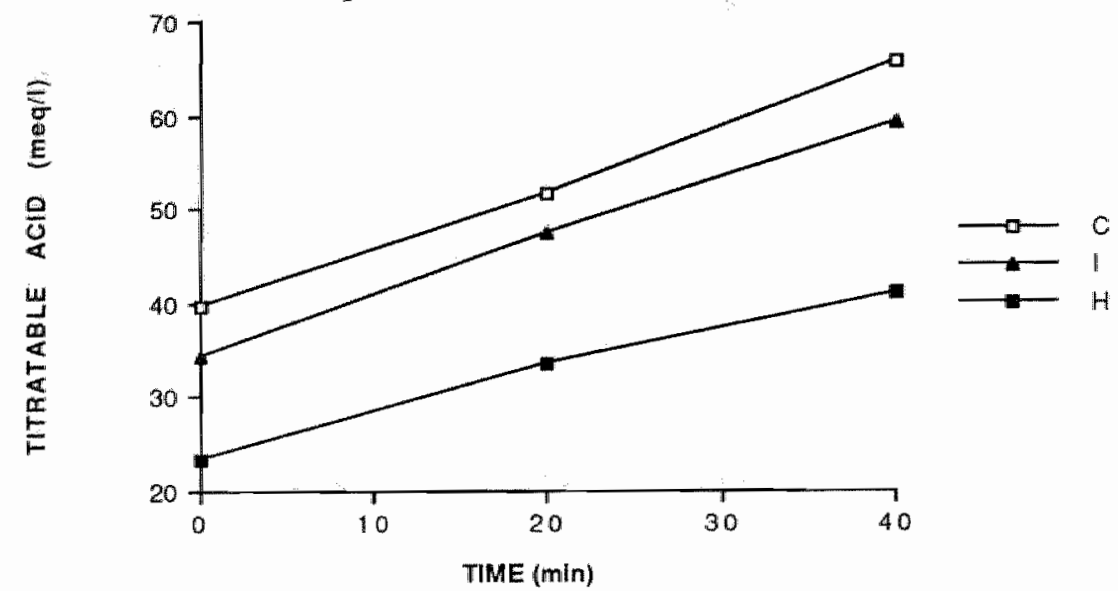

Fig. 2. Exp. 1: Acid concentration in gastric residue after ingestion of $C, I$, and $H$.

Osmolality of the gastric residue over time is presented in Fig. 3. A similar pattern of adjustment based upon dilution with secretion was obserwed. Osmolality increased over time with the control drink, since it was hypotonic, relative to the secretion. Decreasing osmolality was observed with $\mathrm{H}$, which was hypertonic relative to secretion. Osmolatity of I was relatively stable.

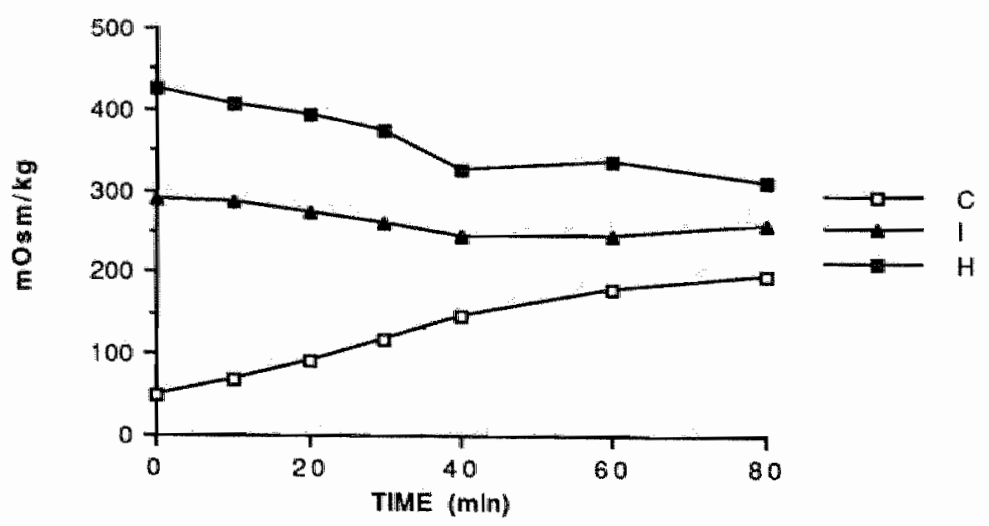

Fig. 3. Exp. I: Osmolality of gastric residue after ingestion of $C, 1$, and $H$. 
Table 3. Gastric residue $\mathrm{pH}$

\begin{tabular}{cccc} 
iime & C & $\begin{array}{c}\text { beverage } \\
\text { I }\end{array}$ & H \\
\hline & & & \\
$0^{*}$ & 2.8 & 3.7 & 4.3 \\
10 & 2.4 & 3.3 & 4.0 \\
20 & 2.1 & 2.8 & 3.5 \\
30 & 2.0 & 2.4 & 3.2 \\
40 & 1.9 & 2.1 & 2.7 \\
60 & 1.5 & 1.8 & 2.4 \\
80 & 1.5 & 1.4 & 1.9 \\
& & & \\
\hline
\end{tabular}

${ }^{*}$ After beverage was ingested and mixed with gastric contents.

\section{EXPERIMENT 2}

Materials and methods

\section{Subjects and experimental design}

Eight male volunteers participated in this study. All subjects were given full description of the experiment and gave written consent. Preliminary tests for familiarisation were conducted as in experiment 1 .

A complete cross-over design was employed in which each subject carried out all treatments. Treatments were assigned in random order without subject knowledge of which drink he had obtained. All trials were done at rest (sitting), in which a similar time table and procedure for intubation was used as in the first experiment. Treatment consisted of ingestion of $8 \mathrm{ml}^{\mathrm{kg} \mathrm{BW}} \mathrm{BW}^{-1}$ of one of eight different beverages. The compositions of five of these beverages are presented in Table 4 . The hypertonic drink $(\mathrm{H})$, which was used in the first experiment, was also tested. In addition, water (W) was tested as well as water with $0.08 \mathrm{~g}^{-1}$ aspartame (C). This was done to test the validity of using this flavoured beverage as a control drink, compared to water in terms of gastric emptying. and secretion. The first five beverages had a base of $150 \mathrm{g.J}-1$ 


\section{Chapter 5}

maltodextrin. The maltodextrin was composed of $63.4 \mathrm{~g} .100 \mathrm{~g}^{-1}$ maltodextrin $10 \mathrm{DE}$ and $16.5 \mathrm{~g} .100 \mathrm{~g}^{-1} 40 \mathrm{DE}$ (Amylum, Aalst, Belgium). The base maltodextrin solution (MD) had an osmolality of 114 mOsm $\mathrm{kg}^{-1}$. The mineral salts sodium chloride and/or potassium chloride were included to be able to evaluate individual effects and possible interaction of sodium and potassium on GE rate.

Table 4. Beverage compositions *

\begin{tabular}{lcrrr}
$\begin{array}{l}\text { beverage } \\
\text { (g.1-1) }\end{array}$ & $\mathrm{Na}^{+}$ & $\begin{array}{c}\mathrm{K}^{+} \\
\left(\mathrm{meq} .1^{-1}\right)\end{array}$ & $\mathrm{Cl}^{-}$ \\
\hline MD & 150.0 & 0 & 0 & 0 \\
K & 150.0 & 0 & 28 & 28 \\
lowNa & 150.0 & 28 & 0 & 28 \\
highNa & 150.0 & 140 & 0 & 140 \\
highNaK & 150.0 & 140 & 28 & 168
\end{tabular}

*Beverages $H$ and $C$ are described in Table $l$ and beverage $W$ was tap water.

Gastric samples for residual drink volume, secretion, $\mathrm{Na}^{+}, \mathrm{K}^{+}$, and $\mathrm{Cl}^{-}$content, $\mathrm{pH}$, and osmolality were taken immediately after administration of the beverage (after mixing with any gastric residue present in the stomach) and at $10 \mathrm{~min}$ intervals for 40 min or until no further gastric sample could be obtained (at which time the stomach was assumed to be empty).

\section{Calculations and statistical methods}

Methods used to analyse, calculate, and transform data for GE and secretion comparisons, to determine electrolyte concentrations, and to measure osmolality, $\mathrm{pH}$, and titratable acid are described in experiment 1. A multiple linear regression analysis was performed to delineate effects of sodium, potassium, osmolality, gastric volume and individual subject differences on GE. 


\section{Results}

\section{Gastric emptying}

Emptying curves of all drinks, except water $(W)$ and the control drink (C), expressed as mean percent of original bolus emptied, overlap one another (Fig. 4). Transformed semi-log lines of the emptying curves of the carbohydrate containing drinks are also displayed in Fig. 4. No significant difference in GE rate based on slopes of these lines was found.
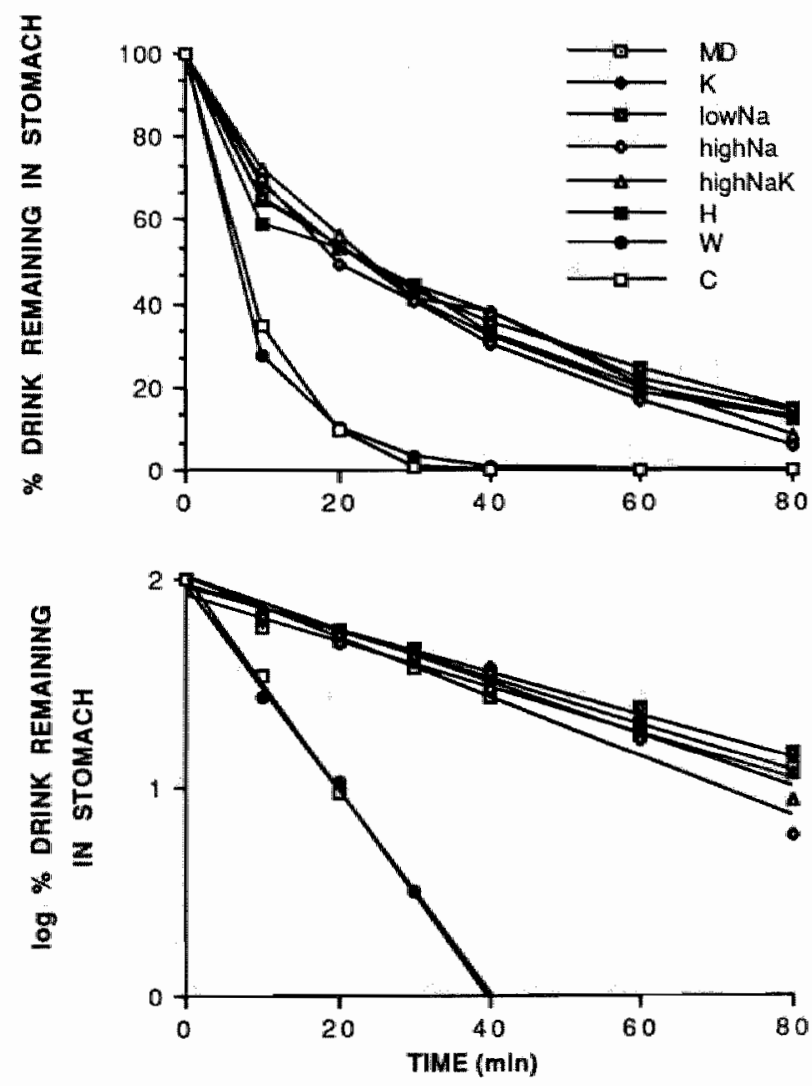

Fig. 4. Exp. II: Gastric emptying of ingested beverages: (above) plots of mean beverage residues expressed as a percentage of original bolus and (below) semi-log plots of the five $15 \%$ maltodextrin beverages with varying sodium and potassium content. 
Multiple linear regression analysis of the first five drinks, basic mallodextrin with varying amounts of sodium and/or potassium, revealed no significant effect of potassium in delaying gastric emptying or of sodium in stimulating gastric emptying. The effects of osmolality and volume were also not observed to be significant in this analysis. However, the regression coefficient for sodium, however weak, was positive $\left(\mathrm{r}^{2}=0.22 ; \mathrm{p}=0.20\right)$. In contrast, a negative (although also weak) correlation was seen with potassium and emptying rate $\left(\mathrm{r}^{2}=-0.20 ; \mathrm{p}=0.11\right)$. Similarly, regression coefficients for volume, and osmolality, with GE rate were positive $\left(r^{2}=0.03\right)$ and negative $\left(r^{2}=-0.01\right)$, respectively.

Between water and the control drink $\left(0.08 \mathrm{~g} . \mathrm{l}^{-1}\right.$ aspartame) no significant differences were found. Both emptied significantly faster than all other solutions (Fig. 4).

\section{Secretion}

In Fig. 5 mean non-drink gastric residue (gastric secretion) present at each sample point is graphically depicted. Mean secretion tended to be larger in treatment $H$ than in all other beverages. Mean secretion of $\mathrm{C}$ and $\mathrm{W}$ tended to be less. Interindividual differences were very large, making standard deviations large and precluding significance.

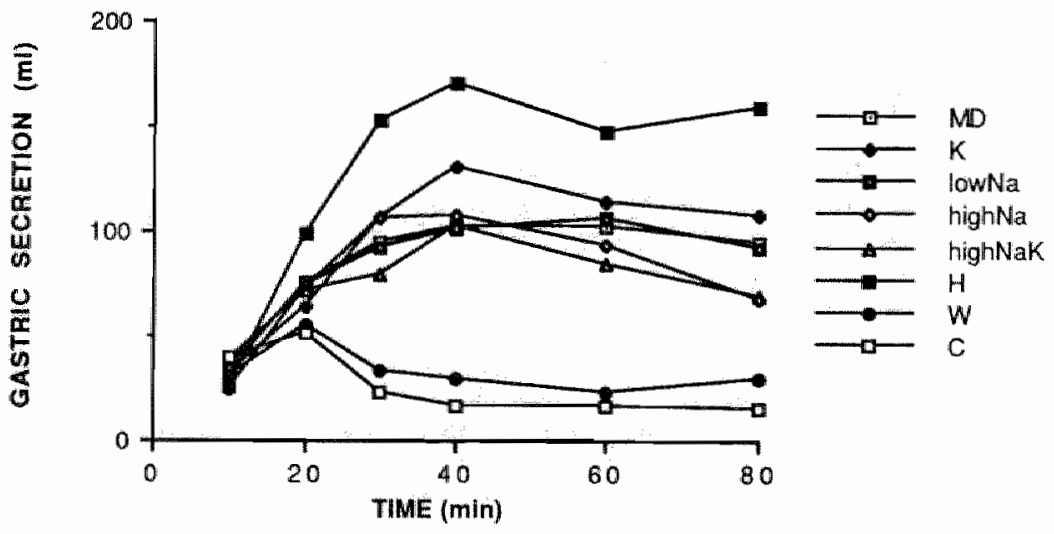

Fig. 5. Exp. II: Gastric secretion volumes observed at each sample point. 

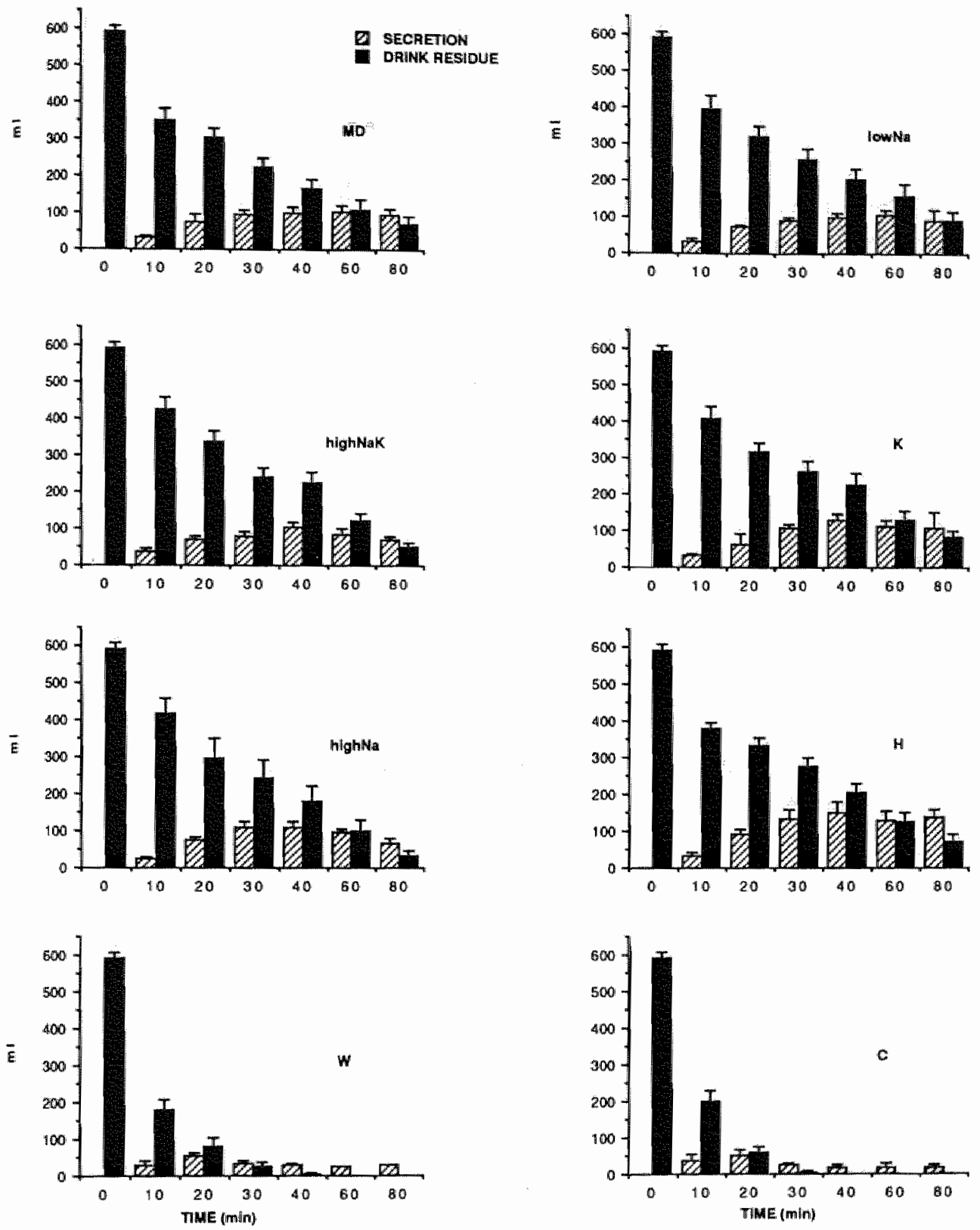

Fig. 6. Exp. II: Mean volume of drink and secretion in the stomach over time for each beverage. 


\section{Chapter 5}

For all beverages the secretion volumes have been set out next to the residual drink volumes at each sample time in Fig. 6. From these data it appears that drink volume alteration over time has very little influence on gastric secretion, since in all drinks gastric secretion yalues reach a peak at 30 and $40 \mathrm{~min}$ and do not alter much after this, while between 40 and $80 \mathrm{~min}$ the residual drink volume decreases markedly in all drinks, decreasing by more than one-half.

Similarly, mineral concentration of secretion remains very constant (Table 5). The only notable differences were with highNa and the the two potassium containing beverages (highNaK and $\mathrm{K}$ ). High Na stimulated a transient absorption of $\mathrm{Na}^{+}$within the first 10 min. $K^{+}$absorption was observed with both $\mathrm{NaK}$ and $\mathrm{K}$, again only in the first $10 \mathrm{~min}$.

Osmolality changes in total gastric residue (Fig. 7) reflect the emptying rate of the ingested beverage. As in experiment 1, a simple dilution of the beverage with the gastric juice accounts for the middling. In all beverages, with the exception of $\mathrm{H}$, a similar situation was observed for gastric pH (Fig. 8). Chloride, secretion volumes, titratable acid, and $\mathrm{pH}$ correlated well in all drinks except in $H$. In all other drinks the amount of secretion accounts for changes in these other parameters. The $\mathrm{pH}$ of $\mathrm{H}$ remained elevated longer than in the other drinks, despite similar or greater volume of secretion.

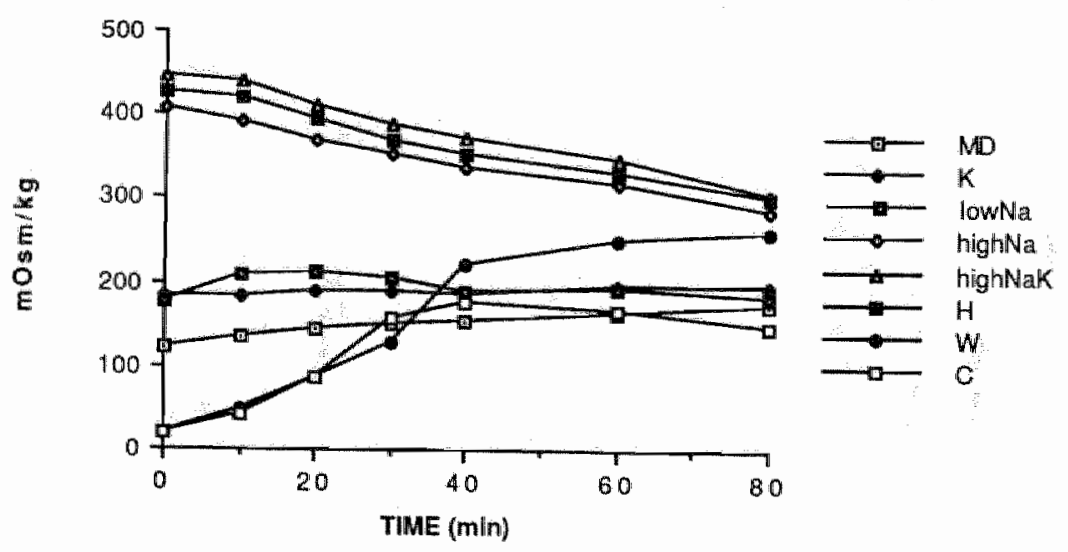

Fig. 7. Exp. II: Osmolality of gastric residue. 


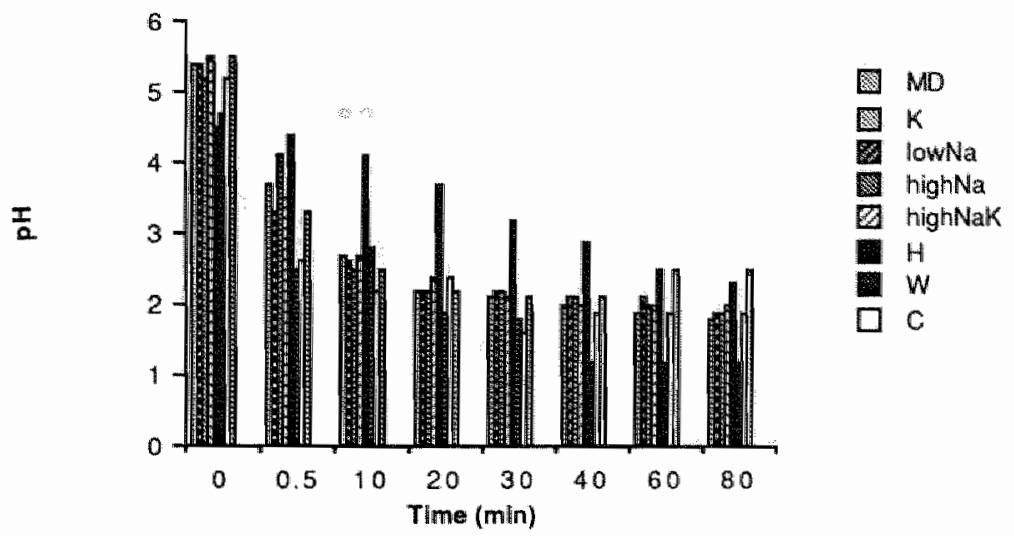

Fig. 8. Exp. 11: Beverage and gastric residue $p H$. Bars for 0 min. represent drink $p H$ before ingestion. Bars at $0.5 \mathrm{~min}$ give value after drink is mixed with siomach contents

\section{Discussion}

The present experiments provide evidence to support the premise that concentration of electrolytes sodium and potassium in gastric secretion in man is quite constant despite variation in sodium and potassium concentration in an instilled beverage. Some flux of sodium and potassium across the gastric mucosa does exist (Frenning, 1974), the former by active transport and the latter by passive diffusion (Makhlouf, 1974), thus it may be assumed that by altering luminal concentrations the net result may be altered. There is also direct experimental evidence with isolated canine, gastric pouches which supports this premise (Dyck et al., 1969). However, slight, but consistent variations in absorption and secretion in relation to the luminal contents in the human stomach under normal, physiological conditions may also exist which are not measurable by the technique employed here. A small error in gastric secretion volume measurement can make for large errors in electrolyte concentration calculations. The variability in volume/secretion measurements inherent in the technique itself is a source of error. 
The fact, also that non-drink is measured actually and not secretion per se may also account for the large variation, particularly at $10 \mathrm{~min}$, since a large portion of what is considered to be secretion at this point may actually be water from rinsing the stomach prior to the test. Although subjects were asked to expectorate continually, the possibility of contamination with saliva also exists. However if large amounts of saliva were passing into the stomach an increased potassium concentration and a decreased sodium concentration would be expected (Gardham \& Hobsley, 1970), except with $\mathrm{K}$ and $\mathrm{NaK}$, with which no increase in $\mathrm{K}^{+}$would be expected. No such changes in this direction were observed between subjects (assuming one subject may expectorate more completely than another) or within a subject over time (assuming after ingestion, with increasing time, there would also be increasing expectorant accumulation).

Differences in $\mathrm{pH}$, osmolality and chloride content of the gastric residue can be, in most cases, accounted for by the differences in GE rate of the different drinks and resulting proportion of gastric secretion which makes up the residue at latter stages of emptying. However, with $\mathrm{H}$, gastric residue $\mathrm{pH}$ remained higher longer than with alı the other beverages tested in experiment 2, when secretion rate was equal to or greater than the other drinks. The buffer capacity of this beverage is apparently greater. How this is achieved remains uncertain.

Based upon the amounts found at the select measuring points, the rate of secretion in carbohydrate containing beverages with similar $\mathrm{pH}$ and osmolality appears fairly constant. The trend for increased secretion with $H$ may possibly be explained by the maintenance of a higher $\mathrm{pH}$, as a lower $\mathrm{pH}$ is one of the factors known to inhibit gastric acid secretion, most probably by a direct effect of $\mathrm{H}^{+}$on $\mathrm{G}$ cells to inhibit gastrin release (Davison, 1989). Gastrin stimulates the parietal cells to produce $\mathrm{HCl}$. Secretion is also made up of an alkaline fraction, including the secretion from chief cells (pepsinogen producing), whose rate of output usually varies with the output of the acid-secreting cells (Hunt, 1959). Additionally, chloride concentration has been observed to remain constant with acid concentrations of from $0-150 \mathrm{mN}$ (Cooke \& Grossman, 1965). These observations may explain how gastric acid secretions, uninhibited by maintenance of a higher $\mathrm{pH}$, may be 
increased and yet the concentration of chloride is not altered. The trend for secretion to be less with $W$ and $C$ is probably related to the decreased osmolality (Costill \& Saltin, 1974; Frenning, 1974) and in part to the very large decrease in volume compared to all other beverages. A stimulatory effect of volume (pressure) in the corpus of the stomach on gastric secretion has been described in several studies (Davison, 1989), however some inconsistency has been observed, studies with beverages of varying composition giving conflicting results (Strunz \& Grossman, 1978),

Regression analysis showed no significant effect of potassium or sodium concentration on gastric emptying. The absence of a large, nutrient specific inhibitory effect of potassium on gastric emptying remains somewhat puzzling in light of preliminary findings in this laboratory and observations by others. The difference in results may be explained by the fact that in our earlier test potassium citrate was used and in the present study potassium chloride was used. However, in Nielsen and co-workers' study (Nielsen et al., 1986) $\mathrm{KCl}$ was also used and the beverage with the highest potassium concentration was least effective in rehydration, as indicated by plasma volume changes. One possible explanation of their results is that the beverage with the highest potassium concentration emptied more slowly from the stomach than the other beverages, although no measurements of gastric emptying rate were made. The concentration of potassium in their study, however, was much greater (138 meq. $\left.{ }^{-1}\right)$ than in the present study.

A lack of stimulation of $\mathrm{GE}$ with the sodium containing beverages is also puzzling. Possibly the high carbohydrate concentration, decreasing GE rate, overshadowed any possible potentiating effect of the added sodium, or perhaps the sodium concentration was too low, relative to the glucose concentration. Nevertheless, the directions of the regression lines when effects of $\mathrm{Na}^{+}, \mathrm{K}^{+}$, volume, and osmolality are fitted, coincide with the expected influences of these factors based upon the literature. Sodium and volume both had positive coefficients and potassium and osmolality both had negative ones. Although the regression coefficients of none of these parameters were significant, the directions of the regressions fit with the indications from the literature that sodium and volume may stimulate $\mathrm{GE}$ and that potassium and osmolality may inhibit GE. 
Table 5. Concentration of electrolytes in secretion (meq.1.1)

\begin{tabular}{|c|c|c|c|c|c|c|c|}
\hline \multicolumn{2}{|c|}{ beverage time } & \multicolumn{2}{|l|}{$\mathrm{Na}^{+}$} & \multicolumn{2}{|l|}{$\mathrm{K}^{+}$} & \multicolumn{2}{|l|}{$\mathrm{Cl}^{-}$} \\
\hline & & mean & $\mathrm{SE}$ & mean & SE & mean & $\mathrm{SE}$ \\
\hline \multirow[t]{6}{*}{ MD } & 10 & 34.2 & 9.0 & 12.01 & 13.7 & 187.0 & 39.5 \\
\hline & 20 & 27.9 & 5.4 & 14.5 & 6.4 & 151.3 & 35.3 \\
\hline & 30 & 23.1 & 6.2 & 11.1 & 2.6 & 114.3 & 25.6 \\
\hline & 40 & 20.2 & 4.5 & 10.5 & 5.4 & 94.5 & 17.2 \\
\hline & 60 & 20.6 & 3.0 & 11.4 & 1.9 & 94.5 & 22.0 \\
\hline & 80 & 20.2 & 2.9 & 11.2 & 1.7 & 90.3 & 16.2 \\
\hline \multirow[t]{6}{*}{$\mathrm{K}$} & 10 & 49.61 & 13.9 & -11.1 & 17.5 & 250.2 & 76.6 \\
\hline & 20 & 25.2 & 6.7 & 8.1 & 1.6 & 145.4 & 21.7 \\
\hline & 30 & 18.3 & 3.4 & 11.7 & 1.7 & 109.0 & 14.1 \\
\hline & 40 & 17.9 & 3.1 & 12.5 & 4.9 & 101.6 & 10.9 \\
\hline & 60 & 17.6 & 2.9 & 13.5 & 1.1 & 97.3 & 8.2 \\
\hline & 80 & 18.3 & 2.9 & 13.8 & 1.0 & 97.3 & 9.5 \\
\hline \multirow[t]{6}{*}{ low $\mathrm{Na}$} & 10 & 47.32 & 22.0 & 22.6 & 6.5 & 152.4 & 24.7 \\
\hline & 20 & 34.3 & 4.2 & 14.1 & 1.5 & 111.4 & 11.7 \\
\hline & 30 & 15.91 & 13.0 & 11.7 & 1.3 & 97.1 & 8.9 \\
\hline & 40 & 29.5 & 3.4 & 11.1 & 3.7 & 96.0 & 11.8 \\
\hline & 60 & 30.4 & 3.3 & 10.8 & 0.7 & 92.1 & 7.9 \\
\hline & 80 & 30.2 & 3.8 & 11.3 & 0.6 & 91.8 & 8.1 \\
\hline \multirow[t]{6}{*}{ highNa } & 10 & -25.05 & 51.1 & 44.2 & 17.9 & 156.5 & 25.3 \\
\hline & 20 & 33.6 & 4.6 & 11.6 & 1.1 & 101.7 & 8.2 \\
\hline & 30 & 34.8 & 8.1 & 10.4 & 1.1 & 100.4 & 7.11 \\
\hline & 40 & 37.71 & 15.8 & 9.5 & 2.8 & 96.3 & 5.0 \\
\hline & 60 & 38.31 & 15.0 & 9.5 & 1.1 & 100.6 & 2.0 \\
\hline & 80 & 37.71 & 14.3 & 11.1 & 0.9 & 100.3 & 2.7 \\
\hline \multirow[t]{6}{*}{ highNaK } & 10 & 2.63 & 37.9 & -2.7 & 9.8 & 102.5 & 14.3 \\
\hline & 20 & 37.91 & 13.7 & 10.7 & 2.5 & 108.4 & 6.9 \\
\hline & 30 & 35.01 & 14.1 & 9.0 & 2.9 & 107.1 & 6.2 \\
\hline & 40 & 28.71 & 15.2 & 6.0 & 3.6 & 97.9 & 4.9 \\
\hline & 60 & 28.91 & 14.3 & 7.7 & 3.3 & 102.3 & 4.0 \\
\hline & 80 & 36.21 & 10.7 & 11.9 & 2.4 & 105.7 & 6.5 \\
\hline
\end{tabular}


Table 5. (cont.)

$\begin{array}{lrrrrrrr}H & 10 & 35.5 & 12.2 & 16.8 & 2.1 & 156.7 & 18.6 \\ & 20 & 29.1 & 5.6 & 10.4 & 0.3 & 100.8 & 6.1 \\ & 30 & 24.0 & 2.9 & 9.6 & 0.9 & 85.1 & 6.4 \\ & 40 & 22.6 & 1.9 & 9.6 & 1.1 & 83.5 & 7.7 \\ & 60 & 22.5 & 1.8 & 9.6 & 1.0 & 84.9 & 7.2 \\ & 80 & 23.4 & 2.1 & 9.8 & 1.2 & 80.9 & 7.1 \\ & & & & & & & \\ & 10 & 38.5 & 8.3 & 43.9 & 18.7 & 422.9201 .8 \\ & 20 & 11.6 & 0.8 & 11.3 & 1.4 & 93.0 & 19.2 \\ & 30 & 18.3 & 4.3 & 11.9 & 1.4 & 88.0 & 16.3 \\ & 40^{*} & 14.6 & 6.1 & 11.0 & 2.0 & 144.5 & 14.3 \\ & 60^{*} & 22.7 & 8.7 & 11.2 & 1.2 & 134.1 & 10.4 \\ & 80 & - & & - & & - & \\ & & & & & & & \\ & 10 & 13.9 & 11.6 & 9.0 & 7.7 & 64.3 & 66.7 \\ & 20 & 18.3 & 3.7 & 12.0 & 0.8 & 92.9 & 16.0 \\ & 30 & 19.6 & 6.1 & 13.7 & 1.4 & 91.2 & 15.5 \\ & 40^{*} & 33.0 & 16.0 & 12.7 & 1.5 & 91.0 & 9.0 \\ & 60 & - & & - & & - & \\ & 80 & - & & - & & & \end{array}$

${ }_{n=2}$ 


\section{References}

1. Barker, G.R., G. Cochrane, G.A. Corbett, J.N. Hunt and S.K. Roberts. Actions of glucose and potassium chloride on osmoreceptors slowing gastric emptying. J. Physiol. 237: 183$186,1974$.

2. Beckers, E.J., N.J. Rehrer, F. Brouns, F. ten Hoor and W.H.M. Saris. Determination of total gastric volume, gastric secretion, and residual meal using the double sampling technique of George. Gut 29: 1725-1729, 1988.

3. Cooke, A.R. and M.I. Grossman. Electrolytes in gastric juice after adrenalectomy and glucocorticoid administration. Physiologiist 8:139.165, 1965.

4. Costill, D.L. and B. Saltin. Factors limiting gastric emptying during rest and exercise. J. Appl. Physiol. 37: 679-683, 1974.

5. Coyle, E.F., D.L. Costill, W.J. Fink and D.G. Hoopes. Gastric emptying rates for selected athletic drinks. Res. Q. 49: 119$124,1978$.

6. Davison, J.S. Gastrointestinal Secretion. London: Wright Publishers (Butterworth \& Co.) 1989.

7. Dyck, W.P., J.L. Werther, J. Rudick and H.D. Janowitz. Electrolyte movement across canine antral and fundic gastric mucosa. Gastroenterology 56: 488-495, 1969.

8. Ferrannini, E., E. Barrett, S.W. Bevilacqua, J. Dupre, and R.A. Defronzo. Sodium elevates the plasma glucose response to glucose ingestion in man. J. Clin. Endocrinol. Metab. 54: 455$458,1982$.

9. Fordtran, J.S. Stimulation of active and passive sodium absorption by sugars in the human jejunum. J. Clin. Invest. 55: 728-737, 1975. 
10. Frenning, B. The effects of large osmolality variations on the gastric mucosal ion permeability. Acta Physiol. Scand. 90: 113, 1974.

11. Gardham, J.R.C. and M. Hobsley. The electrolytes of human alkaline juice. Clin. Sci. 39: 77-87, 1970.

12. Hunt, J.N. Gastric emptying and secretion in man. Physiol. Rev. 39: $491-533,1959$.

13. Hunt, J.N. and J.D. Pathak. The osmotic effect of some simple molecules. J. Physiol. 154: 254-269, 1960.

14. Makhlouf, G. M. A model for passive transport of potassium by the stomach: evidence by in vitro studies. Am. J. Physiol. 227: $1285-1288,1974$.

15. Makhlouf, G.M., J.P.A. McManus and W.I. Card. A quantitative statement of the two-component hypothesis of gastric secretion. Gastroenterology 51: 149-171, 1966.

16. Moore, J.G. and E. Englert. The circadian rhythm of gastric acid secretion in man. Nature 226: 1261-1262, 1970.

17. Nielsen, B., G. Sjogaard, J. Ugelvig, B. Knudsen and B. Dohlman. Fluid balance in exercise dehydration and rehydration with different glucose-electrolyte drinks. Eur. J. Appl. Physiol. 55: $318-325,1986$.

18. Rehrer, N.J., E.J. Beckers, F. Brouns, F. ten Hoor, and W.H.M. Saris. Exercise and training effects on gastric emptying of carbohydrate beverages. Med. Sci. Sports Exerc. 21: 540-549 1989.

19. Schultz, S.G. and P.F. Curran. Stimulation of intestinal sodium absorption by sugars. Am. J. Clin. Nutr. 23: 437-440, 1970. 
Chapter 5

20. Shay, H. and J. Gershon-Cohen. Experimental studies of gastric physiology in man. II. A study of pyloric control. The roles of acid and alkaline. Surg. Gynecol. Obstet. 58: 935-955, 1934.

21. Strunz, U.T. and M.I. Grossman. Effect of intragastric pressure on gastric emptying and secretion. Am. J. Physiol. 4: E552E555, 1978. 


\section{CHAPTER 6}

\section{Effects of dehydration on gastric emptying and gastrointestinal distress while running}

\section{Abstract}

Gastrointestinal distress is commonly reported by athletes after ingestion of a beverage. We speculate that ingestion may be occurring after dehydration has taken place. The high prevalence of GI disorders in marathon runners who have lost $\geq 4 \%$ body weight support this theory. To test this theory, the effects of dehydration and dehydration in combination with endurance running on gastric emptying (GE) and frequency of gastrointestinal (GI) complaints were tested in this experiment. A complete cross-over study was designed.

Sixteen subjects ingested $8 \mathrm{ml} . \mathrm{kg} \mathrm{BW}^{-1}$ of a $7 \%$ carbohydrate (296 mOsm. $\mathrm{kg}^{-1}$ ) solution after a euhydration or dehydration regime running or at rest. Dehydration ( $4 \%$ BW loss) was produced by $60 \%$ maximal speed running at $30^{\circ} \mathrm{C}$ or by intermittent sauna exposure at $100^{\circ} \mathrm{C}$. Euhydration experiments were conducted with a $2 \mathrm{~h}$ rest period with water administered at 20 and 40 min. Gastric drink volumes where measured every ten minutes for $40 \mathrm{~min}$. Emptying curves were compared using semi-log transformation of the percentage emptying data and simple linear regression. The slope of each line was used as a measure of average GE rate.

Dehydration-exercise resulted in slower GE than in all other treatments $(p<.05)$. ANOVA revealed significant effects of dehydration $(p<0.05)$ and exercise $(p<0.05)$, these two effects being additive in delaying $\mathrm{GE}$.

GI complaints were reported by $37.5 \%$ of the subjects during dehydration-exercise experiments. No GI disturbance was reported in other tests. Core body temperature was significantly higher after the dehydration-exercise regime $\left(39.1^{\circ} \mathrm{C}\right)$ than after 
the rest-dehydration regime $\left(37.9^{\circ} \mathrm{C}\right) \quad(p<0.05)$.

It is concluded that dehydration and/or thermal effects delay GE and may be related to a higher prevalence of GI disturbance.

\section{Introduction}

There appears to be a relationship between dehydration during endurance exercise and gastrointestinal dysfunction. Results of a field study indicate that body weight losses in the range of $4-5 \%$ during marathon running are associated with an increased prevalence of gastrointestinal (GI) disorders (16).

Neufer observed delayed gastric emptying (GE) in a laboratory where body weight loss averaged $5 \%$ (12). Reports by endurance athletes who complain of GI problems occurring only after they drink during long competition may partly be explained by these results. Contrary to the supposition that GI disturbance is caused by the ingestion of fluid is the finding from laboratory experiments that following ingestion of fluid $(150-600 \mathrm{ml}) \mathrm{GI}$ complaints were virtually non-existent at rest as well as during bicycling and running $(14,15)$. This discrepancy may be partly due to the fact that in practice, the athletes that complain of GI disturbance after drinking may only be drinking after dehydration has already occurred, as it is known that voluntary fluid consumption during exercise does not keep pace with needs $(18,10)$. The intention of the present study was to evaluate the effects of dehydration, exercise, and the combination of dehydration with exercise on gastric emptying and the prevalence of gastrointestinal complaints.

\section{Material and methods}

\section{Subjects}

Only male individuals who had completed half-marathons or longer competitions and were presently conducting occasional training runs in excess of $1.5 \mathrm{~h}$ were allowed to participate in the experiments. 
Subject characteristics are presented in Table 1. All subjects received a complete written description of the experiment and were provided with an informed consent form to sign.

Pre-trials were conducted including a maximal exertion test on a treadmill. After warming-up for $10 \mathrm{~min}$ at $10 \mathrm{~km} \cdot \mathrm{h}^{-1}$ the speed of the treadmill was increased by $2 \mathrm{~km}^{-\mathrm{h}^{-1}}$ every $2.5 \mathrm{~min}$ until the heart rate reached 160 b.p.m. (150 b.p.m. for subjects who were known to have a lower maximal heart rate) at which point the speed was increased by $1 \mathrm{~km} \cdot \mathrm{h}^{-1}$ every $2.5 \mathrm{~min}$ until exhaustion. After the maximal exertion test, trial placement of a nasogastric tube was conducted to allow for self-selection and to reduce anxiety on the first test day.

Table 1. Subject characteristics (males; $n=15$ )

\begin{tabular}{|c|c|c|c|}
\hline & mean & $\pm S E$ & range \\
\hline Age $(y r)$ & 30.9 & \pm 1.60 & $(22-41)$ \\
\hline $\begin{array}{l}\text { Weight }(\mathrm{kg}) \\
\text { Max. running }\end{array}$ & 71.9 & \pm 1.46 & $(64-83)$ \\
\hline speed $\left(\mathrm{km} \cdot \mathrm{h}^{-1}\right)$ & 19.2 & \pm 0.26 & $(18-22)$ \\
\hline
\end{tabular}

\section{Daily protocol}

Subjects were instructed to eat and drink normally and to only do light training the day prior to an experiment. No solid food was to be consumed $12 \mathrm{~h}$ prior to coming to the laboratory. However, during the evening prior to the laboratory visit all fluids were allowed. On the morning of the experiment only water was to be consumed. At 8:00 a.m. subjects came to the laboratory and consumed a liquid breakfast consisting of 5 ml.kg BW-1 Powerplay ${ }^{\circledR}$, a low fat liquid meal containing $24 \%$ protein, $13 \%$ fat, $63 \%$ carbohydrate. The mean energetic content of this meal was $1500 \mathrm{~kJ}$. Exactly $1.5 \mathrm{~h}$ after breakfast a nasogastric tube was placed. Thirty minutes thereafter subjects began the hydration or dehydration regime. The stomach contents were emptied, the stomach was rinsed, and a recovery test was completed, as has been fully described elsewhere (14). 


\section{Treatments}

All treatments were conducted on separate days over a three month period, with no testing of one subject on sequential days. A complete cross-over design was utilised. Fifteen of the original 16 subjects completed all treatments.

Dehydration-exercise treatment

The dehydration-exercise experiment (DE) was conducted in the laboratory where a constant dry-bulb temperature of $30^{\circ} \mathrm{C}$ was maintained. Relative humidity ranged from $52-55 \%$. During this treatment subjects ran on a treadmill at $60 \%$ maximal speed (60\% max). Although oxygen consumption was not measured, heart rate was monitored continually during the maximal exertion test. The heart rates corresponding to this exercise intensity were well below the anaerobic threshold (no plateauing of heart rate was seen, additionally, several of the subjects had conducted maximal exertion tests prior to this experiment where oxygen consumption was measured). The speed was chosen to simulate that of a long training run. Subjects found this speed quite slow at the beginning of the experiment, but the majority found it difficult to maintain in the latter stages of the experiment. A fan was continually blowing directly on each subject and any visible sweat was periodically wiped off with a towel. Subjects ran until $4 \%$ body weight loss was achieved or until $2 \mathrm{~h}$, whichever came first. A time limit was set to preclude extreme differences in time to last meal, which may influence gastric emptying. In addition, the time limit was set to avold the possibility of exhaustion occurring before the experiment was completed. Subjects were briefly stopped to be weighed (after towel drying), after $1 \mathrm{~h}$ and thereafter at intervals of 30 or 15 min. As the weight loss approached $4 \%$ the time between weighings was shortened. After $2 \mathrm{~h}$ or when $4 \%$ body weight loss was achieved, subjects stopped running briefly for complete drying and final body weight measurements. All clothes were removed, excepting runing shorts, as was done for initial body weight measurements. In 10 of the 16 subjects rectal temperature was also taken immediately after this first dehydration phase was completed. 
Immediately following measurements the subjects returned to the treadmill where $8 \mathrm{ml} . \mathrm{kg} \mathrm{BW}^{-1}$ of an isotonic, carbohydrateelectrolyte containing beverage (Isostar ${ }^{(B)}$ ) was administered and $60 \%$ max exercise was continued. Thereafter samples were taken for $40 \mathrm{~min}$ to determine volume of drink still present in the stomach as well as gastric secretion at several points throughout the emptying curve. All beverages were administered and samples were extracted via the nasogastric tube.

\section{Dehydration-rest experiment}

In the dehydration-rest experiments (DR) a $2 \mathrm{~h}$ saunadehydration regime replaced the exercise-dehydration regime. Subjects were repeatedly exposed to a dry sauna $\left(100^{\circ} \mathrm{C}\right)$ for intervals of 12-15 min with intermittent cooling-off periods of 10-12 min. After each sauna exposure subjects dried off and were weighed. When $4 \%$ body weight loss was achieved, or when $2 \mathrm{~h}$ had elapsed, subjects dried off and final body weights and rectal temperatures were taken. The subjects then sat down and were administered $8 \mathrm{ml.kg} \mathrm{BW-1}$ of the test beverage and gastric samples were taken.

\section{Euhydration-exercise treatment}

For euhydration experiments the $2 \mathrm{~h}$ dehydration protocol was replaced by a $2 \mathrm{~h}$ wait period where $250 \mathrm{ml}$ tap water was administered at $20 \mathrm{~min}$ and $40 \mathrm{~min}$.

In the euhydration-exercise experiment (EE) subjects began warming-up for $10 \mathrm{~min}\left(2 \mathrm{~km} \cdot \mathrm{h}^{-1}\right.$ less than $60 \%$ max speed) at $1 \mathrm{~h} 50 \mathrm{~min}$, then at $2 \mathrm{~h}$ the test drink was administered, after which $60 \%$ max exercise started.

\section{Euhydration-rest treatment}

In the euhydration-rest experiment (ER) subjects remained sitting while the isotonic, carbohydrate-electrolyte beverage was administered and samples were being taken.

In all treatments subjects were asked to urinate immediately prior to the beginning of the $2 \mathrm{~h}$ hydration or dehydration phase and again after $2 \mathrm{~h}$, immediately prior to the consumption of the test beverage and the $40 \mathrm{~min} G E$ test period. This was done to 
standardise pre-experimental conditions and to reduce the likelihood of the need to urinate during the run. If subjects needed to urinate during the dehydration period, body weights were taken before and after so as to correct for this loss when calculating $4 \%$ body weight loss.

\section{Gastric emptying measurements}

The colorimetric double-sampling technique of George, as modified by Beckers et al. (8), was used to measure remaining drink volumes and secretion volumes. Emptying rate of the isotonic, carbohydrate-electrolyte beverage, following the hydration or dehydration regime, was measured over a $40 \mathrm{~min}$ period. Samples were taken at $0,10,20,30$, and $40 \mathrm{~min}$ according to protocol (Fig. 1).

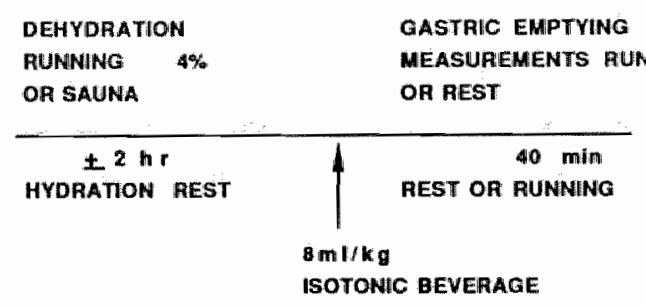

Fig. 1. Experimental protocol for various treatments, dehydration or euhydration with exercise or at rest.

\section{Statistics}

To make comparisons between treatments possible transformation of the data was performed. The percentage of the original bolus that was emptied at a given time was first calculated, since each subject was given a slightly different volume dependent upon body weight. Since the emptying curves were exponential a semi-log transformation of the percentage data was then made. The slopes of the linear regression lines were compared to give a figure for the speed of emptying over the total emptying curve.

Analysis of variance (ANOVA) was conducted to test the effects of hydration and exercise and to account for inter-individual 
differences. Differences among selected treatment means were compared using Wilcoxon's signed-rank test. A level of significance was set at 0.05 . Data are presented as means and standard errors of means.

\section{Results}

The mean running time for the dehydration protocol was $1.87 \mathrm{~h}$, with a range of $1.35-2.00 \mathrm{~h}$. Average absolute weight loss was $2.64 \mathrm{~kg} \pm 0.98$ representing $3.74 \% \pm 0.26$ of the total body weight. Neither weight loss, nor average time to loss was significantly different in the sauna experiment. Howewer, rectal temperature was significantly higher as a result of exercise in combination with dehydration (Table 2).

Table 2. Body weight loss and rectal temperature in the dehydration-rest $(D R)$ and dehydration-exercise (DE) experiments

DR DE mean $\pm \mathrm{SE}$

Rectal temp. $\left({ }^{\circ} \mathrm{C}\right)$

$\begin{array}{ll}37.80 & 39.10^{*} \\ \pm 0.14 & \pm 0.12\end{array}$

Absolute body weight loss ( $\mathrm{kg}$ )

$\begin{array}{ll}2.40 & 2.64 \\ \pm 0.11 & \pm 0.10\end{array}$

Relative body weight loss (\%)

$$
\begin{array}{ll}
3.33 & 3.74 \\
\pm 0.13 & \pm 0.07
\end{array}
$$

*DR vs. $D E$ significant difference $(p<0.01)$.

Gastrointestinal distress was reported by six of the original 16 subjects $(37.5 \%)$ during the dehydration-exercise experiment. Complaints included stomach ache, nausea, vomiting, and lower abdominal pain. Nausea was often accompanied by slight 


\section{Chapler 6}

vertigo. In the majority of instances the symptoms occurred immediately after ingestion of the test beverage. In some subjects the symptoms persisted, however, in the majority of the subjects the symptoms were of short duration (less than 10 min). One subject vomited during the DE test and withdrew from the experiment. No gastrointestinal disturbance was reported during the dehydration-rest experiment or during the euhydration experiments.

Gastric emptying (GE) rates, based upon slopes of the transformed data ${ }_{n}$ varied significantly as a result of exercise and dehydration. No significant differences between mean emptying rates of euhydration-rest (ER), euhydration-exercise (EE), and dehydration-rest were observed. However there was a tendency for mean emptying rate of $E R$ to be faster than DR or EE. Dehydration exercise (DE) resulted in the slowest $G E$, being significantly slower than all other treatments (Table 3).

Table 3. Slopes of gastric emptying curves after semi-log transformation

Treatment Slope SE

$\begin{array}{lll}\begin{array}{l}\text { Dehydration (DE) } \\ \text { Exercise }\end{array} & -0.0301^{*} & .007 \\ \begin{array}{l}\text { Dehydration (DR) } \\ \text { Rest }\end{array} & -0.0402 & .010\end{array}$

Euhydration (EE) $\quad-0.0409 \quad .011$
Exercise

Euhydration (ER)

Rest

*DE significantly different than all other treatments $(p<0.05)$.

ANOVA revealed a significant main effect of dehydration and exercise on gastric emptying (GE) $(p<0.05)$. 
The effects, both to slow $\mathrm{GE}_{\text {, }}$ were additive. Subject, included as a dependent variable, was also found to be highly significant $(\mathrm{p}<0.01)$. Inter-individual differences are known to be large, certain individuals being characterised by a slow $\mathrm{GE}$, others by a faster GE (6). These consistent differences between individuals can mask treatment differences when comparing treatment means. However, the relative effect of a certain treatment is evident when the influence of inter-individual variation is included in the ANOVA.

To illustrate the shape of the actual emptying curves, the data for dehydration-exercise (DE) and euhydration-exercise (EE), expressed as a percent of the original $@ 600 \mathrm{ml}$ bolus, are plotted in Fig. 2a. During exercise only $18.9 \%$ of the original drink remained with EE whereas with DE $30.2 \%$ remained after 20 min. After $40 \mathrm{~min} 1.7 \%$ and $9.3 \%$, respectively, remained. Logarithmic transformation of these data display linearity, $r$ for EE being 1.0 and 0.98 for DE (Fig. 2b).
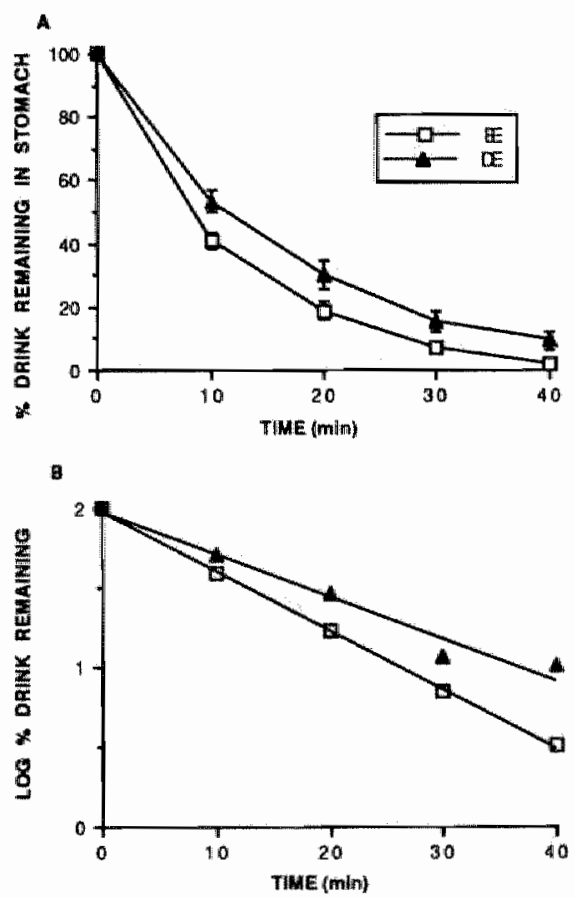

Fig. 2a. Gastric emptying of an isotonic, carbohydrate-electrolyte beverage during exercise after dehydration (DE) or euhydration regime (EE). Fig. 2b. Semi-log transformation of these curves. 


\section{Chapter 6}

In Fig. 3a the other most important comparison is displayed, that of $D R$ versus $D E$. Also during rest, prior dehydration tended to slow GE of the isotonic beverage, although not as significantly as was the case when dehydration and exercise were combined. Semi-log curves are displayed in Fig. $3 b$, these transformed data also displaying linearity.
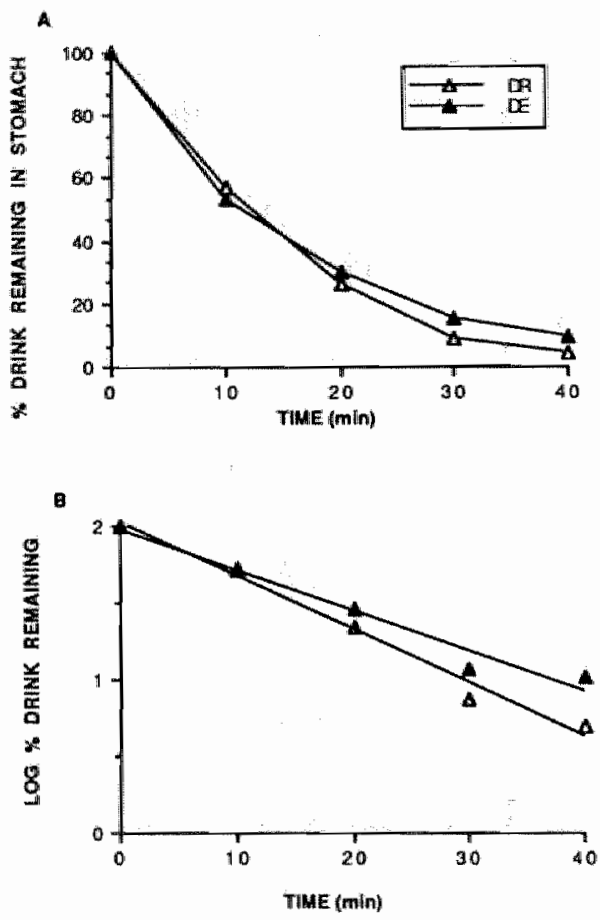

Fig. 3a. Gastric emptying of an isotonic, carbohydrate-electrolyte beverage at rest (DR) or during exercise (DE) after a dehydration regime. Fig. 3b. Semi-log transformation of these carves. 


\section{Discussion}

The results of the present study support those of Neufer et al. (12) in demonstrating a delayed $\mathrm{GE}$ as a result of dehydration and thermal stress during exercise. Owen et al. (13) however, saw no effect of a warm environment $\left(35^{\circ} \mathrm{C}\right)$ on gastric emptying during a $2 \mathrm{~h}$ run as compared to a similar $2 \mathrm{~h}$ run in a cooler environment $\left(25^{\circ} \mathrm{C}\right)$. However, in Owen et al.'s study fluid was given throughout exercise and not only after dehydration as in the present study. Another point to be taken into consideration when evaluating Owen et al.'s results is the lack of gastric secretion measurements. Only total gastric volumes were compared, which can often be misleading when the intent is to measure the emptying of one beverage relative to another, or in one condition versus another. To make valid comparisons the amount of actual drink emptied must be known. An example of the difference that can be obtained in results is found in earlier work of Foster et al. where apparent differences between GE rates of two drinks of varying compositions, based upon total gastric residue, were no longer significant when secretion was accounted for $(8,11)$.

Also, differences that may have been apparent when points along the total emptying curve are known, may not be apparent when the drink rolume is measured only at the end of the protocol. An example of the significance of these differences can be observed in a comparison made in our laboratory of the effect of exercise intensity on gastric emptying (14).

It is impossible to conclude, based on the results of the present experiment, whether the determining factor is the rise in core body temperature or the dehydration per se. Neufer et al. (12) did find a highly significant inverse correlation between rectal temperature and the amount of water emptied from the stomach after a $400 \mathrm{ml}$ bolus during $15 \mathrm{~min}$ of running at $50 \%$ $\mathrm{VO}_{2}$ max. Similarly a significant negative correlation was found between heart rate and GE. 
Since in both Neufer et al.'s experiment and in the present experiment a rising core body temperature was found in combination with dehydration the ultimate causative factor is impossible to isolate during exercise-dehydration experiments. In the present study results of the rest experiment in the sauna, where rectal temperature was lower than during exercisedehydration (Table 2), and $\mathrm{GE}$ was faster, tends to point at a thermal effect controlling GE. However, during exercise there are other factors to be taken into account. During exercise the circulation to the abdominal viscera can be decreased by as much as $70-80 \%$ (5). Thus, this difference in the two experiments, DE versus DR must not be overlooked. In addition, during dehydration blood volume is reduced. Costill et al. found a plasma volume decrease of $16-18 \%$ with body weight loss of $4 \%$ (7). This decrease in circulation to the GI region in combination with a decreased blood volume may bring about the disturbance in normal GI function which is manifested by a decreased gastric emptying.

This alteration in GI function may be related to the common occurrence of GI complaints in this study when exercise and dehydration were combined. Ischaemia of the gastrointestinal region may be related to these symptoms. The theory proposed by Hubbard et al. (9) of energy depletion (at a cellular level) in relation to hyperthermia may also explain the relationship that is observed between dehydration and alteration of GI function. Although the role of dehydration in predisposing one to GI malfunction during endurance running is given support by these results, numerous other factors most certainly may be of influence in runner's GI disturbance. The effect of catecholamines and opiate-like substances in the blood as a result of intense exercise (3) are known to influence motility and may delay gastric emptying (4). Levels of numerous GI hormones are also known to be altered as a result of marathon running and may also be involved in the development of GI irregularities (17).

The stress situation of a race and metabolic changes associated with it must also not be left out of the picture. Physical as well as mental stress is known to influence GI function. (1). The high frequency of GI disturbance reported in field marathon studies, $40-50 \%$, versus the incidence in the present laboratory study, 
$37.5 \%$, may be reflecting the difference in stress experienced by runners. In addition to the difference in psychological state is the difference in exercise intensity. The standardised nature of the laboratory study must also be taken into consideration. In addition to the familiar, non-competitive sphere, is the preexercise dietary regime. The fact that breakfast was liquid, lowfat, low-fiber, and was consumed at least $2 \mathrm{~h}$ before exercise, and that no residue was in the stomach when exercise started, may also have reduced the risk of GI disturbance.

Nevertheless, when all these factors are held constant the effect of dehydration on gastric function is clearly to delay emptying and increase the risk of GI complaints when combined with endurance running.

\section{Conclusions}

Based upon the results of the present study, which support those of Neufer et al. (12), it can be concluded that effects of dehydration and hyperthermia during endurance running not only may affect performance by reducing cooling capacity but may also play a role in predisposing one to Gl symptoms. From earlier work in this laboratory (15) it has been shown that quite large quantities (@900 $\mathrm{ml}^{-1} \mathrm{~h}^{-1}$ ) of water as well as carbohydrate-electrolyte containing beverages are well tolerated during rest as well as during endurance bicycling and running. In addition to being well tolerated, they are also quite readily emptied (@800 ml.h-1). In the present study, however, dehydration associated with a body weight loss of $3.5-4 \%$ during endurance running has been observed to bring about a delayed GE of a similar bolus, as well as an increased risk of GI distress. The lesson is quite clear to the athlete who will attempt to supplement with fluids during exercise: drink sufficiently, early on during a potentially dehydrating exercise bout, before a state of dehydration is reached. Drinking during endurance running after dehydration where $3.5-4 \%$ of the body weight is lost is less than efficient in reinstating fluid balance and may possibly lead to GI problems. 


\section{References}

1. Barclay, G.R. and L.A. Turnberg. Effect of cold-induced pain on salt and water transport in the jejunum. Gastroenterology 94 : $994-998,1988$.

2. Beckers, E.J., N.J. Rehrer, F. Brouns, F. ten Hoor, and W.H.M. Saris. Determination of total gastric volume, gastric secretion and residual meal using the double sampling technique of George. Gut, 19: 1725-1729, 1988.

3. Bortz, W.M., P. Angwin, and I.N. Mefford. Catecholamines, dopamine and endorphin levels during extreme exercise. N. Engl. J. Med. 365: 466-467, 1981.

4. Carrio, I., M. Estorch, R. Serra-Grima, et al. Gastric emptying in marathon runners. Gut 30: 152-155, 1989.

5. Clausen, J.P. Effect of physical training on cardiovascular adjustments to exercise in man. Physiol. Rev. 57: 779-815, 1977.

6. Collins, P.J., M. Horowitz, D.J. Cook, P.E. Harding, and D.J.C. Sherman. Gastric emptying in normal subjects - a reproducible using a single scintillation camera and computer system. Gut 24: $1117-1125,1983$.

7. Costill, D.L. and W.J. Fink. PJasma volume changes following exercise and thermal dehydration. J. Appl. Physiol. 37(4)" 521$525,1974$.

8. Foster, C., D.L. Costill, and W.J. Fink. Gastric emptying characteristics of glucose and glucose polymer solutions. Res. Q. 51: $299-305,1980$.

9. Hubbard, R.W., C.B. Matthew, M.J. Durkot, and R.R. Francesconi. Novel approaches to the pathophysiology of heatstroke: the energy depletion model. Ann. Emerg. Med. 16: 1066-1075, 1987. 
10. Kristal-Boneh, E., J.G. Glusman, C. Chaemovitz, and Y. Cassuto. Improved thermoregulation caused by forced water intake in human desert dwellers. Eur.J. Appl. Physiol., 57: 220$224,1988$.

11. Neufer, P.D., D.L. Costill, W.J. Fink, J.P. Kirwan, R.A. Fielding, et al. Effects of exercise and carbohydrate composition on gastric emptying. Med. Sci. Sports Exerc. 18: 658-662, 1986.

12. Neufer, P.D., A.J. Young, and M.N. Sawka. Gastric emptying during exercise: effects of heat stress and hypohydration. Eur. J. Appl. Physiol. 58:433-439, 1989.

13. Owen, M.D., K.C. Kregel, P.T. Wall, and C.V. Gisolfi. Effects of ingesting carbohydrate beverages during exercise in the heat. Med. Sci. Sports Exerc. 18: 568-575, 1986.

14. Rehrer, N.J., E. Beckers, F. Brouns, F. ten Hoor, and W.H.M. Saris. Exercise and training effects on gastric emptying of carbohydrate beverages. Med. Sci. Sports Exerc. 21: 540-549, 1989.

15. Rehrer, N.J., F. Brouns, E. Beckers, F. ten Hoor, and W.H.M. Saris. Gastric emptying with repeated drinking during running and bicycling. Int. J. Sports Med. 11: 238-243, 1990.

16. Rehrer, N.J., G.M.E. Janssen, F. Brouns, and W.H.M. Saris. Fluid intake and gastrointestinal problems in runners competing in a $25-\mathrm{km}$ race and a marathon. Int. J. Sports Med. 10 (suppl. 1): $22-25,1989$.

17. Riddoch, C. and T. Trinick. Gastrointestinal disturbances in marathon runners. Brit. J. Sp. Med. 22: 71-74, 1988.

18. Strydom, N.B., C.H. Wyndham, C.H. van Graan, L.D. Holdsworth, and J.F. Morrison. The influence of water restriction on the performance of men during a prolonged march. S. Afr. Med. J. 40: 539-544, 1966. 


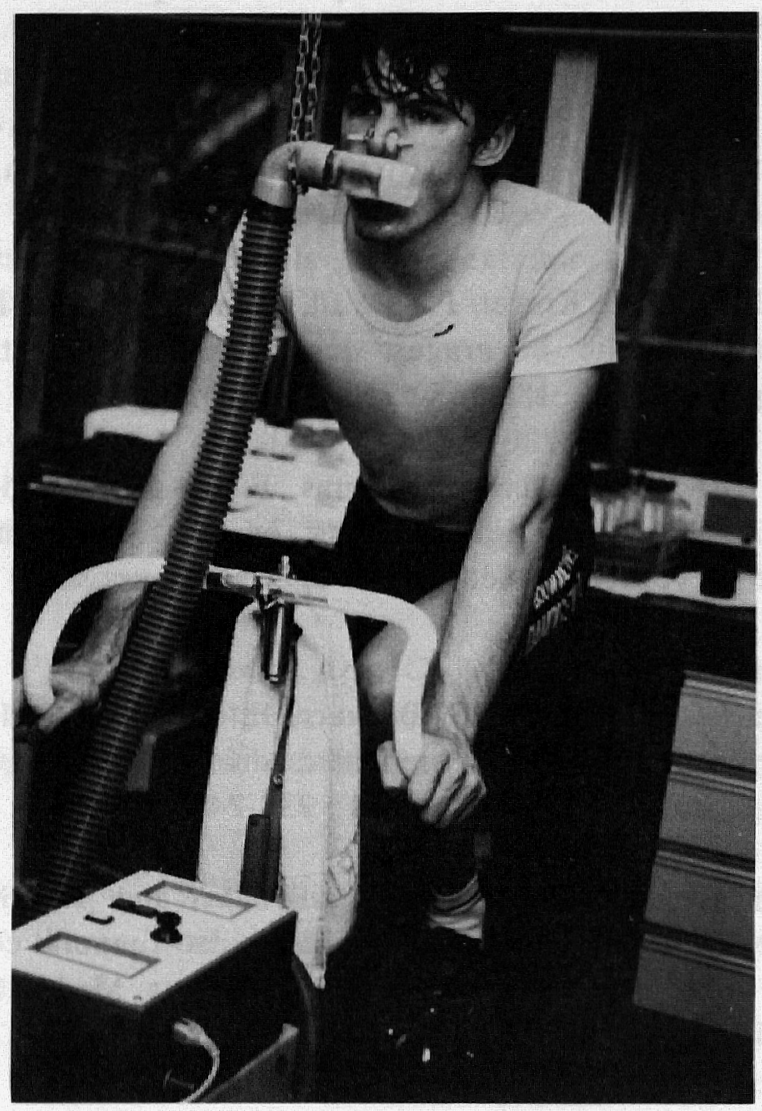

124 


\section{CHAPTER 7}

\section{Limits to supplementation during exercise: gastric emptying, intestinal absorption and oxidation}

\section{Abstract}

This study addresses the question: Do gastric emptying (GE) rates determine the rates of fluid awailability and exogenous carbohydrate ( $\mathrm{CHO}$ ) oxidation during intense endurance exercise? Eight male subjects bicycled for $80 \mathrm{~min}$ at $70 \%$ $\dot{\mathrm{V} O}{ }_{2} \max$. Beverage was consumed at $0\left(8 \mathrm{ml}^{\mathrm{kg}} \mathrm{kg}^{-1} \mathrm{BW}\right), 20,40$ and $60 \mathrm{~min}\left(3 \mathrm{ml} . \mathrm{kg} \mathrm{BW}^{-1}\right)$. Beverages were water $\left(\mathrm{H}_{2} \mathrm{O}\right), 4.5 \%$ glucose $(4.5 \mathrm{G}), 17 \%$ glucose $(17 \mathrm{G})$ and $17 \%$ maltodextrin $(17 \mathrm{MD})$. All $\mathrm{CHO}$ beverages contained $20 \mathrm{meq} . \mathrm{I}^{-1} \mathrm{NaCl}$. Gastric emptying (GE) of beverage was calculated from stomach residue measured at $80 \mathrm{~min}$. Total $\mathrm{CHO}$ and fat oxidation was calculated from $\dot{\mathrm{V}} \mathrm{CO}_{2}$ and $\dot{\mathrm{VO}}_{2}$ measurements. Exogenous $\mathrm{CHO}$ oxidation was measured by using $13 \mathrm{C}$ enriched sugars and measuring isotope enrichment of breath $\mathrm{CO}_{2}$. Water uptake was estimated by including $2 \mathrm{H}_{2} \mathrm{O}$ in the beverage and measuring ${ }^{2} \mathrm{H}$ enrichment in blood. In 80 min of exercise, $1294 \pm 31 \mathrm{ml}$ (mean $\pm \mathrm{SE}$ ) of beverage was ingested; the volumes emptied with $\mathrm{H}_{2} \mathrm{O}(1257 \pm 32 \mathrm{ml})$ and $4.5 \mathrm{G}(1223 \pm 32 \mathrm{ml})$ were greater than with $17 \mathrm{G}(781 \pm 56 \mathrm{ml})$ and $17 \mathrm{MD}(864 \pm 71 \mathrm{ml})(\mathrm{p}<.05)$. Total CHO oxidised was similar with all drinks. In all trials, only a portion of the exogenous CHO was oxidised within the $80 \mathrm{~min}$ exercise period. Although the total amounts oxidised were not significantly different, there was an increase in oxidation of exogenous CHO over time. This increase was greater with $17 \mathrm{G}$ and $17 \mathrm{MD}$ than with $4.5 \mathrm{G}$. Fiftyfour percent of the $\mathrm{CHO}$ ingested as $4.5 \mathrm{G}$ was oxidised whereas only $19 \%$ and $18 \%$ of that ingested as $17 \mathrm{G}$ and $17 \mathrm{MD}$, respectively, was oxidised. This represents $57 \%, 32 \%$ and $27 \%$ of the $\mathrm{CHO}$ emptied from the stomach with $4.5 \mathrm{G}, 17 \mathrm{G}$, and $17 \mathrm{MD}$, 
respectively. ${ }^{2} \mathrm{H}$ accumulation in the blood was more rapid with $4.5 \mathrm{G}$ and $\mathrm{H}_{2} \mathrm{O}$ than with $17 \mathrm{G}$ or $17 \mathrm{MD}$. GE rate and the rate of $2 \mathrm{H}$ accumulation were positively correlated $(\mathrm{p}<.01)$. CHO emptied $(\mathrm{g})$ was correlated with oxidation rate $(p<.01)$. Although oxidation parallels $G E$, it is not solely limiting, since much more is emptied than is oxidised. Separate jejunal perfusion tests at rest were conducted with the same beverages on seven of the subjects, to measure net intestinal absorption of water and solutes. The results in these tests indicate that the rate of glucose absorption increases as the concentration of the solution in the intestine increases, suggesting that GE may play a greater role than intestinat absorption in decreasing the availability of CHO from concentrated solutions. Net water absorption was greater from the dilute glucose, $\mathrm{NaCl}$ containing solution (4.5G) than from water. Additionally, net water absorption was observed from an isotonic, concentrated glucose polymer, $\mathrm{NaCl}$ containing solution (17MD) (although less than that observed from water) and net secretion was observed with the hypertonic, concentrated glucose, $\mathrm{NaCl}$ containing solution (17G). In conclusion, $\mathrm{GE}$ appears to be an important, initial regulator when orally supplementing water and CHO. However, based upon jejunal absorption and exogenous CHO oxidation measurements, GE is not exclusively responsible for rates of water incorporation into the body pool or rates of exogenous $\mathrm{CHO}$ oxidation.

\section{Introduction}

Supplementation with carbohydrate (CHO) has been advocated during intense endurance exercise to replace fluid losses and to provide additional carbohydrate (CHO) in situations where endogenous reserves may become limiting. During the past two decades information regarding availability of fluids ingested during exercise has been açcumulating. We (32), and others $(4,5)$, have made estimations of fluid (water) and CHO availability based upon gastric emptying (GE) rates. However, no information was obtained in these studies on the limitations set by intestinal absorption. Furthermore, measurements of $\mathrm{GE}$ and intestinal absorption do not provide information on the 
oxidation of the ingested $\mathrm{CHO}$ and the contribution made to energy expenditure. Measurements of the oxidation of orally ingested $\mathrm{CHO}$ have been made by several researchers who have speculated upon GE based on characteristics of the CHO solutions used $(3,37,39)$. The appearance of ingested $\mathrm{CHO}$ (3) and water $(7,8,23)$ in blood has also been measured. However, in these studies the amount emptied from the stomach was unknowm.

Two properties of CHO-containing beverages are known to influence GE rates: osmolality and $\mathrm{CHO}$ (glucose) concentration. For any given sugar, concentration and osmolality are directly related. However, different forms of CHO (disaccharide and to a greater degree oligo- and polysaccharide (starch) make it possible to have a solution of lower osmolality with similar CHO concentration, compared to a monosaccharide solution. From published results it is not clear which of these factors is more critical in delaying GE nor is it apparent whether these factors play a similar role in determining intestinal absorption, and to what degree these processes determine the rates of incorporation of water into body water and utilization of orally ingested carbohydrate. The present study questions the premise that GE is the limiting factor for incorporation of water into body pools and for the oxidation of orally ingested CHO. Further, it is questioned if $\mathrm{CHO}$ concentration and osmolality have similar effects on GE rate as well as on absorption and utilization rates. Therefore the present study was designed to measure the incorporation of ingested water into body water, oxidation of $\mathrm{CHO}$, and the amounts of water and CHO emptied from the stomach, from solutions in which either CHO or osmolality was varied during intense endurance exercise. Additionally, relative rates of net intestinal absorption of $\mathrm{CHO}$ and water of these solutions have also been measured in rest.

\section{Methods}

\section{Subjects}

Eight trained male athletes participated in this study. Subjects were given full oral and written explanation of the procedures before giving written consent. The study was approved by the Medical Ethical Committee of The University of Limburg. The 
subjects were triathletes or competitive cyclists aged $28.5 \mathrm{yr} \pm$ 2.8 (mean $\pm \mathrm{SE}$ ), body mass $76.1 \pm 1.8 \mathrm{~kg}$ and $\forall \mathrm{VO}_{2} \max 5.0 \pm$ 0.1 l.min $^{-1}$.

\section{Experimental procedures}

\section{Pre-trial}

All subjects came to the laboratory for a preliminary trial one to two weeks prior to the first experimental session. Maximal workload was determined by an incremental exertion test on an electronically braked, cycle ergometer (Lode, Groningen, The Netherlands). Oxygen consumption was measured with a SensorMedics 2900 analyser (Anaheim, CA, U.S.A.). After the maximal workload test a nasogastric tube was placed, so that subjects could make a decision as to participation with full knowledge of the procedure and to reduce anxiety on the first study day.

\section{Treatment trials}

Exercise studies were conducted for $80 \mathrm{~min}$ with repeated beverage ingestion. Measurements of fluid balance, gastric emptying, fluid absorption and carbohydrate oxidation were made. At least two weeks separated $13_{\mathrm{C}}$ labeled $\mathrm{CHO}$ ingestion trials for a given subject. When water or non-labeled carbohydrate trials were performed, at least two weeks and at least one long-lasting, glycogen depletion, exercise session was required to have taken place since the last $13 \mathrm{C}$ trial. Subjects were asked to train easily and to eat a CHO-rich diet for fortyeight hours prior to each test. Subjects were instructed not to consume certain products which are known to have a naturally high content of ${ }^{13} \mathrm{C}$ sugars for 2 weeks prior to and during the experimental period.

\section{Protocol}

At 8:00 a.m., after an overnight fast, a standardised liquid breakfast (5 ml.kg BW-1 Powerplay (B) was given which provided, on the average, $1500 \mathrm{~kJ}$ and comprised $24 \mathrm{en} \% \mathrm{CHO}$. At 9:00 a.m. subjects were weighed (naked), and thereafter an 
indwelling catheter was placed in a forearm vein and a resting blood sample was taken. At 9:30 a.m. resting breath samples were taken for measurement of the baseline $13 \mathrm{C} / 1^{2} \mathrm{C}$ ratio in expired $\mathrm{CO}_{2}$. Samples were drawn directly from the mixing chamber of the gas exchange analyser. At 9:50 a.m., a 10 min warm-up began, consisting of 5 min cycling at $30 \% \quad \mathrm{VO}_{2} \mathrm{max}$ followed by $5 \mathrm{~min}$ at $50 \% \dot{V O}_{2} \max$. At 10:00 a.m. the first bolus ( $8 \mathrm{ml.kg} \mathrm{BW}^{-1}$ ) was ingested while the work load was increased to an intensity requiring $70 \% \mathrm{VO}_{2}$ max. All beverages were given at a temperature of $15{ }^{\circ} \mathrm{C}$. The schedule of drinking, and breath and blood sampling is displayed in Fig. 11 . Two subjects were tested on the same day in most instances, subjects starting the protocol $5 \mathrm{~min}$ apart.

After $80 \mathrm{~min}$, subjects discontinued exercise, a nasogastric tube was placed and gastric samples were taken to determine remaining beverage volume. In two individuals after completion of the $80 \mathrm{~min}$ protocol and $1 \mathrm{~h}$ of rest, exercise was restarted at $70 \% \mathrm{VO}_{2} \max$ for $30 \mathrm{~min}$ while intermittent breath samples were collected for gas exchange and oxidation measurements.
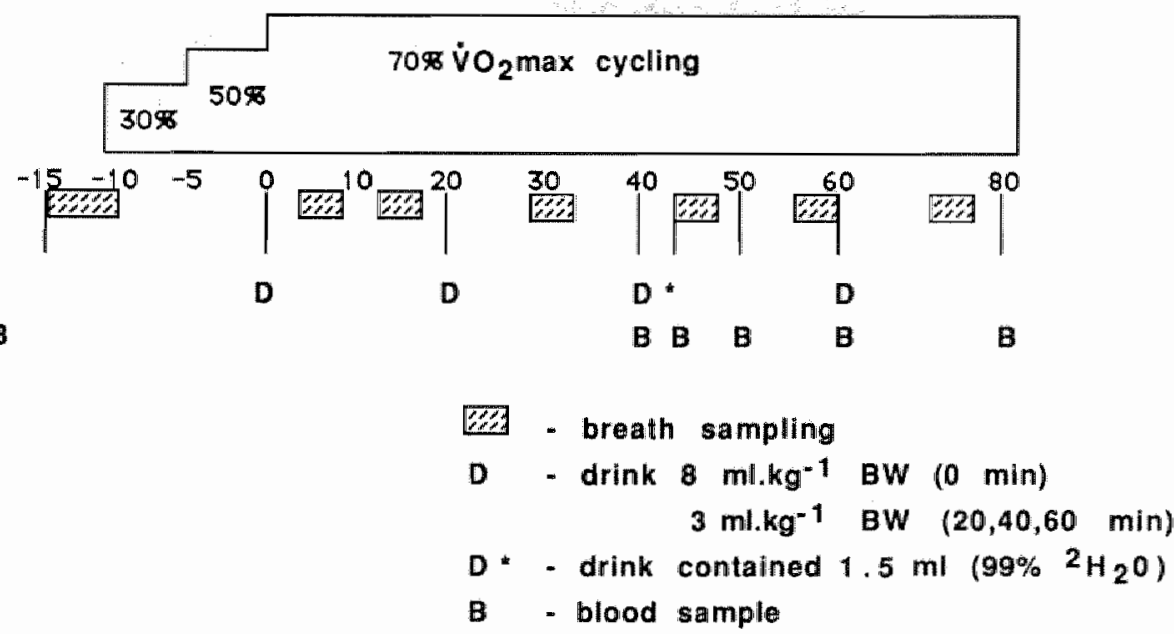

Fig. 1. Protocol 


\section{Experimental techniques}

\section{Gastric emptying}

Beverage volume remaining in the stomach was measured using George's double sampling technique as applied by Beckers et al. (1). All beverages contained $20 \mathrm{mg}^{-1}$ phenol red dye. Immediately after the $80 \mathrm{~min}$ exercise protocol a nasogastric tube was placed and one double-sampling measurement was made. This involved taking a sample of the gastric contents and then adding $10 \mathrm{ml}$ of a phenol red solution (500 mg. $\mathrm{l}^{-1}$ ), mixing with the remaining residue for $30 \mathrm{sec}$, and then taking a second sample. In this manner, the remaining beverage volume can be calculated and, by subtraction from known total volume ingested, the beverage volume emptied from the stomach can be calculated (as opposed to other methods in which only total gastric residue, including secretion, is measured; see Chapters 1 and 2 for discussion).

\section{Fluid balance}

To give an indication of fluid balance, body weights were recorded before and after exercise and plasma volume changes were calculated. Nude body weight was taken immediately prior to and directly after exercise. Plasma volume changes were calculated from changes in hematocrit and hemoglobin according to Dill and Costill (9).

\section{Deuterium accumulation}

Appearance of deuterium in the blood after oral ingestion of the different beverages labelled with $2 \mathrm{H}_{2} \mathrm{O}$ was used to obtain a relative estimate of water uptake. The rate of accumulation in the circulation is the net result of the rates of gastric emptying, intestinal absorption and movement into and out of the extracellular space. After $40 \mathrm{~min}$ of exercise at $70 \% \quad \mathrm{VO}_{2} \mathrm{max}$, when subjects were essentially in steady state, a $1.5 \mathrm{ml}$ dose of $99.85 \mathrm{At} \% 2 \mathrm{H}_{2} \mathrm{O}$ (Academy of Sciences, Leipzig, Germany) was included in the beverage bolus ingested. At 42,50, 60 and 80 min of exercise blood samples $(2 \mathrm{ml})$ were taken. Deuterium was measured in the plasma with mass spectrometry according to Westerterp et al. (40). Excess deuterium values (actual minus 
baseline enrichment) were used for making comparisons.

Statistics were conducted using values at $80 \mathrm{~min}$ and the slopes of the accumulation curves determined by least squares regression (representing rate of accumulation of deuterium).

\section{Carbohydrate oxidation}

Total oxidation of carbohydrates (exogenous and endogenous) was calculated from the $\mathrm{VO}_{2}$ and the respiratory exchange ratio assuming that the protein contribution was negligible. To measure exogenous carbohydrate oxidation use was made of the fact that ${ }^{13} \mathrm{CO}_{2}$ is released when $13 \mathrm{C}$ enriched sugars are oxidised (16). Exogenous CHO oxidation can thus be determined using $13 \mathrm{C}$ sugars in a $\mathrm{CHO}$ load, when normal daily consumption of sugars is restricted to sugars with a lower $13 \mathrm{C}$ enrichment and the baseline ${ }^{13} \mathrm{C} /{ }^{12} \mathrm{C}$ ratio in expired $\mathrm{CO}_{2}$ is monitored. During the last minute of breath sampling periods, as designated in Fig. 1, collections were made directly from the mixing chamber of the gas monitor into evacuated $20 \mathrm{ml}$ tubes (Vacutainers). All samples were collected in duplicate and analysed for $13 \mathrm{CO}_{2}$ isotope enrichment in a Finnigan Delta $S$ isotope ratio mass spectrometer (IRMS) (Bremen, Germany). Vacutainers were loaded into an autosampler system (Gilson 222 sample changer) which was on line to the IRMS; both instruments were under IBM PC/AT control. A similar system has been previously described (34); however, in contrast with this methodology, $\mathrm{Ar} / \mathrm{CO}_{2}$ ratio was not used to calculate the amount of $\mathrm{CO}_{2}$ in breath samples, since independent $\mathrm{CO}_{2}$ measurements were made.

A small portion of the free glucose solutions was made up of $D$ glucose $99 \mathrm{At} \%{ }^{13} \mathrm{C}_{6}$ (Isotec, Inc. Miamisburg, Ohio, U.S.A.). This was added to glucose obtained from potato starch (Avebe, Foxhol, The Netherlands) to give $2^{13} \mathrm{C}$ of -13.69 and -13.57 (\% vPDB standard). The maltodextrin used for $17 \mathrm{MD}$ was naturally enriched with $2^{13} \mathrm{C}$ of $-7.91 \%$ (Amylum, Aalst, Belgium). Identical exercise tests were done to determine background or endogenous $13 \mathrm{C}$ levels, using $4.5 \%$ glucose without $13 \mathrm{C}$ glucose addition. Background $\partial^{13} \mathrm{C}$ in exhaled $\mathrm{CO}_{2}$ was not different in 


\section{Chapter 7}

this trial versus the water trial.

Carbohydrate oxidation was calculated in $15 \mathrm{~min}$ blocks. To calculate exogenous carbohydrate oxidation, background ${ }^{13} \mathrm{CO}_{2}$ enrichment values from control run $(4.5 \mathrm{g.t}-1$ glucose, nonenriched) were subtracted from corresponding values during treatment. $13 \mathrm{C}$-enrichment during treatment corrected in this way was divided by $13 \mathrm{C}$-enrichment of the oral carbohydrate to calculate the proportion of $\mathrm{CO}_{2}$ derived from oxidation of exogenous CHO. This proportion was multiplied by $\mathrm{VCO} 2$ to obtain the amount of $\mathrm{CO}_{2}$ derived from exogenous $\mathrm{CHO}$ per min.

\section{Intestinal perfusion}

Seven of the eight subjects returned to the laboratory for a separate set of experiments at rest, in which the triple lumen perfusion technique was employed to measure net intestinal absorption of fluid and solutes. Perfusion was done within 10 $\mathrm{cm}$ distal to the duodeno-jejunal junction and samples were extracted $15 \mathrm{~cm}$ (mixing segment) and $45 \mathrm{~cm}$ (test segment) distal to the perfusion site. Values for absorption of water and solutes were calculated from samples obtained after steadystate was achieved. For details of the perfusion technique, including analyses of solutes and calculations, see Leiper and Maughan (20). The same beverages as those used in the exercise experiments were tested. Additionally, all beverages contained 500 mg.l-1 polyethylene glycol 4000 as a non-absorbable marker. This method gives absolute values for intestinal absorption (or secretion) of water and CHO from the varying solutions once they are present in the intestinal lumen. To assess glucose absorption when the $17 \%$ maltodextrin solution was perfused, acid hydrolysis (18) of the original perfusion solution and luminal samples was carried out before measuring the glucose concentrations.

Beverage composition analyses

Osmolality of the beverages was measured using freezing-point depression (Osmomat 030, Gonotech, Berlin, Germany). A double check on the concentrations of the beverages was conducted by freeze-drying a liquid sample and performing bomb calorimetry. Freeze-dried portions of the beverages were also 
analyzed for $13 \mathrm{C}$ enrichment after oxidation.

\section{Tratments}

Exercise tests were repeated by each subject for the five different beverages: water $\left(\mathrm{H}_{2} \mathrm{O}\right), 4.5 \mathrm{~g} .100 \mathrm{ml}^{-1} 13 \mathrm{C}$ enriched glucose $(4.5 \mathrm{G}), 17 \mathrm{~g} .100 \mathrm{ml}-113 \mathrm{C}$ enriched glucose (17G), 17 g. $100 \mathrm{ml}^{-1}$ naturally $13 \mathrm{C}$ enriched maltodextrin (17MD) and 4.5 g. $100 \mathrm{ml}^{-1}$ glucose (control for background $13 \mathrm{C}$ ). During this control run, with non-enriched $\mathrm{CHO}_{\text {n }}$ only breath samples were taken; no ${ }^{2} \mathrm{H}_{2} \mathrm{O}$ was included in the beverage and no gastric or blood samples were taken. All carbohydrate containing beverages contained $20 \mathrm{meq} . \mathrm{1}^{-1} \mathrm{NaCl}$. Each beverage contained $20 \mathrm{mg} \cdot \mathrm{I}^{-1}$ phenol red dye, which was necessary for determination of gastric emptying of the treatment beverages. Beverages containing added $13 \mathrm{C}$ enriched glucose were made in one batch and portions were frozen until needed, to assure uniform isotope enrichment. For triple lumen perfusion trials $4.5 \mathrm{G}, 17 \mathrm{G}$ and $17 \mathrm{MD}$ were made up with the same ingredients as for the exercise trials, but no $13 \mathrm{C}$ enriched glucose was added to $4.5 \mathrm{G}$ and $17 \mathrm{G}$. Osmolalities of the beverages were 313,1223 and $301 \mathrm{mOsm} \cdot \mathrm{kg}^{-1}$ for $4.5 \mathrm{G}, 17 \mathrm{G}$ and $17 \mathrm{MD}$, respectively.

\section{Statistics}

Friedman ANOVA was used to compare differences in the volumes of beverage and the amounts of CHO emptied from the stomach, the amounts of exogenous and total CHO oxidised in 80 min, the rates of deuterium accumulation, net absorption of water and glucose, and plasma volume and body weight changes. The amounts of exogenous and total CHO oxidised over time were compared with a repeated measures (2 way) ANONA. Individual treatment mean comparisons were made with Wilcoxon's signed-rank analysis. Multiple linear regression was performed to evaluate relative influences of gastric emptying and intestinal absorption on incorporation of ingested water into body water and oxidation of ingested $\mathrm{CHO}$. 


\section{Chapter 7}

\section{Results}

\section{Gastric emptying}

Mean volume ingested in all exercise trials was $1294 \pm 31 \mathrm{ml}$ (mean $\pm \mathrm{SE}$ ) over the $80 \mathrm{~min}$. Mean volumes emptied for the various treatments were, $1257 \pm 32 \mathrm{ml}\left(\mathrm{H}_{2} \mathrm{O}\right), 1223 \pm 32 \mathrm{ml}$ $(4.5 \mathrm{G}), 781 \pm 56 \mathrm{ml}(17 \mathrm{G})$ and $864 \pm 71 \mathrm{ml}$ (17MD), giving mean emptying rates of $16,15,10$ and $11 \mathrm{ml} \cdot \mathrm{min}^{-1}$, respectively. There were no differences in mean volume emptied in 80 min between $4.5 \mathrm{G}$ and $\mathrm{H}_{2} \mathrm{O}$, or between $17 \mathrm{G}$ and $17 \mathrm{MD}$. Both $4.5 \mathrm{G}$ and $\mathrm{H}_{2} \mathrm{O}$ emptied faster than both $17 \%$ solutions $(p<.05)$. The mean amounts of carbohydrate ( $\mathrm{CHO}$ ) ingested and emptied with the different beverages are displayed in Fig. 2. The amount of $\mathrm{CHO}$ emptied after $80 \mathrm{~min}$ with both $17 \mathrm{G}$ and $17 \mathrm{MD}$ was greater than with $4.5 \mathrm{G}$. However, the proportion of the total amount of CHO ingested which was emptied was less with $17 \mathrm{G}(60 \%)$ and $17 \mathrm{MD}(67 \%)$ than with $4.5 \mathrm{G}(95 \%)$.
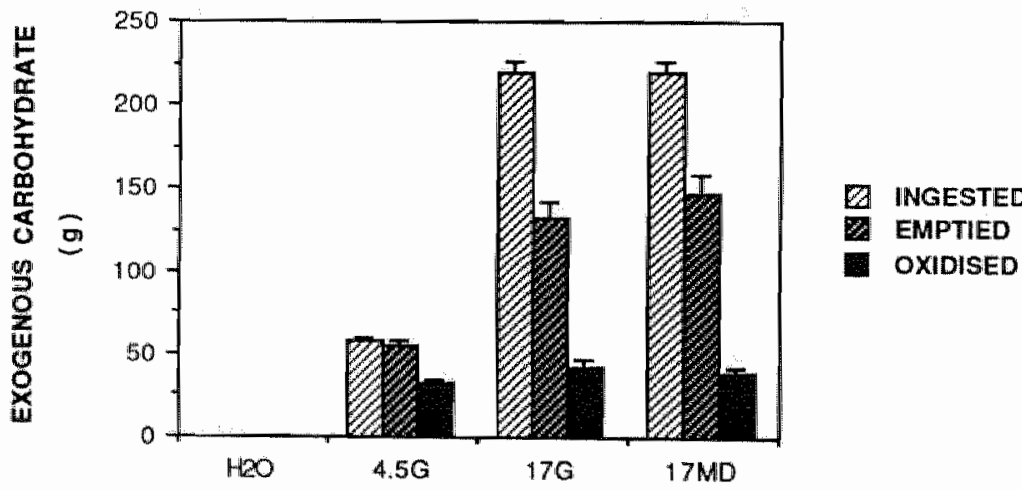

OXIDISED

Fig. 2. Mean ( $\pm S E$ ) amounts of CHO ingested, emptied from the stomach and oxidised (exogenous). 

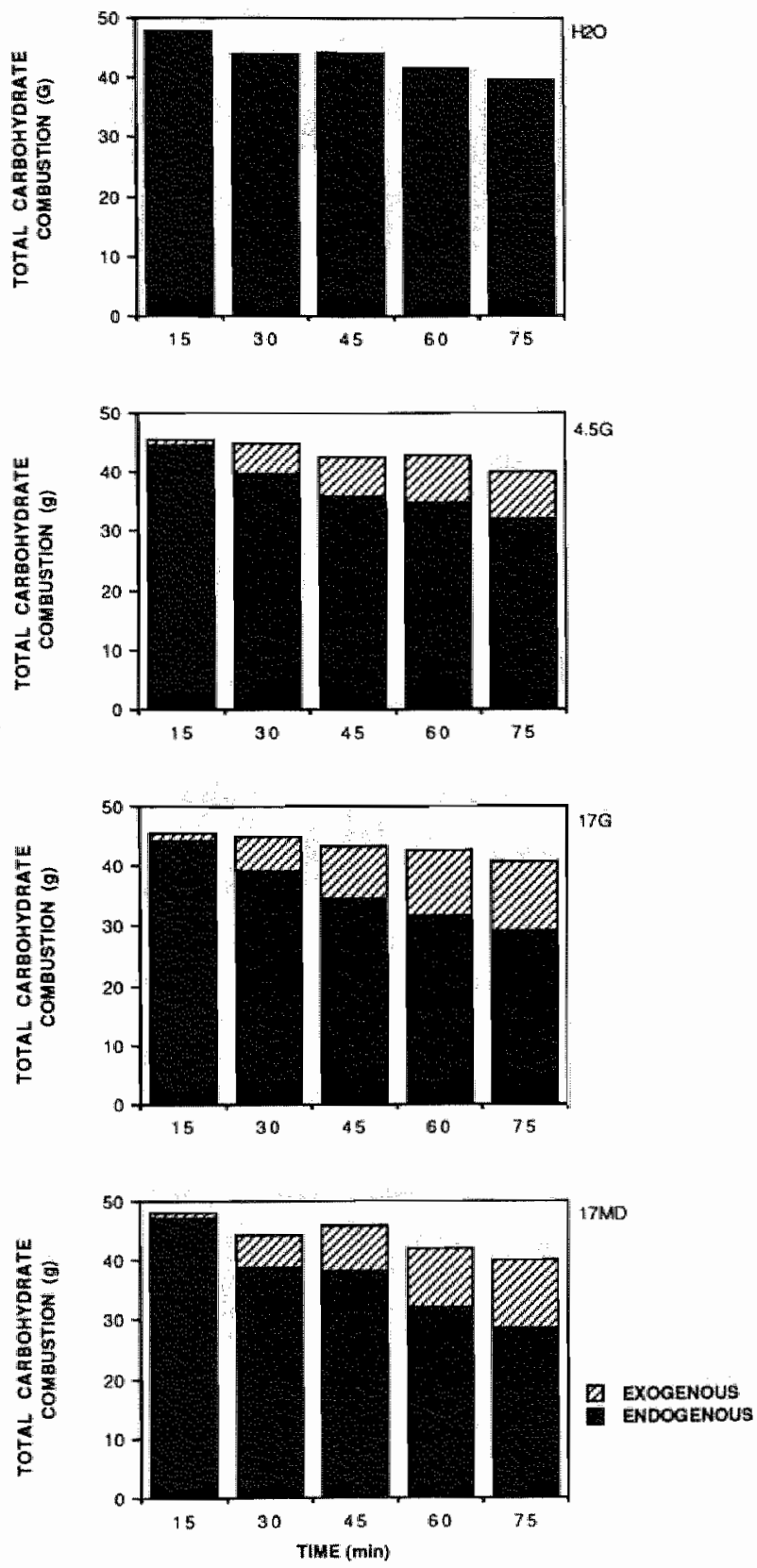

Fig. 3. Mean amounts of exogenous and endogenous CHO oxidised with the different beverages. 


\section{Carbohydrate oxidation}

The mean amounts of exogenous CHO oxidised in $80 \mathrm{~min}$ are also displayed in Fig 2. The total amount of CHO oxidised was similar with all beverages. The amount of exogenous CHO oxidised in 80 min was not significantly different between $\mathrm{CHO}$ treatments, $31.5 \pm 2.7 \mathrm{~g}(4.5 \mathrm{G}), 42.0 \pm 4.6 \mathrm{~g}$ (17G) $39.1 \pm 2.9 \mathrm{~g}$ (17MD). Carbohydrate oxidation, divided into exogenous and endogenous contribution, is depicted in Fig. 3. There was a trend for the rate of CHO oxidation to decrease with time. The amount of exogenous CHO oxidised, however, increased with time and with the amount of CHO fed. When repeated measures (2-way) ANOVA was performed on the amounts of exogenous CHO oxidised each $15 \mathrm{~min}$, through $75 \mathrm{~min}$, for the different $\mathrm{CHO}$ containing beverages, a significant beverage $x$ time interaction was observed $(p<.01)$. This indicates that as the exercise time increased the proportional contribution of orally provided $\mathrm{CHO}$ to total CHO utilised varied significantly between treatments. When Wilcoxon"s signed-rank analysis was performed, the amounts of exogenous CHO oxidised at 30-45 min, 45-60 min and $60-75 \mathrm{~min}$ were greater with $17 \mathrm{MD}$ and $17 \mathrm{G}$ than with $4.5 \mathrm{G}$ $(p<.05)$.

Most of the ingested CHO was not oxidised (Fig. 2); however, multiple linear regression revealed a significant correlation between total exogenous CHO oxidised and $\mathrm{CHO}$ emptied from the stomach $(p<01)$. The discrepancy between amounts ingested and amounts oxidised cannot be totally accounted for by the delay in gastric emptying. There were large differences in the total amount of CHO being emptied from the stomach, with the different treatments, but the differences in total exogenous CHO utilised were trivial in comparison. In Fig. 4 the amounts of orally ingested CHO oxidised and remaining in the stomach, intestines and other tissues (calculated by difference) after 80 min of exercise are displayed.

When the oxidation data are described in terms of percentage CHO ingested and emptied, the discrepancy between what was emptied and what was oxidised was greatest in the $17 \%$ solutions. With $4.5 \mathrm{G}, 57 \%$ of the $\mathrm{CHO}$ which was emptied was oxidised, whereas with $17 \mathrm{G}$ and $17 \mathrm{MD}$ only $32 \%$ and $27 \%$, respectively, of that which was emptied was oxidised. 
GE, absorption, and oxidation

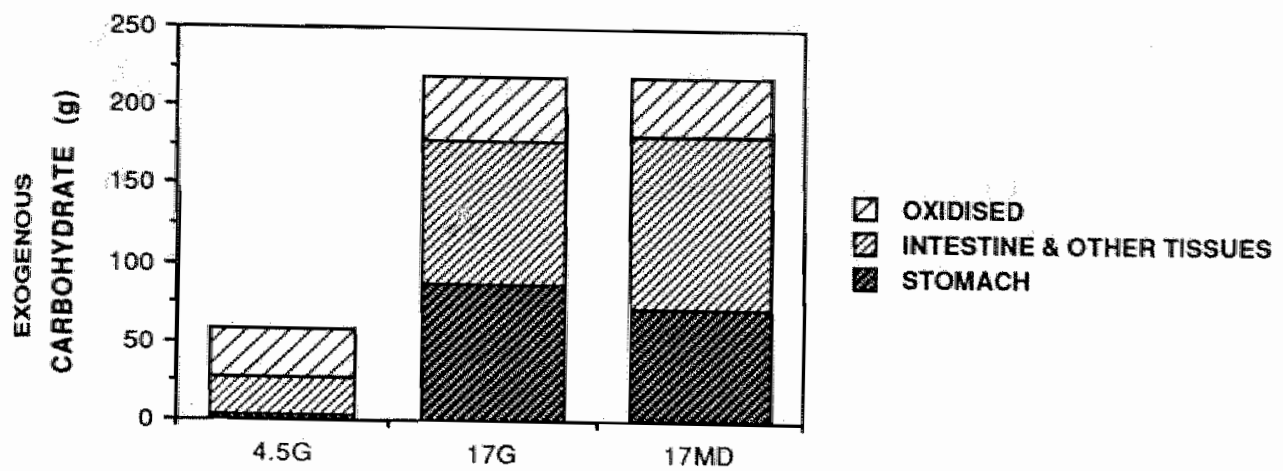

Fig. 4. CHO oxidised, remaining in the stomach and, by calculating the difference, remaining in the intestine and other tissues after $80 \mathrm{~min}$.
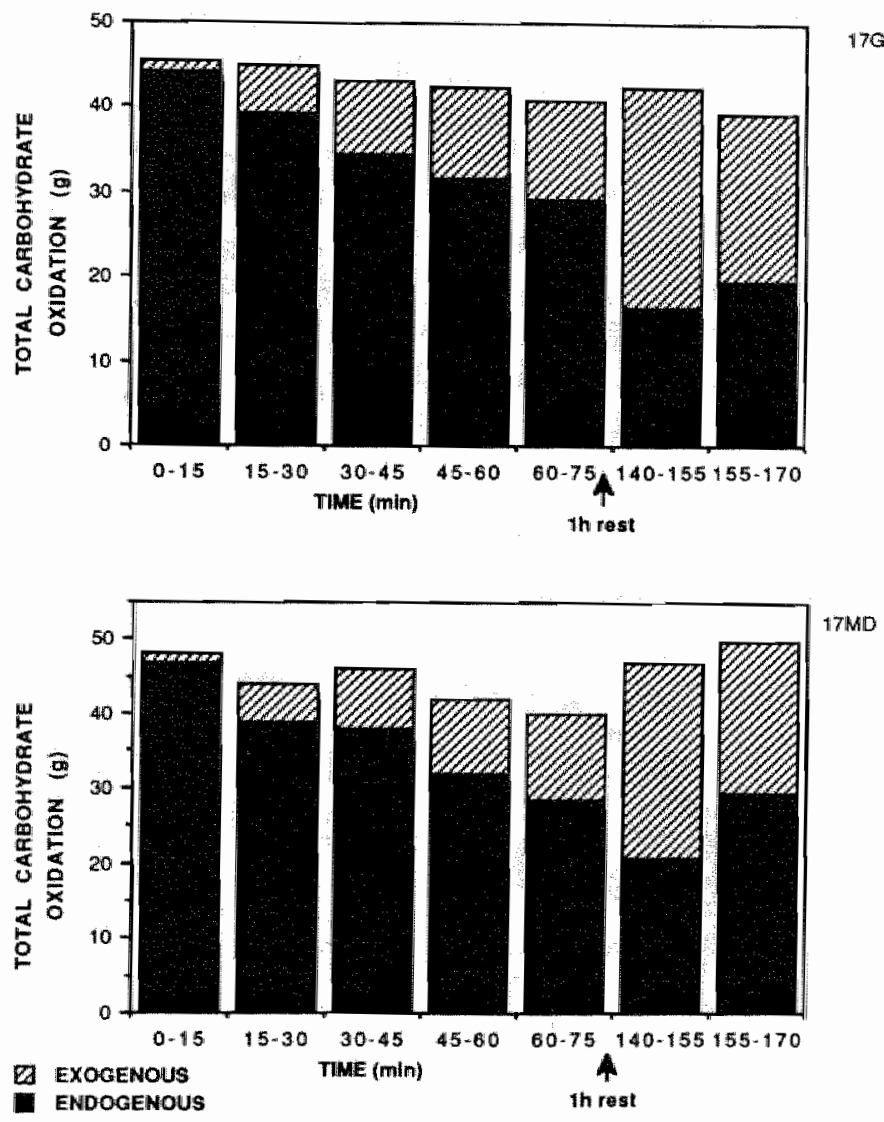

Fig. 5. Mean amounts of CHO oxidised during the 80 min exercise trial and after $I$ h rest, wen exercise was resumed for an additional 30 min $(n=2)$. No additional beverage was given after the $80 \mathrm{~min}$ protocol. 
After the initial $80 \mathrm{~min}$ of exercise, a $1 \mathrm{~h}$ rest period followed by $30 \mathrm{~min}$ of exercise at the same intensity as during the initial exercise, brought about large increases in the proportion of exogenous $\mathrm{CHO}$ which was utilised with both 17MD and $17 \mathrm{G}$ (Fig. $5)$.

\section{Deuterium accumulation}

Accumulation of deuterium in the blood after ingestion of the labeled bolus at $40 \mathrm{~min}$ resulted in accumulation curves shown in Fig. 6. Analysis of the $80 \mathrm{~min}$ blood values and of slopes of the accumulation curves revealed similar differences between treatments. When deuterium accumulation was expressed as a percent of a $6 \mathrm{~h}$ post-exercise urine value (which represents complete equilibration of the ingested tracer with body water) the same treatment differences were observed. With treatments $\mathrm{H}_{2} \mathrm{O}$ and $4.5 \mathrm{G}, 100 \%$ of the dose was absorbed in $40 \mathrm{~min}$, whereas with $17 \mathrm{G}$ and $17 \mathrm{MD}$ only $45 \%$ and $54 \%$, respectively, of the dose was absorbed in $40 \mathrm{~min}$. The rate of accumulation, as well as the degree of accumulation at $80 \mathrm{~min}$ was greater with $\mathrm{H}_{2} \mathrm{O}$ and $4.5 \mathrm{G}$ than with $17 \mathrm{G}$ and $17 \mathrm{MD}$. Mean slopes were $.82 \pm$ $.12\left(\mathrm{H}_{2} \mathrm{O}\right), .66 \pm .02(4.5 \mathrm{G}), .27 \pm .02(17 \mathrm{G})$ and $.31 \pm .04$ (17MD).

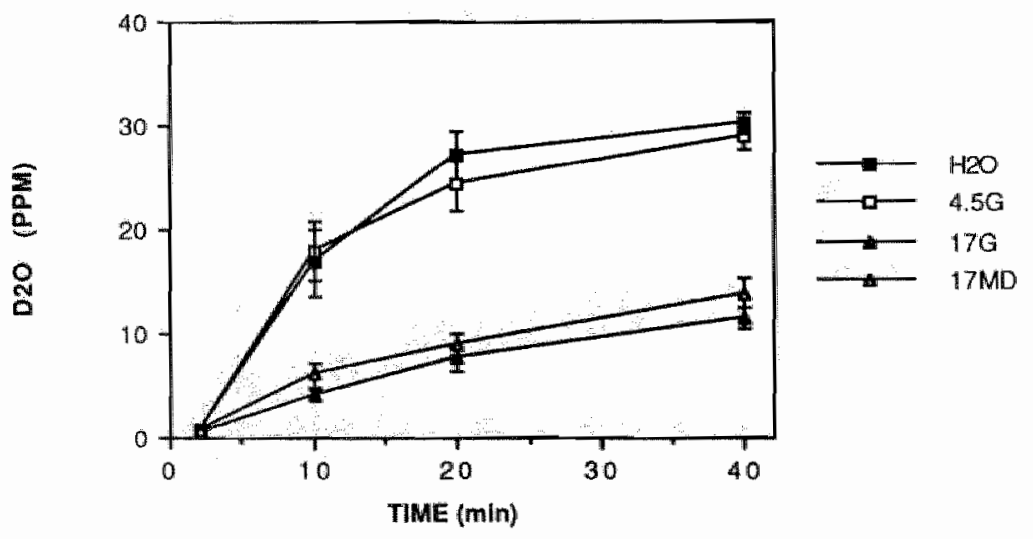

Fig. 6. Deuterium accumulation in blood after a $1.5 \mathrm{ml}$ dose of $99 \mathrm{At} \%$ $2^{2} \mathrm{H}_{2} \mathrm{O}$ was given in the $40 \mathrm{~min}$ beverage bolus. Time in min after ${ }^{2} \mathrm{H}_{2} \mathrm{O}$ ingestion. 
When linear regression was performed a significant correlation was observed between the rate of deuterium accumulation in the blood (slope) and the gastric emptying rate $(p<01)$.

\section{Triple lumen perfusion}

Water absorption across the jejunal mucosa was affected by the composition of the beverage infused (Fig. 7). One-way ANOVA showed a significant treatment (beverage) effect on water absorption $(p<.05)$. Differences in treatment means were significant for all paired comparisons $(p<.05)$. Net secretion was observed with $17 \mathrm{G}\left(-50.2 \mathrm{ml}_{\mathrm{cm}} \mathrm{cm}^{-1} . \mathrm{h}^{-1}\right)$ (negative values indicate secretion), whereas perfusion of the other beverages resulted in net water absorption. There were, however, large individual differences. Net secretion was observed in one individual with $\mathrm{H}_{2} \mathrm{O}\left(-1.2 \mathrm{ml} . \mathrm{cm}^{-1} \cdot \mathrm{h}^{-1}\right)$ and in one individual with $17 \mathrm{MD}\left(-0.3 \mathrm{ml} \cdot \mathrm{cm}^{-1} \cdot \mathrm{h}^{-1}\right)$. There was also one individual who absorbed from $17 \mathrm{G}\left(5.0 \mathrm{ml} . \mathrm{cm}^{-1} \cdot \mathrm{h}^{-1}\right)$. The large standard error with $17 \mathrm{G}$, however is due primarily to one individual who secreted more than twice as much as the mean of the other subjects $\left(-178.0 \mathrm{ml}: \mathrm{cm}^{-1} \cdot \mathrm{h}^{-1}\right)$. Even if this individual is removed from the analyses there is still net secretion, resulting in a significant difference in water flow compared to all other treatments.

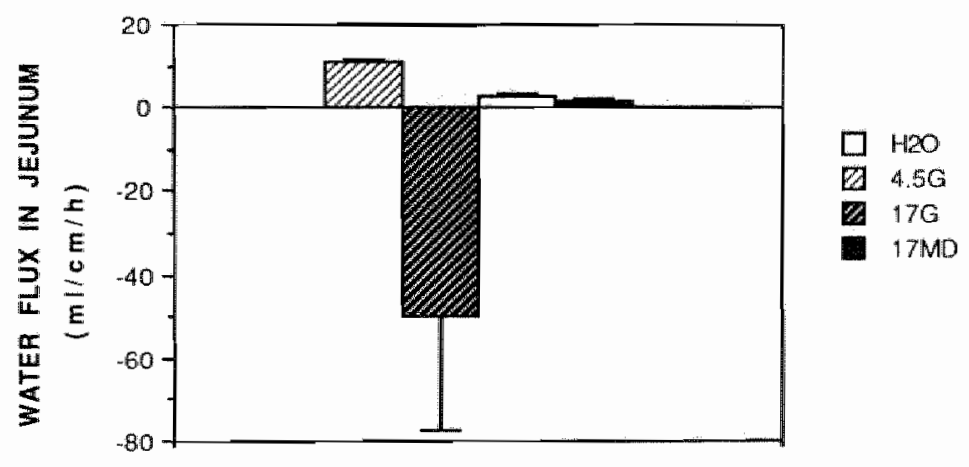

Fig. 7. Net water absorption with triple lumen perfission at rest. 
Mean steady-state glucose absorption rates with triple lumen perfusion were $2198 \pm 382 \mu \mathrm{mol} . \mathrm{cm}^{-1} \cdot \mathrm{h}^{-1}$ (4.5G), $7150 \pm$ $2177 \mu \mathrm{mol} . \mathrm{cm}^{-1} \cdot \mathrm{h}^{-1}$ (17G) and $477 \pm 138 \mu \mathrm{mol} . \mathrm{cm}^{-1} . \mathrm{h}^{-1}$ (17MD). The large standard error for glucose absorption from $17 \mathrm{G}$ was due to one individual who absorbed far more than the others $(17162 \mu$ mol.cm-1.h-1). This was not the same individual who had such a high secretion rate with $17 \mathrm{G}$. If he is excluded from the data set, the mean for $17 \mathrm{G}$ would be $5147 \pm$ $1012 \mu \mathrm{mol} . \mathrm{cm}^{-1}, \mathrm{~h}^{-1}$. ANOVA revealed a significant difference in glucose absorption with treatment. Wilcoxon's signed-rank comparisons between individual treatment means demonstrated significant differences in absorption of glucose between all pairs. Even when the influence of gastric emptying on the rate at which fluid is made available for absorption is removed, as with intestinal perfusion, absorption of $\mathrm{CHO}$ in the jejunum is greater from a more highly concentrated solution beverage, which is also found to empty more CHO per min from the stomach.

Plasma volume and body weight changes

Changes in plasma volume and body weight, as a result of the 80 min exercise bout, are given in Table 1.

Table 1. Plasma volume ( $P V)$ and body weight (BW) changes as a result of $80 \mathrm{~min}$ exercise and prescribed beverage ingestion (means $\pm S E$ )

$\begin{array}{llll}\text { Beverage } & \triangle P V & \triangle B W & \triangle B W \\ & (\%) & (\mathrm{kg}) & (\%)\end{array}$

\begin{tabular}{rrrl}
\hline $4.5 \mathrm{G}$ & $-9.8 \pm 1.5$ & $+0.44 \pm 0.10$ & $+0.6 \pm 0.1$ \\
$17 \mathrm{G}$ & $-14.2 \pm 1.3$ & $+0.58 \pm 0.15$ & $+0.8 \pm 0.2$ \\
$\mathrm{H}_{2} \mathrm{O}$ & $-10.2 \pm 1.3$ & $+0.70 \pm 0.12$ & $+0.9 \pm 0.2$ \\
$17 \mathrm{MD}$ & $-14.1 \pm 3.0$ & $+0.58 \pm 0.16$ & $+0.8 \pm 0.2$ \\
\hline
\end{tabular}


ANOVA revealed no significant beverage effect on plasma volume changes. There was, however a trend for the $17 \mathrm{G}$ and $17 \mathrm{MD}$ ingestion during exercise to result in greater plasma volume decreases. When multiple linear regression analysis was performed with plasma volume change as the dependent variable, and deuterium accumulation rate and subjects as the independent variables, the multiple $R$ was .715. Deuterium accumulation did not make a significant contribution to the regression $(p<.28)$. A similar regression analysis was performed with plasma volume as dependent variable and volume of beverage emptied, water absorption (jejunal perfusion) and subjects as independent variables. The multiple $R$ in this instance was .722 and the volume emptied did make a significant contribution to the regression $(\mathrm{p}<.04)$. Body weight changes were negligible, with no significant treatment effect.

\section{Discussion}

The volume of beverage emptied was significantly influenced by beverage composition, as would be expected based upon earlier results of ours (32) and others (for review see Murray (27)). Both the highly concentrated free glucose solution (17G) and the maltodextrin solution (17MD) emptied significantly slower than water or the dilute $\mathrm{CHO}$ solution $(4.5 \mathrm{G})$. The retarding effect of increasing glucose concentration on $\mathrm{GE}$ rate has long been recognised (30). There has been some controversy as to the effect of type of carbohydrate, particularly when the type (eg. polymer versus free glucose) gives large differences in beverage osmolality with no difference in carbohydrate content. Some have found significant differences in emptying rate with polymer and free glucose solutions with the same glucose content $(13,36)$ and others have not $(17,28)$. However, if these studies are looked at closely and the techniques evaluated so that only remaining beverage volume in the stomach (not total gastric volume, which includes secretion) is compared, only small differences are found. These differences are much less than expected on the basis of osmolality differences. 
Volumes emptied after $80 \mathrm{~min}$ of repeated drinking with water and $4.5 \mathrm{G}$ were similar. These results are also supported by earlier observations with an isotonic, CHO and electrolyte containing solution (32). This solution contained $7 \mathrm{~g} \mathrm{CHO.100}$ $\mathrm{ml}^{-1}$ and was composed primarily of sucrose. It also found to empty similarly to water after one large bolus, when measurements were made throughout emptying and rates were compared. Although the amount of fluid emptied from the stomach was greater with $4.5 \mathrm{G}$ and $\mathrm{H}_{2} \mathrm{O}$ than with $17 \mathrm{G}$ and $17 \mathrm{MD}$, the amount of CHO emptied in $80 \mathrm{~min}$ was substantially greater with $17 \mathrm{G}$ and $17 \mathrm{MD}$.

The proportion of exogenous $\mathrm{CHO}$ oxidised increased with time during exercise. This increase was greater with $17 \mathrm{G}$ and $17 \mathrm{MD}$ than with $4.5 \mathrm{G}$. Total $\mathrm{CHO}$ oxidation was not different between CHO treatments, determined primarily by exercise intensity (2). The total CHO oxidation was not significantly different with $\mathrm{H}_{2} \mathrm{O}$, but, there was a trend for decreased CHO oxidation and increased fat oxidation with time. The differences in exogenous $\mathrm{CHO}$ oxidation as exercise time increased are in line with differences seen after $2-4 \mathrm{~h}$ of exercise, in which concentrated solutions made a significantly greater contribution to what was oxidised (29). These findings are also in line with those of Mosora et al. (26) who found that the amount of exogenous CHO oxidised was proportional to the $\mathrm{CHO}$ dose averaged over $7 \mathrm{~h}$ following ingestion, at rest. More $\mathrm{CHO}$ was emptied with the $17 \%$ glucose and $17 \%$ maltodextrin solutions, and the contribution to oxidation was greater than with the $4.5 \%$ solution as exercise time proceeded; however, the difference was not nearly so large as was the difference in the amount of CHO which was emptied from the stomach or in the relative rate of absorption across the jejunal mucosa.

In this study the two beverages $17 \mathrm{G}$ and $4.5 \mathrm{G}$ provided $220 \mathrm{~g}$ and $58 \mathrm{~g}$ of $\mathrm{CHO}$, respectively, in $80 \mathrm{~min}$, whereas only $42.0 \mathrm{~g}$ and $31.5 \mathrm{~g}$, respectively, were oxidised. Although the $17 \mathrm{G}$ drink provided 3.8 times more $\mathrm{CHO}$, only 1.3 times more $\mathrm{CHO}$ was oxidised. Several factors appear to form physical and metabolic barriers such that the CHO availability for oxidation is relatively more limited with $17 \mathrm{G}$ than with $4.5 \mathrm{G}$ when expressed as a 
percentage of the dose given. In this respect, the stomach appears to be an important moderating barrier in that it retained $88 \mathrm{~g}$ CHO with $17 \mathrm{G}$ and only $3 \mathrm{~g}$ with $4.5 \mathrm{G}$. If we assume that the relative rates of carbohydrate absorption observed with jejunal perfusion also apply to the exercise situation, then the jejunum would not be an important moderating barrier, since the absorption rate of $\mathrm{CHO}$ from $17 \mathrm{G}$ was 3.3 times faster than the absorption rate of $4.5 \mathrm{G}$, while 3.8 times more $\mathrm{CHO}$ was provided. However, it is not at all clear that the assumption is valid. Exercise may delay intestinal absorption, and the possibility that this occurs differentially with the ingestion of beverages of varying $\mathrm{CHO}$ content cannot be eliminated.

If, however, relative absorption rates from the perfusion experiments can be extended to the exercise studies, then a third modulating effect must exist which more or less equalises the amount of CHO oxidised with $17 \mathrm{G}$ and $4.5 \mathrm{G}$. When $13 \mathrm{C}$. labelled $\mathrm{CHO}$ is taken up by the blood during exercise, then only part of the CHO will be directed towards the oxidation pool in the exercising muscles. Glycogen synthesis may occur in nonexercising muscles during exercise and glycogen synthesis cannot be excluded in certain fibres of the exercising muscles (type II fibres)(19). It is possible that more $13 \mathrm{C}$ CHO is directed towards these pools with $17 \mathrm{G}$ than with $4.5 \mathrm{G}$.

The other question raised by this study was concerning fluid availability. Deuterium accumulation in the blood after oral ingestion has been used as a measurement of the incorporation of water by tissues $(7,8,23,31,33,38)$. Appearance of deuterium in the blood is a product of GE, intestinal absorption, and to a lesser degree, gastric absorption (33). The accumulation of deuterium is also influenced by the rate at which the deuterium leaves the circulation and enters other body water pools. Davis et al.'s results (7) have shown deuterium accumulation to vary with beverage composition. The relative differences in accumulation are similar to the expected relative differences in GE rate of the beverages tested, based upon composition. In the present study, the measured $\mathrm{GE}$ rates correlated with deuterium accumulation rates $(\mathrm{R}=.90 ; \mathrm{p}<.01)$. However, no difference was observed between accumulation of 


\section{Chapter 7}

$2 \mathrm{H}$ from $\mathrm{H}_{2} \mathrm{O}$ and $4.5 \mathrm{G}$, whereas triple lumen perfusion with these same solutions, in the same individuals, demonstrated significantly greater water absorption from $4.5 \mathrm{G}$ than from $\mathrm{H}_{2} \mathrm{O}$. Gisolfi et al. (14) have also observed no difference in deuterium accumulation in blood after intestinal perfusion with a $6 \%$ carbohydrate-electrolyte solution and water (both containing deuterium), yet observed greater net water absorption from the carbohydrate-electrolyte solution, based upon direct measurement of pollyethylene glycol concentration changes. On the basis of these results he suggested that the difference in results can be due to the fact that deuterium accumulation more or less represents uni-directional flow (absorption, not secretion) and as such is not representative of net intestinal absorption.

Both techniques have their limitations, since deuterium uptake is only representative of uni-directional flow and intestinal perfusion disregards changes in flow rate of solution to the intestine due to gastric emptying and secretion above the initial perfusion site or absorption in the rest of the intestine below the test segment. One other problem with interpreting the perfusion data in the present study is the fact that deuterium uptake and combustion data were collected during exercise while perfusion data were collected in rest.

Although Fordtran and Saltin (10) found no effect of exercise on intestinal absorption, results of Maughan et al. (25) have demonstrated differences in efflux from the circulation to the tissues as well as differences in deuterium accumulation with exercise at varying intensities (23), necessitating similar physiological state when comparing different solutions. Furthermore, absolute deuterium accumulation values may give erroneous results in rest if the rate of disappearance from the bloodstream is not measured and corrected for, since during rest the rate of disappearance from the blood is slow, compared with that during exercise when mixture with total body water is practically instantaneous (25; Rehrer, unpublished). However, there are no data to suggest that relative differences in GE or absorption between solutions found at rest would be different during exercise. 
The assumption is made that although absolute rates of absorption and secretion may be altered during exercise, relative differences in GE and absorption will still be present when comparing different solutions.

Advantages of a glucose polymer over a free glucose solution are not obvious looking at GE rate, water uptake as measured by deuterium accumulation, or oxidation rates of the orally ingested CHO. However, one observes an apparent advantage with a glucose polymer when comparing the net water flux across a $30 \mathrm{~cm}$ segment of the upper jejunum. Net absorption was observed with the polymer (17MD) whereas net secretion was observed with the hypertonic, free glucose solution (17G). These results are supported by those of others in which water movement across the intestine has been shown to be related to the osmolality of the succus within the test segment (12). Intestinal secretion is increased with hypertonic intestinal perfusion $(21,35)$ and a decrease in plasma volume has also been observed with intestinal perfusion (35) as well as with ingestion of hypertonic solutions (24). This may explain the clinical symptoms associated with dumping syndrome. Deuterium uptake values do not reflect the difference in net water absorption between $17 \mathrm{G}$ and $17 \mathrm{MD}$, as measured with triple lumen perfusion. This discrepancy may again be explained by the fact that deuterium only measures uni-directional flow or may be explained by the possibillity that although there was net secretion at one point, absorption can take place further down the intestine.

Another inconsistency with the triple Jumen results is that net absorption of glucose from 17MD was significantly less than with $17 \mathrm{G}$ and $4.5 \mathrm{G}$. However, no difference in oxidation of orally ingested $\mathrm{CHO}$ between $17 \mathrm{G}$ and $17 \mathrm{MD}$ was observed, with both resulting in significantly greater exogenous CHO oxidation with time. This finding is supported by Massicotte et al. (22) who also observed no difference in oxidation between a glucose solution and a glucose polymer solution. The discrepancy between apparent absorption of glucose and oxidation may be an artifact of the triple lumen technique.

Although, the perfusion technique does give a measure of the absorption capacity of this section of the intestine, the 
physiological rate at which absorption may accur is unknown, since fluid is provided to the jejunum at a constant rate $(10 \mathrm{ml}$. $\mathrm{min}^{-1}$ ). This rate is similar to the mean rates of emptying observed in this study $\left(10-16 \mathrm{ml} . \min ^{-1}\right)$. The naturally occurring and variable delay, however, in gastric emptying, due to beverage composition, is negated here.

Furthermore, these absorption, or secretion, rates represent only this one section of the intestine, and different areas of the intestine have different absorptive and secretory capacities (11). Also, in the case of oligo- and polysaccharides, the absorption of glucose is dependent upon the presence of the splitting enzymes which are not uniformly distributed throughout the intestine (15).

Since the triple lumen perfusion technique involves perfusion of only a very small segment of the intestines, the net absorption of a glucose polymer may be underestimated. Since amylase is primarily present in the duodenum, and to a lesser degree in the saliva, the breaking of the interior alpha-1,4 linkages in long chained polysaccharides to oligosaccharides is limited and this may account for the decrease in glucose absorption from 17MD. However, this solution is made up to a large extent of alpha limit dextrins, and other smaller oligosaccharides. These are split by oligosaccharidases that are present in highest concentrations in the jejunum, at the brush-border surface membrane, and are also present in physiologically active concentrations in the ileum (15). It may be that the membrane surface area required to hydrolyse the amount of carbohydrate presented as oligosaccharides was simply not sufficient to allow the absorption which could occur over the entire intestine. It is also possible that the capacity to hydrolyse oligosaccharides is less than the capacity to transport glucose. This is supported by the fact that with the free glucose solution, glucose absorption across the $30 \mathrm{~cm}$ section of the jejunum was greater. Monosaccharides inhibit enzyme activity of oligosaccharidases (specifically for the type of monosaccharide released by hydrolysis) (15). Thus, product inhibition may make the splitting enzymes self limiting. This regulatory mechanism also keeps the osmolality of the luminal contents from rising dramatically. 
Since the duodenum is by-passed, and the majority of amylase activity avoided, the increase in osmolality of $17 \mathrm{MD}$, due to hydrolysis, when perfused is less than would be expected with oral ingestion. However, the product inhibition of monosaccharides on oligosaccharidases, assuring that only as much as can be absorbed is hydrolysed, might further limit osmolality increase in the jejunum and thus, the maltodextrin beverage may still have an osmotic advantage above that of the free glucose solution. This would mean that a difference in water flux may still exist, although probably less disparate than was observed with jejunal perfusion. This supposition is supported by results with rats. Daum et al. (6) found that perfusion of the entire rat intestine with a $10 \%$ glucose polymer solution stimulated less intestinal secretion than with a $10 \%$ glucose solution. Furthermore, the luminal osmolality of succus in the duodenum with the $10 \%$ polymer solution, although greater than the original solution, was still much lower than with the $10 \%$ glucose solution.

In conclusion, gastric emptying is not absolutely limiting for water uptake or exogenous carbohydrate oxidation. However, gastric emptying does play a major role in minimising the differences in carbohydrate availability from two carbohydrate containing solutions in which the carbohydrate concentration varies greatly. A large difference in the amount of carbohydrate ingested is not reflected in a large difference in oxidation of exogenous carbohydrate. In both situations, when a dilute $(4.5 \%)$ or a concentrated (17\%) solution is given, only a portion of the amount of carbohydrate emptied from the stomach is oxidised, although this portion is greater with a $4.5 \%$ solution than with a $17 \%$ solution. It is doubtful that intestinal storage plays a substantial role in minimising the difference in carbohydrate availability, based upon absorption rates of glucose, as directly measured during triple lumen perfusion.

Furthermore, gastric emptying rates are similar for a dilute (4.5\%) carbohydrate, sodium containing solution and water, yet net water absorption is significantly greater with the dilute glucose, sodium containing solution. 


\section{References}

1. Beckers, E.J., N.J. Rehrer, W.H.M. Saris, F. Brouns and F. ten Hoor. Determination of total gastric volume, secretion and consumed meal using the double sampling technique of George. Gut 29: 1725-1729, 1988.

2. Christensen, E.H. Der Stoffwechsel und die respiratorischen Funktionen bei schwerer körperlicher Arbeit. Arb. Physiol. 5: $463-478,1932$.

3. Costill, D.L., A. Bennett, G. Branam, and D.O. Eddy. Glucose ingestion at rest and during prolonged exercise. J. Appl. Pysiol. 34: 764-769, 1973.

4. Costill, D.L., W.F. Kammer, and A. Fisher. Fluid ingestion during distance running. Res. Q. 21: 520-525, 1970.

5. Coyle, E.F., D.L. Costill, W.J. Fink, and D.G. Hoopes. Gastric emptying rates of selected athletic drinks. Res. Q. 49: 119-124, 1978.

6. Daum, F., M.I. Cohen, H. McNamara, and L. Finberg. Intestinal osmolality and carbohydrate absorption in rats treated with polymerised glucose. Pediat. Res. 12: 24-26, 1978.

7. Davis, J.M., W.A. Burgess, C.A. Slentz, and W.P. Bartoli. Fluid availability of sport drinks differing in carbohydrate type and concentration. Am. J. Clin. Nutr. 51: 1054-1057, 1990.

8. Davis, J.M., D.R. Lamb, W.A. Burgess, and W.P. Bartoli. Accumulation of deuterium oxide in body fluids after ingestion of $\mathrm{D}_{2} \mathrm{O}$ labeled beverages. J. Appl. Physiol. 63: 2060-2066, 1987.

9. Dill, D.B., and D.L. Costill. Calculation of percentage changes in volumes of blood plasma, and red cells in dehydration. $J$. Appl. Physiol. 37: 247-248, 1974. 
10. Fordtran, J.S., F.C. Rector, and N.W. Carter. The mechanisms of sodium absorption in the human small intestine. J. Clin. Invest. $47: 884-900,1968$.

11. Fordtran, J.S., F.C. Kector, M.F. Ewton, N. Sloter, and J. Kinney. Permeability characteristics of the human small intestine. J. Clin. Invest. 44: 1935-1945, 1965.

12. Fordtran, J.S. and B. Saltin. Gastric emptying and intestinal absorption during prolonged severe exercise. J. Appl. Physiol. 23: $331-335,1967$.

13. Foster, C., D.L. Costill, and W.J. Fink. Gastric emptying characteristics of glucose and glucose polymer solutions. Res. Q. 51: 299-305, 1980.

14. Gisolfi, C.V., R.W. Summers, H.P. Schedl, T.L. Bleiler, and R.A. Oppliger. Human intestinal absorption: direct vs. indirect measurements. Am. J. Physioll. 258: G216-G222, 1990.

15. Gray, G.M. Carbohydrate digestion and absorption. N. Engl. J. Med. 23: 1225-1231, 1975.

16. Halliday, D. and M.J. Rennie. The use of stable isotopes for diagnosis and clinical research. Clin. Sci. 63: 485-496, 1982.

17. Hunt, J.N. The site of receptors slowing gastric emptying in response to starch in test meals. J. Physiol. 154: 270-276, 1960.

18. Jansson, E. Acid soluble and insoluble glycogen in human skeletal muscle. Acta. Physiol. Scand. 113: 337-340, 1980.

19. Kuipers, H., H.A. Keizer, F. Brouns, W.H.M. Saris. Carbohydrate feeding and glycogen synthesis during exercise in man. Pflu. Arch. 410: 652-656, 1987.

20. Leiper, J.B. and R.J. Maughan. Absorption of water and solute from glucose-electrolyte solutions in the human jejunum: effect of citrate or betaine. Scand. J. Gastroenterology 24: $1089-1094,1989$. 
21. Leiper, J.B. and R.J. Maughan. Absorption of water and electrolytes from hypotonic, isotonic and hypertonic solutions. J. Physiol. 373: 90P, 1986.

22. Massicotte, D., F. Peronnet, G. Brission, K. Bakkouch, and C. Hillaire-Marcel. Oxidation of a glucose polymer during exercise: comparison with glucose and fructose. J. Appl. Physiol. 66: 179183, 1989.

23. Maughan, R.J., J.B. Leiper, and B.A. McGaw. Effects of exercise intensity on absorption of ingested fluids in man. Exp. Physiol. 75: 419-421, 1990.

24. Maughan, R.J., C.E. Fenn, M. Gleeson, and J.B. Leiper. Metabolic and circulatory responses to the ingestion of glucose polymer and glucose/electrolyte solutions during exercise in man. Eur. J. Appl. Physiol. 56: 356-362, 1987.

25. Maughan, R.J., S. Rodger and J.B. Leiper. Clearance rate of water tracer from the circulation at different exercise intensities in man. Med. Sci. Sports Exerc. 22: s51 (abstract), 1990.

26. Mosora, F., M. Lacroix, A. Luyckx, N. Pallikarakis, F. Pirnay, G. Krzentowski, and P. Lefebvre. Glucose oxidation in relation to the size of the oral glucose loading dose. Metabolism 39: 1143$1149,1981$.

27. Murray, R. The effects of consuming carbohydrateelectrolyte containing beverages on gastric emptying and fluid absorption during and following exercise. Sports Med. 4: 322$351,1987$.

28. Owen, M.D., K.C. Kregel, P.T. Wall and C.V. Gisolfi. Effects of ingesting carbohydrate beverages during exercise in the heat. Med. Sci. Sports Exerc. 18: 568-575, 1986. 
29. Pallikarakis, N., B. Jaindrain, and F. Pirnay, F. Mosora, M. Lacroix, S. Luyckx, and P.J. Lefebvre. Remarkable metabolic activity of oral glucose during long-duration exercise in humans. J. Appl. Physiol. 60: 1035-1042, 1986.

30. Pierce, H.B. The absorption and utilization of carbohydrates. J. Nutr. 10: 689-716, 1935.

31. Pinson, E.A. Water exchanges and barriers as studied by the use of hydrogen isotopes. Physiol. Rev. 32: 123-134, 1952.

32. Rehrer, N.J., E. Beckers, F. Brouns, F. ten Hoor and W.H.M. Saris. Exercise and training effects on gastric emptying of carbohydrate beverages. Med. Sci. Sports Exerc. 21: 540-549, 1989.

33. Scholer, J.F. and C.F. Code. Rate of absorption of water from stomach and small bowel of human beings. Gastroenterology 27: $565-577,1954$.

34. Schrimgeour, C.M., and M.J. Rennie. Automated measurement of the concentration and $13 \mathrm{C}$ enrichment of carbon dioxide in breath and blood samples using the Finnigan MAT breath gas analysis system. Biomed. Environ. Mass. Spectrom. 15: 365-367, 1988.

35. Sessions, R.T., V.H. Reynolds, J.L. Ferguson and H.W. Scott. Correlation between intraduodenal osmotic pressure changes and $\mathrm{Cr}^{51}$ blood volumes during induced dumping in men with normal stomachs. Surgery 52: 266-278, 1962.

36. Sole, C.C. and T.D. Noakes. Faster gastric emptying for glucose-polymer and fructose than for glucose in humans. Eur. J. Appl. Physiol. 58: 605-612, 1989.

37. van Handel, P.J., W.J. Fink, G. Branam, and D.L. Costill. Fate of $14 \mathrm{C}$ glucose ingested during prolonged exercise. Int. J. Sports Med. 1: 127-131, 1980. 


\section{Chapter 7}

38. Visscher, M.B., E.S. Fetcher, C.W. Carr, H.P. Gregor, M.S. Bushey and D.E. Barker. Isotopic tracer studies on the movement of water and ions between intestinal lumen and blood. Am. J. Physiol. 142: 550-575, 1944.

39. Wagenmakers, A.J.M., F. Brouns, W.H.M. Saris and D. Halliday. Maximal oxidation of oral carbohydrates during exercise. Med. Sci. Sports Exerc. 22: s120 (abstract), 1990.

40. Westerterp, K., W.H.M. Saris, M. van Es, and F. ten Hoor. Use of the doubly labeled water technique in humans during heavy sustained exercise. J. Appl. Physiol. 61: 2162-2167, 1986. 


\section{CHAPTER 8}

\section{Fluid intake and gastrointestinal problems in runners competing in a $25-\mathrm{km}$ race and a marathon}

\section{Abstract}

A group of 114 previously untrained subjects, 31 females and 83 males were followed for 18 months while training for at marathon. Forty-four of the subjects completed a survey regarding fluid intakes and gastrointestinal (GI) disturbances during competition for both their first $25-\mathrm{km}$ race (run after one year of training) and their first marathon. GI problems were common. Among the individuals surveyed, $25 \%$ had GI complaints in the $25 \mathrm{~km}$ race. In the marathon, $52 \%$ complained of GI distress. Mean fluid consumption was low $(25-\mathrm{km}: 109 \mathrm{ml}$; marathon: $577 \mathrm{ml}$ ). Body weight losses in the marathon were substantial (mean $=3.2 \% \mathrm{BW}$, range $1.5-6.2 \%$ ) indicating sweat losses greater than fluid replacement. Mean loss was greater in men than in women (men: $3.4 \% \mathrm{BW}$; women: $2.6 \% \mathrm{BW}, \mathrm{p}<.05$ ). GI complaints were not associated with larger drink intakes. In contrast, dehydration above a certain limit appears to increase the frequency of GI disorders. In the marathon, $80 \%$ of the runners who lost $>4 \%$ BW had GI problems. It is possible that reduced blood flow to the GI region is compromised via the exercise itself as well as by a reduced blood volume, which may disrupt normal secretions and absorption in the digestive tract. A rising core body temperature, associated with decreased sweating at high levels of dehydration, may also be related to Gl dysfunction. 


\section{Introduction}

Fluid balance plays a decisive role in maintaining optimal body functions, particularly when an activity is performed that induces large fluid losses. A fluid loss of as little as $2 \%$ of the body weight decreases endurance performance $(1,10)$. With water losses of $4-5 \%$ of the body weight, physiological function is impaired $(4,21,18)$. Water loss occurring as a result of sweating comes from the blood, intracellular and interstitial pools $(8,9,20)$ and causes a reduction in circulatory capacity, cooling, and exercise efficiency $(2,21)$, therefore drinking is advised for optimal performance and feelings of well-being during endurance exercise. Another problem for distance runners in particular is the common occurrence of gastrointestinal (GI) disorders. Keeffe (15) reported that $40 \%$ of over 700 marathon runners surveyed had GI complaints. The occurrence of such complaints appeared more frequently in younger runners than in older runners (possibly due to inexperience) and more frequently in females than in males.

Cramping of the intestines and possibly of the stomach may be related more to problems induced by dehydration and type of exercise than to the fluids taken before and during exercise (3). As part of a project investigating the metabolic effects of training for the marathon the possibility presented itself to study in detail the problems involving GI function in a group of alike trained novice runners during their first experiences in endurance competition.

Specifically, the purpose of this study was to examine the relationship between fluid intake, fluid loss, runing distance and finishing time, and the prevalence of GI problems.

\section{Materials and Methods}

A group of 114 previously untrained subjects was followed for 18 months. They began a training regime with the ultimate goal to complete a marathon $(42.2 \mathrm{~km})$. For complete details of the training program see Janssen et al. (1989) After training for one year, a $25-\mathrm{km}$ race was run and after one and one-half years a marathon was run. All subjects had the option of running one of 
six different marathons over a four month period. The ambient temperature ranged from $6-24{ }^{\circ} \mathrm{C}$ and the relative humidity ranged from $45-85 \%$. All races were officially organised competitions. Seventy-eight of the 114 subjects ran the marathom. Due to logistical problems complete data were collected for only forty-four of these runners for both the 25 . $\mathrm{km}$ race and the marathon. Selection was at random, not allowing for self-selection. There were 12 women and 32 men in the group surveyed; the ratio of women to men being similar to that in the total group. Subject characteristics are presented in Table 1.

Table 1. Subject characteristics

men
Mean (range)

$\begin{array}{lrr}\text { Age (yr) } & 34(21-54) & 31(22-43) \\ \text { Height }(\mathrm{cm}) & 179(166-193) & 167(155-186) \\ \text { Weight }(\mathrm{kg}) & 73(58-90) & 60(50-71)\end{array}$

Times were recorded and questions were asked regarding drink consumption prior to and during the race, time of the last prerace meal and incidence of GI disorders during training in general and specifically during the race. After evaluating the results of the $25 \mathrm{~km}$ race it was decided to quantify fluid losses during the marathon by weighing subjects before and immediately after finishing the marathon. Symptoms surveyed included nausea, vomiting, stomach ache, side ache, intestinal cramps, and diarrhoea. Side ache was included as a GI symptom although the exact aetiology is unknown. As part of a subsample of the marathon project in which more detailed information was gathered, 38 of the 44 subjects completed laboratory tests in which the maximal running speed and maximum heart rate were measured previous to participating in the marathon. During the marathon the heart rate was monitored in these subjects (Sporttester(B) Average running speed was also 
calculated from the total time taken to complete the marathon. These two variables were expressed as percent of maximal obtained values for heart rate and running speed in laboratory tests. Mann-Whitney analysis for non-normal data (22) was used to compare frequency of symptoms, fluid losses, and finshing times between men and women and to examine possible correlations between frequency of disorders and finishing time, running intensity, fluid intake, and fluid loss. Differences with a p-value equal to or smaller than .05 were accepted as statistically significant.

\section{Results}

Men ran significantly faster in the $25-\mathrm{km}$ race $($ mean $=119$, range $=103-145 \mathrm{~min})$ than women $($ mean $=133$, range $=117-$ $149 \mathrm{~min}) \quad(p<.01)$. Finishing times were similar for men and women in the matathon (mean $=224$, range $=191-295$; mean $=$ 232 , range $=208-281$, respectively). Fluid intakes among surveyed runners in both the $25-\mathrm{km}$ race and marathon were low (109 \pm 14 and $577 \pm 46 \mathrm{ml}$, means $\pm \mathrm{SE}$, respectively). There were no significant differences between men and women. Fluid intakes were not significantly correlated with finishing times in either the $25-\mathrm{km}$ race or marathon. The mean fluid loss in the marathon was $3.2 \pm 1.0 \mathrm{~kg}$. Fluid lasses in men were significantly greater than in women (Table 2).

Table 2. Fluid losses during the marathon

$$
\text { men women }
$$

$\begin{array}{lll}\text { Absolute BW loss (kg) } & 2.45 * *(1.1-4.6) & 1.50(0.8-2.6) \\ \text { \% BW loss } & 3.40^{* *}(1.7-6.2) & 2.6(1.5-4.5)\end{array}$

Body weight ( $B W$ ) loss significantly greater in men than in women. ** $p<.01$. 
GI complaints were common in both the $25 \mathrm{~km}$ race and the marathon, having been reported by one-fourth to one-half of all surveyed runners. However, in the $25-\mathrm{km}$ race far fewer men had GI problems than women. These men also experienced far fewer problems in the $25-\mathrm{km}$ race than in the marathon. In the marathon, men and women alike had a high frequency of GI disorders (Table 3).

Table 3. Frequency of all runners surveyed experiencing one or more GI disorder (\%)

\begin{tabular}{llll}
\hline & men & women & both \\
& & & \\
\hline $25-\mathrm{km}$ & 12.5 & $58.3^{* *}$ & 25.0 \\
Marathon & 56.3 & 41.7 & 52.3 \\
& & & \\
\hline
\end{tabular}

Frequency of $G I$ distress significantly greater in women than in men in the $25-\mathrm{km}$ race. $* * 0<.01$.

In the shorter race $(25-\mathrm{km})$ the predominant complaints were of the upper gastrointestinal tract, nausea, stomach, and side aches, whereas in the longer race $(42.2 \mathrm{~km})$ intestinal distress was also reported (Table 4).

Table 4. Frequency of specific GI complaints among all runners surveyed (\%)

\begin{tabular}{lcc}
\hline & $25-\mathrm{km}$ & Marathon \\
\hline Nausea & 11 & 11 \\
Stomach ache & 2 & 5 \\
Side ache & 16 & 23 \\
Intestinal cramps & 0 & 18 \\
diarrhoea & 0 & 0 \\
\hline
\end{tabular}


No direct correlation between fluid loss and prevalence of GI disorders was observed at lower lewels of dehydration, however above a certain threshold ( $4-5 \% \mathrm{BW}$ loss), the frequency of GI complaints increased dramatically (from $50 \%$ to $80 \%$ ) (Fig. 1).

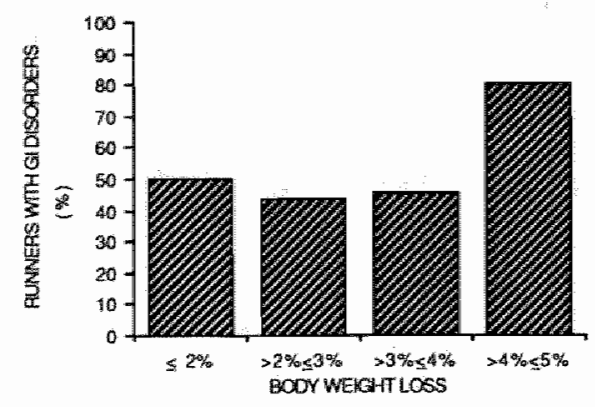

Fig. 1. Fluid loss (W BW loss) and frequency of GI disorders (\%) among marathon runners. Distribution of the group $(n=44)$ with respect to fluid loss: $B W \leq 2 \% \quad n=6, B W>2 \% \leq 3 \% \quad n=16$.

$B W>3 \% \leq 4 \% n=\|, B W>4 \% \leq 5 \% n=\|$.

No correlation was found between the time of the last meal and the occurrence of GI disturbances. However, there was very little variance in the time of the last meal, almost all the surveyed athletes having eaten three to five hours before the race. No information was gathered in relation to the composition of the last pre-race meal. In the group of 38 subjects no correlation was found between frequency of GI disturbances and metabolic stress as measured by average heart rate during the marathon as a percent of maximal heart rate. MannWhitney analyses revealed no significantly higher average heart rates in those subjects who had GI problems. There was also no increased incidence of GI problems noted with increased metabolic stress as measured by average running speed during the marathon expressed as percent of maximal running speed (Table 5). 
Table 5. Running intensity and heart frequency during marathon (\% maximal) in runners with and without $G I$ complaints

n \%max heart rate \%max running speed
means $\pm \mathrm{SE}$

$\begin{array}{llll}\text { GI problems } 20 & 88.6 \pm 0.5 & 65.5 \pm 1.3 \\ \text { No Gl problems } 18 & 89.3 \pm 0.8 & 69.9 \pm 1.5\end{array}$

No significant differences between runners with and without GI complaints.

\section{Discussion}

These data collected from novice runners coincide with observations among well-trained marathon runners whose average weight loss during a marathon was $2.8 \mathrm{~kg}$ and $4.3 \%$ BW (16). In the vast majority of distance runners, far less fluid is ingested immediately prior to and during competition, than is lost. Our observation that men had greater sweat losses than women who completed the marathon with similar finishing times coincides with findings of others $(5,13)$ who found that sweat rates with heat exposure were greater in men than in women. Although in some studies no difference in sweat response between men and women was found when corrections were made for hormonal phase and other physiological characteristics which typify women versus men. It appears that a higher core temperature is required before sweating is initiated in women (14). This gender difference may be related to differences in body composition and an hidromeiotic effect (wet skin suppressing sweat secretion) (12). These losses in body water represent a possible contributing factor to decreased performance, via decreased circulatory capacity, decreased 
ability to cool and increased risk of gastrointestinal disorders (3). When dehydration results in reduced plasma volume, blood supply to the periphery and particular organ systems may be compromised as the exercising musculature competes with these regions for the decreased wolume of blood (17). It is documented that in the early stages of exercise there is a shift of blood away from renal and splanchnic circulation and that dehydration may further reduce splanchnic blood flow $(7,19)$. A reduced blood flow may be associated with gut ischaemia. Long lasting or intermittent, high intensity exercise may cause GI disturbances, particularly when this results in dehydration. The suggestion made by many athletes that larger fluid intakes cause gastrointestinal problems during exercise is not supported by our results, within the range of beverage intakes measured. On the contrary, only large fluid deficits appear to be related to a higher prevalence of GI problems $(>4 \%$ BW loss, $80 \%$ GI problems). No relationship was observed between finishing time and fluid intake, however all subjects drank very little relative to fluid losses.

As would be expected, fluid losses were greater on the days when the ambient temperature was higher. Average weight loss ranged from $2.9 \%$ at $5^{\circ} \mathrm{C}$ to $4.6 \%$ at $24{ }^{\circ} \mathrm{C}$. It is possible to speculate that not only the degree of dehydration may be related to GI problems, but that an increased core body temperature, resulting from a higher ambient temperature, dehydration and a reduced sweat rate, may also play a role in the development of GI malfunction.

From the results of the subsample group it can be concluded that relative metabolic stress within the range of aerobic capacity, where one would expect to be exercising in an endurance event sucli as the marathon, is not the main factor in predisposing GI problems during endurance running. It is theorised that a large factor contributing to the development of GI disturbance in the runner is a mechanical one. Field studies which we conducted to measure vibration during exercise demonstrated that the integral of accelerations of the body per minute is almost doubled in running versus bicycling (Chapter 4). The movement of internal organs as a result of the intrinsic properties of this type of exercise, with a large vertical component, may explain why GI complaints are quite common 
in runners $(23,15)$ but seldom in bicyclists and skaters.

The effect of training on prevalence of GI problems has yet to be thoroughly examined. Quite possibly the high prevalence of GI problems seen in our study and in that of Keeffe (15) is due in part to the limited experience the participants have had under racing conditions. The fact that in Keeffe's study a higher prevalence of GI symptoms was observed among younger runners may be exemplary of this, younger runners being less experienced in general. More experienced runners have also been noted as having GI problems. Case studies have been reported of runners with severe GI distress (including cramping, loose stools, and bloody diarrhoea) $(6,11)$. The same individuals with continued training (after recovery, when the episode was severe enough to require rest) have few or no further episodes. This points to a training effect, whether it be a physical conditioning to withstand the assaults, or a better selfevaluation and feed-back mechanism where the athlete cuts back before problems arise. It is possible to speculate that a training effect of reduced incidence of GI distress may be an adaptation to the quick accelerations and decelerations experienced while running by the surrounding muscles and the organs themselves. Or possibly there is a self-selection process whereby runners predisposed to GI problems quit before they ever could become experienced runners.

Summarising the results, it is concluded that distance runners consume less fluid than is lost during long competition. The problem for men appears to be more severe than for women, based upon sweat losses, relative and absolute. However, overheating may be just as great a problem or greater in women because of decreased sweating, resulting from the higher core temperature required before sweating is initiated (14). It can only be suggested that maintaining fluid balance may help to prevent gastrointestinal problems as well as to prepare for the best possible performance by assuring adequate maximal circulation and cooling capacity. In addition, from these results there are no indications that increased fluid intakes cause GI problems. 


\section{References}

1. Armstrong, L.E., D.L. Costill and W.J. Fink. Influence of diuretic induced dehydration on competitive running performance. Med. Sci. Sports Exerc. 17: 456-461, 1985.

2. Astrand, P.O. and B. Saltin. Plasma and red cell volume after prolonged severe exercise. J. Appl. Physiol. 19: 829-832, 1964.

3. Brouns F., W.H.M. Saris and N.J. Rehrer. Abdominal complaints and gastrointestinal function during long-lasting exercise. Int. J. Sports Med. 8: 175-189, 1987.

4. Buskirk, T., P.F. Iampietro and D.E Bass. Work performance after dehydration: effects of physical conditioning and heat acclimatization. J. Appl. Physiol. 12: 189-194, 1958.

5. Candas, V., J.P. Libert, J.C. Sagot and J.J. Vogt. Thermophysiological responses to humid heat: sex differences. J. Appl. Physiol. 78: 240-242, 1982.

6. Cantwell, J.D. Gastrointestinal disorders in runners. JAMA 246:1404-1405, 1981.

7. Clausen, J.P., K. Klausen,. B. Rasmussen and J. Trap-Jensen. Central and peripheral circulatory changes after training of the arms or legs. Am. J. Physiol. 225: 675-682, 1973.

8. Costill, D.L. and K.E. Sparks. Rapid fluid replacement following thermal dehydration. J. Appl. Physiol. 34: 299-303, 1973.

9. Costill, D.L., G. Branam, D. Eddy and W.J. Fink. Alteration in redcell volume following exercise and dehydration. J. Appl. Physiol. 37: 912-916, 1974.

10. Craig, F.N. and E.G. Cummings. Dehydration and muscular work. J. Appl. Physiol. 21: 670-674, 1966. 
11. Fogoros, R.N. Runners trots: gastrointestinal disturbances in runners. JAMA 243: 1743-1745, 1980.

12. Gonzallez, R.R., K.B. Pandolf and A.P. Gagge. Heat acclimation and decline in sweating during humidity transients. J. Appl. Physiol. 36: 419-425, 1974.

13. Grucza, R., J.L. Lecroart, G. Carette, J.J. Hauser and Y. Houdas. Effect of voluntary dehydration prior to heat exposure on thermo-regulatory responses to heat in men and women. Eur. J. Appl. Physiol. 56: 317-322, 1987.

14. Fox, R.H., B.E. Lofstedt, P.M. Woodward, E. Erikson and B. Werkstrom. Comparison of thermoregulatory function of men and women. J. Appl. Physiol. 26: 444-453, 1969.

15. Keeffe, E.B., D.K. Lowe, J.R. Goss and R. Wayne. Gastrointestinal symptoms of marathon runners. West. J. Med. 141: $481-484,1984$.

16. Maron, M.B., S.M. Horvath and J.E.Wilkerson. Acute blood biochemical alterations in response to marathon running. Eur. J. Appl. Physiol. 34: 173-181, 1975.

17. Nadel, E.R. Non-thermal influences on the control of skin blood flow have minimal effects on heat transfer during exercise. Yale J. Biol. Med. 59: 321-327, 1986.

18. Ribish, P.M. and W.G. Herbert. Effects of rapid weight reduction and subsequent rehydration upon the physical working capacity of wrestlers. Res. Q. 41: 536-641, 1970.

19. Rowell, L.B., J.R. Blackmon and J.R. Bruce. Indocyanine green clearance and estimated hepatic blood flow during mild to maximal exercise in upright man. J. Clin. Invest. 43: 1677-1690, 1964.

20. Rowell, L.B. Les effects de la déhydration sur la thermorégulation. Influence sur la performance. Comptes rendus du Collogue de Saint-Etienne, Saint-Etienne, France, p. 81, 1979. 
21. Saltin, B. Aerobic work capacity and circulation at exercise in man with special reference to the effect of prolonged exercise and/or heat exposure. Acta Physiol. Scand. Suppl. 230, 1964.

22. Snedecor, G.W. and W.G. Cochran. Statistical Methods, Ames, Iowa, U.S.A., Iowa State University Press p. 144, 1980.

23. Sullivan, S.N. The gastrointestinal symptoms of running. N. Engl. J. Med. 304: 203, 1981. 


\section{CHAPTER 9}

\section{Gastrointestinal symptoms and physiological changes as a result of ultra-endurance running}

\section{Abstract}

One hundred and seventy-two competitors of the Swiss Alpine Marathon, Davos, Switzerland, 1988, volunteered for this research project. Of these volunteers 170 (158 men, 12 women) finished the race $(99 \%)$. The race length was $67 \mathrm{~km}$ with an altitude difference of $1900 \mathrm{~m}$ between highest and lowest points. Mean age was $39 \mathrm{yr}$. Average finishing times were $8 \mathrm{~h}$ $18 \mathrm{~min}$ (men) and 8 h $56 \mathrm{~min}$ (women). Body weight loss averaged $3.4 \%$ body weight $(3.3 \pm 0.2 ; 4.0 \pm 0.4$; mean $\pm S E$, men and women, resp.). Blood samples from a subgroup of 89 subjects (6 women and 83 men) were taken prior to and immediately after completion of the race.

Changes in haemoglobin (Hb) $\left(9.3 \mathrm{mmol}^{-1}\right.$ pre-race, 9.7 mmol.1-1 post-race) and haematocrit (Hct) (0.44 pre-race, 0.48 post-race) were in line with the moderate level of dehydration displayed by changes in body weight. Mean plasma volume decrease was $8.3 \%$. No significant changes in plasma osmolatity, sodium, or chloride were observed, but plasma potassium did increase by $5 \%$ (4.2 meq. $\mathrm{l}^{-1}$ pre-race, $4.4 \mathrm{meq} \cdot \mathrm{l}^{-1}$ post-race). Mean fluid consumption was $3290 \pm 103 \mathrm{ml}$.

Forty-three percent of all subjects, and $33 \%$ of those who gave blood samples, complained of gastrointestinal (GI) distress during the race. No direct relationship between quantity or quality of beverage consumed with prevalence of GI symptoms was found. The circulating concentration of several GI hormones was measured and several were found to be elevated significantly after the race (gastrin, VIP, PHI, motilin), but larger changes were not found to be significantly correlated with GI symptoms. Plasma cortisol, epinephrine, and norepinephrine 

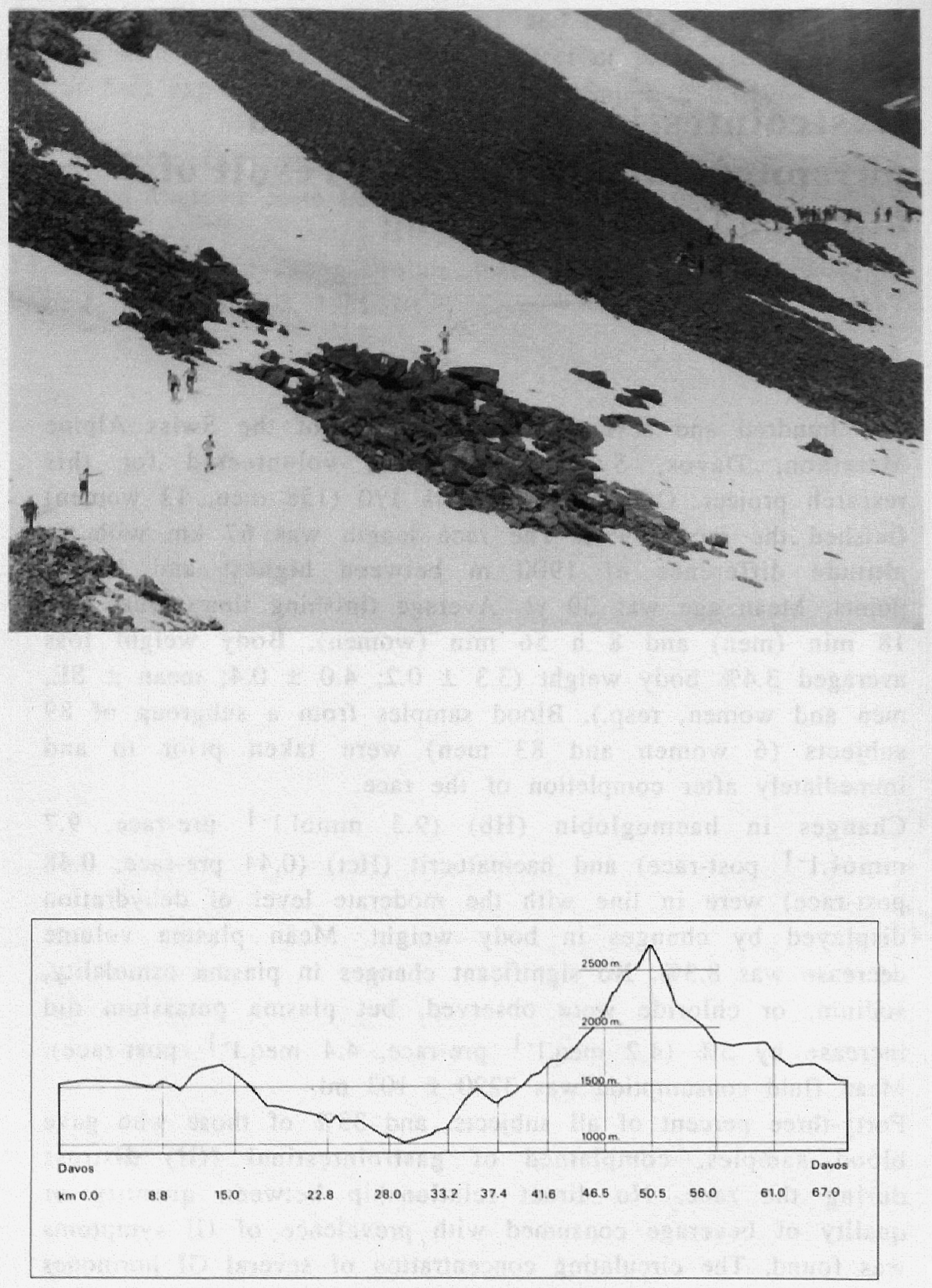

Fig. 1. Cross-sectional profile of the race course. 
concentrations were significantly higher after the race compared to resting values. There was a trend for post-race norepinephrine values to be lower in sufferers of GI disturbance. Specifically in those runners with intestinal cramps, the post-race plasma norepinephrine concentration was significantly lower. Also the resting plasma cortisol concentration was significantly lower in those individuals who developed intestinal cramps during the race.

Plasma CK, ALAT, and ASAT activities were increased following the race, which may indicate tissue damage. A rise in plasma potassium post exercise was observed in individuals with GI complaints $\left(.29 \pm .07\right.$ meq. $\mathrm{l}^{-1}$ increase), whereas no rise was observed in individuals without GI symptoms. An inability of the $\mathrm{Na}^{+} / \mathrm{K}^{+}$purmp to keep pace with needs in skeletal muscle tissue (as well in the intestinal tract) may account for the high plasma potassium values immediately following exercise, and may play a role in the development of GI disorders. However, many other sources of $\mathrm{K}^{+}$release may account for the elevated plasma $\mathrm{K}^{+}$(skeletal muscle, liver, and red blood cells) in sufferers and the correlation between rise in $\mathrm{K}^{+}$and $\mathrm{GI}$ symptoms may be an indirect one.

\section{Introduction}

Over the last decade research on marathon running and endurance exercise in general has contributed greatly to the growing body of knowledge concerning normal and abnormall physiological function. Extreme situations, such as competitive endurance events, push the human body to its limits. The weak links and the intricate coupling of metabolic pathways with substrate availability can be more clearly identified when the system is stressed.

A number of physiological and biochemical changes have been described in conjunction with marathon running. In addition to what may be considered normal responses to the physical stress of this type of exercise are abnormal changes and health risks. 
One ailment which has gained some attention in the past several years is gastrointestinal (GI) disturbance in association with long distance running: Although much descriptive data have been reported, little information has been gathered regarding the aetiology of GI symptoms, or preventive measures which can be taken to avoid these problems. GI complaints are common among marathon runners (Brouns, et al., 1987; Fogoros, 1980). Prevalence has been reported to range from 30-50\% (Keeffe et al., 1984; Rehrer et al., 1989). Several possible factors which may predispose to GI disturbance have been described.

Dehydration at levels of $4-5 \%$ body weight loss has been found to be associated with increased prevalence of GI distress among marathon runners (Neufer et al., 1989; Rehrer et al., 1990).

During competition, specific aspects of the dietary intake of triathletes have been observed to be associated with GI symptoms. Greater fat, fibre and protein intakes (solid food) and hypertonic beverage $\left(>800 \mathrm{mOsm} \cdot \mathrm{kg}^{-1}\right)$ ingestion were associated with GI distress (van Kemenade, 1989). Intensity of exercise is speculated to increase risk of GI disorder, as well as training status, well trained athletes with more experience being less prone to these ailments (Brouns et al., 1987).

In a foot race such as the marathon $(42.2 \mathrm{~km})$ where sweat losses easily reach $11 . h^{-1}$ and fluid intake is problematic, fluid balance is difficult to maintain. In ultra-marathon competition $(>42.2 \mathrm{~km}$ ) one would expect that the changes and symptoms appearing as a result of marathon runing would be accentuated.

The Swiss Alpine Marathon in Davos Switzerland is a demanding $67 \mathrm{~km}$ race with steep inclines, declines, and rugged terrain, which make this race particularly demanding. Since the first year of its conception, 1986, data from a number of participants have been gathered, in cooperation with the organization, regarding body weight changes, and a number of plasma parameters to monitor health status of the participants (Frey, 1988). Results presented in this article come from data collected during the third runing of the Swiss Alpine Marathon in 1988. 
The goals of this research project were to further investigate GI dysfunction, and to gather information regarding hydration status and physiological stress, which may or may not be related to GI symptoms.

\section{Methods}

The Swiss Alpine Marathon is a $67 \mathrm{~km}$ ultra-marathon run on a circular course with an altitude difference of $1900 \mathrm{~m}$ between the highest and lowest points. The profile of the course is shown in Fig. 1. On both sides of the mountain pass, reached at $50 \mathrm{~km}$, are inclines and declines of as much as $23 \%$.

Drink posts were provided approximately every $7 \mathrm{~km}$ with water as well as beverages containing carbohydrate and electrolytes being made available. Competitors were recruited for the research project one or two days before the race, when they came to pick up their start numbers. An attempt was made to recruit as many competitors as possible for the project.

On race day at 8:00 a.m., when the race began in Davos, the temperature was $11{ }^{\circ} \mathrm{C}(\mathrm{db})$ with relative humidity of $72 \%$. At the $50 \mathrm{~km}$ point, Sertig Pass, at 11:00 a.m. the temperature was $7^{\circ} \mathrm{C}$ (db) with relative humidity of $64 \%$. One hundred and seventy of the 172 rumners who volunteered for the research project $(99 \%)$ completed the total distance within the alloted time $(12 \mathrm{~h})$. There were 875 participants in total (including 50 women) who finished the race within the limit.

Resting blood samples $(10 \mathrm{ml})$ were taken $24-48 \mathrm{~h}$ prior to the race from the first 101 participants who volunteered. At this time, subjects were familiarised with the questionnaire which would need to be filled out after the race. Of these 101 subjects, 89 ( 6 women and 83 men) finished the race and gave a blood sample after the race. On the morning of the race, body weights were measured. The questionnaire included a list of all refreshment posts and drinks offered at each post and space to write in number of cups at each post. The volume contained in one cup, maximally filled, was $150 \mathrm{ml}$. Since cups were not completely filled and spilling was common, an average content of $100 \mathrm{ml}$ per cup was registered. 
Additionally, a list of possible gastrointestinal ailments was printed and space was provided to mark at which kilometer(s) a problem occurred.

Subjects were met at the finish line by research assistants and led $50 \mathrm{~m}$ to a temporary laboratory: Blood samples $(20 \mathrm{ml})$ and body weights were taken as quickly as possible. On the average, a time lag of 3-5 min separated finishing and the taking of blood samples.

\section{$\underline{\text { Subjects }}$}

The experimental group included 158 men and 12 women. Mean finishing time for the men was $8 \mathrm{~h} 18 \mathrm{~min}$ and $8 \mathrm{~h} 56 \mathrm{~min}$ for the women. Included among the subjects were the first finishing woman ( 6 h $45 \mathrm{~min}$ ) and fifth $\operatorname{man}(5 \mathrm{~h} 41 \mathrm{~min}$ ), as well as individuals who finished in just under $12 \mathrm{~h}$. Ninety-one percent of the subjects had run a marathon $(42.2 \mathrm{~km})$ or longer race previously and $58 \%$ had run the Swiss Alpine Marathon previously. In general it can be concluded that the subjects were experienced and well trained, based upon previous race experience and the high percentage of finishers. The group surveyed can be considered representative of the total group of competitors, based upon finishing times and places. The mean age for the men was 40 years (range 20-72 yr) and for the women 35 years (range $26-46 \mathrm{yr}$ ). Body weights were obtained from six of the 12 women and 87 of the 158 men prior to the race and from five and 86 of these subjects, respectively, after the race. Mean pre-race weights were $60.7 \pm 3.2 \mathrm{~kg}$ and $71.7 \pm$ $8.9 \mathrm{~kg}$ for women and men, respectively.

\section{Blood analyses}

Blood was sampled from a forearm vein. A portion of whole blood was analysed for haematocrit ( $\mathrm{Hct}$ ) and haemoglobin ( $\mathrm{Hb}$ ) immediately after drawing. A portion of blood $(2 \mathrm{ml})$ was collected in separate tubes for GI hormone analyses. Plasma glucose, osmolality, sodium, potassium, chloride, the enzymes creatine phosphokinase (CK), and aspartate aminotransferase (ASAT) and alanine aminotransferase (ALAT), the GI hormones vasoactive intestinal polypeptide (VIP), motilin, gastrin, peptide HI (PHI), as well as catecholamines and cortisol were measured. Details of sample preparation and analyses for GI hormones are 
published elsewhere (19). For catecholamine analyses, glutamine was added to the plasma. Plasma samples were held on ice until put into deep-freeze storage $\left(-70^{\circ} \mathrm{C}\right)$ until further analyses could be conducted.

Haemoglobin was determined by the met-haemoglobin technique and haematocrit by the standard micro-capillary centrifuge method. Plasma osmolality was determined by the freeze-point method (Osmomat 030, Gonotech, Berlin, Germany). Plasma $\mathrm{Na}^{+}$and $\mathrm{K}^{+}$were determined by flame photometry (Instrumentation Laboratory 243, Lexington, MA, U.S.A.). Catecholamines were analyzed with HPLC (Smedes et al., 1982). CK, ASAT, and ALAT were determined with commercial enzyme kits (Boehringer, Mannheim, Germany). Plasma glucose was determined by the GOD-perid method. Cortisol was determined by radio-immunoassay (Diagnostic Products $\mathrm{CO}_{n}$, Los Angeles, CA, U.S.A.).

\section{Statistical analyses}

Non-parametric analyses were used since the data were not normally distributed. Unless otherwise stated, all results are presented as mean ( \pm SE). Mann-Whitney analysis was applied to variables where a difference in subjects with GI symptoms versus those without symptoms was expected. A similar analysis was also completed for each specific GI disorder: nausea, vomiting, diarrhoea, etc., in comparing post-race and pre-race values and the differences (post-race minus pre-race) in the sufferers versus non-sufferers, as well as prevalence of complaints in males versus females. To compare pre- and postrace values Wilcoxon's signed-rank test for paired data was used. Simple linear regression was performed when looking for a correlation between variables with a range of values. A $95 \%$ confidence interval was defined in testing for significant differences between means.

Results

Body weight changes

Body weight losses of $2.4 \pm 0.1 \mathrm{~kg}$ ( $3.3 \%$ of body weight) in men and $2.3 \pm 0.2 \mathrm{~kg}(4.0 \%)$ in women were measured. The mean 
weight loss $(3.4 \%)$, including both men and women, was less than what was observed in the two previous years' competitions (1986: 5.5\%; 1987: 6.6\%) (Frey, 1988).

\section{Intakes}

All subjects drank during the course of the race. During competition fluid intake was $3335 \pm 107 \mathrm{ml}$ in men and 2746 $\pm 338 \mathrm{ml}$ in women. Water was the most commonly consumed beverage. From the $3290 \mathrm{ml}$ consumed (combined average men and women) $1723 \mathrm{ml}$ was water, $479 \mathrm{ml}$ was a beverage containing $18 \%$ carbohydrate $\left(312 \mathrm{~kJ} .100 \mathrm{ml}^{-1} ; 380 \mathrm{mOsm} \cdot \mathrm{kg}^{-1}\right)$ (Perform (B)) and $569 \mathrm{ml}$ was a beverage containing $7 \%$ carbohydrate (138 kJ.100 ml-1; 298 mOsm.kg-1) (Isostar(B). Based on the average intakes of these two beverages, mean carbohydrate intake was at least $129 \mathrm{~g}$. A wide variety of other beverages provided by the athletes themselves were consumed. The intake of all these other beverages combined averaged 518 ml. No estimation of the additional carbohydrate contribution from these drinks was made since they were frequently selfmade and no quantitative or qualitative estimation of the ingredients was possible. Solid foodstuffs, mostly pieces of fruit, were sporadically consumed by $85 \%$ of the subjects.

\section{Gastrointestinal symptoms}

Gastrointestinal distress was reported by $43 \%$ of the runners surveyed. One or more GI symptom was reported by $42 \%$ of the men and $57 \%$ of the women. Diarrhoea was more common among the women and there was a trend for women to have intestinal cramps more frequently than men. The frequency of specific disorders is shown in Table 1.

\section{Blood parameters}

Increases in $\mathrm{Hct}$ and $\mathrm{Hb}$ concentration were observed (Table 2), which are in line with the moderate level of dehydration indicated by body weight losses. Based upon $\mathrm{Hct}$ and $\mathrm{Hb}$ values before and after the race, a mean plasma volume decrease of 8.3\% was calculated using the formula of Dill and Costill (1974). Plasma osmolality did not change significantly (305 mosm.kg-1. pre-race, 304 mOsm.kg-1 post-race). 
Table I. Percentage runers reporting GI problems

\begin{tabular}{lccc}
\hline Symptoms & All & Male & Female \\
\hline Nausea & 15 & 14 & 25 \\
Vomiting & 2 & 2 & 0 \\
Stomach ache & 11 & 12 & 0 \\
Side ache & 19 & 17 & 42 \\
Intestinal cramps & 9 & 8 & 25 \\
Diarrhoea & 6 & 4 & $25 *$ \\
& & & \\
\hline
\end{tabular}

* Significant difference between men and women $(p<05)$.

Table 2. Blood Parameters

Pre-race Post-race

$\begin{array}{lrrrc}\text { Hct } & 0.444 \pm & 0.003 & 0.476 \pm 0.003 * \\ \text { Hb (mmol. } 1^{-1} \text { ) } & 9.2 \pm & 0.1 & 9.6 \pm & 0.1 * \\ \text { Osmolality (mOsm.kg-1) } & 305.3 \pm & 0.8 & 303.9 \pm & 0.8 \\ \text { Sodium (meq. } \mathrm{I}^{-1} \text { ) } & 139.1 \pm & 0.4 & 142.3 \pm & 0.4 \\ \text { Potassium (meq. } \mathrm{I}^{-1} \text { ) } & 4.24 \pm & 0.03 & 4.38 \pm & 0.05 * \\ \text { Chloride (meq. } \mathrm{I}^{-1} \text { ) } & 103.4 \pm & 0.2 & 102.8 \pm & 0.4\end{array}$

* Significant post-race increase $(p<.05)$. 


\section{Chopter 9}

Concentrations of sodium and chloride remained unchanged while plasma potassium concentration increased significantly (Table 2). Plasma creatine phosphokinase (CK), aspartate aminotransferase (ASAT) and alanine aminotransferase (ALAT) activities were all significantly increased immediately following the race compared with rest values. These changes are graphically presented in Fig. 2 .
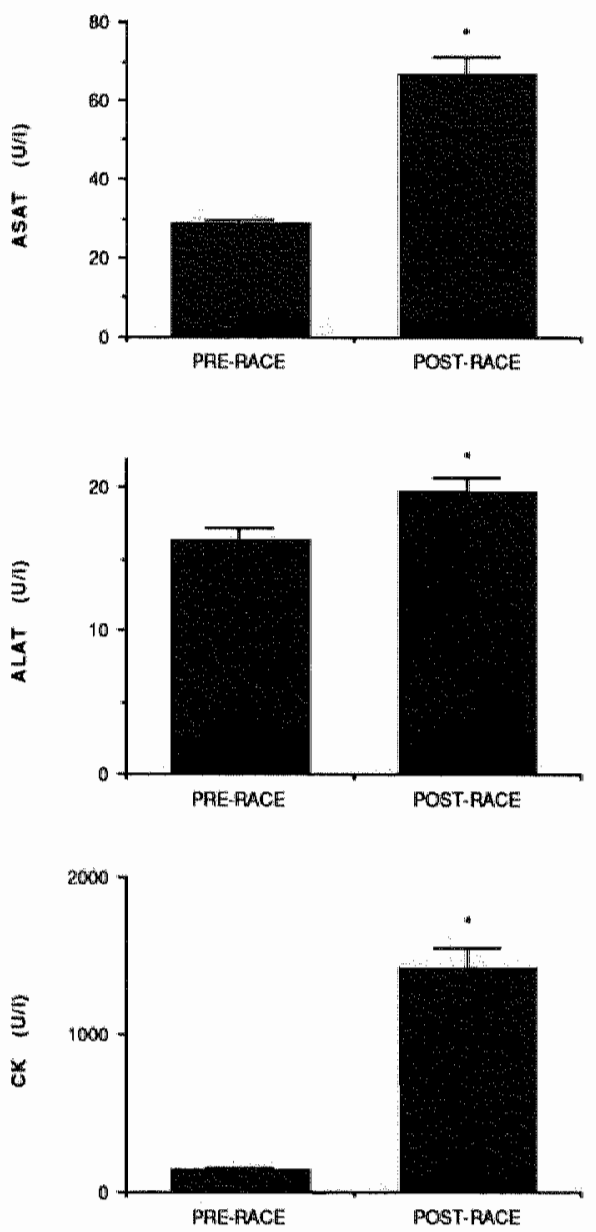

Fig. 2. Plasma skeletal muscle and liver enzyme activities. All post-race activities were significantly elevated $(p<05)$. 
Plasma glucose was not significantly altered after the race (5.7 $\pm 0.1 \mathrm{mmol}^{-1}$ ) compared with resting, pre-race values $(5.2 \pm$ 0.1 mmol. $1^{-1}$ ). Gastrointestinal hormone concentrations in plasma are presented in Table 3. All Gl hormones assayed were observed to be significantly increased post-race. The post-race concentrations of these hormones approach levels that in rest. would be considered pathological.

Table 3. Gl hormones

Pre-race Post-race

$\begin{array}{lcr}\left.\text { Gastrin (ng.1 }{ }^{-1}\right) & 71.6 \pm 11.9 & 159.6 \pm 17.8^{*} \\ \left.\text { VIP (ng.1 }{ }^{-1}\right) & 28.8 \pm 2.6 & 224.3 \pm 20.1^{*} \\ \text { Motilin (ng.1 }{ }^{-1} \text { ) } & 146.4 \pm 13.0 & 214.1 \pm 15.1^{*} \\ \text { PHI (ng. } 1^{-1} \text { ) } & 37.7 \pm 2.5 & 311.1 \pm 27.5^{*}\end{array}$

* Significant post-race increase $(p<.05)$.

Plasma epinephrine, norepinephrine, (Fig. 3) and cortisol concentrations (Fig. 4) were significantly increased post-race. Post-race plasma cortisol concentrations were significantly correlated with lower (faster) finishing times.

\section{Correlation of parameters with GI symptoms}

No correlation between body weight change and prevalence of GI distress was observed. The mean plasma volume decrease was $11 \pm 3 \%$ in those with GI complaints and $6 \pm 2 \%$ in those without. Although this apparent difference was not significant, the trend is in line with earlier observations.

There was, however, no correlation found between the amount of fluid ingested during the course of the race and GI symptoms. 
Chapter 9
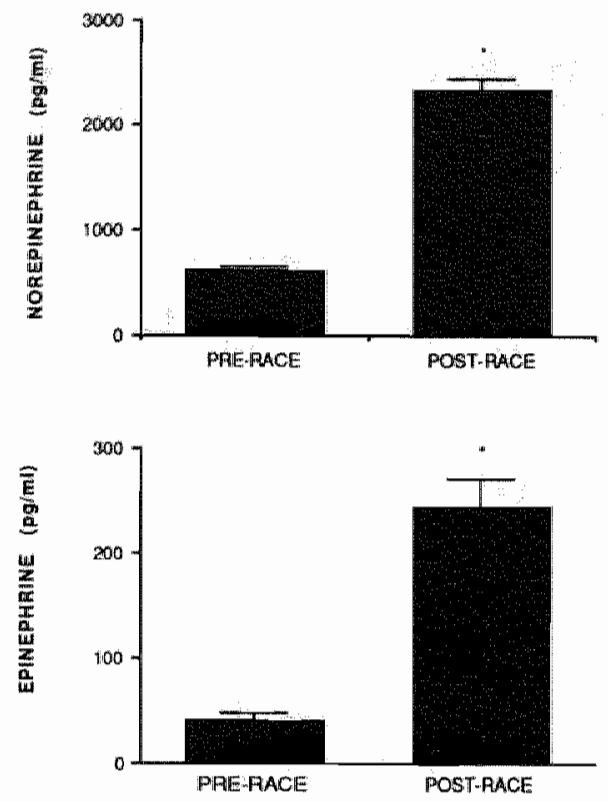

Fig. 3. Plasma epinephrine and norepinephrine concentrations. Postrace concentrations of both catecholamines were significantly increased $(p<.05)$.

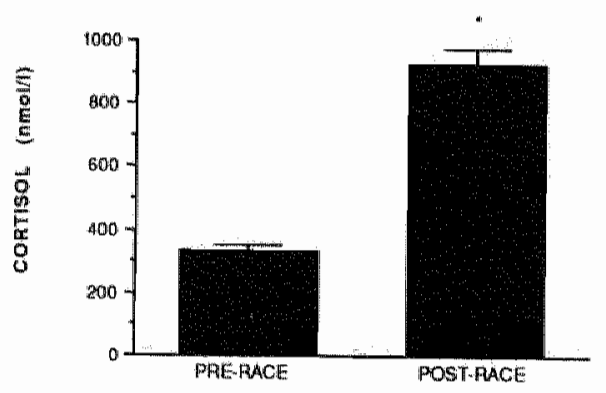

Fig. 4. Plasma cortisol concentrations. Post-race concentration was significantly increased $(p<.05)$. 
Also no correlation with quantity of any one of the carbohydrate-containing sport drinks offered with prevalence of GI complaints was observed. Also no direct correlation with total amount of $\mathrm{CHO}$ ingested, from the two sources provided by the organization, with GI complaints was observed. Since the composition of other beverages consumed, not provided by the organization, varied widely no analysis of the effects of these beverages could be carried out.

The rise in GI hormones in the plasma after the race (measured as difference from rest value) was not different in the sufferers versus the non-sufferers.

There was a trend for post-race norepinephrine to be less in sufferers $(2047 \pm 139)$ than in non-sufferers $(2559 \pm 190)$ $(p=.08)$ and the difference from rest value to be less in sufferers $(\mathrm{p}=.06)$. Comparing plasma values in sufferers by specific complaints, a trend was observed for those individuals with diarrhoea to have lower pre-race epinephrine levels. Individuals with intestinal cramp had significantly lower prerace cortisol (Fig. 5) as well as post-race norepinephrine (Fig. 6). Greater post-race plasma potassium concentration was also observed in the group which experienced GI distress. This difference was significant if individuals with "side-ache" were excluded (Fig. 7). No difference in plasma sodium or chloride changes was observed between sufferers and non-sufferers.

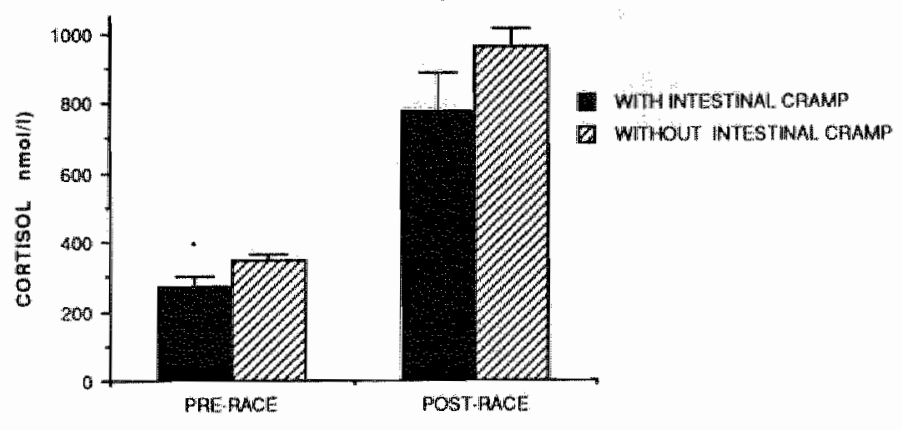

Fig. 5. Cortisol concentrations in individuals with and without intestinat cramp. Premace cancentration was lower in individuals with cramp $(p<.05)$ 


\section{Chapter 9}

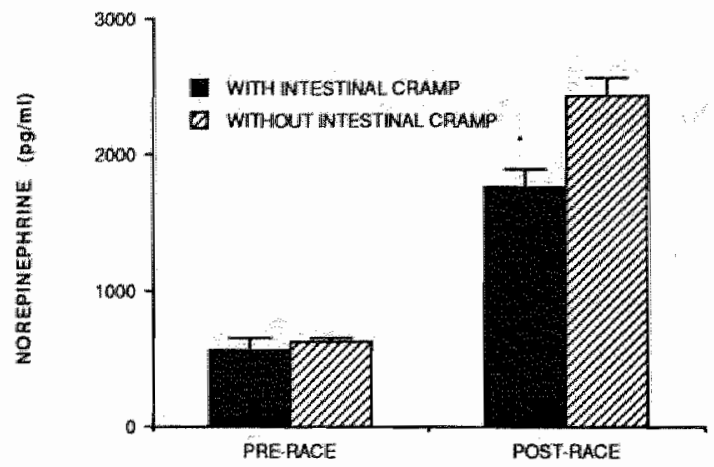

Fig. 6. Norepinephrine concentrations in individuals with and without intestinal cramp. Post-race concentration was lower in individuals with cramp $(p<.05)$.

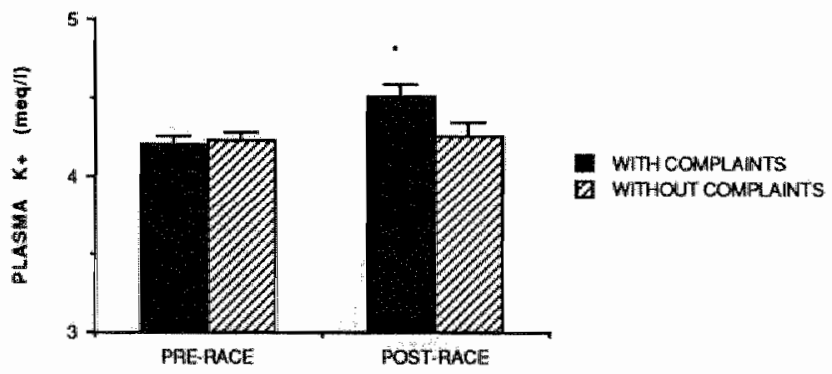

Fig. 7. Plasma potassium concentrations in individuals with and without GI symptoms. Post-race concemtration was greater in individuals with symptoms $(p<.05)$. 


\section{Discussion}

The prevalence of GI disturbance among ultra-marathon runners surveyed is similar to that reported among marathon runners (Keeffe et al., 1984; Rehrer et al., 1989). Similarly, the body weight losses measured as a result of this $67 \mathrm{~km}$ foot-race were similar to those reported as a result of marathon competition (Rehrer et al., 1989), despite the fact that the time to run this race was approximately double that taken to run a marathon. Accounting for this discrepancy are two factors. One is that fluid intakes were greater during this endurance race, approximately 31 , versus 0.51 , which has been measured in marathon runners, when weight losses were similar (Rehrer et al., 1989). Another difference is that running speed was lower during the ultra-marathon which would, under similar weather conditions, result in decreased sweat rates. Overt hyperthermia was not observed; the (cool) weather conditions and reduced running intensity probably also contributed to maintenance of normal temperature regulation.

Despite similar weight losses, the relationship noted in marathon runners between body weight loss (level of dehydration) and GI distress was not found in this group of ultra-marathon runners. Plasma volume changes, however, point at a relationship between dehydration and GI symptoms. Other factors, which may or may not be coupled with fluid intake, may also influence the prevalence of GI symptoms.

If glucose is limited at a membrane/tissue level the ionic pump may be impaired resulting in the accumulation of $\mathrm{Nat}$ collects intracellularly and $\mathbb{K}^{+}$extracellularly from active muscle tissue, where glycogen is depleted. It is a fine coupling of electrolytes with glucose transport that maintains cellular homeostasis, substrate availability, and cell/membrane integrity. The increase in post-race plasma $\mathrm{K}^{+}$concentration supports the idea of a pump inhibition or inability to keep pace with the repeated stimulation (primarily in skeletal muscle) as a result of longlasting, moderately intense exercise. In this situation intracellular reaccumulation may not keep pace with the $\mathrm{K}^{+}$ released through repolarisation. Since a $3-5 \mathrm{~min}$ delay occurred 
before sampling and since samples were taken from a peripheral vein, these values may be lower than what would be found during or immediately after cessation of exercise at a sampling site close to the largest mass of exercising musculature (eg. femoral vein). Return to normal plasma $\mathrm{K}^{+}$values after short-term, intense exercise occurs very quickly after exercise is stopped. After exercise which results in plasma values ranging from 8-10 $\mathrm{mM}$, plasma $K^{*}$ returns to pre-exercise values in 3 min (Sejersted and Medbo, 1989). The quick recovery after the cessation of exercise is accounted for by an increased blood flow to the musculature which was not involved in the exercise and uptake in inactive muscles simultaneously with a decreased $\mathrm{K}^{+}$ leak when exercising muscles cease exercising. Thus, the plasma $\mathrm{K}+$ concentrations measured may not reflect the extent of an increase that may have been present during exercise.

Several other explanations for the larger increase in plasma $\mathrm{K}^{+}$ concentration, observed in subjects with GI distress, are possible. An increased utilization of liver and muscle glycogen in those individuals may have contributed to the plasma $\mathrm{K}^{+}$ increase since $\mathrm{K}^{+}$is stored with glycogen (Fenn, 1940). Also, skeletal muscle, liver, or red blood cell damage (Davidson, 1969) may contribute to an increased plasma $\mathrm{K}^{+}$concentration. In the present study, however, CK, ASAT, and ALAT activities, indicating tissue damage, were not found to be increased in those individuals with GI disturbance above levels found in those without these symptoms, and yet plasma $\mathrm{K}^{+}$concentration was greater in those with symptoms. Thus, differences in skeletal muscle or liver damage are unlikely to explain the difference in plasma $\mathbb{K}^{+}$concentration in those with Gll symptoms.

The relationship between the presence of GI distress and the increased plasma $\mathrm{K}^{+}$concentration remains unclear. This finding may be related to the fact that potassium has a concentration dependent effect on circular and longitudinal muscles of the duodenum (Kimura et al., 1984). It is also possible that the increased plasma $\mathrm{K}^{+}$concentrations observed in sufferers is not directly causing the GI distress. It may be that the metabolic milieu (eg., glycogen store, training status, exercise intensity) in 
these individuals is such that both increased plasma $\mathbb{K}^{+}$ concentration and increased risk of GI disturbance occur.

Carbohydrate consumption was rather low (approximately 124 $\mathrm{g}$, based upon mean intakes of the two carbohydrate containing drinks at designated aid stations). This may have contributed to a faster glycogen depletion in working muscles and a localised glucose shortage. Although plasma giucose levels are maintained this does not necessarily reflect the substrate availability at a cellular or tissue level.

The fact that in this study dehydration level (body weight loss) was not correlated with GI dysfunction may reflect the difference in rehydration solutions consumed. In an early study of marathon runners where this relationship was observed (Rehrer, 1989), supplementation was almost exclusively with a beverage containing carbohydrate and electrolytes. In the present study more than half of the fluid consumed was plain water. Although it has been shown that dehydration alters GI physiology and may play a role in the development of GI distress, particularly when it results in hyperthermia, the influence may not be a direct one. As Hubbard has outlined in the "energy depletion model for hyperthermia" (Hubbard et al., 1987), the effects observed may be brought about by insufficiency of the ionic pump and energy depletion at a cellular level. Ionic pumping $\left(\mathrm{Na}^{+} / \mathrm{K}^{+}\right.$in skeletal muscle and $\mathrm{H}^{+} / \mathrm{K}^{+}$in gastric mucosal membrane (Schrijen, 1981) maintains the function and integrity cells. It is proposed that increased temperature increases the energy demand and increases the demand for ionic pumping. When ionic pumping cannot meet the demands it may further result in insufficient glucose pumping and energy deficit whereby the rate of pumping is then further reduced. Alternatively, when available glucose is limited the rate of ionic pumping is also limited. This may explain why muscular fatigue is concomitant with an increased extracellular (plasma) $\mathrm{K}^{+}$concentration (Sejersted and Melbo, 1989; Sjogaard, 1989).

The trend for post-race norepinephrine values to be less in sufferers than in non-sufferers may be a result rather than a cause of GI disorder. Runners experiencing these symptoms may slow down their pace and thus norepinephrine levels later in 


\section{Chapter 9}

the race may not be as high as those who maintain ruming at a higher intensity since norepinephrine levels are known to be higher as exercise intensity increases (Galbo et al., 1977). There is also the possibility that these subjects were overtrained, which may result in depression of the pituitary-adrenocortical system. It is also possible to speculate that the difference in GI symptoms relative to the catecholamine response may be related to the fact that norepinephrime and epinephrine stimulate absorption of glucose and sodium in the intestine (Aulsebrook, 1965), so that those with a normal catecholamine response are better able to utilise ingested fluids and carbohydrate.

The significance of the fact that the runners who suffered from intestinal cramp had lower resting plasma cortisol levels is uncertain and can only be speculated upon. Individuals with lower cortisol levels may be less able to adapt to a high level of energy expenditure. Fat utilization as well as liver glycogenolysis and gluconeogenesis are stimulated by cortisol (Galbo, 1983) which serves to potentiate catecholamine functions (Lamberts et al., 1975). GI symptoms may arise in response to a reduction in available substrate to GI tract tissues. Supporting this idea is the fact that strength and work capacity have been observed to be decreased with adreno-corticosteroid insufficiency (Korge and Roosson, 1975). In individuals with Addison's disease abdominal pain and diarrhoea are common. These symptoms have been attributed to cortisol deficiency (Jensen, 1976). The difference in cortisol concentrations in rest in these two groups may also reflect a difference in training status. Trained subjects, given the same relative work load, often have higher cortisol concentrations in plasma (Bloom et al., 1976). Training status has been pointed to as one of the factors influencing the prevalence of GI symptoms in runners, less well-trained runners thaving more problems (Brouns et al., 1987). On the other hand it must also be considered that the subjects with low plasma cortisol concentrations before the race are over-trained. Overtraining syndrome has been characterised by lower plasma cortisol levels and a decreased cortisol response to exercise, among other metabolic adaptations (Kuipers and Keizer, 1988). 
Thus it may be that the lower pre-race cortisol concentrations in runners with intestinal cramps are less well trained or overtrained, and that the cramp is not a direct consequence of the plasma cortisol concentrations.

When finishing time is used as an indication of exercise intensity, there is no difference between those with GI symptoms and those without. Finishing time, however is a measure of absolute intensity and it may be that relative intensity is different in the two groups.

Concentrations of all GI hormones measured increased after the race, as has been observed in marathon runners. (Riddoch, 1990). There was, however, no correlation of rise in any of the GI hormones and the occurrence of GI symptoms. The rise in GI hormones may be more metabolic, in response to the energy demands, rather than specifically being related to alteration in GI function. For example, VIP stimulates lipolysis (Frandsen and Moody, 1973), glycogenolysis and gluconeogenesis (Matsumura et al., 1972). Supporting the idea that energy demands stimulate this increase is the fact that increases in plasma VIP concentrations have been observed during starvation and energy deficiency as well as during prolonged exercise (Oktedalen et al., 1983). Also, supporting the metabolic role of VIP is the lack of change in plasma concentrations during short term moderate to intense physical exercise $\left(60-100 \% \mathrm{VO}_{2} \mathrm{max}\right)$ but significant rise in long term exercise (Galbo, 1979).

Plasma activities of the enzymes CK, ASAT, and ALAT were all significantly elevated after the race, indicative of tissue damage. The CK activities observed $3.5 \mathrm{~min}$ after finishing this ultramarathon were comparable to values found $24 \mathrm{~h}$ after a marathon (Janssen, 1988). It may be assumed that these plasma activities would continue to rise for $24 \mathrm{~h}$ after the race (Apple et al., 1985). The high enzyme activities can be attributed to the large eccentric component of running downhill and the length of the race. Ewen running on a level surface includes an eccentric component, which, if carried on for long enough and at a high enough intensity, results in a rise in plasma activity of these enzymes. Also the steepest and largest amount of downhill running occurs after $50 \mathrm{~km}$. It can be assumed that glycogen 
deposits in the dominant working muscle fibres are depleted at this time. This may increase the amount of tissue damage occurring as a result of the continued (downhill) running due to a larger stress on the elastic components of the muscles (Thomson et al., 1975). The question remains whether greater carbohydrate supplementation during exereise can prevent or decrease the amount of tissue damage. Further it is questioned if the relationship obserwed between higher post-race plasma $\mathrm{K}^{+}$ concentration and $\mathrm{GI}$ distress reflects another consequence of cellular energy depletion and if endogenous carbohydrate supplementation can reduce the prevalence of these symptoms. 


\section{References}

1. Apple, F.S., M.A. Rogers, D.C. Casal, W.M. Sherman and I.L. Ivy. Creatine kinase-MB isoenzyme adaptations in stressed human skeletal muscle of marathon runners. J. Appl. Physiol. 58: $149-153,1985$.

2. Aulsebrook, K.A. Intestinal absorption of glucose and sodium: effects of epinephrine and sodium. Biochem. Biophys. Res. Com. 18:165-169, 1965.

3. Bloom, S.R., R.H. Johnson, D.M. Park, M.J. Rennie and W.R. Sulaiman. Differences in the metabolic and hormonal response to exercise between racing cyclists and untrained individuals. J. Physiol. 258: 1-18, 1976

4. Brouns, F, W.H.M. Saris and N.J. Rehrer. Abdominal complaints and gastrointestinal function during long-lasting exercise. Int. J. Sports Med. 8: 175-189, 1987.

5. Davidson, R.J.L. March or exertional haemoglobinurea. Seminars in Haematology 6: 150-161, 1969.

6. Dill, D.B. and D.L. Costill. Calculation of percentage changes in blood volumes of blood, plasma, and red cells in dehydration. J. Appl. Physiol. 37: 247-248, 1974.

7. Fenn, W.O. The role of potassium in the physiological processes. Physiol. Rev. 20: 377-415, 1940.

8. Fogoros, R.N. Gastrointestinal disturbances in runners. "Runners trots" JAMA 243: 1743-1744, 1980.

9. Frandsen, E.K. and A.J. Moody. Lipolytic action of a newly isolated vasoactive polypeptide. Horm. Metab. Res. 5: 190-199, 1973.

10. Frey, W.O. Wasser- und Electrolyte Haushalt bei extremer Ausdauerleistung, am Beispiel bis Alpine Marathon. Ph.D. Thesis, University of Zurich, Zurich, Switzerland, 1988. 
11. Galbo, H. Hormonal and metabolic adaptation to exercise. George Thieme Verlag, New York, Stuttgart p. 5, 1983.

12. Galbo, H., J. Hilsted, J. Fahrenkrug and O.B. Schaffilitzky de Muckadell. Fasting and prolonged exercise increase vasoactive intestinal polypeptide (VIP) in plasma. Acta Physiol. Scand. 105: $374-377,1979$.

13. Galbo, H., E.A. Richter, J. Hilsted, J.J. Holst, N.J.Christensen and J. Henriksson. Hormonal regulation during prolonged exercise. N.Y. Acad. Sci. 301: 72-80, 1977.

14. Hubbard, R.W., C.B. Matthew, M.J. Durkot and R.P. Francesconi. Novel approaches to the pathophysiology of heatstroke: the energy depletion model. Ann. Emerg. Med. 16: 1066-1075, 1987.

15. Janssen, G.M.E. Marathon running. Functional changes in male and female volunteers during training and contests. Ph.D. Thesis, University of Limburg, Maastricht, The Netherlands p. $106,1988$.

16. Jensen, D. The principles of physiology. Appleton-CenturyCrofts, New York p. 1117, 1976.

17. Keeffe, E. B., D. K. Lowe, J. R Goss et al. Gastrointestinal symptoms of marathon runners. West J. Med. 141: 481-484, 1984.

18. Kemenade M. van, W. Meester and N. J. Rehrer. Voeding in relatie tot maag-darmklachten bij de triathlon. Ned. Tijd. Diët. 44: 8-12, 1989.

19. Kimura, I. and M. Kimura. Potassium induces relaxation and hyperpolarization of circular muscles but contraction of longitudinal muscles of pig duodenum. Br. J. Pharmac. 83: 187$193,1984$. 
20. Korge, P. and S. Rooson. The importance of adrenal glands in the improved adaptation of trained animals to physical exertion. Endokrinologie 64: 232-238, 1975.

21. Kuipers, H. and H.A. Keizer. Overtraining in elite athletes. Review and directions for the future. Sports Med. 6: 79-62, 1988.

22. Lamberts, S.W.J., H.A.T. Timmermans, M. KamerBlankenstijn and I.C. Birkenhager. The mechanism of the potentiating effect of glucocorticoids on catecholamine induced lipolysis. Metabolism 24: 681-689, 1975.

23. Matsumura, M, H. Akiyashi and S. Fujji. Effects of gastrointestinal and related hormones on glycogenolysis and gluconeogenesis in cultured liver cells. J. Biochem. 82: 1073$1076,1972$.

24. Neufer, P.D., A.J. Young and M.N Sawka. Gastric emptying during exercise: effects of heat stress and hypohydration. Eur. J. Appl. Physiol. 58: 433-439, 1989.

25. Oktedalen, O., P.K. Opstad, J. Fahrenkrug and F. Fonnum. Plasma concentration of vasoactive intestinal polypeptide during prolonged physical exercise, calorie supply deficiency and sleep deprivation. Scand. J. Gastroenterol. 19: 59-64, 1983.

26. Rehrer, N.J., G.M.E. Janssen, F. Brouns and W.H.M. Saris. Fluid intake and gastrointestinal problems in runners competing in a $25-\mathrm{km}$ race and a marathon. Int. J. Sports Med. 10 (suppl 1): S22-S25, 1989.

27. Rehrer, N.J., E.J. Beckers, F. Brouns, F. ten Hoor and W.H.M. Saris. Effects of dehydration on gastric emptying and gastrointestinal distress while running. Med. Sei. Sports Exerc. 22: (in press), 1990. 
28. Riddoch, C. Exercise induced gastrointestinal symptomshormonal inwolvement. Ph.D. Thesis, The Queen's University of Belfast, 1990.

29. Schrijen, J.J. Structure and mechanism of gastric $\left(\mathrm{K}^{+} / \mathrm{H}^{+}\right)$ ATPase. Ph.D. Thesis, University of Nijmegen, Nijmegen, The Netherlands, 1981.

30. Sejersted, O.M. and J.I.Medbo. Plasma potassium changes with high intensity dynamic exercise (abstract). Int. J. Sports Med. 10: S98-S99, 1989.

31. Sjogaard, G. Exercise induced potassium fluxes and postexercise recovery (abstract) Int. J. Sports Med. 10: S99-S100, 1989.

32. Smedes, F, J.C. Kraak and H. Poppen. Simple and fast solvent extraction system for selective and quantitative isolation of adrenaline, noradrenaline, and dopamine from plasma and urine. J. Chrom. 231: 25-39, 1982.

33. Thomson, W.H.S., J.C. Sweetin and I.J.D. Hamilton. ATP and muscle enzyme efflux after physical exertion Clin. Chem. Acta 59: $241-245,1975$. 


\section{CHAPTER 10}

\section{Gastrointestinal complaints in relation to dietary intakes in triathletes}

\section{Abstract}

Gastrointestinal (GI) symptoms are common among endurance athletes. This article deals with the relationship between symptoms and dietary intakes in triathletes. Several studies have reported on the prevalence of GI problems among marathon runners. These problems apparently occur more frequently in runners than in practitioners of other more "gliding" sports, such as bicyclists. In this study triathletes were surveyed since competition includes both bicycling and running and a wide variety of both fluids and solid foodstuffs are commonly ingested. Type and frequency of GI symptoms, and quantity and quality of ingested fluids and solids in relation to these symptoms were surveyed. Components of the race-day diet which were associated with GI distress were increased percentage of fat, protein and fibre in the diet, and hypertonic, carbohydrate containing beverages.

\section{Introduction}

Gastrointestinal (GI) symptoms frequently occur in endurance athletes. Numerous surveys and case studies have given evidence that these symptoms occur regularly in long-distance runners. Among marathon runners a prevalence of $30-50 \%$ has been reported $(6,13,21,26)$. The most prominent symptoms reported include nausea, vomiting, stomach ache, intestinal cramps, and diarrhoea. In addition to these complaints are the less severe complaints of abdominal bloating, eructation, and flatulence. 
Although symptoms are commonly reported in runners, very little information is available as to prevalence among practitioners of other endurance sports, where intensity and exercise time are similar. The paucity of reports of GI symptoms among bicyclists, cross-country skiers, speed skaters, etc. may lead one to conclude that these symptorns are not as common a problem in these types of sports where concussions are less. The common practice of cyclists and skiers eating solid food immediately prior to and during competition, whille runners often abstain, supports the idea that the type of movement plays a role in GI function during exercise and development of GI symptoms. Numerous other factors have been reported as possibly having an influence on the development of GI symptoms during exercise. These include nutritional factors (2), stress factors (1), hydration status $(10,14)$, and changes in GI function as a result of these and possibly other stimuli.

The present study was designed to evaluate the possible relationship between race-day nutritional intakes in triathletes and prevalence of GI complaints. Triathletes were chosen to study since both bicycling and running are included in competition, and because a wide variety of solid food as well as fluids are commonly ingested.

\section{Materials and methods}

A retrospective telephone survey was conducted with triathletes contacted via triathlon clubs in The Netherlands and Belgium. Data were gathered concerning the most recent halftriathlon completed. Data were collected from half-triathlon competition, instead of full triathlon competition, to increase sample size and decrease the time-lag between competition and the survey, since typically, more half-triathlons are completed in a year. A half-triathlon includes $1.9 \mathrm{~km}$ swimming, followed by $90 \mathrm{~km}$ bicycling, and thereafter, $21.1 \mathrm{~km}$ running.

A questionnaire was read to subjects over the telephone which included questions of quantity and composition of fluids and solids ingested on race day, prior to and during competition. A list of GI symptoms was included and, if one or more had occurred, the time of occurrence was noted. 
In addition, the finishing time of the race in question, the best half-marathon time, and data regarding training status, and personal statistics (age, height, and weight) were collected. Data were only collected from males and no selection was made as to age.

The amounts of food and drink consumed were asked in household measures. For the calculation of nutritional composition of the dietary intakes the Dutch Nutritional (NEVO) Tables (11), a computer program designed to calculate amounts macro- and micro-nutrients in foodstuffs, and information from producers of particular products were used. Percent energy, carbohydrate, fat, and protein, in addition to total amounts of solid food in grams and liquids in milliliters were calculated per pre-determined periods. The race day was divided up into ten periods: 1.) breakfast, 2.) after breakfast until $30 \mathrm{~min}$ prior to the start, 3.) the last half hour before the start, 4.) while swimming, 5.) between swimming and bicycling, 6.) bicycling (first half), 7.) bicycling (second half), 8.) between bicycling and running, 9.) while running, and 10.) immediately following the race (within $15 \mathrm{~min}$ after the finish). In the final calculations, periods 5 and 6 as well as 8 and 9 were combined because very little was consumed between swimming and bicycling and between bicycling and running. The occurrence of unintentional water intake during swimming was noted since ingested pollutants or other components of the swimming water may result in GI disturbance.

Osmolality of all types of drinks consumed by the triathletes prior to and during competition was tested in the laboratory using the freeze-point method (Osmomat 030, Gonotech, Berlin, Germany). Carbohydrate content of the various beverages as consumed was determined using manufacturers specifications with correction being made for dilution deviations. The osmolality and carbohydrate content of the various drinks consumed are displayed in Table 1. Comparisons were made using the Mann-Whitney and Chi square tests with a confidence intervall of $95 \%$. 
Table 1. Osmolality and carbohydrate content of beverages consumed during the half-triathlon.

\begin{tabular}{lll}
\hline Product & $\begin{array}{l}\text { Osmolality } 1 \\
\left(\mathrm{mOsm}_{\mathrm{kg}} \mathrm{kg}^{-1}\right)\end{array}$ & Carbohydrate $^{2}$
\end{tabular}

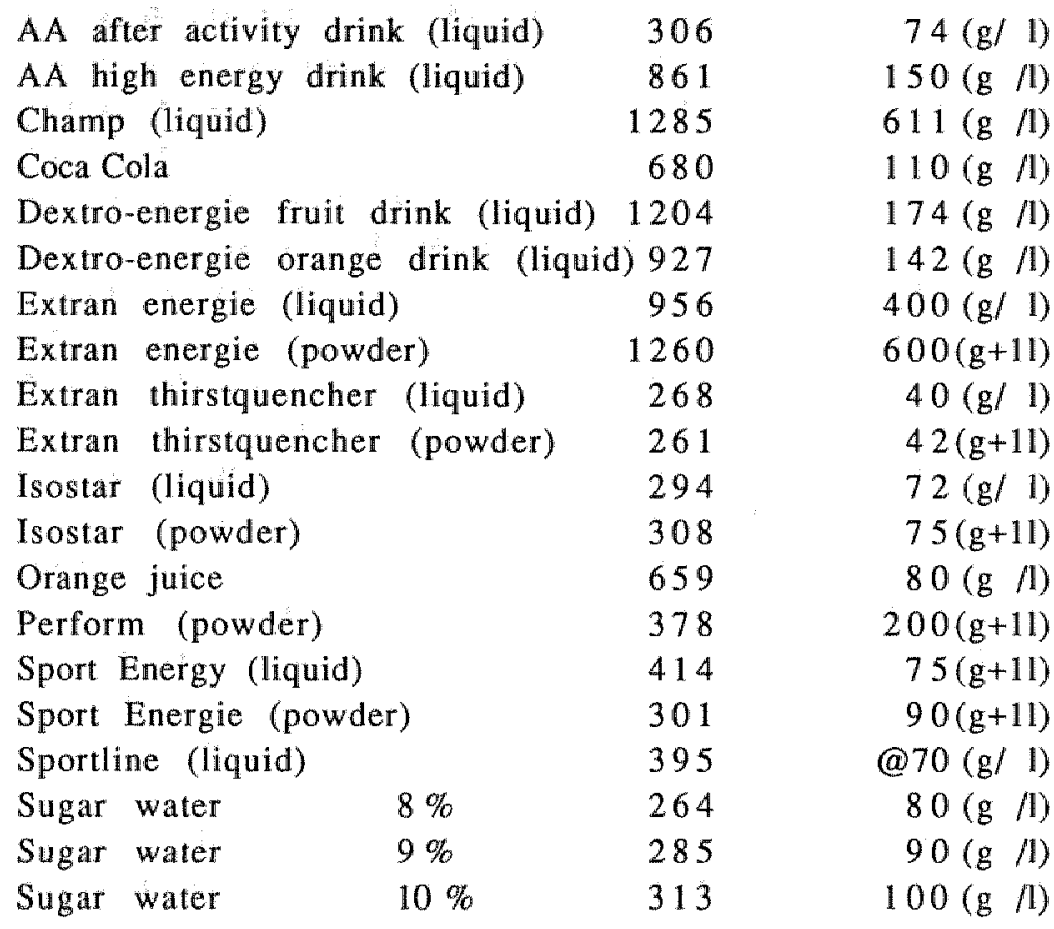

1 Osmolality of beverages was measured both in the laboratory of the Department of Human Biology at the University of Maastricht and at the Central Toxicology and Nutrition Institute. CIVO-TNO, in Zeist.

2 Carbohydrate content was based upon the manufacturer's declaration and how the product was prepared by the athlete. The designation $(g+1 l)$ was used to denote $g$ of carbohydrate added to 1 full litre. 
All GI complaints were noted. "Severe" complaints included nausea, vomiting urge, vomiting, stomach ache, intestinal cramps, and diarrhoea. "Non-severe" complaints included eructation, flatulence, and abnormal pressure (bloating) in the abdominal region. Difference in timing of meals was evaluated in relation to the occurrence of GI problems.

\section{Results}

\section{Subjects}

Fifty-seven subjects participated in the survey. Fifty-five were included in the data set. Two were excluded, one because of his training status (more than two standard deviations less than the mean) and one because of insufficient data. Mean age, weight, and training status for the total group and for those with and without GI symptoms are given in Table 2. No significant differences were observed in the prevalence of GI symptoms relative to subject characteristics or hours spent training. Similarly when those with severe GI symptoms were set apart, no differences were observed.

Table 2. Mean age, height, weight, and average training time per week

Total group With GI symptoms Without symptoms

mean SD mean SD mean SD

$\begin{array}{lrrrrrr}\text { Age (yr) } & 31 & 6 & 30 & 5 & 31 & 6 \\ \text { Height (cm) } & 179 & 13 & 181 & 7 & 180 & 6 \\ \text { Weight (kg) } & 74 & 7 & 72 & 7 & 75 & 7 \\ \text { Swimming (h) } & 3.4 & 1.4 & 3.2 & 1.1 & 3.6 & 1.6 \\ \text { Bicycling (h) } & 8.3 & 2.8 & 8.3 & 2.7 & 8.4 & 3.0 \\ \text { Running (h) } & 5.0 & 1.8 & 4.4 & 1.3 & 5.6 & 2.0\end{array}$

There were no significant differences between the groups. 
Forty-nine percent of the triathletes surveyed had one or more GI symptom. Twenty-nine percent had one or more severe symptom. Complaints were most common during running and were least common during swimming (Table 3). The prevalence of specific severe complaints is displayed in Fig. 1. The most common complaints were the less disturbing symptoms of eructation and flatulence. Furthermore, these two complaints were more often than not accompanied by one or more severe complaint. Further results regarding the correlation of GI symptoms with intake is henceforth limited to those complaints listed as severe.

Table 3. Prevalence of GI complaints among all triathletes surveyed $(n=55)$

$\begin{array}{lll} & \mathrm{n} & \% \\ \text { GI complaint } & 27 & 49\end{array}$

Severe

GI Complaint ${ }^{1}$

swimming

bicycling

running

Including individuals who had one or more symptom.

\section{Upper GI tract symptoms}

In the last half hour prior to the race a greater percentage of fat was consumed by those individuals with a vomiting urge than by those without these symptoms $(9 \%, 1 \%$, resp. $\mathrm{p}<.05)$. A similar trend was observed in those who vomited $(10 \%, 1 \%$, resp. $p=.12)$. There was also a trend for mean protein intake to be greater in individuals with an urge to vomit $(11 \%)$ and individuals who vomited $(14 \%)$ than in those without these symptoms (1\%). 


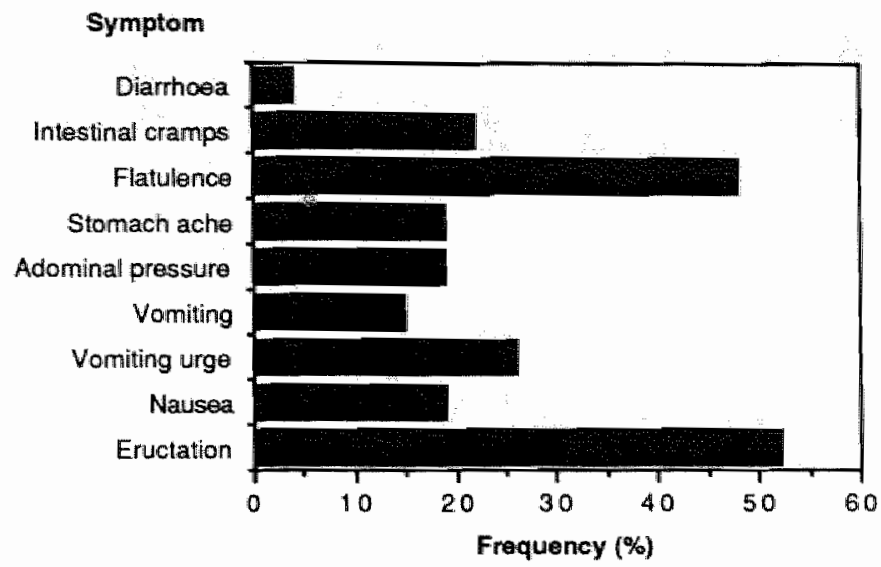

Fig. 1. Distribution of GI symptoms in triathletes with one or more symptom $(n=27)$.

A greater percentage of individuals who had a vomiting urge or vomited had consumed a hypertonic beverage $(>325 \mathrm{mOsm}$. $\mathrm{kg}^{-1}$ ) while bicycling (93\%) than among those without these symptoms $(40 \%) \quad(p<.05)$. Additionally, four of the five individuals with stomach cramps had also ingested a strongly hypertonic ( $>800 \mathrm{mOsm} . \mathrm{kg}^{-1}$ ) bewerage.

Solid food was more frequently consumed closer to the start of the race by individuals who vomited while swimming than those without this symptom. All athletes who vomited while swimming had eaten between breakfast and one-half hour before the start of the race, while only $27 \%$ of the athletes without this symptom had eaten in this time period. Similarly, $100 \%$ of the individuals who vomited had eaten in the last half hour before the start and only $14 \%$ of those without this complaint had eaten in this time period. A similar trend was seen in those with romiting urge while swimming.

\section{Lower Gl tract symptoms}

Fibre rich products (full-grain containing foodstuffs) were consumed in the last meal before competition by all triathletes who experienced intestinal cramps immediately after the race. Only $10 \%$ of those athletes without this complaint had eaten fibre rich products. 
Only one person had diarrhoea; he experienced this immediately after the race. Interesting to note is that this individual had consumed $200 \mathrm{~g}$ more solid food than the mean (Table 4). Forty percent of the 55 surveyed triathletes defecated prior to competition. No correlation between defecation prior to the race and GI symptoms during competition was found.

Table 4. Solid food consumption (g) during the half-triathlon in relation to GI symptoms

\begin{tabular}{|c|c|c|c|c|}
\hline \multirow[t]{2}{*}{ Symptom } & \multicolumn{2}{|c|}{ With symptom } & \multicolumn{2}{|c|}{ Without symptom 1} \\
\hline & mean & $\mathrm{SD}$ & mean & SD \\
\hline Nauseat & 325 & 224 & 500 & 237 \\
\hline Vomiting urge & 395 & 219 & 500 & 2.42 \\
\hline Vomiting & 240 & 268 & 500 & 232 \\
\hline Stomach ache & 395 & 215 & 495 & 242 \\
\hline Intestinal cramp & p 570 & 267 & 475 & 237 \\
\hline diarrhoea 2 & 705 & 0 & 480 & 239 \\
\hline
\end{tabular}

$I_{\text {No }}$ significant differences between groups were observed. ${ }^{2}$ Only one subject had diarrhoea.

Gl symptoms and beverage consumption

No relationship was observed between the amount of fluid consumed during the race and prevalence of any one symptom or GI symptoms in general (Table 5). A greater percentage of athletes who drank a hypertonic beverage ( $>325 \mathrm{mOsm} \cdot \mathrm{kg}^{-1}$ ) experienced GI disturbance (Table 6). There was a trend for individuals who drank a hypertonic beverage and experienced GI distress to have consumed a lesser total volume of fluids during the race $(2663 \pm 292)$ (mean \pm SE) than those who drank a hypertonic beverage but had no GI complaints (3632 \pm 439 ). 
Table 5. Beverage consumption (ml) during the triathlon in relation to GI symptoms

\begin{tabular}{lrrrr}
\hline Symptom & \multicolumn{2}{c}{ With symptom } & \multicolumn{2}{c}{ Without symptom ${ }^{1}$} \\
& mean & SD & mean & SD \\
Nausea & 1940 & 846 & 2210 & 917 \\
Vomiting urge & 1740 & 438 & 2250 & 941 \\
Vomiting & 1540 & 463 & 2220 & 914 \\
Stomach ache & 2380 & 1136 & 2160 & 892 \\
Intestinal cramp & 2340 & 1332 & 2160 & 858 \\
diarrhoea $^{2}$ & 2170 & 0 & 2180 & 915 \\
& & & & \\
\hline
\end{tabular}

$I_{\text {No }}$ significant differences between groups were observed. 2 Only one subject had diarrhoea.

Table 6. Frequency of severe GI complaints and osmolality of beverage

n

$\%$

Hypotonic/isotonic

$(<325 \mathrm{mOsm} / \mathrm{kg})$

$4 / 36$

11

Hypertonic 1

$(>325 \mathrm{mOsm} / \mathrm{kg}$ )

$8 / 19$

42

$I_{A}$ significant difference in frequency between hypo-lisotonic and hypertonic was observed $(p<.05)$. 


\section{Discussion}

The obserwed occurrence of severe gastrointestinal symptoms among triathletes during competition (29\%) concurs with earlier reports of GI disturbance in triathletes (25), marathon runners $(6,13,21,26)$, and ultra-marathon runners $(15,28)$. When the less severe symptoms of excessive eructation, flatulence, and abdominal bloating were included the prevalence increased to $49 \%$. The finding that severe complaints accurred more frequently during the running phase of competition than during either swimming or bicycling is possibly related to the mechanical jarring which is twice as large during running versus bicycling (16). Sullivan, having given triathletes a questionnaire regarding frequency of symptoms during both training and competition, found that the majority of respondents $(38 \%)$ only thad symptoms while running, and only $5 \%$ had similar symptoms in all three sports (25).

Results of the present study indicate that several components of the race-day diet may be related to GI symptoms. Increased amounts of protein, fat, and increased beverage osmolality, all factors which decrease gastric emptying, were correlated with an increased number of athletes with GI symptoms. Results of several studies indicate that average emptying rates vary widely between individuals $(12,14)$. When gastric emptying rates where compared in individuals who frequently experienced GI distress while running with those who did not, no significant differences in mean gastric emptying rate of a carbohydrate containing beverage during exercise was observed (17). Apparently, a slowed emptying rate, relative to one's norm, may be associated with problems of the upper Gl tract. This may possibly be related to effects of increased volume and pressure in the stomach, which may be further increased by gastric secretion. A positive correlation has been observed between gastric secretion and gastric residue osmolality (24) and there is evidence suggesting that gastric secretion is increased with increasing beverage osmolality $(5,18)$. Thus, with strongly hypertonic beverages, the larger remaining gastric volume, due to a reduced gastric emptying rate, may be further increased by increased gastric secretion. Hypertonic solution presence in the intestine is known to increase intestinal 
secretion (9). If the residue is still hypertonic upon reaching the intestine, increased intestinal secretion would be expected. Supporting our findings are reports from Maughan et al. (8) of Gl distress with strongly hypertonic beverage ingestion (1915 and 1945 mOsm. $\mathrm{kg}^{-1}$ ). If substantial amounts of carbohydrate are dumped into the intestine one may experience abdominal bloating and osmotic diarrhoea, in addition to vasomotor symptoms associated with a decrease in blood volume (23). Total fluid intake tended to be less in individuals who consumed hypertonic beverages and experienced GI disturbance. Lower fluid intakes may have resulted in dehydration. Although no indicators of fluid balance were measured, the possibility of dehydration is a distinct one, based upon the large body weight losses which have been measured in triathletes as a result of competition (19). In fact, Kreider et al. observed heat complications, coupled with abdominal and leg cramps, in five of nine triathletes during competition (7). This further supports the suggestion that dehydration/thermal stress may, in some situations, be related to the GI symptoms observed in endurance athletes.

Dehydration is known to decrease blood volume (20). Severe exercise reduces blood flow to the intestines (4). These two facts, taken logether, may account for the increase in GI disturbance observed when exercise and dehydration are combined. A reduced blood flow may be associated with intestinal ischaemia, which in turn may cause intestinal malabsorption of carbohydrates (27) and abdominal discomfort. In support of this is the fact that clinically diagnosed "intestinal angina" has been attributed to relative ischaemia (3), and that gut tissue specimens of marathon runners experiencing bloody diarrhoea show the same morphological changes as in the ischaemic gut (22).

The ingestion of hypertonic beverage, which increases gastrointestinal secretions, results in net fluid loss from the circulation. Thus the ingestion of a hypertonic beverage during exercise, in a dehydrated state, may have an effect on blood supply to the cells of the gastrointestinal tract. The actual mechanism which causes cramping is uncertain. Whether it is ischaemia, accumulated toxins, or intracellular/extracellular 
electrolyte imbalance which results in the symptoms observed can only be speculated upon.

In summary, triathlon competition carries with it the same risks as in marathon running in terms of gastrointestinal complications. More symptoms were reported during rumning than during either swimming or bicycling. Additionally the increased frequency of solid food consumption and with it increased intakes of fat, protein, and dietary fibre give evidence to support the idea that these specific dietary components may increase the risk of GI dysfunction. Increased beverage osmolality was also shown to be linked with GI symptoms. A possible link with dehydration was observed, the combination of hypertonic beverage ingestion and low fluid intake tended to increase the prevalence of severe symptoms. 


\section{References}

1. Barclay, G.R. and L.A. Turnberg. Effect of psychological stress on salt and water transportation in the human jejunum. Gastroenterology 93: 9197, 1987.

2. Brouns, F., W.H.M. Saris and N.J. Rehrer. Abdominal complaints and gastrointestinal function during long lasting exercise. Int. J. Sports Med. 8: 175-189, 1987.

3. Burns, G.P. and W.G. Schenk. Effects of digestion and exercise on intestinal blood flow and cardiac output. Arch. Surg. 98: 790$794,1969$.

4. Clausen, J.P., K. Klausen, B. Rasmussen et al. Central and peripheral circulatory changes after training of the arms or legs. Am. J. Physiol. 225: 675-682, 1973.

5. Costill, D.L. and B. Saltin. Factors limiting gastric emptying during rest and exercise. J. Appl. Physiol. 37: 679-683, 1974.

6. Keeffe, E.B., D.K. Lowe, J.R. Goss et al. Gastrointestinal symptoms of marathon runners. West. J. Med. 141: 481-484, 1984.

7. Kreider, R.B., T. Boone, W.R. Thompson, S. Burkes and C.W. Cortes. Cardiovascular and thermal responses of triathlon performance. Med. Sci. Sports Exerc. 20: 385-390, 1988.

8. Maughan, R.J., C.E. Fenn and J.B. Leiper. Effects of fluid, electrolyte and substrate ingestion on endurance capacity. Eur. I. Appl. Physiol. 58: 481-486, 1989.

9. Miller, T.G. Intestinal intubation. Cleveland Clin. Q. 16: 68, 1949.

10. Neufer, P.D., A.J. Young and M.N. Sawka. Gastric emptying during exercise: effects of heat stress and hypohydration. Eur. J. Appl. Physiol. 58: 433-439, 1989. 
11. NEVO: The Dutch Food Tables 1986-1987, NEVO-VoVo, The Hague, 1987.

12. Ramsbottom, N. and J.N. Hunt. Effect of exercise on gastric emptying and gastric secretion. Digestion 10: 1-8, 1974.

13. Rehrer, N.J., G.M.E. Janssen, F. Brouns and W.H.M. Saris. Fluid intake and gastrointestinal problems in runners competing in a $25-\mathrm{km}$ race and a marathon. Int. J. Sports Med 10 (suppl 1): s22-s25, 1989.

14. Rehrer, N.J., E.J. Beckers, F. Brouns, F. ten Hoor and W.H.M. Saris. Effects of dehydration on gastric emptying and gastrointestinal distress while running. Med. Sci. Sports Exerc. 22: (in press), 1990.

15. Rehrer, N.J., E.J. Beckers, F. Brouns, C. Riddoch, B. Villiger, P.P.C.A. Menheer, W. Frey and W.H.M. Saris. Gastrointestinal symptoms and physiological changes as a result of ultraendurance exercise. (in review).

16. Rehrer, N.J. and G. Meijer. Biomechanical vibration in running versus bicycling. J. Sports Med. 43: (in press), 1990.

17. Rehrer, N.J., F. Brouns, E.J. Beckers F. ten Hoor and W.H.M. Saris. Gastric emptying with repeated drinking during running and bicycling. Int. J. Sports Med. 11: 238-243, 1990.

18. Rehrer, N.J., E. Beckers, F. Brouns, F. ten Hoor and W.H.M. Saris. Training effects on gastric emptying of carbohydrate beverages. Med. Sci. Sports Exerc. 21: 530-539, 1989.

19. Rensburg, J.P., A.J. Kielblock and A. van der Linde. Physiologic and biochemical changes during a triathlon competition. Int. J. Sports Med. 7: 30-35, 1986.

20. Ribish, P.M. and W.G. Herbert. Effects of rapid weight reduction and subsequent rehydration upon the physical working capacity of wrestlers. Res. Q. 4: 536-641, 1970. 
21. Riddoch, $C$. and T. Trinick. Gastro-intestinal disturbances in marathon runners. Brit. J. Sports Med. 22: 71-74, 1988.

22. Schaub, N., H.P. Spichtin and G.A. Stalder. Ischämische Kolitis als Ursache einer Darmblutung bei Marathonlauf? Schweiz. Med. Wochenschr. 115: 454-457, 1985.

23. Sessions, R.T., V.H. Reynolds, J.L. Ferguson and H.W. Scott. Correlation between intraduodenal osmotic pressure changes and $\mathrm{Cr}^{51}$ blood volumes during induced dumping in men with normal stomachs. Surgery 52; 266-278, 1962.

24. Sole, C.C. and T.D. Noakes. Faster gastric emptying for glucose polymer and fructose solutions than for glucose in humans. Eur. J. Appl. Physiol. 58: 605-612, 1989.

25. Sullivan, N. Exercise induced symptoms in triathletes. Phys. Sports Med. 15: 105-108, 1987.

26. Sullivan, S.N. The gastro-intestinal symptoms of running. N. Engl. J. Med. 304: 915, 1981.

27. Williams, J.H., M. Mager and E.D. Jacobson. Relationship of mesenteric bloodflow on intestinal absorption of carbohydrates. J. Lab. Clin. Med. 63: 853-863, 1964.

28. Worobetz, L.J. and D.F. Gerrard. Gastrointestinal symptoms during exercise in enduro athletes: Prevalence and speculations in etiology. N.Z. Med. J. 98: 644-646, 1985. 


\section{CHAPTER 11}

\section{Discussion}

Supplementation with carbohydrate containing fluids is employed to prolong exercise and improve the performance of high intensity endurance exercise. Benefits to be obtained are:

1) maintenance of fluid balance (euhydration) and with it maintenance of plasma volume (which in turn influences stroke volume and peripheral circulation) and the sweating response to a thermal challenge

2) an increase in the availability of carbohydrate, the primary substrate for the muscle.

The work presented in this thesis has been designed to address aspects of gastrointestinal (GI) function during exercise, which influence the success in achievement of these stated objectives.

Included in this research were studies investigating the role of gastric emptying (GE) in supplementation. Gastric emptying has been touted as limiting the availability of orally ingested fluid, limiting the volume of water which is available for absorption and limiting the amount of carbohydrate available for oxidation. The amount of carbohydrate which is emptied per unit time is suggested to be constant regardless of carbohydrate concentration (McHugh and Moran, 1979; Brener et al., 1983). Further, gastrointestinal symptoms related to endurance exercise were characterised and the relationship with metabolic and physiological changes that occur during exercise was explored. Acute effects of diet on GI symptoms and a number of possible mechanisms involving alterations in GI function have been noted.

Results of the studies herein described support the notion that gastric emptying rate is important in regulating fluid and carbohydrate availability. However, GE is not the only factor which determines the rate of assimilation of ingested water into body water or the rate at which ingested carbohydrate is oxidised. Although later phases of digestion and metabolism 
further delay or limit the incorporation of substrate and fluid, gastric emptying can initially delay emptying of a beverage to such a degree that what occurs at later stages is already largely influenced. This is supported by the results of the experiments presented in Chapter 7 in which, after ingestion of a $17 \%$ glucose or maltodextrin solution approximately one-third of the amount ingested was still in the stomach at the end of the experiment. The present studies could not support the contention that CHO delivery to the intestine is constant. Although the volume emplied with a less concentrated solution was greater than with a more concentrated glucose solution, the amount of CHO passing through the pylorus was still observed to vary greatly with different carbohydrate solutions (Chapter 2).

\section{FACTORS WHICH INFLUENCE GASTRIC EMPTYING}

\section{Training}

With regard to the factors which influence gastric emptying of beverages during exercise, the following observations have been made. There appears to be no effect of training on gastric emptying of fluids during exercise. No difference was observed between trained bicyclists and untrained individuals in emptying $8 \mathrm{ml} . \mathrm{kg}-1 \mathrm{BW}(\sim 600 \mathrm{ml})$ of different carbohydrateelectrolyte containing beverages or water (Chapter 2).

These results are in opposition to those of Carrio et al. (1989) who found that well-trained marathon runners had faster gastric emptying rates than untrained individuals at rest. One possible explanation for the contradictory results is that in the study of Carrio et al. emptying of a solid meal was monitored, and in the present study emptying of fluids was measured. It is possible that motility of the trained runners was greater in response to a solid meal. Alterations in motility may influence the emptying of fluids and solids differently. Also their study was done at rest and the study presented in Chapter 2 was done during exercise. One would expect, however, that if there were differences in $\mathrm{GE}$ rates between trained and untrained individuals they would be most apparent during the exercise for which the one group had specifically trained. As mentioned, the method of measuring emptying was different. Carrio and coworkers used a meal labeled with technecium and a gamma 
camera, whereas in the studies presented in this thesis, a dyedilution, double sampling technique was used (Beckers et all, 1988). However, in a recent study in which the emptying of fluids was measured simultaneously with the gamma camera and double sampling techniques, similar results were obtained (Beckers et al., 1990).

\section{Exercise intensity}

With all but very intense exercise GE rate is not appreciably altered as a resuit of exercise itself. In the present study, when several measurements were made of beverage volume over time, no effect of exercise at 50 or $70 \%$ of maximal exertion capacity over the whole emptying curve was observed (Chapter 2). However, at one or two sample points early on, the volume remaining was larger with $70 \%$ exercise than in rest, with carbohydrate containing beverages. This may explain why some authors have found differences with moderate exercise and others have not, since some conclusions are based on volumes remaining at only one time, often 15 or $20 \mathrm{~min}$ after ingestion, and others have based their conclusions on emptying rates determined by multiple sample times over a longer period, as was done in the experiments presented in Chapter 2. The trend we observed for decreased emptying with increased exercise intensity, albeit transient, was only observed with carbohydrate containing beverages and not with water.

Fordtran and Saltin (1964), on the contrary, observed slight decreases with exercise of approximately $70 \% \quad \mathrm{VO}_{2} \max$ with water only and not with carbohydrate containing beverages. However, others have also observed exercise induced retardation of GE with carbohydrate solutions (Ramsbottom and Hunt, 1974; Costill and Saltin, 1974; Sole and Noakes, 1989).

The effect of exercise on GE remains disputed. Early works of Campbell et al. (1928) and Hellebrandt and Tepper (1934) suggested that GE was increased with low intensity exercise. Results of Neufer et al. (1989) support these findings, having observed increased $\mathrm{GE}$ up to and including $65 \% \mathrm{VO}_{2} \mathrm{max}$, relative to rest. The work presented in Chapter 2, however, supports the results of Costill and Saltin (1974) and Fordtran and Saltin (1967), who observed no appreciable effect on GE 


\section{Chapter 11}

with exercise of less than $70 \% \mathrm{VO}_{2} \mathrm{max}$.

These results, regarding the effect of intensity of exercise on GE with two main types of exercise, running and bicycling, show little consistent effect until very high intensity exercise is conducted. Where alterations were observed, the magnitude was not large and would not be expected to be of physiological consequence for hydration during exercise.

\section{Type of exercise}

It has been speculated that the faster GE rate observed by Neufer and co-workers and the slower rate found by others results from a difference in the type of exercise used. Neufer and co-workers" study was conducted with running exercise and that of others with cycling. The theory is that GE is possibly enhanced only with low level running and not bicycling, since the pressure on the pyloric sphincter and lower portion of the stomach would be expected to be greater with running, possibly having a similar effect as volume does in stimulating gastric emptying.

In Chapter 4 jostling (cumulative accelerations) of the abdominal region was observed to be greater during running than bicycling. This may lead one to conclude that acceleration of the stomach would also be greater. However, in Chapter 3 no difference in GE rate was observed when the same individuals were tested while cycling and running at $70 \% \quad \dot{V O}_{2} \max$. This work has since been supported by Houmard et al. (1990), who also observed no difference in $\mathrm{GE}$ in the same individuals while cycling and running.

\section{The effect of volume on gastric emptying}

Volume was observed to have a large stimulatory effect on GE, supporting all earlier observations concerning the effect of volume on GE (Marbaix, 1898; Hunt and MacDonald, 1954). This results in exponential emptying after a large bollus, as was observed in the present studies with all beverages, carbohydrate containing as well as non-carbohydrate, after a bolus of $8 \mathrm{ml} . \mathrm{kg} \mathrm{BW}^{-1}(\sim 600 \mathrm{ml})$. This type of emptying pattern has been previously described (Hunt and Spurrell, 1951). The practical importance of this observation is often overlooked when attempts are made to maximise fluid provision during 
athletic endeavour. The advice given to most athletes is to take in small quantities of beverage frequently during exercise; however, if larger quantities were ingested a faster GE rate would result.

With large boli of carbohydrate-containing beverage the opposing influences of volume and carbohydrate content are present. In Chapter 3 the beverage was repeatedly ingested after one large bolus, in an attempt to maintain a large volume in the stomach. The question addressed was whether the fastphase rate of emptying would be continued due to the enhancing effect of volume or whether emptying rate would be delayed due to the inhibitory effect of the carbohydrate content. Prolonged fast-phase emptying was observed with a $7 \%$ carbohydrate solution but not with an $18 \%$ solution. Thus, fastphase emptying can be prolonged, dependent upon the carbohydrate concentration.

It has been speculated that there is a limit to the volume effect, with a maximum rate of emptying with a volume of approximately $600 \mathrm{ml}$ (Costill and Saltin, 1974). However, Hunt and Spurrel (1951) found increasing rates with volumes up to $750 \mathrm{ml}$. And more recently, Mitchell and Voss (1990) observed increasing emptying rates with volumes of up to $23 \mathrm{ml} \cdot \mathrm{kg}^{-1} \cdot \mathrm{h}^{-1}$ which resulted in a gastric residue of over $1000 \mathrm{ml}$. It may be that an adaptation or training effect on emptying large volumes occurs (C. Foster, personal communication). This may explain the difference between Costill and Saltin's and Mitchell and Voss' results.

\section{The effect of dehydration on gastric emptying}

Other factors which may play a role in regulating GE rate during exercise were also examined. One factor which is of importance in relation to exercise is dehydration. The combination of dehydration and exercise was observed to decrease gastric emptying rate. These results, presented in Chapter 6, are supported by those of Neufer et al (1989). However, Owen et al. (1986), who measured gastric emptying of water in a relatively cool environment $\left(25^{\circ} \mathrm{C}\right)$, versus a hot environment $\left(35^{\circ} \mathrm{C}\right)$, observed no difference in remaining gastric residues after exercising in the heat for $2 \mathrm{~h}$. One explanation for these seemingly conflicting results is that in Owen's experiments 
subjects were allowed to drink continuously throughout exercise and were not first dehydrated, before they were given a beverage. Another possible explanation for Owen's divergent results are related to the technique. No measurement of secretion was made and only final gastric residue after 2 h was used to compare emptying rates. Whether reduced emptying rate in a state of dehydration in combination with exercise is a result of a decreased blood flow to the gastrointestinal tract, a specific thermic effect, or alteration of intracellular-extracellular ion balance and membrane characteristics, can only be speculated upon. Nevertheless, one can conclude that if dehydration occurs during exercise a vicious circle ensues because GE is markedly decreased.

\section{The effect of electrolyte composition on gastric emptying}

Preliminary research in this laboratory and observations by Coyle et al. (1978) suggested that the inclusion of potassium in a beverage ingested during exercise may decrease the gastric emptying rate. Gastric emptying of an isotonic sodium chloride solution has been shown to be quicker than that of water (Shay and Gershon-Cohen, 1934; Hunt and Pathak, 1960). However, in the study presented in Chapter 5, no effect of sodium or potassium on gastric emptying of a $15 \%$ carbohydrate solution was observed.

\section{Carbohydrate concentration and osmolality}

The effect of increasing carbohydrate concentration to decrease GE is dramatic and in line with all other previous research at rest as well as during exercise. That this is a result of osmolality receptors in the duodenum has been postulated by Hunt and Knox (1968). One matter of controversy exists as to which factor is decisive in limiting GE: glucose content per se, or osmolality of a solution.

The relative emptying rates of two solutions, of equal carbohydrate (glucose) content but with widely varying osmolalities (e.g. a free glucose solution versus a glucose polymer solution) are difficult to predict, not knowing the relative importance of osmolality and glucose content and also not knowing to what degree a polymer is hydrolysed in the duodenum, at the site of the theorised osmoreceptors. Foster et 
al. (1980) observed increased GE with a glucose polymer solution, relative to a free glucose solution. However, the difference in GE rate was calculated from total gastric residue volumes. When only beverage volume was compared no significant difference was observed. Sole and Noakes (1989) also compared a free glucose and glucose polymer solution and did observe a relatively faster GE of the polymer solution when only remaining beverage was compared. In Chapter 7 , no significant difference in gastric emptying rate was observed between two carbohydrate solutions identical in all aspects, except that one was glucose polymer and the other a free glucose solution. In Chapter 2, a trend was observed for a glucose polymer (15\%) and fructose $(3 \%)$ containing beverage to empty faster than a free glucose solution with an equivalent amount of glucose as was contained in the polymer solution. The slight differences in emptying rate occasionally observed between free glucose solutions and glucose polymer solutions are not nearly as large as the differences one might expect based upon the large differences in osmolality.

\section{GASTROINTESTINAL SECRETIONS}

The effects of osmolality

Perhaps the most important observation made by Foster et al. (1980) was that gastric secretion was greater after ingestion of a free glucose solution than after ingestion of a similar glucose polymer solution, the former having a greater osmolality. Additionally, a significant, positive correlation of gastric secretion with osmolality of the aspirate was observed in Sole and Noakes' study (1989). In the present studies a trend for increased gastric secretion volume (Chapter 2) and a significant increase in intestinal secretion upon jejunal perfusion (Chapter 7) with free glucose solutions relative to similar glucose polymer solutions was observed.

Carbohydrate oxidation rates for similar polymer and free glucose solutions were not found to be different. With these results, one may conclude that it is not the rate of carbohydrate delivery or increased utilization which makes glucose polymers 
attractive for exercise supplementation and oral rehydration solutions, but the possible decrease in gastrointestinal secretions and with it decreased losses of fluid from plasma and tissues to the lumen. Albeit possibly only a transient influx with hypertonic solutions it may worsen dehydration effects and may account for the increased prevalence of gastrointestinal symptoms obserwed among athletes who ingest strongly hypertonic beverages.

The trend for a greater amount of gastric secretion with a free glucose solution versus a glucose polymer solution of equal glucose concentration, and no difference in secretion among solutions varying widely in carbohydrate concentration but with less of a difference in osmolality (Chapter 5), suggests that osmolality plays a greater role in gastric secretion than carbohydrate concentration.

\section{Other factors influencing gastric secretion}

In Chapter 5 evidence is presented suggesting that when a beverage which maintains a high $\mathrm{pH}$ is ingested the secretion is maintained at a higher rate than when a solution is ingested which rapidly decreases the $\mathrm{pH}$. It is postulated that disinhibition of gastric secretion (especially gastric acid secretion) occurs as a result of maintenance of a higher gastric residue $\mathrm{pH}$. Volume was also observed to stimulate gastric secretion. This is a well established effect (Hunt and MacDonald, 1954).

Volume of gastric secretion was not observed to be altered with exercise. Our observations are in line with the work of Feldman and Nixon (1982) who also observed no change in gastric acid secretion. However, others have found decreased gastric secretion in response to exercise in dogs (Konturek et al., 1973) and man (Hellebrandt and Hoopes, 1934; Markiewicz et al., 1977; Ramsbottom and Hunt, 1974). The differences in gastric secretion between rest and exercise observed by some researchers may possibly be accounted for by differences in gastric volume due to a decrease in GE observed with very high intensity exercise. 


\section{Gastric secretion of electrollytes}

Very little difference was observed in the electrolyte content of the gastric secretion when solutions of widely varying composition were instilled (Chapter 5). Higher concentrations of sodium as well as potassium resulted in greater absorption in the stomach of sodium and potassium respectively, although only for a brief time, shortly after ingestion.

\section{GASTRIC EMPTYING IN RELATION TO ABSORPTION AND OXIDATION}

In Chapters 2 and 3 varying rates of water and carbohydrate emptying were observed, primarily due to differences in beverage composition and gastric volume. Conclusions based on these data can only be made with regards to the amount of fluid and carbohydrate available for absorption. These data do not tell us how much water is incorporated into the body pool or how much exogenous carbohydrate can be oxidised. The experiments presented in Chapter 7 were conducted in an attempt to evaluate the role of gastric emptying in determining fluid and carbohydrate availability as measured by incorporation of ingested water into the total body water pool and oxidation of ingested carbohydrate. Results of this study, using deuterium-labeled water, demonstrate a strong correlation between rate of gastric emptying and water assimilation.

However, enhanced intestinal absorption of water from a sodium containing, isotonic carbohydrate solution, above that from water alone, demonstrated by jejunal perfusion, is not reflected in the deuterium accumulation data presented in Chapter 10. Whether deuterium absorption reflects the actual net inward flux (from lumen to tissues), or whether polyethylene glycol dilution, measured during intestinal perfusion, reflects the actual situation, is debated. The shortcomings of both techniques are discussed in Chapter 7. Clinical data have shown that recovery from severe dehydration (as in cases of diarrhoea induced by bacterial or viral infection) is more efficient with orally ingested hypotonic or isotonic glucose-sodium solutions than with plain water (Farthing, 1990). 
From these results one may speculate that net absorption of water is greater from a glucose-sodium solution ingested orally. Gastric emptying of a concentrated CHO solution (eg. 17\% glucose) is delayed, relative to a less concentrated solution. Athough this does reduce the amount of ingested CHO which is available for absorption and oxidation, nevertheless, much more CHO is emptied per unit time with a more concentrated solution than with a less concentrated solution. However, much less is actually oxidised than what is emptied with the $17 \%$ glucose solution. Sixty percent of the CHO ingested is emptied but only $19 \%$ of that ingested is oxidised. Where the glucose remains which is emptied but not oxidised can only be speculated upon. The large capacity of the intestines leads to the suggestion that much of the unoxidised CHO could be found here. However, the results from the triple lumen perfusion study (Chapter 7) do not support the contention that the intestines are rate limiting for the absorption of glucose within the range of concentrations used in this study. The difference in net glucose absorption between a $17 \%$ and a $4.5 \%$ glucose solution was of the same order of magnitude as the difference in glucose concentration. Recent data from Coyle and co-workers (1991) also support this premise. They infused glucose during exercise to obtain hyperglycaemia and could also not account for a portion of the glucose administered (not oxidised and not in the blood). . Furthermore, studies with rats by Kuipers and co-workers (1986) have demonstrated that after glucose feedings during exercise, a portion of the labeled CHO fed could not be accounted for by oxidation, incorporation into glycogen in active muscles and liver, nor found in the intestines or the stomach. Moreover, there was more glucose remaining in the stomach than in the intestines. In this study glycogen deposits in resting musculature were not examined. It may be, as has been speculated in Chapter 7, that glycogen synthesis in resting muscles may account for the "missing" CHO. The possibility of fat synthesis can also not be discounted. 


\section{GASTROINTESTINAL SYMPTOMS DURING EXERCISE}

Gastrointestinal symptoms are common among endurance athletes, the percentage of marathon runners reporting symptoms in the study described in Chapter 8 being similar to that reported by others (Keeffe et al., 1984; Riddoch and Trinick, 1988). Symptoms are reported to be more common among women (Keeffe et al., 1984). A higher prevalence among women who $\operatorname{ran}$ in a $25-\mathrm{km}$ race was also noted in the present study. However, when the same group of subjects ran a marathon, no difference was observed. Variation in the phase of the menstrual cycle may account for the inconsistency, since more GI symptoms occur during menstruation (Whitehead et al., 1990).

\section{Effect of dehydration on GI symptoms}

Fluid intakes were very low during both the $25-\mathrm{km}$ race and the marathon. Mean ( \pm SE) fluid intake in the $25-\mathrm{km}$ race was 109 \# $14 \mathrm{ml}$, and in the marathon, $577 \pm 46 \mathrm{ml}$. The most noteworthy correlation found was between body weight loss and GI symptoms. Above $4 \%$ body weight loss, the prevalence was far greater ( $80 \%$ with symptoms) than with less of a weight loss. Below this level of dehydration a prevalence of $50 \%$ was still found.

A laboratory study (Chapter 6) confirmed an effect of dehydration on gastrointestinal function during running exercise. Thirty-six percent of the subjects had GI complaints when a carbohydrate containing beverage was given after dehydration, with running exercise. Comparative trials with the same beverage, performing exercise in the hydrated state, and after dehydration in rest (sauna exposure) did not result in GI problems. Also noteworthy is the fact that the combination of exercise and dehydration resulted in a higher core body temperature than did dehydration by heat alone. It is uncertain whether the alteration in GI function resulted from the fluid loss directly (including plasma volume decrease) or indirectly due to hyperthermia and consequences thereof, or a combination of the two. 


\section{Hormonal influences}

Several GI hormones were observed to increase to pathological levells as a result of a $67 \mathrm{~km}$ foot-race (Chapter 9). These results are similar to those reported by Sullivan et al. (1984) and Riddoch (1990). However, no correlation was observed between symptoms and elevated concentrations of any of the GI hormones measured. A few perplexing correlations of symptoms and "stress" hormones were observed. Mean pre-race plasma cortisol concentration was lower in individuals who developed intestinal cramps during the race. It is speculated that low plasma cortisol may be a sign of being "overtrained" and may result in less of a "feed-forward" response in terms of substrate mobilisation. Early exhaustion, or energy deficit, may play a role in GI dysfunction. Post-race norepinephrine was also lower in these individuals, which might be a result of the symptoms rather than causative. It is speculated that runners with symptoms may slow down and therefore the post-race norepinephrine levels would be expected to be lower than in the individuals who maintain a higher exercise intensity. This brings to light the danger in interpreting correlations. Causation is not proven. Furthermore, plasma concentrations must also be interpreted with care, the values not necessarily representing the situation at at tissue level.

\section{Electrolytes, energy deficit, and hyperthermia}

Post-race plasma potassium concentration was increased to a greater extent in those athletes with symptoms. There may be a loss of $\mathrm{K}+$ from ischaemic gut cells and/or from active muscles which may or may not be related to GI symptoms. It is, however, speculated that cellular integrity and intracellularextracellular ionic balance may be disturbed and this could be related to the development of GI symptoms. This line of reasoning may also explain the relationship between dehydration/hyperthermia and GI dysfunction. Symptoms of hyperthermia have been explained by a local tissue energy deficit and decreased ionic transport (via $\mathrm{Na}+/ \mathrm{K}+$ pump insufficiency) which results in accumulation of $\mathrm{Na}+$ intracellularly and $\mathrm{K}+$ extracellularly (Hubbard, 1987). 


\section{Blood flow alterations}

Alternatively, direct effects of dehydration on blood flow to the intestines (plasma volume decrease) and the exercise effect to reduce blood flow to the intestines may also explain some of the symptoms. Intestinal blood flow alterations can affect absorption of water (Sjovall et al., 1986) and carbohydrate (Williams et al., 1964) and oxygen supply to the intestines (Bortoff, 1988). Plasma volume decrease has also been observed to be related to nausea in dumping syndrome (Sessions et al., 1962). In any case, a decreased GE related to dehydration and exercise has been observed, whether this is causative or results from the symptoms seen with dehydration and exercise is uncertain.

\section{Mechanical effects}

GI problems are much more common when individuals are running than when bicycling or swimming, the findings in Chapter 10 supporting those of Sullivan (1987). However, since no difference in GE rate with these two activities was observed (Chapter 3) it is doubtful if a difference in GE rate, intrinsic to the activity, is causative. Furthermore, individuals who commonly experience GI distress running were not observed to have a slower GE rate than other athletes tested (Chapter 3). The amount of vibration, however, which was observed to be twice as large during running as bicycling (Chapter 4), may in part be responsible for the increased GI symptoms with running versus bicycling (Chapter 10).

\section{Effects of food and fluid intakes}

The fact that while running very small amounts of fluids are normally ingested suggests that during this activity a greater risk of gastrointestinal dysfunction as a result of dehydration or heat stress is present. During bicycling the ease of ingestion allows for larger volumes to be consumed and the increased convection cooling while bicycling also helps prevent overheating.

However, when looking at the "race-day" diet and GI symptoms, several dietary components known to decrease GE rate (fat and protein) were found to make up a greater percentage of the diet in those with stomach ache, nausea and vomiting. 
Additionally, strongly hypertonic beverage ingestion was associated with an increased prevalence of Gl symptoms. The combination of hypertonic beverage ingestion with dehydration in particular, increased the risk. Plasma volume, decreased by exercise and dehydration, would be further decreased by increased gastrointestinal secretions, stimulated by the presence of hypertonic beverage in the gastric and intestinal lumen. Decrease in the plasma volume and presence of large amounts of carbohydrate in the colon induce a number of vasomotor and intestinal symptoms, including bloating, cramps, borborygmus, flatulence, nausea and, occasionally, vomiting and diarrhoea (Sessions et al., 1962).

A relationship between fibre intake and intestinal symptoms was observed. Increased transit time (Cordain et al., 1986) resulting from increased motility or simply a physical effect of repeated vertical accelerations (Chapter 4) may result in a greater amount of fibre in the colon over a given time. This larger amount of undigested carbohydrate would induce increased intestinal secretions as well as provide more substrate for bacterial degradation. The increased core body temperature observed during exercise may also increase the rate of bacterial fermentation. Increased fermentation of the fibre in the colon would result in increased production of $\mathrm{H}_{2}$ and other byproducts of fermentation including volatile fatty acids. An accumulation of these substances coupled with an increased influx of fluid into the colon may account for the observed symptoms.

From the previous discussion it is obvious that no one factor is responsible for all gastrointestinal symptoms experienced during exercise. There are many different maladies included in this general designation and, in some cases, these may be entirely unrelated to exercise. There is also more than one possible cause for a given symptom. Further research is needed to define the relationship between gastric emptying and intestinal function, and the effects of altered blood flow to the splanchnic region during exercise on gastrointestinall function. 


\section{CONCLUSIONS}

In conclusion, no one factor determines gastric emptying and secretion rates or is responsible for GI symptoms, all of which may reduce the rate at which beverage supplemented during exercise is actually available for absorption and utilisation. The individual differences in GI function (GE, intestinal absorption and secretion) are enormous, much larger than differences between groups of individuals, such as groups categorised by training status of predisposition for GI symptoms. Certain individuals are observed to be consistently slow emptiers and others fast emptiers, regardless of the amount of training in a particular sport, where drinking is only regularly performed during exercise by those who train for that sport (Chapter 2). Furthermore, one individual may experience massive intestinal secretion from a given beverage, while another may actually absorb water from it (Chapter 7). CHO absorption also varies widely between individuals (Chapter 7 ). When individuals are divided into groups according to frequency of GI symptoms during exercise, no difference in GE rates is observed. There is a day to day variation in $\mathrm{GE}$ rate within an individual but this is not as large as the inter-individual difference (Beckers et al., unpublished data). Relative responses to different beverages are consistent, eg. increasing the $\mathrm{CHO}$ content of a beverage substantially will reduce the volume emptied per unit time.

Nevertheless, based upon the results presented here, in the context of the literature to date, one may make some general conclusions as to what should be ingested during endurance exercise in which situation, to maximise fluid and carbohydrate provision and to reduce the risk of gastrointestinal distress. When extrapolating from research data, however, one also does well to remember that the hormonal and metabolic milieu may be very different during a laboratory experiment than during actual competition in the field. 


\section{Chapter II}

\section{Suggestions for future research}

The results presented in this thesis leave many questions unanswered and provide the basis for future research. One area which is in need of more specific research concerns the relationship between exercise, blood flow to the intestines and intestinal absorption. Additionally, the relationship between intestinal absorption rates of glucose and water and gastric emptying rates has not been thoroughly investigated. New techniques, less invasive and more sensitive than those used in the past, should allow for more detailed study of these questions in humans. 


\section{References}

1. Beckers, E.J., J.B. Leiper, J. Davidson, H.G. Gemmell, F.W. Smith, N.J. Rehrer, F. Brouns, W.H.M. Saris and F. ten Hoor. A comparison of aspiration and scintigraphic techniques for measurement of gastric emptying rates of liquids in man. Proceedings of the Physiological Society, Glasgow Meeting, June 28-29, p. 107p, 1990.

2. Beckers, E.J., N.J. Rehrer, F. Brouns, F. ten Hoor and W.H.M. Saris. Determination of total gastric volume, secretion, and residual meal using the double sampling technique of George. Gut 29: 1725-1729, 1988.

3. Bortoff, A. Influence of exercise on gastrointestinal function. In: Horton, E.S. and R.L. Terjung (Eds.) Exercise, Nutrition, and Energy Metabolism, pp. 159-171, Macmillan Publ. Co., New York, 1988.

4. Brener, W., T.R. Hendrix and P.R. McHugh. Regulation of the gastric emptying of glucose. Gastroenterology 85: 76-82, 1983.

5. Campbell, J.M.H., G.O. Mitchell and A.T.W. Powell. The influence of exercise on digestion. Guy's Hospital Reports 78: $279 \cdot 293,1928$.

6. Carrio, I., M. Estorch, R. Serra-Grima, M. Ginjaume, R. Novitol, R. Calabuig and F. Vilardell. Gastric emptying in marathon runners. Gut 30: 152-155, 1989.

7. Cordain, L., R.W. Latin and J.J. Behnke. The effects of an aerobic running program on bowel transit time. J. Sports Med. 26: $101-104,1986$.

8. Costill, D.L. and B. Saltin. Factors limiting gastric emptying. J. Appl. Physiol. 37: 679-683, 1974.

9. Coyle, E.F., M.T. Hamilton, J.G. Alonso, S.J. Montain and J.L. Ivy. Carbohydrate metabolism during intense exercise when hyperglycemic. (Submitted) 1991. 
10. Farthing M.J.G. (ed.) Symposium Proceedings: Oral rehydration therapy: Past, Present and Future. Manila, October 31, 1989 in Clin. Ther. 12: (supplement A): 1-42, 1990.

11. Feldman, M. and J.V. Nixon. Effect of exercise on postprandial gastric secretion and emptying in humans. J. Appl. Physiol. 53: 851-854, 1982.

12. Fordtran J.S. and B. Saltin. Gastric emptying and intestinal absorption during prolonged severe exercise. J. Appl. Physiol. 23: $331-335,1967$.

13. Foster, C., D.L. Costill and W.J. Fink. Gastric emptying characteristics of glucose and glucose polymer solutions. Res. Q. 51: 299-305, 1980.

14. Hellebrandt, F.A. and S.L. Hoopes. Studies on the influence of exercise on the digestive work of the stomach. I: Its effect on the secretory cycle. Am. J. Physiol. 107: 348-354, 1934.

15. Hellebrandt, F.A. and R.H. Tepper. Studies on the influence of exercise on the digestive work of the stomach. II: Its effect on emptying time. Am. J. Physiol. 107: 355-363, 1934.

16. Houmard, J.A., P.C. Egan, R.A. Johns, P.D. Neufer, T.C. Chenier and R.G. Israel. Gastric emptying during running and cycling. Med. Sci. Sports Exerc, 22(suppl.): s90 (abstract), 1990.

17. Hubbard, R.W., C.B. Matthew, M.J. Durkot and R.R. Francesconi. Novel approaches to the pathophysiology of heatstroke: the energy depletion model. Ann. Emerg. Med. 16: 1066-1075, 1987.

18. Hunt, J.N. and M.I. Knox. Regulation of gastric emptying. Handbook of Physiology Vol. IV. pp.1917-1935, Am. Physiol. Soc., Washington, D.C., 1968.

19. Hunt, J.N. and I. MacDonald. The influence of volume on gastric emptying. J. Physiol. 126: 459-474, 1954. 
20. Hunt, J.N. and W.R. Spurrel. The pattern of emptying of the human stomach. J. Physiol. 113: 157-168, 1951.

21. Keeffe, E.B., D.K. Lowe, R. Goss and R. Wayne. Gastrointestinal symptoms of marathon runners. West. J. Med. 141: 481-484, 1984.

22. Konturek, S.J., J. Tasier and W. Obtulowicz. Effect of exercise on gastrointestinal secretions. J. Appl. Physiol. 34: 324-328, 1973.

23. Kuipers, H., D.L. Costill, D.A. Porter, W.J. Fink and W.M. Morse. Glucose feeding and exercise in trained rats: mechanisms for glucose sparing. J. Appl. Physiol. 61: 859-863, 1986.

24. Marbaix, O. Le passage pylorique. Cellule 14: 249-330, 1898.

25. Markiewicz, K., M. Cholewa, L. Gorski and J. Chimura. Effect of physical exercise on gastric basal secretion in healthy men. Acta Hepato-Gastroenterol. 24: 377-380, 1977.

26. McHugh, P.R. and T.H. Moran. Calories and gastric emptying: a regulatory capacity with implications for feeding. Am.J. Physiol. 236: R254-R260, 1979.

27. Mitchell, J.B. and K.W. Voss. The influence of volume of fluid ingested on gastric emptying and body fluid balance. Med. Sci. Sports Exerc. 22 (suppl.): $\$ 90$ (abstract), 1990.

28. Neufer, P.D., A.J. Young, M.N. Sawka. Gastric emptying during exercise: effects of heat stress and hypohydration. Eur. J. Appl. Physiol. 58: 433-439, 1989.

29. Owen, M.D., K.C. Kregel, P.T. Wall and C.V. Gisolfi. Effects of ingesting carbohydrate beverages during exercise in the heat. Med. Sci. Sports Exerc. 18: 568-575, 1986.

30. Ramsbottom, N. and J.N. Hunt. Effect of exercise on gastric emptying and gastric secretion. Digestion. 10: 1-8, 1974. 
31. Riddoch, C. Exercise induced gastrointestinal symptomshormonal involvement. Ph.D. Thesis, The Queen's University of Belfast, 1990.

32. Riddoch, $C$. and $T$. Trinick. Gastrointestinal disturbances in marathon runners. Brit. J. Sports Med. 22: 71-74, 1988.

33. Sessions, R.T., V.H. Reynolds, J.L. Ferguson and H.W. Scott. Correlation between intraduodenal osmotic pressure changes and $\mathrm{Cr}^{51}$ blood volumes during induced dumping in men with normal stomachs. Surgery 52: 266-278, 1962.

34. Sjovall, H., H. Abrahamsson, G. Westlander, R. Gillberg, S. Redfors, $M$. Jodal and $O$. Lundgren. Intestinal fluid and electrolyte transport in man during reduced circulating blood volume. Gut 27: 913-918, 1986.

35. Sole, C.C. and T.D. Noakes. Faster emptying for glucosepolymer and fructose solutions than for glucose in humans. Eur.J.Appl. Physiol. 58: 605-612, 1989.

36. Sullivan, S.N., M.C. Champion, N.D. Christofides, T.E. Adrian and S.R. Bloom. Gastrointestinal regulatory peptide responses in long-distance runners. Phys. Sports Med. 12: 77-82, 1984.

37. Sullivan, S. Exercise-associated symptoms in triathletes. Phys. Sports Med. 15: 105-108, 1987.

38. Whitehead, W.E., L.J. Cheskin, B.R. Heller, J.C. Robinson, M.D. Crowell, C. Benjamin and M.M. Schuster. Evidence for exacerbation of irritable bowel syndrome during menses. Gastroenterology 98: 1485-1489, 1990.

39. Williams, J.H., M. Mager and E.D. Jacobson. Relationship of mesenteric blood flow to intestinal absorption of carbohydrates. J. Lab. Clin. Invest. 63: 853-863, 1964. 
In summary the following conclusions can be made:

1. There is no effect of endurance training (with drinking) on gastric emptying of a $\sim 600 \mathrm{ml}$ liquid bolus during exercise.

2. There is no physiologically important effect of exercise intensity ( $\leq 70 \% \dot{\mathrm{VO}_{2}}$ max) on gastric emptying.

3. There is no effect of type of exercise (bicycling $v$. running) on gastric emptying.

4. Adding sodium (140 meq. $\left.\mathrm{l}^{-1}\right)$ and/or potassium (28 meq. $\left.\mathrm{l}^{-1}\right)$ to a carbohydrate containing beverage has no effect on gastric emptying rate.

5. Strongly hypertonic $\left(>800 \mathrm{mOsm} . \mathrm{kg}^{-1}\right.$ ) beverages increase gastrointestinal secretions, which may explain the increased prevalence of gastrointestinal symptoms in individuals who consume these types of beverages during endurance exercise.

6. Gastric emptying rate of an isotonic carbohydrate and sodium containing solution is equal to that of water, but intestinal absorption of water from the former is faster.

7. A glucose polymer solution offers little advantage relative to an isoenergetic glucose solution in terms of gastric emptying rate and oxidation rate of the carbohydrate, but may be of advantage due to reduced gastrointestinal secretions.

8. Gastric emptying can alter the amount of carbohydrate available for oxidation, but is not ultimately limiting for the amount of orally ingested carbohydrate which is oxidised during exercise.

9. Dehydration during exercise decreases the gastric emptying rate of a beverage and increases the risk of GI symptoms.

10. No one factor accounts for exercise-related GI symptoms; dietary as well as physiological factors influence the risk. 


\section{SAMENVATTING}

Dit proefschrift gaat nader in op de fysiologie en het functioneren van het maagdarmkanal tijdens langdurige inspanning. Het gedane onderzoek spitst zich toe op de eerste fase van het verteringsproces van vloeistoffen, namelijk de maaglediging.

In verschillende studies is nagegaan wat de invloed van de trainingstoestand, de soort en intensiteit van de inspanning, de vochtbalans en de samenstelling van de geconsumeerde drank is op de maaglediging tijdens inspanning en in rust. De resultaten laten zien dat inspanning met een intensiteit van 70 procent, of minder, van het maximale zuurstofopnamevermogen geen effect heeft op de snelheid waarmee een vloeistof de maag verlaat. De snelheid van de maglediging blijkt bij hardlopen en fietsen eveneens gelijk te zijn. Tevens is bij de geteste intensiteiten eveneens geen effect van training waar te nemen. Bij getrainde fietsers die er aan gewend zijn om tijdens de inspanning grote hoeveelheden drank te consumeren, blijkt de maaglediging niet sneller te zijn als bij ongetrainde personen.

De samenstelling van de drank (voornamelijk de hoeveelheid koolhydraten blijkt belangrijk te zijn) en het volume van de drank in de maag hebben wel een direct effect op de maaglediging. Als de concentratie koolhydraten in een oplossing hoog is, neemt de maaglediging van deze oplossing, gemeten in milliliters per minuut, af. Daarentegen neemt de hoeveelheid energie die de maag met deze oplossing verlaat, toe.

Een groot vloeistofwolume in de maag blijkt de maaglediging te versnellen. Na het innemen van een grote hoeveelheid drank is de maagledigingsnelheid hoog. Is het maagvolume vervolgens afgenomen, dan daalt ook de maagledigingssnelheid. Herhaald drinken (b.y. iedere $20 \mathrm{~min} 150 \mathrm{ml}$ ) kan, als hierdoor een aanzienlijk volume in de maag gehandhaafd blijft, de maaglediging stimuleren. De snelheid waarmee de drank de maag verlaat, kan dan op een hoog niveau gehouden worden. Dit effect van het volume op de maaglediging kan echter teniet gedaan worden indien de concentratie koolhydraten in een 
drank hoog is. Het remmende effect van de hoge koolhydraatconcentratie zal dan het stimulerende effect van het volume teniet doen.

Koolhydraten welke tijdens de inspanning door middel van een drank worden ingenomen, worden na hun absorptie in het maagdarmkanaal gebruikt voor de energievoorziening. Dit laatste blijkt echter niet zo snel te gaan als het tempo waarmee zij uit de maag naar de darm zijn getransporteerd. Naast de maagledigingssnelheid blijken dus andere factoren de snelheid waarmee oraal toegediende koolhydraten gebruikt worden voor de energievoorziening te beinvloeden. Een matig geconcentreerde oplossing van koolhydraten en natriumchloride blijkt de maag even snel te verlaten als gewoon drinkwater. Daarentegen is echter de absorptie van water in de darm groter indien de koolhydraat-electrolyten oplossing wordt gedronken.

De concentratiesterkte van een drank, uitgedrukt als osmolariteit (osmotische druk veroorzaakt door het aantal deeltjes in oplossing) van de geconsumeerde drank, beinvloedt de secretie van vocht door de maag en de darmen. Een toegenomen osmolaliteit leidt tot een grotere vochtsecretie en daardoor tot een afnamen van de netto vocht absorptie.

Resultaten van verschillende veld- en laboratoriumstudies hebben aangetoond dat de vochtbalans in het lichaam van invloed kan zijn op het ontstaan van maag- en darmstoornissen. Indien het lichaam gedehydreerd is, blijkt de maaglediging vertraagd te zijn.

Andere factoren, die het optreden van magdarmklachten kunnen beinvloeden, blijken de hoeveelheid vet, eiwit en voedingsvezels te zijn welke in de maaltijden op de dag van de wedstrijd door de atleten geconsumeerd worden.

Maaglediging, vochtsecretie in het maagdarmkanaal en het al of niet optreden van maag-darmstoornissen zijn alle direct van invloed op de snellheid waarmee een drank, welke tijdens de inspanning wordt geconsumeerd, biologisch beschikbaar wordt voor de lichaamsstofwisseling.

Uit de resultaten wan dit proefschrift kan worden geconcludeerd 
dat de hiervoor genoemde maagdarm processen worden beinvloed door een reeks van factoren. Hierdoor kan men nooit een enkele factor voor een vertraagde maagontlediging danwel het optreden van maagdarmproblemen als causale factor aanwijzen.

Inter-individuele verschillen in de snelheid waarmee een drank wit de maag geledigd wordt, de groote van de maagdarmsecretie die daarbij optreedt en de mate van darmabsorptie blijken groot te zijn. Deze verschillen bij één individu (bijvoorbeell waarnemingen van verschillende testdagen) blijken vaak zelfs groter te zijn dan de verschillen die waargenomen worden tussen verschillende groepen testpersonen, zoals deze waren ingedeeld voor bijvoorbeeld trainingsstatus of predispositie naar maagdarmklachten.

Sommige personen blijken altijd langzame "maagledigers" te zijn terwijl anderen hele snelle "maagledigers" kunnen zijn, onafhankelijk van het niveau van de trainingstoestand in een bepaalde sport, allsook het drinkgedrag bij die betreffende sport. Verder blijkt ook dat de mate waarin vocht door de darm wordt afgescheiden bij het ene individue veel groter kan zijn dan bij het andere individu, alhoewel beiden dezelfde drank ingenomen hebben. Hetzelfde geldt voor de absorptie van water uit de betreffende drank. Ook de absorptie van koolhydraten blijkt tussen verschillende mensen sterk te kunnen verschillen.

Indien men individuen indeelt in groepen, naargelang het optreden van maagdarmklachten tijdens inspanning, blijkt de gemiddelde maaglediging tussen de groepen niet te verschillen. Er zijn weliswaar grote individuele verschillen mast de specifieke effecten van de drankcomposities (weinig of zeter geconcentreerde koolhydraatoplossingen) zijn consequent. Ds meet geconcentreerde dranken ledigen altijd langzamer als de minder geconcentreerde dranken.

Niettemin kan men aan de hand van de resultaten weergegeven in dit proefschrift en gebaseerd op de beschikbare wetenschappelijke literatuur, enkele algemene conclusies trekken met betrekking tot de vloeistof- en koolhydraatvoorziening tijdens duur inspanning alsmede met betrekking tot het verminderen van het ristco om maagdarmklachten tijdens de inspanning op te lopen. 
Samenvattend kunnen de volgende conclusies worden getrokken:

1. De mate van training heeft geen effect op de maglediging tijdens inspanning na het drinken van $600 \mathrm{ml}$ vloeistof.

2. De intensiteit van de inspanning ( $\leq 70 \%$ VัO2 $\max$ ) heeft geen belangrijk fysiologisch effect op de maaglediging.

3. Het type van de inspanning (fietsen ten opzichte van lopen) heeft geen invloed op de maaglediging.

4. De toevoeging van natrium (140 meq.1 $\left.{ }^{-1}\right)$ en/of kalium (28

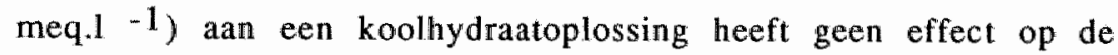
maaglediging van deze oplossing.

5. Sterk hypertone oplossingen $\left(>800 \mathrm{~mm} \mathrm{Osm.} \mathrm{Kg}^{-1}\right.$ ) leiden tot een vergrote secretie van mag- en darmsappen. Dit kan de grotere incidentie voor maagdarmklachten bij sporters die dit soort oplossingen tijdens duur inspanning innemen, verklaren.

6. De maaglediging van een isotone koolhydraat en natrium bevattende oplossing is even snel als die van water. Echter, de absorptie in de darm van de eerstgenoemde oplossing is sneller.

7. Een oplossing die glucosepolymeren bevat, heeft weinig voordelen ten opzichte van een iso-energetische glucose oplossing voor wat betreft de maaglediging en de snelheid waarmee koolhydraat wordt geoxideerd. Een voordeel van de glucosepolymeren bevattende oplossing kan echter gelegen zijn in de geringere maagdarmsecretie.

8. De maaglediging kan van invloed zijn op de hoeveelheid koolhydraat die beschikbaar komt yoor oxidatie, maar is niet limiterend voor de hoeveelheid van het oraal toegediende koolhydraat die geoxideerd wordt. 
9. Wanneer tijdens inspanning dehydratie optreedt, neemt de maagledigingssnelheid van een vloeistof af; in een dergelijke situatie neemt het risico op het optreden van maagdarmklachten, ook na drinken, toe.

10. Voor het optreden van maagdarmklachten tijdens inspanning is niet één enkele factor verantwoordelijk; zowel voedingsfactoren als fysiologische veranderingen hebben hierop een invloed. 


\section{DANKWOORD/ACKNOWLEDGEMENTS}

Many individuals have been important in my life and have influenced the direction which I have gone, to ultimately lead to the attainment of my doctorate in The Netherlands. Thanks are due to many:

Aan Hans, moe en mijn hele aangenomen familie die mij naar Nederland hebben "gelokt" en mij zo thuis hebben laten voelen dat ik hier met vreugde ben gebleven.

Also, to Dave Costill who made the perfect suggestion that $\mathbb{I}$ contact Harm Kuipers in Maastricht. En aan Harm Kuipers, die mij met Wim Saris heeft doorverbonden.

To D. V. Maurice, who taught me so much about science (and chickens). His example and training taught me the value and excitement of "pure" science. He also encouraged me, long before I was so certain that there was a future in it, to pursue that aspect which was closest to my heart, sport and nutrition thus. Did he somehow know that I was secretly spending hours in the library reading Scandinavian journals where not a word about chickens was mentioned?

To moeder. Stephen and the memory of Hal, who support me always with everything, even if it is a bit far from home.

En natuurlijk, nooit te vergeten de lessen geleerd met Fred. Though we both learned some difficult lessons from each other, the memory of what remains is the pleasure of helping you with your Ph.D. research, gaining experience on the way. When my turn arrived, I was prepared for the challenge. Fred, je heb me ook laten zien hoe je tussen de mensen moet gaan en niet van een afstand naar je mentors kijken, maar ze leren kennen. Ook voor de ideen om maag en darm onderzoek te gaan doen, hoewel $\mathrm{ik}$, in het begin, het maag leeg hevelen 's morgens vroeg nog al beroerd vond. To both Fred Brouns and Wim Saris do I owe much gratitude, not only for making it financially possible for me to complete research which culminated in my $\mathrm{Ph} . \mathrm{D}$., but for acknowledging me as a colleague. My ideas were contemplated with serious consideration. 
Not every underling researcher is given the chance to design studies. Fred's ideas for the first couple of lab studies and first field study provided fertile material from which to extract as many questions as answers. I can only hope this manner of writing proposals, "submitting" them to the work-group for suggestions, modifications, rejections or acceptance will be allowed to the upcoming young scientists of the future. Collecting samples doesn't alone make scientists; interpretation of research results and thinking through the next step in search of "the holy Grail" allows for that bit of self determination necessary to develop.

As the years have gone by since I first appeared at Wim's doorstep, have I fully begun to appreciate the fact that Wim gave me the chance without knowing very much about me. I will always appreciate that in Wim, the willingness to take a "gok". Further, to Fred and Wim, for giving the gentle push in the back to speak in public, when 1 was actually a bit frightened yet. I have grown through the trust and experience and now look forward to the chance to share my ideas with others.

Sharing data with Foppe ten Hoor brought with it shared enthusiasm and fresh ideas. Foppe always seems to have a new way of looking at things.

Most recently I have taken great pleasure and found a source of intellectual stimulation in the "boeiende" speculative conversations with Ton Wagenmakers, die voor mij telkens opnieuw het mooie van de wetenschap bevestigt.

Wat uitwoeren van het onderzoek zelf betreft, zijn er veel mensen te bedanken. The substantial contributions of Ed Beckers to almost every research project were key to the smooth running of the experiments. Ed's reliability and congeniality expedited the daily routine of experimentation.

Monique van Kemenade and Wineke Meester, the first two students that $\mathbb{I}$ advised, who carried out the study presented in Chapter 10, made me realise how proud one can be and what satisfaction one can have in seeing one's students excel.

Ook wil ik Lut, Christien en Corke bedanken voor het meewerken aan mijn laatste laboratorium proef. Lut en 
Christien hebben het feit bevestigd dat de Nederlandse moppen over Belgen onterecht zijn.

Richard en Ine Wauben wil ik ook bedanken voor hun bijdragen. Ook mijn dank aan de afdeling Medische Informatica en Statistiek en de DIV voor de menige klusjes die werden opgeknapt.

Klaas Westerterp en Loek Wouters verdienen ook mijn dank voor de mass spectroscopy gegevens. Ook Loek en Paul Schoffelen voor het oplossen van de technische probleempjes die wel eens verschenen.

Also to Dave Halliday, who was generous enough to lend his expertise, time and equipment to make the isotope ratio mass spectroscopy measurements in breath samples possible.

To Chris Riddoch for his part in the determination of the GI hormone measurements and for jumping in with both feet in the collection of data for the Swiss Alpine Marathon field study. Essential to this field study were Fred and Ed's organisation, as I took my turn as a subject, and the co-operative efforts of $B$. Villiger, W. Frey, A. Tuffli, and the many volunteers from Wander Ltd., the race organisation and the ThurgauischSchaffhausische Höhenklinik.

Ook wil ik P. Menheere bedanken voor de cortisol bepalingen. En Harm, Gerrit en Peter voor het delen van het sport lab met geduld en interesse. Ook aan Harm voor de mogelijkheid om zo maar binnen te vallen om wat te gaan vragen.

Ook Hans Keizer, voor wie ik vaak als proefpersoon funktioneerde in ruil yoor wat open, uiteenlopende gesprekken over zijn, mijn, en sportonderzoek in het algemeen.

En ook wat 't marathon onderzoek betreft wil ik Eugene Janssen bedanken. Het delen wan jouw proefpersonen werd op prijs gesteld. Nog steeds blijft jouw nauwe betrokkenheid met de sport de basis voor een wetenschappelijke en vriendschappelijke overeenkomst.

Mijn lof gaat ook uit naar menig proefpersoon die veel en veel over had voor de wetenschap en, ik hoop, voor het uitbreiden van de kennis over hun eigen lichaam. Ook aan de lopers en 
loopsters, wielrenners, triathletes, mijn vrienden, tegenstanders; en proefpersonen, die mij leerden hoe mijn onderzoek in de praktijk te brengen.

Op het sekretariaat wil ik vooral Ine, Truus en Marco bedanken woor de grotere en kleinere klusjes die werden op geknapt.

Ahhh, en Djoeke, wat kan ik zeggen. Een even-tussen-door hardloop maatje, mijn eerste paar jaar hier. Zo'n vriendschap blijft even verfrissend.

En aan Gerwin, Ellen en Daphne, kamergenoten. Gezelschap, steun en het uitwisselen van ideen, wie had gedacht dat het delen van een kamer leuk zou zijn?

En aan Desirée H., voor de steun door moeilijke tijden, wijsheid van mens en gevoel. Jouw vragen zorgden ervoor dat ik basal ging denken over het onderzoek dat doet mij basal te gaan denken en dat ik de kern van mijn onderzoek ben gaan zoeken. Voor Desirée is het citaat "A faithfull friend is the medicine of life" (Ecclesiastics 6.16) zeer geschikt.

I have had the generous friendship and (sometimes biting) criticism of Ron Maughan the last year and have benefited greatly from both. Additionally, the co-operative research with Ron and John Leiper has been as pleasant as productive.

En aan mijn buren die steun aan een alleenstaande boerin/voedingsfysiologe/verslatafde hardloopster geven.

And Andrea, dear Andrea, we studied together and laughed together. May we always continue to question each other, give honest answers, and still laugh.

And to Peter Klopfer, who taught me to love the science of sport. And, of course, to Martha, who let me see that you can accomplish anything and everything you want, "just put one foot in front of the other".

Bovendien heb ik van jullie allemaal geleerd dat de tijd voor vrienden, collega's en familie nooit verloren is, zelfs tijdens promotie werk. 
Curriculum vitae

Nancy Jane Rehrer

Birth: October 13, 1955, Fort Wayne, Indiana, U.S.A.

1971-1974 South Side High School, Fort Wayme, Indiana, U.S.A. High School Diploma

1974-1979 Duke University, Durham, N. Carolina, U.S.A.

B.A. Environmental Biology

1.978-1980 Structure House Diet Clinic, Durham, N. Carolina, U.S.A. Part-time dietary assistant

1980-1983 Clemson University, Clemson, S. Carolina, U.S.A. (Agricultural School)

M.Sc. Nutrition

1983-1984 Duke University, Durham, N. Carolina, U.S.A.

Part-time research technician

1984-1985 Agricultural University, Wageningen, The Netherlands Junior Fellowship in Nutrition

1984-present Member of the the International Federation of University Women (IFUW), Dutch chapter (VVAO)

1986-present University of Limburg, Maastricht, The Netherlands Research assistant (Ph.D. candidate)

1990

Reviewer for Med. Sci. Sports Exerc. and Int. J. Sports Med. 


\section{Articles published concerning research presented in this thesis:}

Rehrer, N.J., G.M.E. Janssen, F. Brouns and W.H.M. Saris. Fluid intake and gastrointestinal problems in runners competing in a $25-\mathrm{km}$ race and a marathon. Int. J. Sports Med. 10: $\$ 22-\mathrm{s} 25,1989$.

Rehrer, N.J., E. Beckers, F. Brouns, F. ten Hoor and W.H.M. Saris. Exercise and training effects on gastric emptying of carbohydrate beverages. Med. Sci. Sports Exerc. 21: 540-549, 1989.

Rehrer, N.J., F. Brouns, E.J. Beckers; F. ten Hoor and W.H.M. Saris. Gastric emptying with repeated drinking during running and bicycling. Int. J. Sports Med. 11: 238-243, 1990.

Rehrer, N.J. and G.A. Meijer. Biomechanical vibration of the abdominal region during running and bicycling. J. Sports Med. 43: (in press) 1990.

Rehrer, N.J., E. Beckers, F. Brouns, F. ten Hoor and W.H.M. Saris. Effects of dehydration on gastric emptying and gastrointestinal distress while running. Med. Sci. Sports Exerc. 22: (in press), 1990.

Rehrer, N.J., F. Brouns, E. Beckers, W.O. Frey, C. Riddoch, B. Villiger, P.P.C.A. Menheere and W.H.M. Saris. Gastrointestinal symptoms and physiological changes as a result of ultra-endurance running. (in review)

Rehrer, N.J., E.J. Beckers, F. Brouns, W.H.M. Saris and F. ten Hoor. Gastric emptying, secretion and electrolyte flux after ingestion of beverages with varying electrolyte compositions. (in review)

Rehrer, N.J., A.J.M.Wagenmakers, E.J. Beckers, D. Halliday, J.B. Leiper, F. Brouns, R.J. Maughan, K. Westerterp and W.H.M. Saris Limits to supplementation: gastric emptying, intestinal absorption and oxidation. (submitted)

Rehrer, N.J., M.C. van Kemenade, T.A. Meester, F. Brouns and W.H.M. Saris. Gastrointestinal complaints in relation to dietary intakes in triathletes. (in review)

van Kemanade M.C., T.A. Meester and N.J. Rehrer. Voeding in relatie tot maag-darmklachten bij de triathlon. Ned. Tijd. Diët. 44: 8-12, 1989. 


\section{Review articles}

Rehrer, N.J. Maag-darm problemen bij duursport. in Saris, W.H.M. and M. Stasse-Wolthuis (Eds.) Spart en Voeding pp. 72-83, Samson Stafleu, Alphen a/d Rijn, 1988.

Rehrer, N.J. Studies in gastric emptying and fluid balance during exercise. J. Hum. Nutr. Diet. (in press), 1991.

Rehrer, N.J. Exercise aspects of dehydration and rehydration. in Brouns, F., W.H.M. Saris and E.A. Newsholme (Eds.) Advances in Nutrition and Topsport (in press) Karger, Basel, 1991.

\section{Abstracts}

Rehrer, N.J., G.M.E. Janssen, F. Brouns and W.H.M. Saris. Fluid intake and gastrointestinal problems in runners competing in a $25 \mathrm{~km}$ race and a marathon. Can. J. Spt. Sci. 13: 28p, 1988.

Rehrer, N.J., F. Brouns, E.J. Beckers, W.H.M. Saris and F. ten Hoor. Gastric emptying during running and cycling. Med. Sci. Sports Exerc. 21: $592,1989$.

Rehrer, N.J., E. Beckers, F. Brouns, W.H.M. Saris and F. ten Hoor. Dehydration alters gastric emptying and incidence of gastrointestinal problems during endurance running. Paavo Nurmi Congress Book p. 337, Finnish Society of Sports Medicine, Turku, 1989.

Rehrer, N.J., M.C. van Kemenade, T.A. Meester, F, Brouns and W.H.M. Saris. Nutrition in relation to Gl complaints in triathletes. Med. Sci, Sports Exerc. 22: s107, 1990.

Rehrer, N.J., E.J. Beckers, F. Brouns, F. ten Hoor and W.H.M. Saris. Gastric function and hypohydration during exercise. Pflu. Arch. 416: s8, 1990 .

Rehrer, N.J., A.J.M. Wagenmakers, E.J. Beckers, D. Halliday, F. Brouns and $\mathrm{K}$. Westerterp. Limits to supplementation: gastric emptying absorption and carbohydrate utilization. Proceedings of Aspects Biochemiques et Phrsiologiques de la Fatigue Musculaire . p. 88, Créteil, France, September, 1990. 